TE WHARE WĀNANGA O TE ŪPOKO O TE IKA A MĀUI

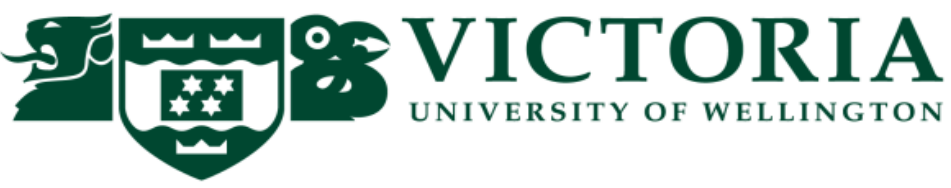

\title{
A SOCIAL-COGNITIVE STUDY OF INDONESIAN GOOGLE EDUCATOR GROUPS
}

\author{
By
}

\section{PRATIWI WINI ARTATI}

\author{
A thesis \\ Submitted to Victoria University of Wellington \\ in fulfilment of the requirements for the degree of \\ Doctor of Philosophy in Education
}

VICTORIA UNIVERSITY OF WELLINGTON 


\begin{abstract}
Self-directed professional learning is distinct from the traditional approach of directed professional development. The introduction of the Internet into Indonesian society provides the opportunity for teachers to use digital tools for their teaching and to access professional learning without attending mandated professional development. An emerging phenomenon in Indonesia is the establishment and use of Google Education
\end{abstract} Groups (GEGs) for professional learning about the use of educational technology (edtech) in the schooling sector. Two research questions guided the examination of Indonesian educators' experiences of GEGs: (1) how do Indonesian educators participate in the GEGs for ed-tech professional learning? and (2) how do the GEGs function to enable Indonesian educators' ed-tech professional learning? Collective case study methodology was applied, and three Google Education Groups were examined, one from a metropolitan area, one from an urban area and the third from a rural context. In each case study, the leader of the group and three group members with varying levels of online engagement were interviewed and online forum conversations were examined. Data were analysed using Stake's method of categorical aggregation leading to within-case assertions and cross-case analysis. A social cognitive perspective was used as a framework to analyse and interpret findings. It was found that the Indonesian educators had an agentic approach to professional learning, which was context-dependent with three major interrelated aspects: the regional-technological environment as context, the individuals as agentic learners, and the connectedness as social learners enabled meaningful learning experiences. The regional-technological environment influenced how the GEGs functioned. The Metropolitan group was innovative and collaborative, focusing on the use of web-based tools to improve productivity of ed-tech practices. The Urban group aimed to explore how they could use web-based tools to improve efficiency through paperless classroom practices and school administration. The Rural group sought to use of web-based tools for simple teaching and learning practices within a context of low bandwidth and limited ICT infrastructure. In addition, certain conditions that support online collaboration and factors that can minimise and optimise ed-tech learning opportunities are identified. Participants overcame limitations and constraints by enacting agency and developing social connectedness in learning through the groups. The group leadership positions were voluntary and found to be driven by a desire to share expertise and practices that support, inspire, and empower others rather than about gaining 
positional authority. Participation in online informal groups such as Google Education Groups appears to be a supportive method of professional learning that facilitates agentic and experiential learning about the use of educational technology in Indonesia. This model can enhance professional learning opportunities for Indonesian educators. It can also be implemented into the design of government-supported ed-tech PD programmes, to create an empowering and safe learning environment that can optimise their potential in learning and improve practice.

Keywords: learning agency, ed-tech professional learning, informal learning groups, social cognitive theory, qualitative research 


\section{Acknowledgement}

Undertaking this $\mathrm{PhD}$ journey has been a truly-life changing experience for me, and it would have not been possible without Allah SWT's guidance and support from many people and significant others. To me, the $\mathrm{PhD}$ Journey is more than just obtaining a degree. Rather, it is a series of life lessons enriched by the wisdom of overcoming adversities and challenges within an academic journey. This journey has provided me with eye opening and immensely valuable experiences beyond my comfort zone. As a Javanese-Indonesian, the elders had taught me that 'ilmu iku kalakone kanti laku'. The essence of this philosophy is about how knowledge is gained with endless effort and strong determination within which the soul will be enlightened and the wisdom it brings provides a guidance to the best version as a being. This philosophy has taught me that striving for excellence can never be done alone without guidance and support. Arriving to this point, I would like to take this opportunity to express my gratitude and appreciation to a number of people whose tremendous support had enabled me to complete this $\mathrm{PhD}$ journey.

I would like to specially express my sincere gratitude and heartfelt appreciation to my primary supervisor, Dr. Louise Starkey and my secondary supervisor, Dr. Vicki Thorpe for the thoughtful guidance, wisdom, and endless support. Having them as my supervisors enabled me to meaningfully engage in the whole process of thesis writing from the initial to the final stage of my doctoral study. Their kindness, patience, and constructive criticism provided me with valuable tools for reflection and critical thinking. Their understanding towards my academic upbringing as an international student, whose first language is not English is also incredible, which makes me feel welcomed, appreciated, and acknowledged.

I would also like to express my sincere gratitude to Indonesian Endowment Fund for Education (LPDP) for fully supporting and sponsoring my doctorate study at Victoria University of Wellington until it is finished. Similarly, I would like to extend my sincere gratitude and appreciation to the Doctoral examination committee chair as well as for the academic support system from Victoria University of Wellington and the Faculty of Education staffs, which facilitated me in completing the study. 
My immense gratitude also goes to all of my participants for their valuable time, knowledge, and experiences to participate in the study. This study would have not been completed without their generous contributions and assistance. May Allah SWT grant them rewards.

I also truly appreciate the support from Centre for Data and Information Technology (Pusdatin) Ministry of Education and Culture Republic of Indonesia. Thank you to the Head of Pustekkom for giving me permission and encouragement to undertake my doctorate study as well as to all of my colleagues and co-workers who have been part of my incredible support system.

To Helen McDonald, thank you for your professional assistance on proofreading my thesis. Your knowledge and expertise had helped me greatly in improving the quality of my thesis writing that suits to the New Zealand's academic writing standard.

To my dearest colleague and best friend, Sukuna, thank you for your tremendous support and encouragement that have helped me through this $\mathrm{PhD}$ journey. Thank you to my beloved Indonesian colleagues and friends in Indonesian Students Association in Wellington (PPIW), Indonesian Community Association in Wellington (KAMASI), and Indonesian Muslim Society in Wellington (UMI) for your incredible support. I would also like to extend my appreciation to Indonesian Ambassador and his family as well as Indonesian staffs in Indonesian Embassy who have become my inspiration during the period of my study here.

I am also forever in debt of endless prayers, tremendous support and greatest encouragement from my family and relatives: my dearest mother, Sri Hendratmastuti. My late grandmother, Sarwosri Hendrokarjatmo. My sweetest sister, Prasasti Wini Lestari. My mother in law, Bekti Siswandari. My (step) father in law, Edy Waluyo. My late father in law, Achmad Said. My sister in law. My maternal aunts and uncles. My nieces and nephews.

Finally yet importantly, I would like to sincerely express my highest gratitude and heartfelt appreciation to my dearest one and only husband, Okky Wahid Hidayat, for his endless prayers, incredible support, love, and patience. With you by my side, this $\mathrm{PhD}$ journey is more worthwhile. 


\section{TABLE OF CONTENTS}

Abstract

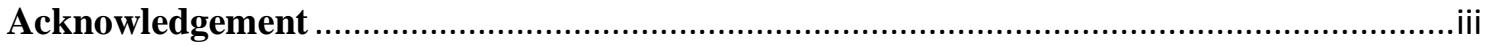

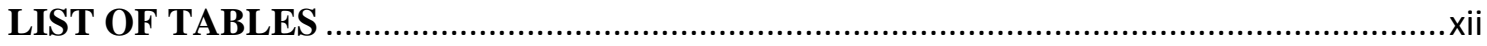

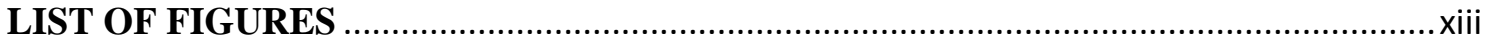

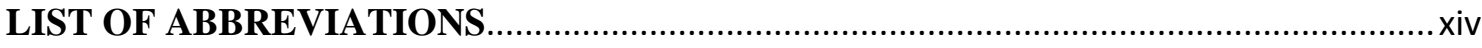

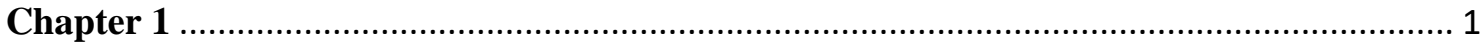

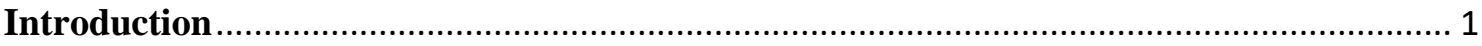

Teacher professional development in Indonesia ...................................................... 1

The educational technology (ed-tech) professional learning in Indonesia .................... 2

The challenges to ed-tech professional learning in Indonesia ...................................... 3

Internet connectivity and technology infrastructure .............................................. 4

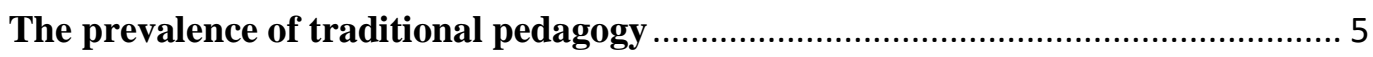

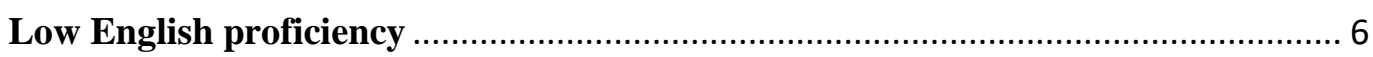

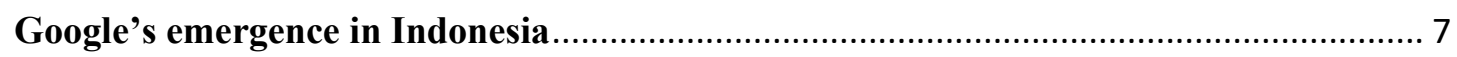

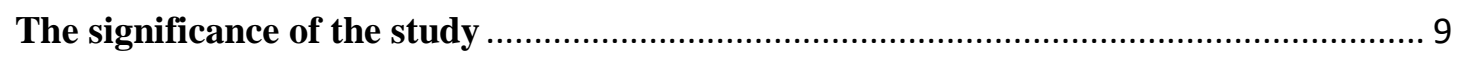

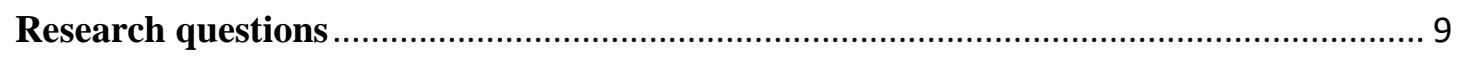

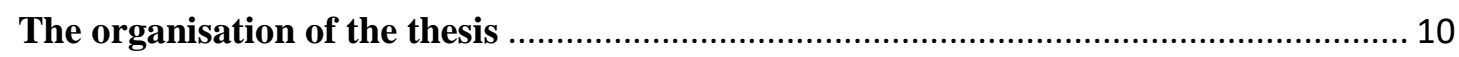

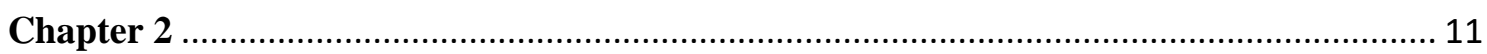

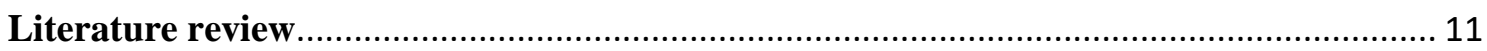

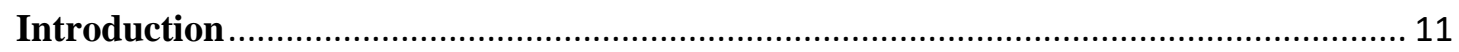

The shifting paradigm of professional development in education ................................. 12

Traditional-formal approach to teacher professional development (TPD) ................. 13

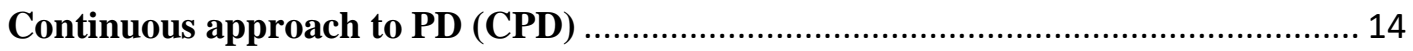

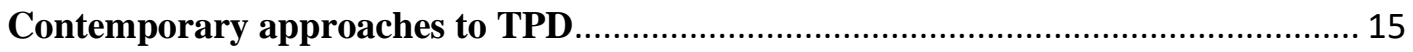

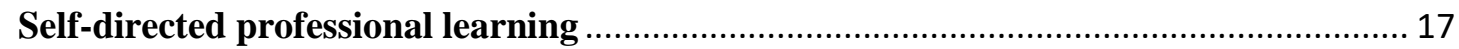

Technology use in self-directed professional learning ……........................................ 21

Current models of teachers' self-directed professional learning .................................... 24

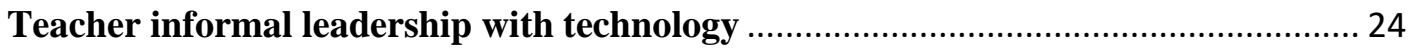

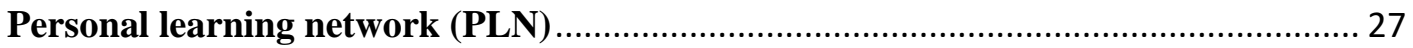

Informally-organised technology-mediated learning collectives ................................. 30

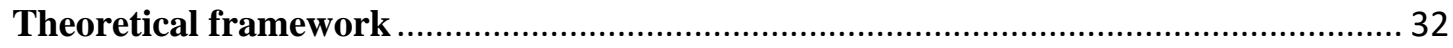

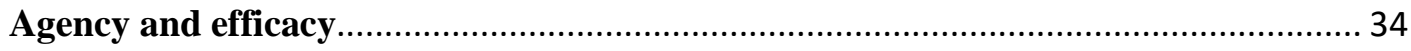

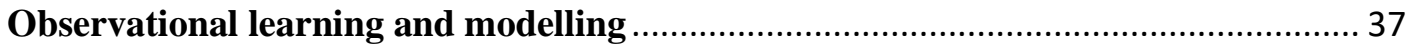

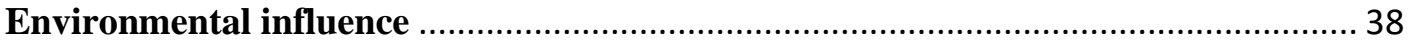

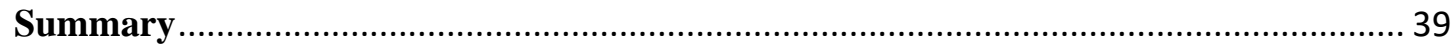




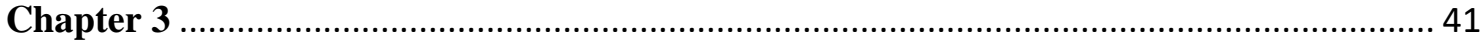

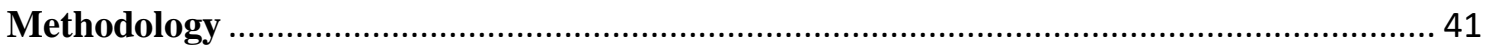

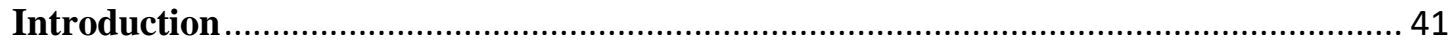

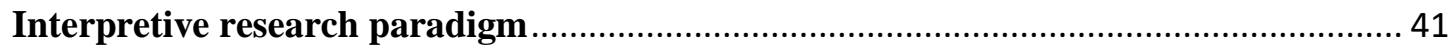

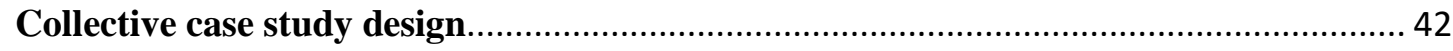

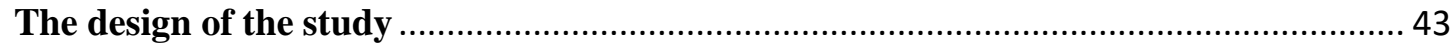

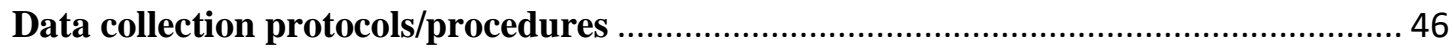

Preparing for data collection (stage 1) ……................................................................. 48

The criteria developed for purposely selecting cases ............................................... 48

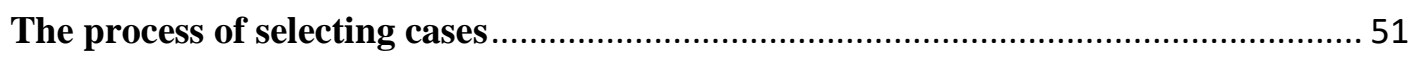

The criteria developed for purposely selecting participants .................................... 51

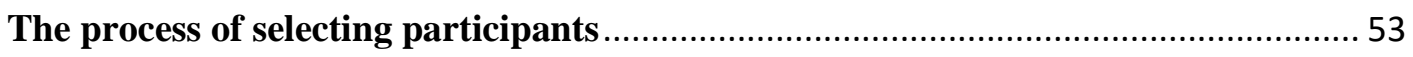

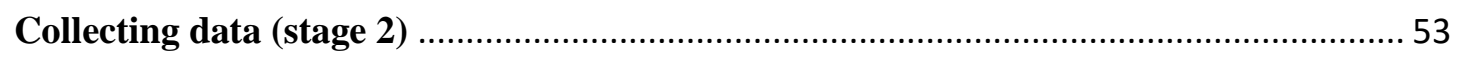

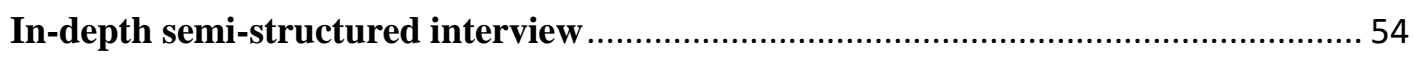

Transcription, translation, and transliteration ..................................................... 56

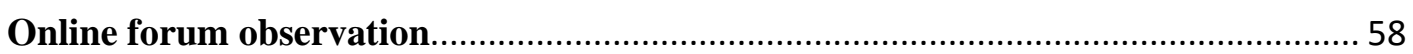

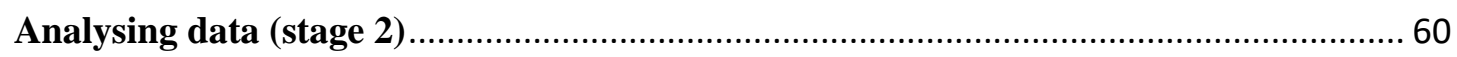

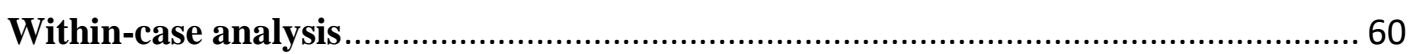

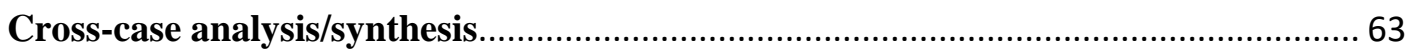

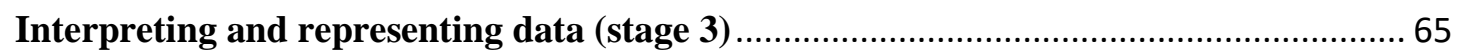

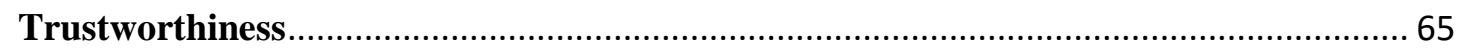

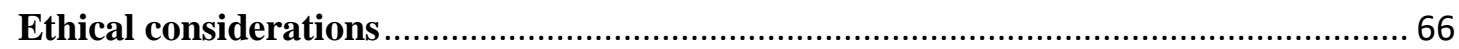

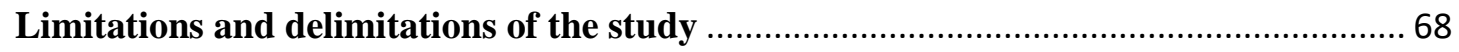

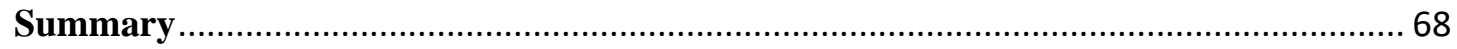

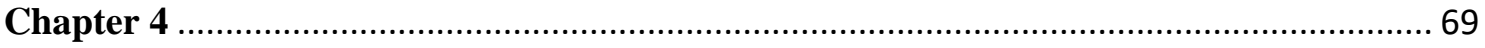

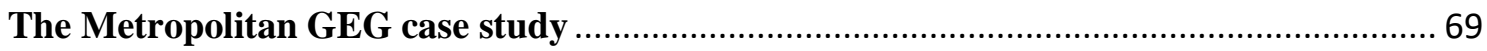

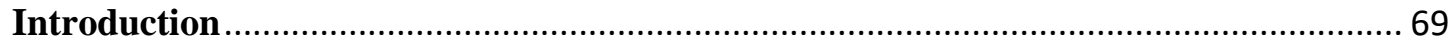

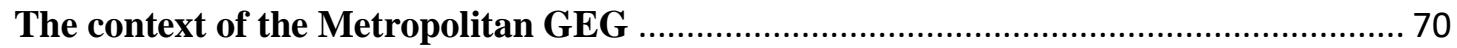

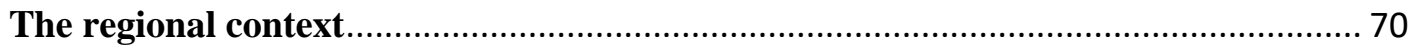

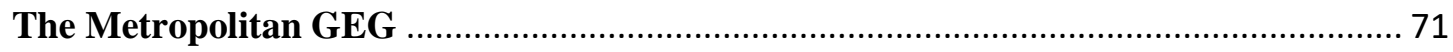

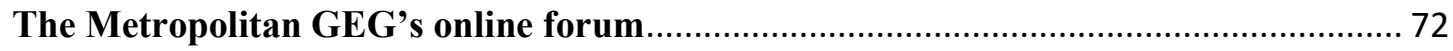

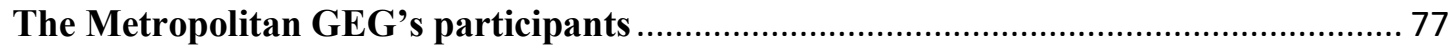

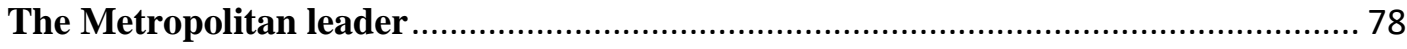

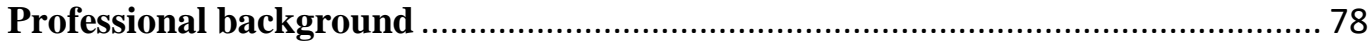

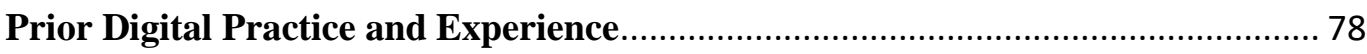

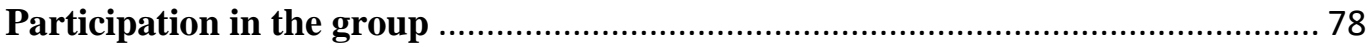




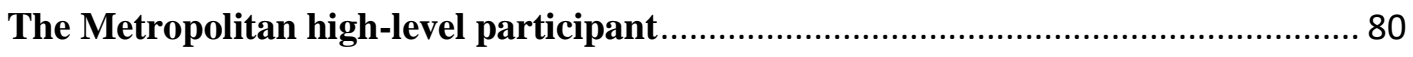

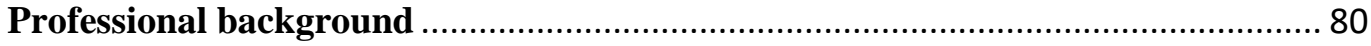

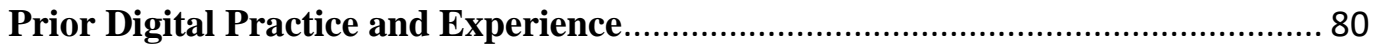

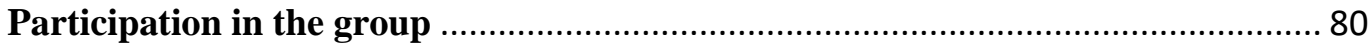

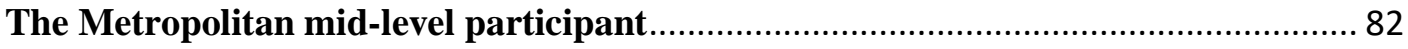

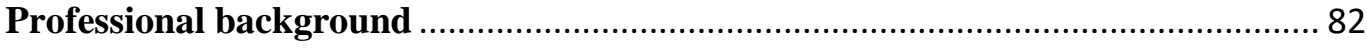

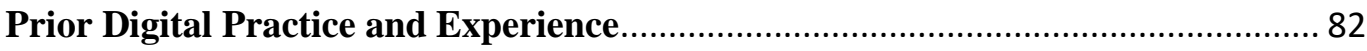

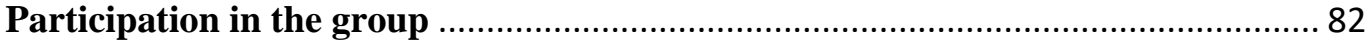

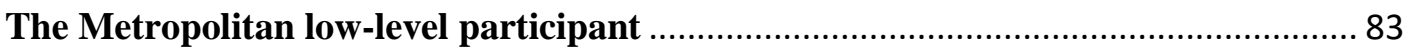

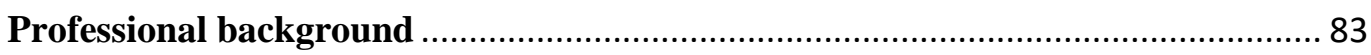

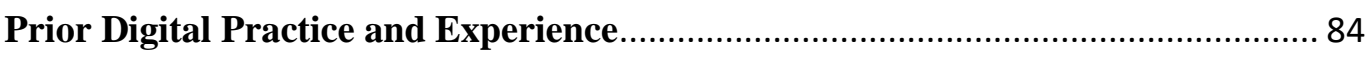

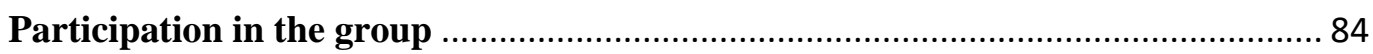

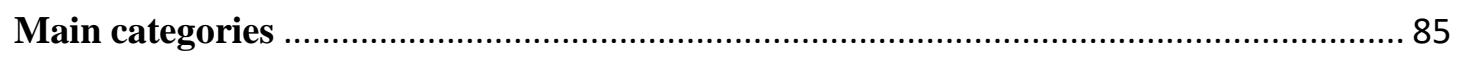

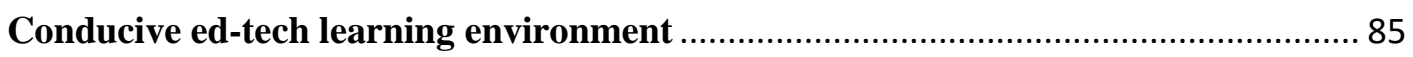

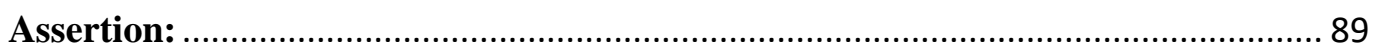

A range of learning opportunities through global networks ...................................... 89

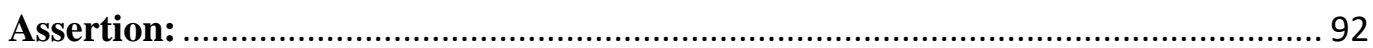

The value of participants' learning experiences in the group ..................................... 93

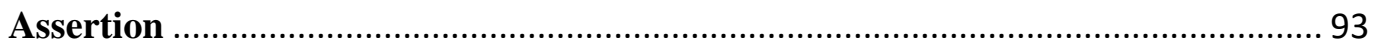

Innovative and collaborative use of web-based tools ................................................... 94

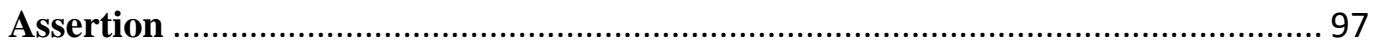

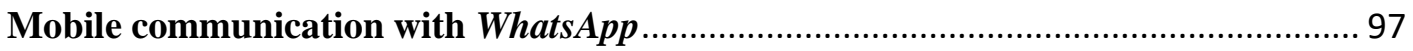

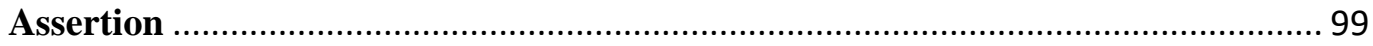

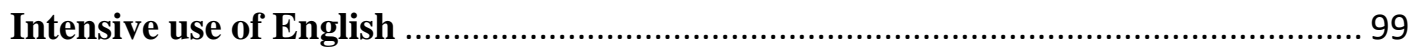

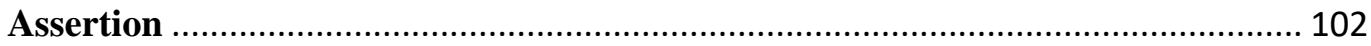

The interconnectivity of face-to-face and online activities ...................................... 102

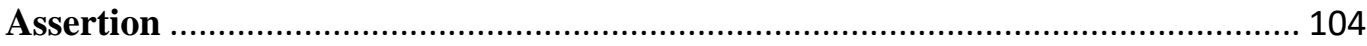

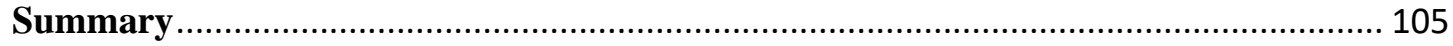

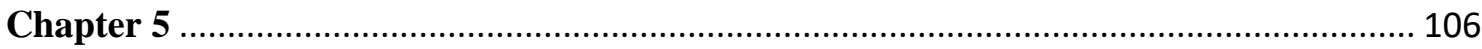

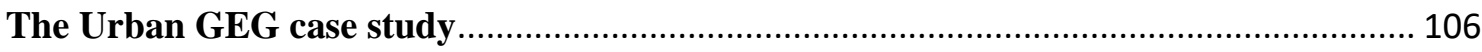

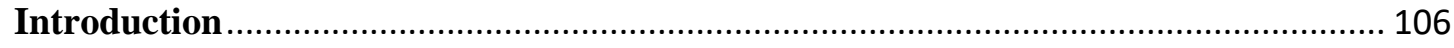

The context of the Urban GEG ….......................................................................... 107

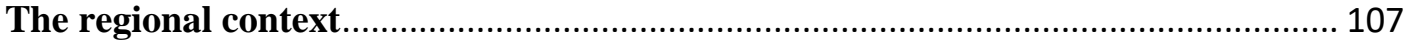

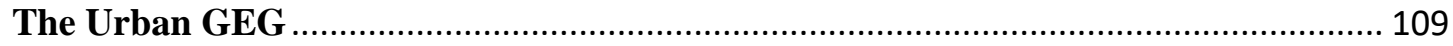

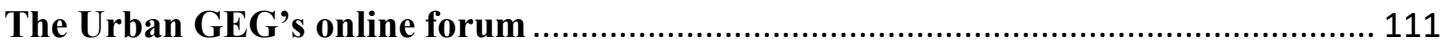

The Urban GEG's participants............................................................................... 114 
The Urban leader

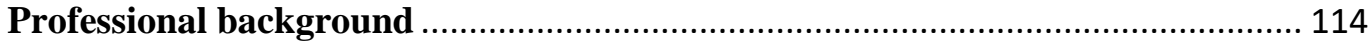

Prior Digital Practice and Experience................................................. 114

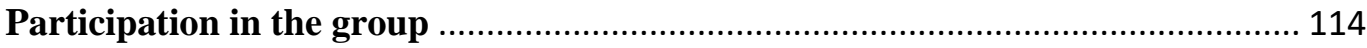

The Urban high-level participant ............................................................. 116

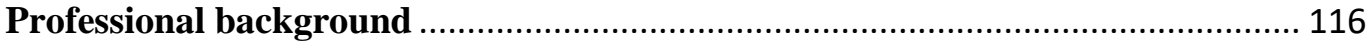

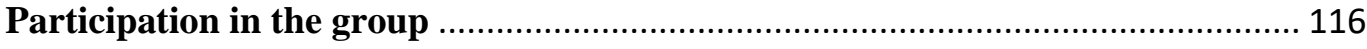

The Urban mid-level participant ............................................................ 118

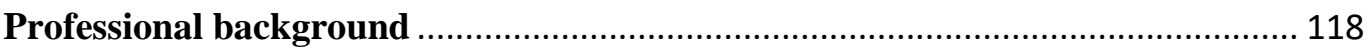

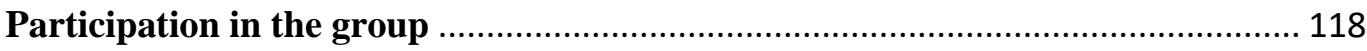

The Urban low-level participant ................................................................ 119

Professional background .......................................................................... 119

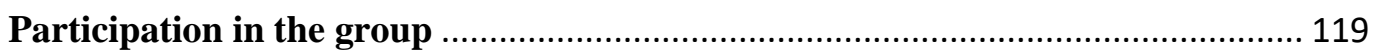

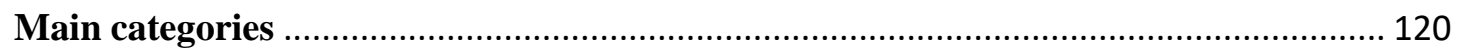

Unreliable Internet access with pervading emphasis on the paper-based education 120

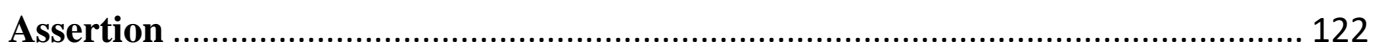

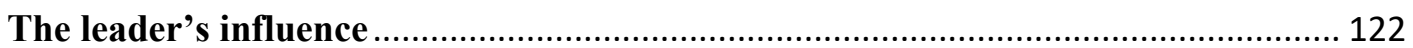

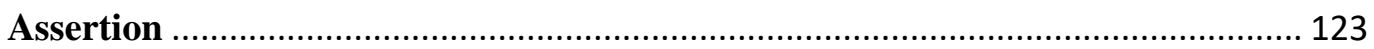

Mobile communication with Telegram ......................................................... 123

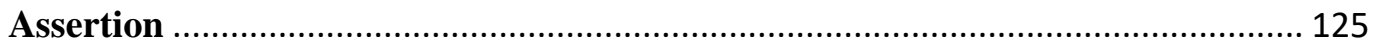

The need for connectedness ...................................................................... 125

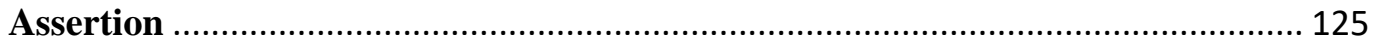

Participants' mentoring activities ............................................................ 126

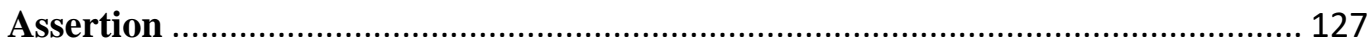

The group's stagnant online forum .......................................................... 127

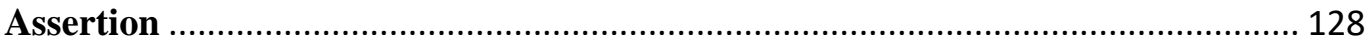

Improved efficiency through paperless professional practice with web-based tools 128

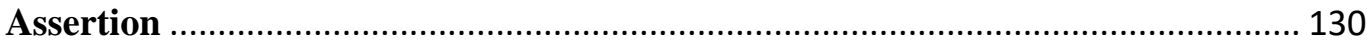

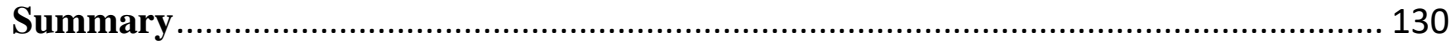

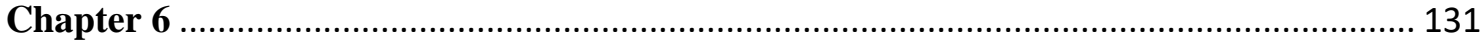

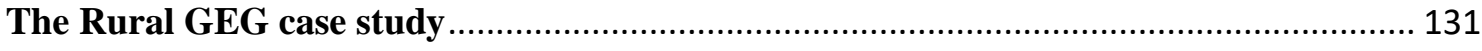

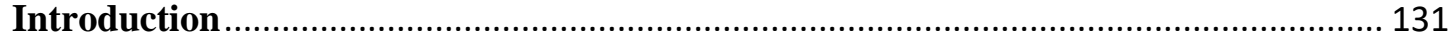

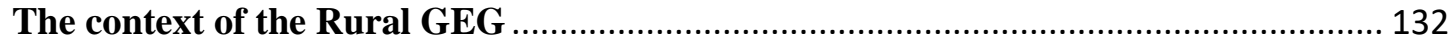

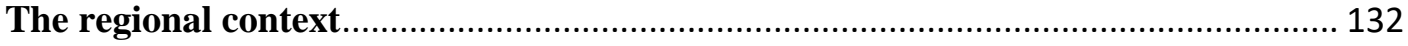

The Rural GEG ..................................................................................... 134

The Rural GEG's online forum ................................................................... 136 
The Rural GEG's participants.

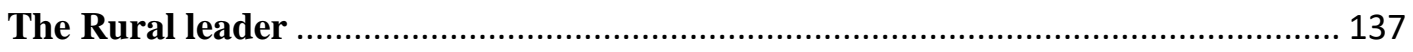

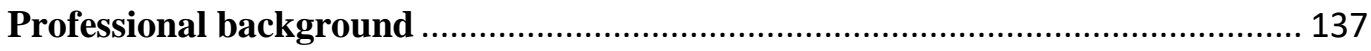

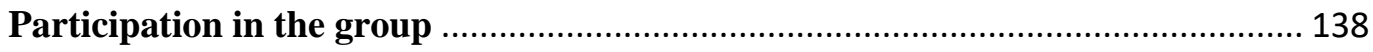

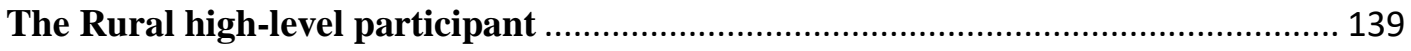

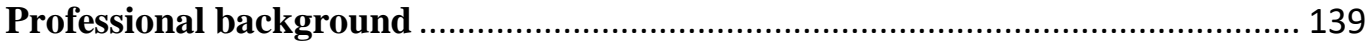

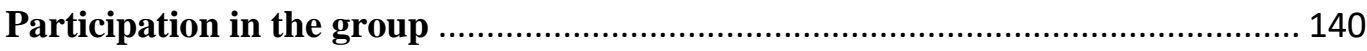

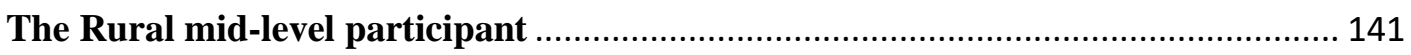

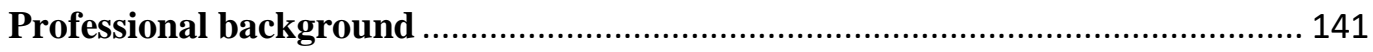

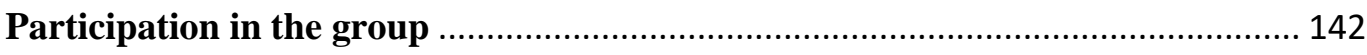

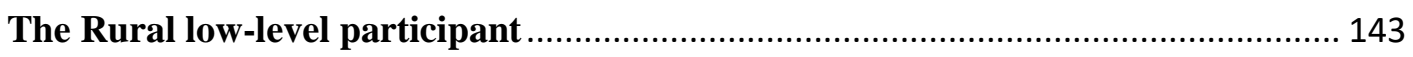

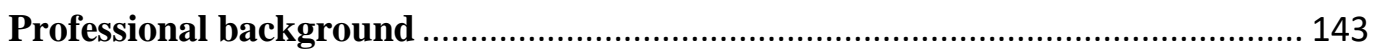

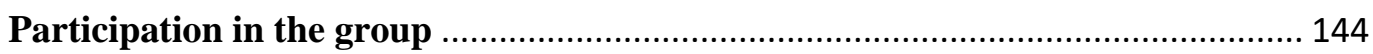

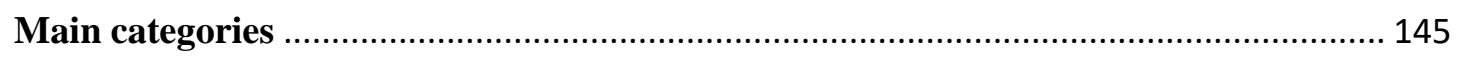

Constrained digital resources and Internet connectivity ...................................... 145

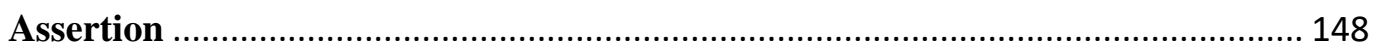

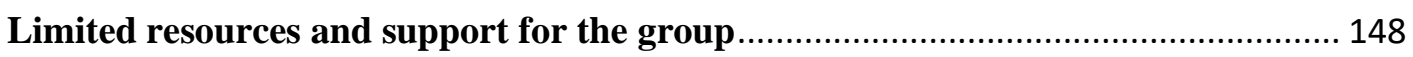

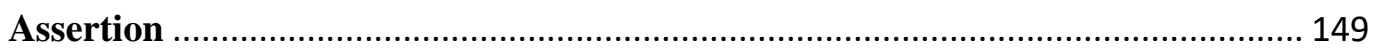

Preference to face-to-face and Telegram communication ......................................... 149

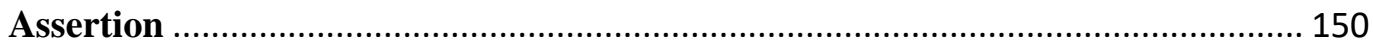

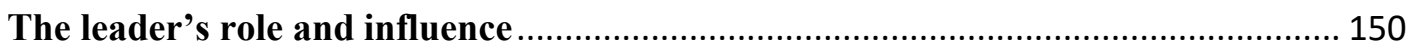

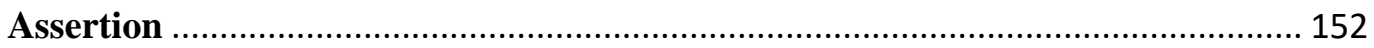

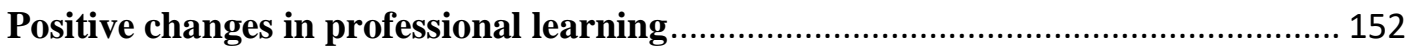

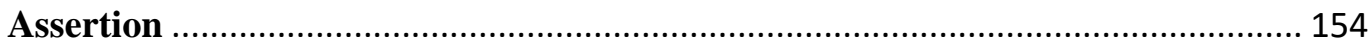

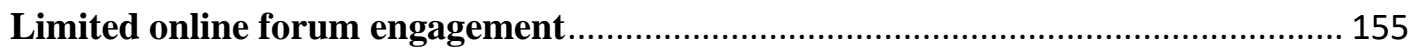

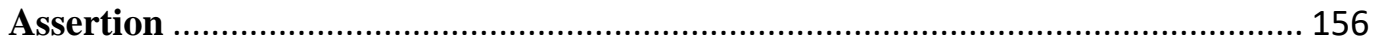

Meaningful learning experiences through mentoring................................................. 156

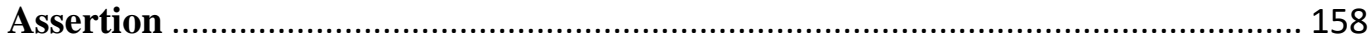

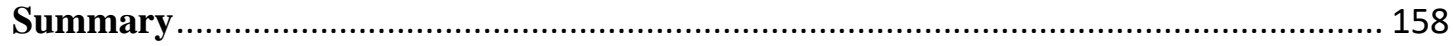

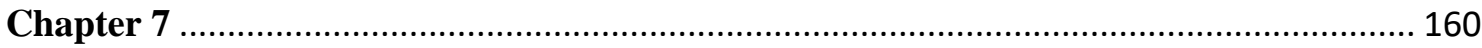

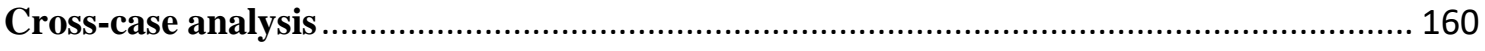

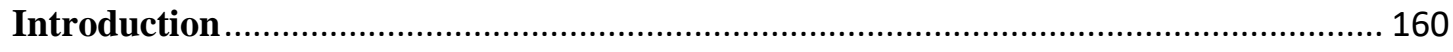

The regional-technological environment ..................................................................... 160

Internet access and school culture: reliable and challenging digital environment ... 160

The online forum's global and local networks, activities, resources ......................... 162

The complementary and substitutive use of mobile communication.......................... 165 


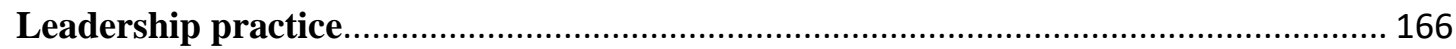

"Leading by sharing the leadership" versus "leading by delegating tasks" ............. 166

Altruism and volunteering through mentoring ........................................................ 169

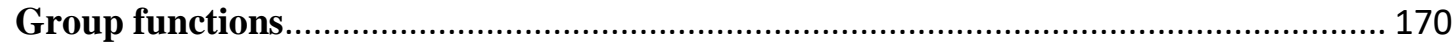

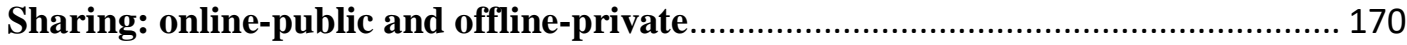

Online communication: multidirectional versus unidirectional interaction.............. 171

Learning: individual and collegial ...................................................................... 173

Ed-tech learning orientation: collaborative and leader-driven ................................ 174

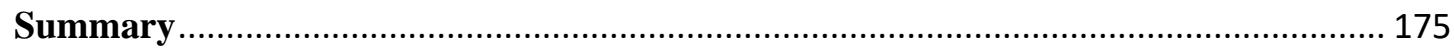

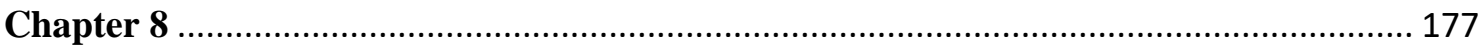

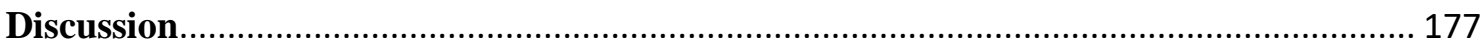

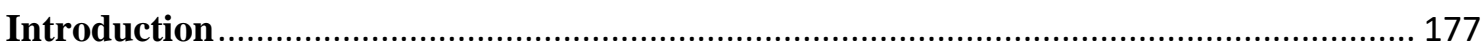

The significance of the findings to answering the research questions .............................. 177

How do Indonesian educators participate in the GEGs for ed-tech professional learning?

How do the GEGs function to enable Indonesian educators' ed-tech professional learning?

Three important aspects in Indonesian educators' ed-tech professional learning in the GEGs

The influence of regional-technological environment on participants' enactment of agency

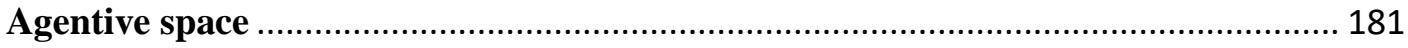

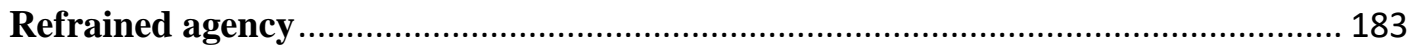

The influence of regional-technological environment on the group learning behaviour

Collaborative and leader-driven group behaviours ................................................. 185

Globally and locally-networked group interaction ................................................ 187

The interdependence of participants' enactment of agency and group learning behaviour

Participants as agentic and experiential learners, but not all reflect on their

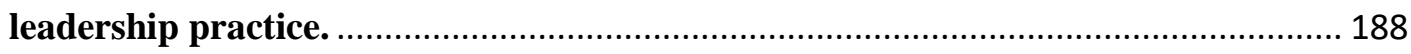

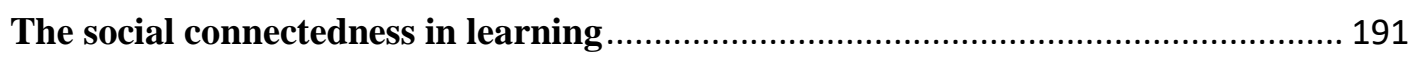

The influence of participants' agency and social connectedness on the group's

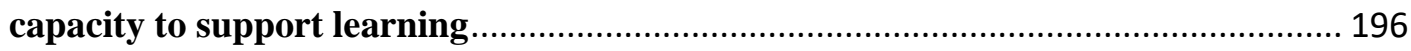

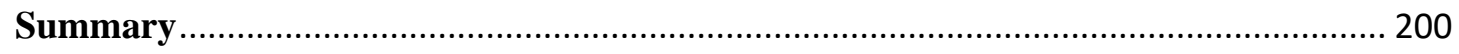

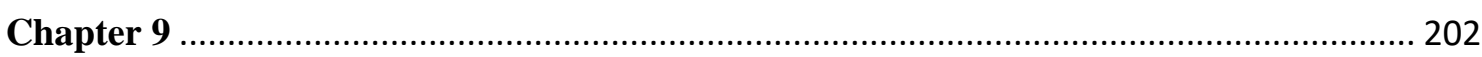

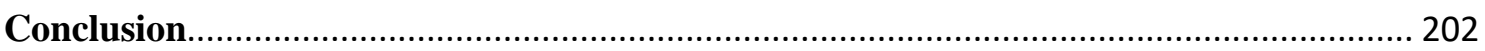

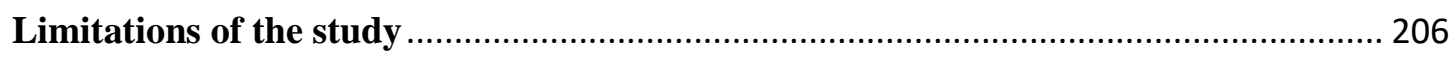


Implications for Indonesian educators' ed-tech professional learning experience 207

Implications for Indonesian PD policy .................................................................. 208

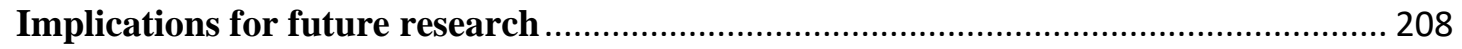

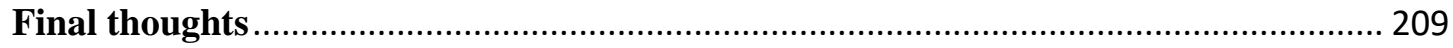

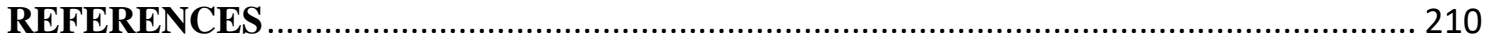

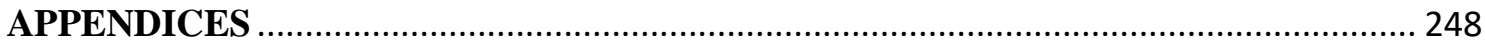




\section{LIST OF TABLES}

Table 1. The criteria for case selection 49

Table 2 . The category of participants' online participation .52

Table 3. Examples of generating initial codes from the Rural GEG case study..... 60

Table 4. An example of the comparison of assertions 64

Table 5. The main categories and assertions in the Metropolitan GEG case study..... 70

Table 6. Examples of highly communicative, appreciative, and supportive posts in the group's online forum

Table 7. Examples of diverse content posted by the leader and the lead team within an actively updated timeline .75

Table 8 . Examples of diverse content posted by members within an actively updated timeline. .76

Table 9. Examples of topics in the group's online forum .85

Table 10. The main categories and assertions in the Urban GEG case study 107

Table 11. Examples of the stagnant timeline of postings activities in the group's online forum 112

Table 12. The main categories and assertions in the Rural GEG case study. 132 


\section{LIST OF FIGURES}

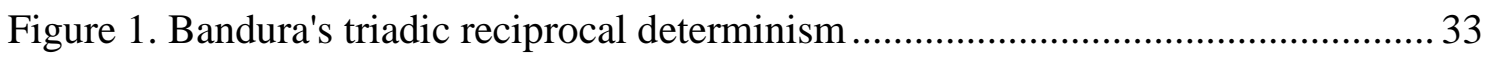

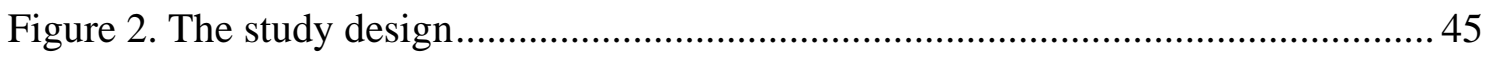

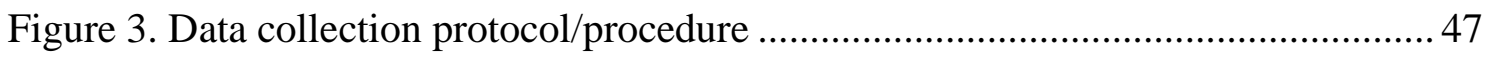

Figure 4. An illustrative example of the mind-mapping of the Metropolitan GEG ....... 62

Figure 5. Examples of the group's global network and interaction ................................ 77

Figure 6. An example of a post about GCE activities posted by the leader .................. 87

Figure 7. Examples of various professional learning activities ................................... 92

Figure 8. An example of a post regarding International recognition towards the group 100

Figure 9. Interconnected face-to-face and online activities (1) .................................. 103

Figure 10. Interconnected face-to-face and online activities (2) ................................ 103

Figure 11. Examples of members' politics and religious-related posts (non ed-tech posts)

Figure 12. examples of the Urban high-level participant's online activities in the group's forum

Figure 13. The interdependence of the regional-technological environment, participants' agency, and group learning behaviour. 199 


\section{LIST OF ABBREVIATIONS}

ed-tech: education technology

ICT: information and communication technology

GEG: Google Educator Group

MGMP/Musyawarah Guru Mata Pelajaran: teacher union of specific subjects

PGRI/ Persatuan Guru Republik Indonesia: National Teacher Union in Indonesia

PD: professional development

TPD: Teacher Professional Development

CPD: Continuous/Continuing Professional Development

TEFL: Teaching English as Foreign Language

OLC: online learning community

RSBI: Pioneer schools with international standard in Indonesia 


\section{Chapter 1}

\section{Introduction}

This thesis presents an investigation into Indonesian educators' self-reported reflections on their experiences participating in Google Educator Group (GEG) for educational technology (ed-tech) professional learning. Using qualitative exploratory collective case study design, this study aims to gain insight into the nature of Indonesian educators' learning experiences in the GEGs and investigate the impact of the GEGs upon ed-tech professional learning. Drawing from Bandura's (2001) social-cognitive theory, this study focuses on the social-cognitive aspects of Indonesian educators' participation in the GEGs. This study provides an initial glimpse into the opportunities and challenges of educators' ed-tech professional learning within the Indonesian context, particularly with web-based tools. As an educational technology specialist working for the Ministry of Education and Culture in in the Republic of Indonesia for more than 12 years, the GEG initiative raised my interest and this has led me to investigate them in order to gain deeper understanding of the nature of professional learning.

In order to have a clearer understanding on the context of this study, it is necessary to look into how Indonesian educators' professionalism is situated. The first section describes teacher professional development in Indonesia. The second section depicts the educational technology (ed-tech) professional learning in Indonesia. The third section identifies the challenges of ed-tech professional learning in Indonesia, and the fourth section briefly describes Google's agenda in Indonesia and the emerging of Indonesian Google Educator Group (GEG).

\section{Teacher professional development in Indonesia}

The dominant model of professional development (PD) for Indonesian educators is a government-organised and mandated traditional approach. Most government-based PD formats in Indonesia are face-to-face didactic sessions comprised of one-off seminars/events and cascaded short courses conducted in centralised locations. Most educators from geographically diverse and dispersed areas need to travel long distances to attend these, which presents further financial challenges (Alwasilah \& Furqon, 2010). In addition, the government-organised and mandated PD programs in Indonesia typically facilitate a small number of representatives of educators sent by their schools (Martin, 2019). 
This centralised and mandatory nature of PD has been criticised as being relatively timeconsuming and not specifically designed for the individual educator's needs (Widodo \& Riandi, 2013). It is also considered to be minimally effective as it does not provide further opportunities and time for reflection or for reflective practice. Most traditional PD seem to have fixed structure and mandatory in nature, leaving educators with limited option and freedom to navigate their own ways of learning and implement it to their practices within diverse contexts (Scott \& Scott, 2010). Accordingly, a study found that educators were less likely to be proactive in knowledge-sharing activities with others in government-organised and mandated traditional approach of PD (Sari, 2012).

There are still a large number of educators who struggle to have access to PD with technology in Indonesia, particularly in rural and remote areas, where there is less support of good quality of information and communication technology (ICT) infrastructure and reliable Internet connectivity that can enable technology-focused PD (Sari, 2012). Hyson and Roesli (2017) identified several issues of PD in poor, rural areas of Indonesia:

- Teacher training was not widely available, with an inadequate supply of PD providers and difficulties connecting with teachers in rural, often remote, parts of the country.

- Most of the government-supported PD had been about brief, one-time basic training focused on transmitting theories and information through didactic methods.

- Teachers reported a great deal of difficulty in applying what they had learned, and observations of practices in typical settings showed a focus on whole-class teaching, with an absence of relevant, playful learning activities (p.3).

Thus, the inflexibility and the ineffectiveness of government-organised and mandated PD and educators' struggles to have access to PD with technology in Indonesia are likely to underpin Indonesian educators' informal practices of professional learning with technology.

\section{The educational technology (ed-tech) professional learning in}

\section{Indonesia}

The informal practice of professional learning with technology in Indonesia is driven by how some educators finding ways to find alternatives for educational technology (ed-tech) learning support that they do not get from traditional and mandated professional development. Web-based and online technologies such as social media, Coursera, and other online forums have been used for ed-tech professional learning by some Indonesian educators outside of their government-organised and mandated PD (Grazella, 2013; Patahuddin \& Logan, 2018), which indicates the significance of access to the digital tools and the Internet connection to support 
educators' learning with technology. For example, Firmansyah and Timmis (2016) revealed that some Indonesian educators who took free courses in Coursera (a free MOOC-based learning platform) engaged in IDCourserians (an independent learning community of Coursera learners) to learn with each other and collaborate through face-to-face and online interaction. Some educators in Indonesia also used Facebook as it offered them with opportunities for professional learning that is personalised and self-driven with their potential affordances to overcome challenges in accessing resources, PD and pedagogical discourse (Patahuddin \& Logan, 2018). A study found that the use of social media has the potential to support Indonesian teachers in undertaking professional learning for local content studies/cultural studies and promoting cooperation and mentoring values (Pheeney \& Klieve, 2015). These studies show the increasing relevance of ed-tech professional learning for educators in Indonesia.

The rise of ed-tech start-ups in Indonesia may influence how educators seek ed-tech learning opportunities outside of their mandated professional development programs. A report by Ken Research (2015) entitled Indonesian Digital Education and E-learning Market Outlook: Rising Trend of Blended Learning to Drive the Future Growth demonstrated that over the last five years, the total spending on digital education in Indonesia had grown where the collaboration between educational institutions and digital education providers had been improved in providing their classrooms with digital technologies. According to this report, there had been a rise in ed-tech start-ups in Indonesia such as Harukaedu, Kelase, Codemi, Ruangguru and many others, which seemed to trigger the increasing use of web-based technologies among Indonesian educators' ed-tech practices. This suggests that the emerging ed-tech start-ups in Indonesia potentially offer valuable resources to support educators' selfdirected ed-tech professional learning outside of government-based professional development programmes.

\section{The challenges to ed-tech professional learning in Indonesia}

As the fourth most populous country in the world, Indonesia is a geographically diverse and socio-culturally unique archipelagic country of 17,508 islands with an estimated population of 253,899,536 people and 5,193,252 square kilometres of regions in three different time zones (Moffatt, 2012). Indonesia's unique socio-cultural factors and complex geographical landscape and its nature of dominant model of traditional professional development (PD) approach present challenges for teachers' professional learning in the digital age. These challenges involve Internet connectivity and technology infrastructure (Cahyono \& Mutiaraningrum, 2015; Relmasira, Thrupp, \& Hunt, 2017), sustained traditional teaching and learning practices 
(Kusmawan, 2015; Palekahelu, Hunt, Thrupp, \& Relmasira, 2016), and low English proficiency (Simatupang, 2017).

\section{Internet connectivity and technology infrastructure}

There are three major challenges to ed-tech professional learning in Indonesia: the disparity of the Internet connectivity and technology infrastructure, the prevalence of traditional pedagogy, and low English proficiency. Mutohar and Hughes (2013) identified a lack of technological facilities in Indonesia. Their study revealed an absence of technology standards in education, and insufficient technical support for the integration of web-based tools for educational practices in the majority of regions, which suggests a challenging task for the Indonesian government to provide equal access and opportunities for education technology PD for all educators across the country.

There were still educators who suffered from a lack of access to the advances of ICT in non-urban areas in Indonesia where they could not be expected to have, or even be exposed to, the same educational resources and opportunities for technology professional learning to those in central city locations (Kusmawan, 2015). According to the Indonesian Statistics Bureau, of the total population of 248 million people who are registered in 512 districts, 57.4 million are domiciled in 183 geographically isolated districts (Reynolds et al., 2015). There were also approximately 122 disadvantaged regions in Indonesia in 2015 (Ardiansyah, Marthen, \& Amalia, 2015) with a lack of digital resources or no access to technology for academic purposes. Teachers who live in the geographically isolated areas are likely to have difficulty accessing professional learning without significant travel and they face limited broadband access. These conditions may impede their ability to overcome challenges in teaching because there are limited means to connect, share, or seek help for problem-solving with other colleagues and this can lead to professional isolation (Buchanan et al., 2013). This suggests that further improvement needed to strengthen Internet connectivity and technology infrastructure in Indonesia to enable access for information and education, particularly in the geographically isolated districts and disadvantaged regions.

The lack of good quality of Internet connectivity and ICT infrastructure is perceived as the major barrier to innovative teaching practices using technology (e.g. Cahyono \& Mutiaraningrum, 2015; Relmasira et al., 2017; Son, Robb, \& Charismiadji, 2011). Significant amounts of isolated and marginalised rural communities of educators and students with no Internet access and no ICT infrastructure still continue to persist (Azzizah, 2015), which seems to correspond to a study identifying the need for better Internet and ICT infrastructural support for educators' education technology professional learning in Indonesia besides policy, moral, 
and financial support (Tanang \& Abu, 2014). The regional gap of technological infrastructure also adds to the challenges of Indonesian educators' technology professional learning. Many local governments are not yet exercising their full authority due to the insufficient capacity of the local governments, which may be related to the quality of access to education and information resources in response to issues and problems arising in the regions (Kusmawan, 2015).

Indonesia is also one of the countries with the highest Internet costs in Asia (Latchem \& Jung, 2009). However, the use of mobile devices for interaction and communication is uniquely more pervasive and extensive where the vast majority of Internet users (85\%) in Indonesia conducting online activities using their mobile phones ("In Indonesia", 2015). A recent study on the potential of mobile phones for teacher training in Indonesia indicated that the price for devices and services was affordable and the coverage area of the mobile network was broad, and this is the reason why it has become the preferred mobile learning device (Yusri, Goodwin, \& Mooney, 2018). According to a study on Global Mobile Behaviour by Millward Brown, Indonesians spend nearly five hours a day on a smartphone, more than any other nationality (Southgate, 2014). Nevertheless, in a report by the The Economist Intelligence Unit (2018), Indonesia was ranked 67th in a list of 82 nations in terms of technological readiness ranking. The report evaluated over 200 countries worldwide in terms of their readiness for technological change. Three factors were examined: access to the Internet, digital economy infrastructure, and openness to innovation. The report ranked Finland, Australia, Singapore, and Sweden the first and among the best in their technological readiness. This suggests how access to the Internet, digital economy infrastructure, and openness to innovation in Indonesia still needs further improvement compared to other reported countries with higher ranks of technological readiness.

\section{The prevalence of traditional pedagogy}

Arguably, traditional pedagogy is still prevalent in the majority of regions in Indonesia and becomes the second major barrier for ed-tech professional learning. Such pedagogy is strongly linked to passive-didactic teacher-directed activities that focus more on sit and listen model of classroom teaching (Sulfasyah, Haig, \& Barratt-Pugh, 2015). Traditional pedagogy is also typically referred to the pre-technology education context of teacher-centered model of teaching delivered via the "chalk-and- talk, marker-and-white board" method and overhead projector (OHP) transparencies (Mbodila \& Muhandji, 2012). The prevalence of traditional pedagogy in Indonesia could indicate the limited use of ICT at school (Palekahelu et al., 2016) and the dominant norm of a stand and deliver instruction among Indonesian teachers (M. Burns 
\& Bodrogini, 2011; Kusmawan, 2015). This suggests that the use of ICT is not yet optimum and effective for transforming teaching and learning practice at all schools to be fully digitally integrated as in the developed countries.

\section{Low English proficiency}

Most of Indonesian educators' English proficiency is still low in this country (Simatupang, 2017), which presents as the third major barrier for ed-tech professional learning as it limits learning from ed-tech practices and content around the world, as well as connecting, interacting, communicating, and collaborating globally. A study found that many Indonesian teachers may not have reached a level of proficiency considered sufficient for effective teaching, particularly in teaching English as foreign language/TEFL (Renandya, Hamied, \& Joko, 2018). Local teachers are still considered to have low levels of competence in English communication skills and have a mixed view of locally and internationally produced materials where the quality of English instruction is also poor (Stockton, 2018). A survey of 27,000 teachers in RSBI (Pioneer schools with international standard) junior secondary, senior secondary and vocational secondary schools (Ipnugraha, 2013) signified that more than half of all teachers and head teachers English proficiency were at the "novice" level, scoring between 10 and 250 on a 990-point scale. The other $45 \%$ of teachers and head teachers had an "elementary" or "intermediate" level of English and there were only $0.7 \%$ of teachers and $0.2 \%$ of head teachers had an "advanced working" or "general professional" level of proficiency in English (Lie, 2017, p.76). Indonesian teachers who favour using English in their practice also seem to be concentrated in Java Island compared to other islands in Indonesia. Zacharias (2005) conducted a survey of Indonesian English teachers working on Java; 67\% exclusively prefer international materials with only $7 \%$ who exclusively prefer local. However, in rural Indonesia, English can appear as rather useless, with almost no exposure as a subject worth learning as the continuation to higher education is often not valued by families (Pasassung, 2003, p.125). This may relate to the Indonesian government's disposition towards the use of English in the national education system, which is seen as undermining Indonesian culture and language due to "western liberal values" (Lauder, 2008) and that it can potentially threaten nationalism (Rahmi, 2016). The ability to communicate in English also crucial to enable global learning and collaboration, which is the key for ed-tech innovation acceleration. Thus, the low English proficiency may limit opportunities for ed-tech professional learning that involves a global context, content, connection, and collaboration. 


\section{Google's emergence in Indonesia}

In 2012, Google launched its representative office in Jakarta, Indonesia as it expanded its scope of ed-tech outreach within south-east Asia region (Kevin, 2012). At the opening of the Google office in Jakarta, the country head at the time, Mr. Rudy Ramawy explained to TechinAsia (Kevin, 2012) that Indonesia had enough potential in the digital economy market that Google could facilitate and therefore, by opening its office in Jakarta, Google wanted to boost the whole tech and Internet ecosystem in Indonesia. In particular, according to Google Indonesia Managing Director, Tony Keusgen, Google Indonesia aims to bringing better access to the Internet and enabling easier access to relevant information in a way that suits the local needs of Indonesians (Marzuki, 2017). Google Indonesia's vice president of product management Caesar Sengupta told Digital News Asia that Indonesia is a country that Google takes very seriously because of its potential size of market, its mobile users advantage, and diverse local opportunities by collaborating with Indonesian government and various national and local companies (Baziad, 2016).

Several projects have been conducted in collaboration with the Indonesian government and various national and local companies. Among these projects are Indonesian-dedicated Google applications (Google Maps Indonesia, Google Voice Search in Bahasa Indonesia, localised Chrome Web store, local business online applications). The Internet-based service and infrastructure such as Google Stations (public Wi-Fi spots) and YouTube Go (Youtube mobile app that can be used with poor connectivity have also been tested specially for Indonesians. The family safety day is a program organised by Google in collaboration with Indonesian Ministry of Communication and Information Technology to make its products safe for family to use. Large-scale digital training programmes using Android-based applications have also been conducted in six cities. Google also implemented initiatives for enhancing and reaching out to Indonesian entrepreneurs and small to medium enterprises through free applications such as Primer and Gapura Digital as well as the Womenwill programme (Marzuki, 2017).

Google Indonesia claims to have a goal for encouraging ed-tech oriented communities that comprised of various professions in education and ed-tech field by providing financial support, technological infrastructure, and trainings. Google Indonesia introduced Google Educator Groups (GEG) as a platform that communities can use for free starting in 2012. GEG is advertised as a community-based platform for educators around the world to connect, learn, collaborate, share, and support each other through globally and locally-run free online and faceto-face events, interaction, and activities. School principals, school administrator, professor, 
lecturers, teachers, or ed-tech practitioners are invited to join. GEG is part of 'Google for Education' products, programs, and philanthropy to support innovation in education with technology (Erlangga, 2015). Prior to 2012 when GEG was first introduced in Indonesia, Google had a global launch of GEGs along with its dedicated online forum on Google Plus $(G+)$ that the groups can use as resources. In response, educators from various countries started to establish GEG communities using Google Plus online forums.

It appears that Google's expansion in Indonesia is primarily driven by 260 million population, which they considered a potential prospect for the digital market of Google products. Google has captured Indonesian people's interest and attention with its marketing campaign of its products and activities by collaborating with important sectors, such as Indonesian government and national institutions. With such collaboration, Google products have been massively introduced into national-scale level programs and activities, which becomes Google's key to expand into various sectors including educators. However, Google's approach to market its products and ed-tech vision may face more complex challenges as not all educators have similar access to technology and information. The introduction to GEG and its dedicated platform of Google Plus Communities in Indonesia may be one of the efforts to get as many educators as it can to be familiar with Google's products.

In Indonesia, a number of educators have voluntarily initiated and led Google Educator Groups (GEGs) as leaders while others have voluntarily joined as members since 2014. Anyone can join for free and participate through online forums (on Google+), instant messaging, and face-to-face events organised and conducted within various regions in Indonesia. Information on the global GEG website displays each groups' ed-tech vision, practices, and activities. According to the participants in this study, Google Indonesia has provided support for leaders to organise local activities in their groups. This support includes financial incentives/grants (around \$200 to \$300 per term), Google merchandise (e.g. T-shirt, stickers, mugs, USB, pen, agenda/notepad), and learning spaces at Google office (that can be used for free). Google Indonesia also provided access to ed-tech leadership training for GEG leaders for free. Financial support from Google Indonesia was given for two years to each GEG, after which the GEGs were considered independent and could stand on their own. However, other forms of nonfinancial support such as web-based tools and applications for education continued to be provided to educators and schools. This suggests that providing incentives for Indonesian educators is an essential strategy to encourage their participation in establishing communities using Google products. However, it is important for Indonesian educators to be more critical of the privacy issues of the data when involving students personal database and information. As 
of no specific educational policy has yet to be established by the Indonesian government regarding data management of students when using Google's products, this should be taken into consideration within the school communities as to how this data privacy issues will be appropriately addressed and the role of Google Indonesia in handling such data.

\section{The significance of the study}

As the digital learning landscape increasingly offers new opportunities for educators' ed-tech learning and practices, there is a need to further understand the potential and significance of enacting agency for educators' professional growth (Goller \& Paloniemi, 2017). This raised my interest in conducting a study on how educators enacted their agency in ed-tech professional learning within the context of their GEGs in Indonesia. Further understanding about the nature of their ed-tech professional learning in the GEGs is essential to gain insights into the opportunities and challenges that Indonesian educators face and experience in ed-tech professional learning. This study contributes to developing knowledge on the changing nature of educators' professional learning through Indonesian educators' social cognitive aspects of their ed-tech professional learning experiences in the GEGs. As an educational technology specialist in the Ministry of Education and Culture in Indonesia, findings in this study will inform my work in facilitating educators' professional learning across Indonesia using information communication technology. Educators, facilitators, school leaders, administrators, policymakers, and stakeholders can also benefit from this research as they can identify what type of support can be provided and cultivated to create a conducive learning environment in their education technology context.

\section{Research questions}

Given the context above, the following questions arise:

\section{Question 1:}

How do Indonesian educators participate in the GEGs for ed-tech professional learning?

\section{Sub-questions:}

- Why do educators engage in a GEG?

- How and what do educators learn through participating in a GEG?

- What do individual educators find beneficial from participating in a GEG? 


\section{Question 2:}

How do the GEGs function to enable Indonesian educators' ed-tech professional learning?

\section{Sub-questions:}

- What roles do individuals have within a GEG?

- What learning activities occur within a GEG?

- What enables or impedes learning within a GEG?

\section{The organisation of the thesis}

This thesis is presented in nine chapters. Chapter 1 presents an introduction to the study. Chapter 2 is a review of the literature relevant to this study. The literature reviews the shifting paradigm of professional development in the field of education from the formal-traditional, the continuous, and the contemporary approaches followed by the examination of teachers' selfdirected professional learning involving the use of technology and its implications to teachers' agency and current models of teachers' self-directed professional learning, the relevance of social cognitive, and the literature gap. Chapter 3 outlines the methodology used in this study, with the justification of selecting an exploratory qualitative collective case study design. Chapters 4, 5, and 6 present the findings of each case study, followed by Chapter 7 which presents the cross-case analysis/synthesis of the findings. Chapter 8 is a discussion of findings and their significance in answering the research questions. Lastly, Chapter 9 draws conclusions and elaborates on the limitations of the study and the implications for future studies and ends with concluding thoughts. 


\section{Chapter 2}

\section{Literature review}

\section{Introduction}

I started my study with an interest in examining Indonesian teachers' professional learning in the GEG, which to my perspective, reflects a unique dimension of professional learning that is informal, self-directed, individually, and collectively situated, and educational technology (ed-tech) driven. This particular dimension of professional learning guided my preliminary review of literature to its process of refinement.

A search on "self-directed and informal teacher professional learning in educational technology" on Google Scholar generated 50,700 results in 0,23 seconds, indicating an emerging specific area of discussion within the literature of teacher professionalism compared to more general-wider areas such as "teacher professional development" with 3,870,000 results in 0,04 seconds; classroom teaching with $2,940,000$ results in 0,07 seconds, or school reform with 3,070,000 results in 0,05 seconds. In self-directed and informal ed-tech learning, teachers become agents in their own learning process; making initiatives and deciding how, what, and with whom to learn reflecting the agentic capabilities in teacher professional learning. This significantly narrowed down my search of literature on teacher professional learning agency with the use of educational technology. Further search of "teacher professional learning agency with the use of educational technology" on Google Scholar resulted in 497.000 hits in 0.17 seconds, which underpinned the scope of my review of literature into studies that emphasised on the shifting paradigm of professional development in education leading to teacher selfdirected professional learning and predominantly three current educational-technology oriented models: teacher informal leadership with technology, personal learning network (PLN), and informally-organised technology mediated learning collectives. Due to the rapid changing nature of the field of educational technology, I focused on research published after 2005.

I reviewed literature a second time during the process of data analysis to consider its alignment with my findings. One major theme I identified from my findings was the significance of agency and how it influenced teachers in self-directing their professional learning with technology within variety of context, which led me to Bandura's social cognitive theory. Further reading on social cognitive theory (Bandura, 1999, 2001) and other researchers' works within social-cognitive perspective resulted in the use of social cognitive theory as a relevant and useful theoretical framework for my study. 
This chapter examines relevant literature related to significance of agency and how it influenced teachers in self-directing their professional learning with technology. The literature review consists of five main sections. In the first section, I examined literature related to the shifting paradigm of professional development in education. I identified three major approaches to teacher professional development and how these contribute to the shifting paradigm: the formal-traditional, the continuous, and the contemporary. The second section of the literature review focuses on teachers' self-directed professional learning involving the use of technology and its implications for teachers' agency. In the third section, I further reviewed literature related to three current educational technology-oriented models of teachers' self-directed professional learning: (1) teacher informal leadership with technology; (2) personal learning network (PLN); (3) informally-organised technology-mediated learning collectives. The fourth section primarily reviews Bandura's social cognitive theory as the theoretical framework of my study. This chapter ends with a summary highlighting the literature review and the gap in the literature.

\section{The shifting paradigm of professional development in education}

In the field of education, professional development (PD) is considered an important key to improving the quality of teachers (Desimone, 2009) and is strongly linked to students' achievement in learning (Yoon, Duncan, Lee, Scarloss, \& Shapley, 2007). The role of professional development is also deemed crucial to support teachers to be responsive to changing and challenging professional demands (Berliner, 2001; Joyce \& Showers, 2002), particularly in the complexity of educational change driven by digital technologies influencing education policies, practice, and schooling structures (Starkey, 2012). Teachers are also expected "to prepare students to be active and successful citizens in the world today and in the future" (Starkey \& Finger in (Voogt, Knezek, Christensen, \& Lai, 2018, p. 1274), which requires them to develop higher level skills, knowledge, and capacity for effective and innovative teaching and learning practice in variety of subjects. For example, developing collective knowledge through professional discussions (Starkey, 2012), developing "digital teaching and professional digital competencies" (Starkey, 2019, p.15), developing skill, knowledge, and disposition to facilitate students with culturally-diverse background (M. Lin \& Bates, 2014), and assessing students' creative collaborative processes in music composition (Thorpe, 2018). It is important for teachers to develop such diverse skills to facilitate today's generation of learners with technology-driven mindset and global cultural background. 
Professional development provides opportunities for teachers to not only develop skill and knowledge needed to improve practice but also thrive successfully in overcoming constant changes and challenges within the profession. For example, through PD, teachers can develop their competencies in practical setting (Knight, 2002) and improve their commitment and satisfaction to overcome attrition and turnover (Dede, Jass Ketelhut, Whitehouse, Breit, \& McCloskey, 2008). Thus, it is important that teachers have continuous access and opportunities for professional growth leading to the reconceptualization of PD as an authentic learning experience (Webster-Wright, 2010) rather than a sit-and-get program such as conferences, courses, and institutes (Garet, Porter, Desimone, Birman, \& Yoon, 2001).

A considerable body of literature on teacher professional development has provided useful insights on the shifting paradigm from three major approaches to teacher professional development: traditional-formal approach (e.g. Eraut, 2000), continuing approach (e.g. Kennedy, 2005), and contemporary-informal approach (e.g. Borko, Jacobs, \& Koellner, 2010). These different approaches signify that teacher professional development is a complex process, undergoes changes, and can be challenging depending on certain contexts, which reflects significant changes in the way PD is perceived and conducted.

\section{Traditional-formal approach to teacher professional development (TPD)}

Traditional-formal model of teacher professional development is commonly designed and provided by external bodies such as government, state departments, training institution, or universities (Levenberg \& Caspi, 2010), which is also known as top-down approach (Baron, 2008). Eraut (2000) described the characteristics of formal PD as having "a prescribed learning framework, an organised learning event package, presence of a designated trainer, award of a qualification credit, and external specification of outcomes" (p.114). Other researchers also described traditional-formal PD as mandatory in nature with structured activities where teachers are required to attend sit-and get series of lecture-based sessions with non-teacher experts (Park, Steve Oliver, Star Johnson, Graham, \& Oppong, 2007). The general outcome of this PD model includes a form of certification, professional learning credits or accreditation (DarlingHammond, 2009). Examples of traditional-formal PD model are in the form short-term or onesession workshops, trainings, seminars, lectures, and conference, which has been criticised by many researchers as being brief, fragmented, incoherent, decontextualized and isolated from real classroom situations (Collinson \& Ono, 2001; Feiman-Nemser, 2001; Villegas-Reimers, 2003). This model of PD tends to focus on what is being taught rather than what is being learned by teachers in the classroom or other practical context (Strucchelli, 2009). Borko (2004) argued that traditional-formal approaches to PD are likely to be fragmented and intellectually 
superficial, disconnected from classroom practices, and unrelated to teachers' actual needs and interests. Other criticisms to traditional-formal PD in the literature were that it was irrelevant to teachers' practice, time-consuming (Guskey, 2014), "meaningless and wasteful” (Guskey, 2002, p.4), and did not meet the needs of teachers (Lloyd \& Duncan-Howell, 2009).

\section{Continuous approach to PD (CPD)}

Continuous PD emphasises the long-term, dynamic process that teachers need to continuously engage in to foster their professional growth (Villegas-Reimers, 2003). Guskey (2002) asserts that continuing professional development enables teachers to build pedagogical knowledge and keep abreast of new technologies that can be used to improve their educational practice. Kennedy's (2005) approach of continuing teacher professional development features:

- Training - the dominant form of CPD for teachers situating teachers in a passive role as recipients of specific knowledge,

- Award-bearing - commonly offered as courses provided by universities,

- Deficit - designed to address perceived deficits in teacher's individual performance,

- Cascade - a series of training designed for teachers who will be trainers for others. This model is commonly employed to overcome situations pertaining to limited resources,

- Standards-based - a centralised model designed to develop standardised competencies for teachers,

- Coaching/mentoring - involving one-to-one learning interaction between a novice as a mentee and a more expert teachers as a coach/mentor,

- Community of Practice - a form of social learning within a community involving more than two people,

- Action-research - involving teachers as participants in their own learning context providing them with more control and direction to improve their practices,

- Transformative - involving range of different conditions providing teachers with opportunities and experiences for transformative practices supporting educational change (p. 237-246).

Kennedy's (2005) models reflect a shift from learning in a mandatory and structured environment with teachers as a passive object to a more liberating, flexible, and personalised learning with teachers as an active subject allowing transformational change in teachers' experiences and practices. This shift is also interpreted as the way teachers can take charge in their professional development in the way that it is more empowering (Hannay, Wideman, \& Seller, 2010). Their notion of teachers taking charge in professional development aligns with Kennedy's (2005) PD models of coaching/mentoring, community of practice, action-research, 
and transformative where teachers appeared to be more in charge in navigating and directing their learning.

\section{Contemporary approaches to TPD}

There has been an increasing debate in the literature on the effectiveness of teacher professional development as the advancement of technology has significantly influenced educational policy, learning landscape, and dynamics of teaching profession leading to contemporary approaches to teacher professional development (e.g. H Borko et al., 2010). Contemporary models describe PD as visionary (Diaz-Maggioli, 2004), situated (Moncada, 2007), transformative (Kennedy, 2005), constructivist-base (Leu, Kinzer, Coiro, \& Cammack, 2004), reformed (Garet et al., 2001), self-directed (Van Eekelen, Vermunt, \& Boshuizen, 2006), often informal(Visser, Evering, \& Barrett, 2014), and digitally-driven (Langset, Jacobsen, \& Haugsbakken, 2018). Guskey (2002) argued that "to be successful, professional development must be seen as a process, not an event" (p. 388) and "it needs to provide teachers with "specific, concrete, and practical ideas that directly relate to the day-to-day operation of their classrooms" (p. 382). It appears that these contemporary models of PD have gained momentum as some researchers reached a consensus that the contemporary PD models have features of what is considered as high-quality PD (e.g. Bautista, Cañadas, Brizuela, \& Schliemann, 2015; Hilda Borko, 2004; Darling-Hammond \& McLaughlin, 2011; Desimone, 2009; Garet et al., 2001) suggesting that such PD models are likely to be more effective than traditional ones. Other features identified in the literature of contemporary PD models are: a) active learning opportunities, and active engagement in exploration, reflection and discussion; b) contexts for collective participation and collegial sharing; c) constructive and non-prescriptive feedback; and d) sustained follow-up support after program completion (Bautista et al., 2015; Desimone, 2009; Sherin \& Han, 2004). These studies suggest that contemporary PD models offer teachers high-quality opportunities to develop their professional skill, knowledge, and practice.

The focus of research into contemporary PD has moved from professional development to professional learning. In the literature of traditional approaches to teacher professional development (TPD), the term professional development, although important, has been criticised as having a passive nuance in practice evoking an image of what someone does to others through mandatory program or activities, such as courses that offer credits or certification (Easton, 2008). In contrast, in the literature of contemporary approaches to TPD, the term professional learning is significantly used to describe a continuous voluntary process of teacher learning where they have more autonomy, voice, and choice to personalise and direct their own learning (Putnam \& Borko, 2000), which corresponds to increasing focus on the literature of 
teacher's agency and professional learning (e.g. Biesta, Priestley, \& Robinson, 2015; Eteläpelto, Vähäsantanen, Hökkä, \& Paloniemi, 2013). Within this context, teacher agency is viewed as a quality in the personal capacity to act (Priestley, Edwards, Priestley, \& Miller, 2012; Schlosser, 2015). The enactment of agency enables teachers as learners to have a sense of ownership and control over their own learning to make choices, act on these choices, and reflect on the implications towards the choices they make (Harteis \& Goller, 2014). It also enables learners to make decisions, take initiatives, act proactively (not only reactively), creatively, innovatively, and find ways to thrive in facing challenges (Eteläpelto et al., 2013; Goller, 2017). This enactment of agency is considered a precursor to meaningful learning experiences that contribute to a stronger sense of efficacy to improve practice (Eun, 2018). These studies share similar contemporary approaches to PD including providing opportunities for agentic learning, which a number of studies found to be vital for creating meaningful experiences. (Reimers \& Chung, 2018) suggested a "fundamental rethinking about what kind of learning experiences lead to deep changes in teacher practice" (p. 11), which brings about a trajectory of how contemporary approaches to PD can lead to creating learning experiences that enables deep changes in teachers' practice.

The literature related to teachers' agency in professional learning highlights the importance of teacher agency to school reform and educational transformation with technology. For example, Imants and Van der Wal (2019) found that the model of teacher agency in professional development and school reform is built on five characteristics:

(1) situates teacher as an actor,

(2) has dynamic relationships,

(3) is inherently contextualized,

(4) includes the professional development and school reform content as variable and,

(5) considers outcomes as part of a continuing cycle

These characteristics align with the essential role of teacher agency in the ongoing transformation of education through the application of ICT where they orchestrated learning resources and activities to match educational provision to the need of teachers (Albion \& Tondeur, 2018). These studies support positive implications of agency to teacher's practice. For example, Wright (2015) found that teachers enacted their agency by making decision of the tools, the lesson design, the class, and the learning purpose to find ways in addressing hindrances, which reflects their active role in crafting the learning process (Newman, 2002) and 
explore opportunities to take the initiative and make a difference, leading to self-efficacy (Hamill, 2003). Thus, these studies posit that the features of high quality teacher professional development identified within contemporary PD models substantially embody teacher's agency enabling transformation and positive implications to practice.

There are five prominent themes in the literature on contemporary approaches to teacher professional development where the role of teacher's agency, social connectedness, and the use of technology to support learning is significant. These themes are self-directed professional learning (e.g. Carpenter \& Linton, 2018; Smith, 2017), the use of technology in teachers' selfdirected professional learning (e.g. Carpenter \& Green, 2017; Jaakkola, 2015), teacher informal leadership with technology (e.g. Clements, 2018; Newton, Riveros, \& da Costa, 2013), personal learning networks (PLN), informally-organised technology-mediated learning collectives (e.g. Lantz-Andersson, Lundin, \& Selwyn, 2018; Trust, 2017), and social cognitive perspective of teachers' self-directed learning (Bandura, 2001, 1999).

Put together, these themes describe an agentic perspective of educators' professional learning and its implications to their professional learning experiences. The following sections further review the literature on each theme and examines its significance to teacher's agency, social connectedness, and the use of technology.

\section{Self-directed professional learning}

The prominent characteristic of self-directed professional learning described in the literature are the acknowledgement of educators' agentic capability in the learning process. Within this self-directed learning process, learners are internally self-motivated and willing to seek learning opportunities (Mushayikwa \& Lubben, 2009) to fulfil their needs and selfregulate them within their own context to achieve their goals (Cho \& Heron, 2015; Spruce \& Bol, 2014). When educators demonstrate the willingness to learn and be engaged in directing their own learning, it enables them to make professional judgements about their learning needs and deciding ways to address them accordingly (Minott, 2010). How professional judgements are made into decisions to address the learning needs corresponds to teacher's active agency in integrating several sources of knowledge and how it is applied in proper context (Tang \& Choi, 2009).

Studies examining the continuum of adult learning from andragogy or self-directed learning (Merriam, 2001; Smith, 2002) to heutagogy or self-determined learning (Blaschke \& Hase, 2015; Hase \& Kenyon, 2001) provide useful insights on educator's agentic capabilities to seek opportunities for professional learning. In andragogy, adult learning is characterised by 
learners being responsible, having control over what they learn, and being independent in managing how they learn (Smith, 2002). For example, planning and diagnosing learning needs, formulating learning objectives, designing and carrying out learning plans, and evaluating the learning process reflecting the capacity for self-direction and emancipation leading to transformation (Merriam, 2001). Heutagogy is the extension of andragogy where learner's capability of self-directness develops into self-determination within a more complex digital learning environment (Hase \& Kenyon, 2001). As an emerging concept within the adult learning continuum, there is, however, little research on heutagogy (Blaschke, 2014) and there is a need for further research that yields evidence of the efficacy of heutagogy within education (Bhoyrub, Hurley, Neilson, Ramsay, \& Smith, 2010). Nevertheless, few examples of empirical evidence support the role of teacher agency and its significance to professional learning in the digital age. For example, how learners used e-learning resources to access what they need and in a way that suits their style of learning (Canţer, 2012); how learners developed a range of resources for learning by being collaborators (Garnett \& O'Beirne in Hase \& Kenyon, 2013); how teachers were more capable through improved learning outcome (Blaschke, 2014); and how teachers became facilitators for others through networked technologies (Jaakkola, 2015). Literature on andragogy and heutagogy suggest that developing agentic capability is central to transformational learning for teachers by findings ways to adapt to constant change within a complex learning environment.

Developing agentic capability includes exerting self-control known as self-regulation (Carver, Johnson, Joormann, \& Scheier, 2014), which leads to self-efficacy ( Bandura, 2001, 1999). Through self-regulation process, people can find ways to be resistant to pressure, deliberate conscious thought, and make rational choice (Baumeister, Sparks, Stillman, \& Vohs, 2008) leading to a belief in one's ability to complete desired task in particular situation (Bandura, 2001). However, self-efficacy needs to be maintained to develop resilience, persistence, and optimism to overcome diverse challenges in a complex situation (Gebbie, Ceglowski, Taylor, \& Miels, 2011). In the context of teacher, Tschannen-Moran and Hoy, (2001) bring out Bandura's (2001) concept of self-efficacy into teacher self-efficacy:

"Teacher efficacy is the teacher's belief in his or her capability to organize and execute the courses of action required to successfully accomplish a specific teaching task in a particular context" (p. 22)

Teachers' self-efficacy is considered to have a significant impact on student academic and cognitive development (Bandura, 1999) and it positively influences teachers' teaching and instructional behaviours (Skaalvik \& Skaalvik, 2007). However, (Gavora, 2010) argues that 
teacher self-efficacy is different from teachers' competence and is more closely linked to teachers' perseverance:

"teacher self-efficacy is a strong self-regulatory characteristic that enables teachers to use their potentials to enhance pupils' learning...It is related to perseverance: the stronger the self-efficacy, the greater the perseverance and the greater the perseverance, the greater the likelihood that the teaching behaviours will be successful" (p. 2)

These studies, therefore, emphasise on how social-cognitive aspects of teachers' self-directed professional learning can lead to teacher self-efficacy through the development of their agentic capabilities.

How teachers manage to self-regulate their own resources in order to effectively cope with the professional demands reflects their efficacy beliefs (Kunter et al., 2013). For example, when educational policy implementation, high-stakes standardisation, or school leadership limits teacher's agency in a way that it de-professionalise and disempower them, it can lower their self-efficacy in being able to make a difference or it can make them feel that they did not matter (Hinnant-Crawford, 2016). This aligns with findings from Cerit's (2013) study where teachers' level of self-efficacy regarding students' engagement and instructional strategies was positively associated with their willingness to enact curriculum reform in their own classrooms. Furthermore, the ability to self-regulate can also change depending on various factors such as cognitive and environment (Nikolaki, Koutsouba, Lykesas, Venetsanou, \& Savidou, 2017). If teachers believe that their attempts on student achievement will fail, they are likely to decrease their efforts in finding ways to heighten student's performance (De la Torre Cruz \& Casanova Arias, 2007), which reflects how cognitive aspect influences action. A recent study on Metrorail commuters' agentive practice on their mobility also confirmed the influence of cognitive and environmental aspects on the ability to regulate (Bergman, Bergman, \& Thatcher, 2019). Their study revealed that there is a reciprocal interaction between agentive practices and environments where the environment can facilitate or constrain the ability to commute. These studies suggest that both cognitive and environmental aspects are influential to enable or refrain agency.

Some researchers found that educators' increased, and decreased levels of agentic capability are linked to their high and low efficacy belief. Teachers with higher level of selfefficacy had more experience, knowledge, and skills than those with lower efficacy belief (López et al., 2013). Barkley (2006) revealed that the high and low efficacy influence how individuals perform, whether he or she will be persistent or surrender all efforts, which is supported by Ross and Bruce (2007) in their study on the characteristics of highly-effective teachers. They identified these teachers as having (1) high goal selection, (2) high exertion of 
effort, (3) persistence, (4) high student achievement, (5) improved instructional practice, (6) willing implementation of innovative teaching ideas, (7) mutual classroom control with students, (8) stimulation of student autonomy, (9) close monitor of lower ability students, (10) improvement of student self-concept, (11) motivation triggered even by failure, (l) acceptance of personal responsibility for successes and failures, (12) resourceful, (13) self-reflective, and (14) victorious over external challenges. These characteristics seem to reflect optimism and confidence, which (Bandura, 1989) referred to as a 'can-do mentality' within his conception of self-efficacy:

"People who have a high sense of perceived self-efficacy in a given domain think and feel differently from those who perceive themselves to be inefficacious" (p. 731).

In contrast, lower self-efficacy or inefficacious people often demonstrate pessimism and insecurity, which can trigger negative experiences or feelings such as stress, burnout, or despair (Ware \& Kitsantas, 2007). Recent studies on teacher's attrition rates indicate that challenging work environment can lower self-efficacy (Jamil, Downer, \& Pianta, 2012; Swanson, 2012). Low sense of self-efficacy is also associated with teacher's dissatisfaction and attrition (Mota, 2010) as well as low self-confidence (Deskins, 2010). Charalambous and Philippou (2010) described inefficacious teachers as being "less willing to move beyond their comfort and safe zone" (p. 14). While successful experiences can increase teachers' self-efficacy, experiences of failure decrease their perceptions of capability (Bandura, 1999; Schunk \& Pajares, 2009). Thus, what seems to differentiate between teachers with higher and lower self-efficacy is their quality of decision-making process, the problem-solving and coping strategies, and the levels of competence. These studies share similar perspective of self-efficacy as a temporal and dynamic construct of cognitive-behavioural-environmental factors where the high or low levels of it depends on certain context, which can contribute to personality.

Self-directed professional learning is considered a platform for teachers to exercise their agentic capabilities, which can positively influence their self-efficacy. For example, Carpenter and Krutka (2014) reported that educators felt enthusiastic, invigorated, empowered and connected by using Twitter as a platform for self-directed, teacher-driven professional learning as it helped them overcoming the feeling of isolation. Carpenter and Linton (2018) also found that self-directed professional learning through Edcamp improved teachers' motivation, confidence, and connectedness as they actively reached out for advice or support and learned from the practice of others. Therefore, it is evident that educators' agentic capabilities, social connectedness, and use of technology in self-directed professional learning are significant components that can contribute to their professional growth. 
There is an emerging body of literature on agentic professional learning reflecting the increasing importance of agency in teacher's self-directed professional learning (e.g. Evans, 2017; Goller \& Harteis, 2017; Vähäsantanen, Hökkä, Paloniemi, Herranen, \& Eteläpelto, 2016). There are three major components of agentic professional learning: influencing at work, contributing to work practices, and the negotiation of professional identity that contributed to sustainable learning and wellbeing at work (Vähäsantanen et al., 2016). These components are often associated with active behaviour with transformative influences in making changes to the previous or present state of affairs (Goller \& Harteis, 2017). This suggests that self-directed professional learning is a form of agentic professional learning that enables opportunities for transformational experiences.

Literature on agentic professional learning highlights educators' increased awareness of empowerment, confidence, and voice in their learning process (Dierking \& Fox, 2012), agentic capacities in using web-based technologies (e.g. Burbules, 2007; Seely Brown \& Adler, 2008) and the participation in informal learning communities (e.g. Palaiologos, 2011; Vescio, Ross, \& Adams, 2008). Studies also suggest that teachers' agency in self-directed professional learning embodies social connectedness in a way that it enables them to create meaningful learning experience as both independent and social learners within the context of their environment (Bandura, 2006; Frost, 2006; Lipponen \& Kumpulainen, 2011; Riveros, Newton, $\&$ Burgess, 2012). These studies provide insights that teachers' agentic capacity in self-directed professional learning is inseparable from social influences and the environmental context.

\section{Technology use in self-directed professional learning}

Technology use is prevalent in the literature on self-directed professional learning reflecting the relevance of technology in teaching practice, which is often referred to as education technology:

"Educational technology (ed-tech) is the study and ethical practice of facilitating learning and improving performance by creating, using, and managing appropriate technological processes and resources” (Januszewski \& Molenda, 2008, p.1).

Lakhana (2014) asserts that although the term education technology has evolved adjusting to technological changes and its use various fields including education sector, Januszewski and Molenda's (2008) definition of educational technology is currently established as the latest working definition in the Association for Educational Communications and Technology (AECT). Regardless of the variety of perceptions towards defining educational technology, what remains significant is the emphasis on the combination the two elements of machines and the human factor that keeps education to its valuable core of morals, discipline and the art of 
living (El Miniawi \& Brenjekjy, 2015). The context of educational technology in this study follows Januszewski and Molenda as well as El Miniawi and Brenjekjy's notions of ed-tech.

Ed-tech is considered a competitive industry, and this may contribute to an evolving use of educational technology that can alter the current educational landscape because where the needs and demands for implementing digital technologies within educational system are increasing. One of the significant implications of education technology is the datafication of education or digitisation of educational data, such as classroom management and student outcome data (Selwyn, 2014). Another example is the influence of technology use on the proliferation of information-sharing mechanisms (Hawkins, 2001), and the advances of technology such as Internet, mobile communication applications, or augmented reality (e.g. Blaschke, Kenyon, \& Hase, 2014; Eberle, 2009; Jaakkola, 2015). Thus, it is vital that educators understand the changes that technology brings to education and improve their ed-tech skills and practices accordingly, such as "digital pedagogy, digital life competencies, social digital competencies, and professional and specialized digital competence" to facilitate today's generation of learners (Tsvetkova \& Kiryukhin, 2019, p.4-8) underpinning the rise of educational technology.

Studies reported positive implications on the use of various technologies such as mobile Internet messaging applications and web-based applications in teachers' self-directed professional learning. For example, Carpenter and Green (2017) reported on the affordance of mobile instant messaging of Voxer to enable positive changes in teachers' instructional practices, attitudes, mindset and disposition, leadership and PD, access and awareness, and opportunities to try new things. Cansoy (2017) found that the use of the WhatsApp group supports knowledge-sharing in the community through four forms of sharing: field knowledge, pedagogical content knowledge, in-school teaching practices, and emotional support among teachers. In an early study of TappedIn, Schlager and Fusco (2003) found that synchronous and asynchronous discussions, with technological support such as whiteboards and web page viewers, allowed teachers to work and learn with diverse group of colleagues and experts beyond local sites:

"Thousands of different people log in each month to engage in activities that include course and workshop sessions, group meetings, and public discussions spanning a wide range of K-12 topics" (p. 204).

These studies inform that the affordances of technology support educators' agentic practices of professional learning by enabling them to independently seek learning resources outside of formal PD and collectively learn with others at any time. 
One of the interesting features of technology-enabled and ed-tech professional learning is the personalisation of learning, which can support digital agency (Passey et al., 2018) and promote digital equity and intercultural education (Resta \& Laferrière, 2015). The ubiquity of digital technologies such as the Internet and web-based tools allows educators to connect to others through interpersonal connections (Elliott, Craft, \& Feldon, 2010), provide educators with opportunities to personalise ways of learning, as well as to collaborate with others and reflect on those experiences for professional growth (Hunter, 2002). Educational appropriations of Twitter in a range of contexts enables ways of stimulating discussion and encouraging contribution (Wright \& Forbes, 2016), which aligns with teachers' needs of empowerment through collaborative discourse as they take the ownership of their own practice (King, 2019). These studies describe the potentials and affordances of digital technologies to empower teachers through agency, equity, and interpersonal connections.

In some cases, however, although some educators were driven to integrate ed-tech in their teaching activities (Hermans, Tondeur, van Braak, \& Valcke, 2008; Stošić \& Stošić, 2013), others might prefer non-ed-tech teaching and learning practices as they live in a technology-limited environment (e.g. developing countries, technology-deprived regions) where digital divide pervades (Guemide \& Benachaiba, 2012). Patahuddin and Logan (2018) explored how Indonesian mathematics teachers engaging with Facebook for informal professional learning using the 'Five Characteristics of Effective Professional Development' (5cEPD) framework. Their study revealed that Facebook was used as a platform for opening opportunities for others, enriching the pedagogical content, appreciation, and discussing current pedagogical practice within positive and supportive online interaction (e.g. comments). This suggests an active and independent effort among some of the Indonesian educators to personalise learning with web-based resources and within Facebook group support.

However, the use of digital technologies and its implications to teachers' self-directed professional depends on variety of aspects such as educators' perceptions, knowledge, skills, understanding, and attitudes towards technology use in education (Mustafina, 2016). In light of teachers' perception towards technology, Wright (2015) found that learning experiences had profound impact to how Maldivian teacher educators' teaching and their ICT use dispositions were shaped. In recent studies, some researchers also found that digital agency (Passey et al., 2018) and digital equity (Resta \& Laferrière, 2015) influenced teachers' use of digital technologies. Chen, Chen, and Kinshuk (2009) found that web-specific self-efficacy and knowledge creation self-efficacy were important antecedents leading to knowledge sharing behaviour in an online environment. These studies support findings from Counts and Fisher's, 
(2010) study where learning and sharing online was not only confined to technicalities, such as information system or technological infrastructure but also to individuals' relation, cognition, and the environment. Therefore, teachers' ed-tech practices cannot seem to be separated from their dispositions and environment, particularly related to agency, equity, and opportunities.

Studies in the developing countries on the use of technology in self-directed professional learning dominates the literature. Although recent studies in such area were found within Indonesian context, they mainly focused on the affordances of technology. Further studies within Indonesian context need to be conducted to examine diverse technological and non-technological aspects that influence learning and its implication to educators' self-directed professional learning.

\section{Current models of teachers' self-directed professional learning}

\section{Teacher informal leadership with technology}

There is little consensus around what constitutes teacher leadership (Neumerski, 2012). The understanding of teacher leadership and what is considered to be the characteristics of a teacher-leader varied throughout the literature (Wenner \& Campbell, 2016). Fullan and Hargreaves (1996) defined teacher leadership as the "capacity and commitment to contribute beyond one's classroom” (p.13). Curtis (2013) expanded the definition of teacher leadership into "specific roles and responsibilities that recognised the talents of the most effective teachers and deploy them in service of student learning, adult learning and collaboration, and school improvement" (p.iii), which was considered as the significant means to inspire the enhancement of teaching (Muijs \& Harris, 2006). Katzenmeyer and Moller (2009) provided a deeper and more complex definition of a teacher leader:

"Teacher leaders lead within and outside of the classroom. A teacher leader is a member and contributor to a community of teacher learners. They are influential in the continued improvement of educational practice; and accept responsibility for achieving the outcomes of their leadership" (p.6).

Thus, it is evident that teachers' leadership roles are perceived as critical resources for instructional and school improvement (Fairman \& Mackenzie, 2012; Mangin \& Stoelinga, 2010).

The perspective towards teacher leadership is changing. Silva, Gimbert, and Nolan (2000) describe changes in the perception of teacher leadership through three waves of evolution. They illustrate the first wave of teacher leadership with formalised, hierarchical, and administrative-oriented leadership roles such as department heads, union representatives to the instructional such as team leader, curriculum developer, or staff developer. However, this type 
of leadership roles can be counterproductive to teachers and it can isolate them away from peers or put teachers into a position where leaving classroom is required to gain more concentration in undertaking such roles (York-Barr \& Duke, 2004).

The second wave of teacher leadership acknowledges "the importance of teachers as instructional knowledge" (Silva et al., 2000, p.780). In this second wave, teachers' leadership role is shifted from administrative to instructional or teaching-oriented roles, such as staff developer or curriculum specialist. However, these roles are still considered more as add-ons to their regular classroom teaching responsibilities. This suggests that the role of a teacherleader has expanded from a mere administrative role to more substantial role, but these leadership roles are still separated from the teaching function.

The third wave of teacher leadership is described as transformational dimension of leadership (Silva et al., 2000) involving new roles such as are "redesigning the school, mentoring colleagues, problem-solving, and engaging colleagues in professional growth activities" (Pounder, 2006, p.533), which can be shared along with the principal and with others in a collaborative culture without the need of formalised position or official status (Frost \& Harris, 2003). The evolving roles of teachers in the third wave of leadership aligns with Spillane, Halverson, and Diamond's (2001) notion of distributed leadership that is based on collegial leadership and peer-influence. Crowther, Ferguson, and Hann (2009) redefined the evolving roles of teachers in the third wave of teacher leadership as transformational leadership allowing teachers to act within their capacity to collectively improve school and communities.

Teachers' transformational leadership is increasingly acknowledged as teachers extend their roles beyond the hierarchical status to bring about transformation in schools and communities, which suggest the informal dimension of teacher leadership:

(1) recognize excellence; (2) emphasize freedom to use judgment; (3) listen to and act on teacher ideas; (4) encourage innovation; (5) provide feedback and coaching; (6) value people as individuals; (7) provide a sense of being included; (8) appreciate diverse perspectives, ideas and work styles; (9) encourage full expression of ideas without fear; and (10) listen to and fairly handle complaints (Reeves, 2008).

Some researchers also considered this informal-transformational leadership roles as "organic rather than imposed" (Smulyan, 2016, p.15), which aligns with the notion of "organised complexity" (Poekert, Alexandrou, \& Shannon, 2016, p.325) leading to reconceptualising teacher leadership based on its emergence (Harris, 2003). 
A significant shift in of teacher leadership's focus and scope was reflected within a continuum. Fairman and Mackenzie (2014) describe this shift from individual initiative or independent work with limited focus and scope to increasingly collective work with a broader focus and scope. This collective work can occur as teachers contribute to their own schools or districts and beyond as they progressively influence other schools, district, or larger population of colleagues (Collinson, 2012). Sebastian, Allensworth, and Huang (2016) asserted that teacher leadership is considered private when it involves a small group of teachers whereas it becomes public as it involves more professional collaboration with more teachers, schools, or other institutions across variety of contexts. This collaboration can lead to the combination of between formal and informal roles that are distributed and shared, which involves collective effort and decision-making process (Alanezi, 2016; Leithwood \& Azah, 2016), which was often referred to as distributed and shared leadership. Both distributed and shared leadership are similar in the way that they are dynamic, relational, inclusive, collaborative, and contextuallysituated (Bolden, 2017), which aligns with Gronn's (2000) term of 'concertive action'. The elements of decision-making process, efforts, and action driving teachers' leadership practice signify how their agency is enacted in conjunction with others: there is no leaders without the existence of others who follow them, share their vision as members or consider them as role models (Kellerman, 2007). Thus, it is important to understand that in teachers leadership practice, agency is both individually and socially enacted through "establishing relationships, breaking down barriers, and marshalling resources" in their daily activities to achieve certain outcome (York-Barr \& Duke, 2004, p.263).

Informal teacher leadership can emerge as teachers lead others in learning to use technology, such as being an educational technology leader (Schrum \& Levin, 2009), network leaders (Katz, Earl, \& Jaafar, 2009), technology coordinator (Banoglu, 2011), and mentors (Bozeman \& Feeney, 2007). This suggests that the use of educational technology has provided opportunities for informal leadership initiatives that emphasise on the importance of teachers' ed-tech expertise and practices as well as their social skills for interschool collaboration (Ruys et al., 2013). For example, being an effective leader in leading innovative change, having a clear vision of education technology, and being education technologically-savvy reflect the quality of ed-tech leaders (Sweeney, 2005). Hately and Schiller (2003) found that ed-tech leaders' expertise included planning and the implementing ICT, improving the access and equity of ICT use, understanding legal and ethical issues, and having an awareness of learning theory, pedagogy, and curriculum development. The role of teachers as mentors or coaches also reflect a form informal leadership that models confidence, openness, persistence, commitment, and the 
pleasure of learning in the face of uncertainty (Claxton, 2004). Mentorship is also considered an essential form of psychosocial support involving the process of sharing knowledge, wisdom, and experiences between learning leaders as mentors and their mentees in informal professional learning (Bozeman \& Feeney, 2007). These studies show the significance of informal leadership opportunities with technology as a form of agentic professional learning in the digital age, enabling educators to achieve their optimum potential with creative, proactive, motivationdriven, and flexible learning experiences.

Teachers with informal leadership practices are often described as having certain characteristics and dispositions. Danielson (2007) defines informal ed-tech leaders as those who experience "professional restlessness" and "leadership itch" due to a greater desire and enthusiasm for responsibility (p.14). This desire and enthusiasm are also featured within the dimension of adaptive leadership:

“...adaptive leadership is an informal leadership process that occurs in intentional interactions of interdependent human agents (individual or collectives) as they work to generate and advance novel solutions" (Uhl-Bien \& Marion, 2009, p.633).

Boylan (2018) found that educators' initiatives and activities as the initiator, organiser, and facilitator of professional learning for others constitute a form of adaptive leadership through mobilising, brokering, and creating networks. His study of teachers' adaptive system leadership in professional development identified four aspects in adaptive leadership: "leader as innovator; leader as responsive and purposeful, leaders as networker, and leader as system worker" (p. 9192), which echoes the notion of teacher activism (Sachs, 2000). Central to teacher activism is influence, the enactment of values, and vision (Bush \& Glover, 2014), moving from being "sage on the stage" to the "guide on the side" as they become expert learners along with their colleagues who are novice learners within their learning communities (Carroll, 2000). Furthermore, Fullan (2001) asserts that how educators own their process of learning requires self-confidence and support from other enthusiastic individuals who believe in them. These studies suggest social relationship and technology can be cultivated to expand educators' agency through informal ed-tech leadership practices, which provides opportunities for meaningful professional learning experiences.

\section{Personal learning network (PLN)}

A personal learning network (PLN) is a system of interpersonal connections and resources (Trust, 2012), a form of self-directed learning activities (Eun, 2018), social, distributed, and situated (Putnam \& Borko, 2000) as well as diverse, flexible, independent, personalised, and multifaceted across four domains: cognitive, social, affective, and identity 
(Trust, Carpenter, \& Krutka, 2018). Thus, a PLN is one's personal specific access to collection of tools, links to people, or sources of information that can be used to facilitate learning (Martindale \& Dowdy, 2010).

Digital technologies can be used for creating and growing educators' PLNs (e.g. (Nussbaum-Beach \& Hall, 2011). For example, teachers can use their PLNs to share ideas about teaching, learning, and classroom practice; finding relevant teaching materials and strategies; updating knowledge about the latest ed-tech trends; and obtaining feedback and emotional support (Xerri, 2017). Twitter, Edmodo, Google Plus communities, Facebook, and Pinterest can be used to extend professional connections and conversations, leading to opportunities for connected learning (Trust, Krutka, \& Carpenter, 2016). Such technologies provide opportunities for teachers to participate and learn with others through various communities, be it online or hybrid, based on their professional interests (Duncan-Howell, 2010). The use of digital technologies in a PLN can increase the likelihood for social actions and the willingness to help others by solving problems or sharing resources in the PLN (Tseng \& Kuo, 2014). With the use of digital technologies in the PLN, educators were exposed to new ideas and the practices of others whenever they need within a personalised learning environment (Goria, Konstantinidis, Kilvinski, \& Dogan, 2019) providing relevant and on-demand sources of information, support, and feedback that they needed in their own context and convenience (Kearney \& Maher, 2018). These studies align with the notion of user-generated learning (Swanson, 2012):

“...user-generated learning is something you do, not something you get. In usergenerated learning, everyone has something to contribute. We are all experts in our own ways. This does not negate the importance of educational research or vetted practices. Instead, user-generated learning reflects that all adults recognize their personal applications of ideas and strategies, and this synthesis and community are a valuable part of the learning process" (p.5).

Thus, the use of digital technologies contributes to nature of PLN that facilitates user-generated learning where learners can "interpret and cultivate the networks and resources to transform the learning practices" (Laferrière, Lamon, \& Chan, 2006, p.85), "use them for problem-solving when needed" (Wenger, Trayner, \& De Laat, 2011, p.15), and "become "networked educators" (Couros, 2010).

The potentials of a PLN is closely linked to various activities facilitated by digital technologies (Tour, 2016). For example, mobile technology in a PLN can be used to "access Internet resources and run experiments in the field, capture, store and manage everyday events as images and sounds and communicate and share the material with colleagues and experts 
around the world" (Sharples, 2002, p.222). A sequence of learning activities in a PLN is described as "catch, read, think, write, post, and serve" (Neubauer, Hug, Hamon, \& Stewart, 2011, p.15). Other specific activities closely associated with a PLN are accessing relevant information, watching Youtube videos or tutorial videos on Youtube channel (Xerri, 2017), and writing comments in the blogs (Robertson, 2011). A recent study identified five types of professional learning activities in the PLN and specific digital technologies that facilitate them: “information retrieval and resources aggregation using digital books, articles, blog posts, video, podcasts, lectures, Twitter, and Delicious; using Diigo to encourage cooperation; using Google document, iPads, and social networks for collaboration; using blogs and Twitter for reflections; using online communication tools and face to face meetings and unconferences for socialising using" (Tour, 2016, p.184-188). Thus, the aforementioned studies describe a PLN as a form of personal access to information of tools and connections to people that can be used as resources for learning. This suggests the prevalence of digital technologies as a personalised support system for educators' self-directed professional learning in a way that it is more effective, relevant, and meaningful.

One of the essential components for supporting effective, relevant, and meaningful learning experience in a PLN is personal access to blended or hybrid learning - a combination of technology-mediated interaction and communication with face-to-face interaction. Studies show that face to face contact is important to help build trust and create a feeling of belonging (Hanraets, Hulsebosch, \& de Laat, 2011) confirming other studies on how blending online and face-to-face interaction and communication enables educators to likely enrich and extend their learning (Allan, Hunter, \& Lewis, 2006; Cesareni, Martini, \& Mancini, 2011). In Indonesia, (Sari, 2012) found that combining the use of mobile communication applications and face-toface meetings can be potential to support Indonesian educators' PLN in their online learning communities. Ranieri, Manca, and Fini (2012) found that personal accesses to blended/hybrid learning communities enables the facilitation of online and offline learning: from online to offline (online functions to maintain offline relationships), and offline to online (offline functions to maintain online relationships). This aligns with Vaughan (2004) and Dunkel Schetter and Brooks' (2009) research on how the combination of online and offline interaction can facilitate deeper relationship building. These are also supported by Xie (2008) who found that personal access to meet others in person within a PLN can strengthen ties in online relationship, which is also considered a potential supplement to facilitate learning (Kling \& Courtright, 2003; Schlager \& Fusco, 2003). These studies suggest the importance of social- 
connectedness within a PLN enabling a personalised and unique learning experiences through meaningful interaction and communication with others as valuable resources.

Despite the acknowledgement of a PLN as a potential tool to support educators' selfdirected professional learning, it is also criticised for contributing to solitude and social isolation (Caron \& Caronia, 2007). Nussbaum-Beach and Hall (2011) was also cautious pointing out that following a lot of people online is not necessarily useful unless it is cultivated for learning purposes. They suggest that having a PLN is a good investment, but it can only come to fruition when effectively cultivated, suggesting that a PLN involves a learner's self-regulatory and reflective functionality in selecting support and resources that are relevant for them. In light of this, Grant and Hsu (2014) asserted that individuals needed to make an extra effort and arrangements to maintain an effective and productive PLN. This suggests that the key to the potential and success of a PLN in supporting educators' self-determined professional learning lies in the hand of educators themselves as learners, which indicates the significance of enacting agency within the process of building and developing a successful and effective PLN.

\section{Informally-organised technology-mediated learning collectives}

Technology enables educators to learn, gain support, and collaborate with others through informally-organised technology-mediated learning collectives (e.g. Trust et al., 2016; Tseng \& Kuo, 2014), which are often referred to as collective mind (Brown, 2007) and collective knowledge (Kimmerle, Moskaliuk, Oeberst, \& Cress, 2015). In informally-organised technology-mediated learning collectives, "teachers getting together for professional development purposes" (Vangrieken, Meredith, Packer, \& Kyndt, 2017, p.48) mediated by various technologies enabling a continuous connection with people and resources (Trust et al., 2016). Such collectives can create digital habitat (Wenger, White, \& Smith, 2009) and affinity space (Gee, 2005) with participatory culture (Jenkins, Purushotma, Weigel, Clinton, \& Robinson, 2009). Therefore, informally-organised technology-mediated learning collectives can offer unique ways and opportunities to engage in learning beyond physical environment.

There has been an increasing discussion on the affordances of informally-organised technology-mediated learning collectives to support teachers' self-directed professional learning. For example, teachers can use these collectives to filter large quantities of potentially useful information and (e.g. (Davis, 2015; Ranieri et al., 2012; Wesely, 2013) and obtain emotional support (Hur \& Brush, 2009; Jimoyiannis \& Tsiotakis, 2016; Trust et al., 2016). For example, teacher-led PD projects and networks in the U.S. (Lieberman \& Pointer Mace, 2009), educators-driven network learning communities (e.g. Earl \& Katz, 2007; Hadfield, 2007; Hattie \& Timperley, 2007), blended/hybrid learning communities (Matzat, 2013), and Singaporean 
teacher networks (Tripp, 2004). These studies reveal how such collectives reflect teachers' agency in seeking diverse self-directed professional learning support and resources in conjunction with their needs of social connectedness.

Empirical studies that have been conducted on online teacher communities show that the advancement of ICT helps the development of such communities in facilitating connected learning, unconstrained by time and geographical locations, supporting professional growth (e.g. Carpenter \& Krutka, 2014; Hur \& Brush, 2009; Kelly \& Antonio, 2016; Macià \& García, 2016; Trust, 2015). The development of ICT tools also enabled ongoing support from online learning communities in teachers' everyday learning (Lantz-Andersson et al., 2018). For example, Trust (2017) found that the Edmodo Math Subject Community provided mathematics teachers a unique learning opportunity where they felt motivated and empowered to make innovative changes to their practices and also enabled them to connect with other teachers within global networks for support that they could immediately apply to their own professional contexts. Duncan-Howell (2010) revealed that educators had been exposed to new ideas and resources about classroom practice through web-based technologies and online communities. Vavasseur and Kim MacGregor's (2008) evaluative study also revealed that educators' application of knowledge through their participation in an online community led to productivity, research, and communication as a meaningful PD experience. Zuidema (2011) discovered that educators who participated in informal, spontaneous conversations in an online, informal, external network reported that it supported collaborative inquiry and reflection. These studies highlight the similarity between informally-organised technology enabled learning collectives and the "bottom-up online communities and networks as important source of professional development" (Macià \& García, 2016, p.291) leading to positive changes in professional practices.

Informally-organised technology-mediated learning collectives offer a unique learning experience and opportunities similar to similar to self-directed professional learning and PLN. For example, In a feasibility study of online learning communities for teacher professional development (OLC4TPD) among Indonesian teachers and teacher educators (Sari, 2012), it was revealed that the OLC4TPD had provided new possibilities for an ongoing and flexible PD model. Sari showed that this model enabled collaborative and reflective professional learning to overcome challenges regarding the lack of financial and human resources as well as geographical limitations. However, there were also issues that had hindered the process of knowledge building, namely, no access to ICT and a lack of ICT literacy, awareness, knowledge, and experiences in professional practices, particularly for teaching and learning 
purposes. This suggests that the quality of learning experiences does not only depend on learners' agentic capabilities alone but also on technological environment, which can be enabling or hindering factor. While good quality of Internet access can support learners' enactment of agency in exploring more opportunities through finding resources and support, poor access to Internet can limit learners from such exploration.

Despite the potential of informally-organised technology-mediated collectives for the professional learning of educators, there are studies that are critical of such collectives. An informally-organised community's consensual and non-conflicting nature, which largely conforms to community norms can lack of criticality (Brown, 2007; Lantz-Andersson, Peterson, Hillman, Lundin, \& Rensfeldt, 2017). Similarly, in Brown and Munger's, (2010) study, although the unstructured virtual community's voluntary and flexible nature of participation and engagement creates a space where learners can share ideas, members are rarely engaged in transformative professional practices. Macià and García (2016) cautiously note that "although participation in communities and networks has positive effects on professional learning, none of the research directly revises the impact on teachers' classroom practices" (p.304). Free-riding passive members are problematic and can be challenging the potential of online learning communities (F. Lin, Lin, \& Huang, 2008). Countering such criticisms, proponents and advocates of OLCs asserted that such communities can potentially offer opportunities for educators to voluntarily engage in shared learning, reflect about teaching practices and receive emotional support, which can transform practices (e.g. Brown \& Munger, 2010; Ranieri et al., 2012; Tseng \& Kuo, 2014). This suggests that further exploration in variety of contexts needed to unravel aspects in informally-organised technology-enabled learning collectives influencing the effectiveness of self-directed learning through meaningful learning experience.

\section{Theoretical framework}

A theoretical framework has a significant role to play in a study:

"It is the blueprint for the entire study that serves as the guide on which to build and support your study, and also provides the structure to define how you will philosophically, epistemologically, methodologically, and analytically approach the dissertation as a whole" (Grant \& Osanloo, 2014, p.13).

The review of literature revealed aspects influencing teacher self-directed professional learning including teachers' agency and behaviour, social environment as well as access and resources related to technology within variety of context. Bandura's $(2001,1999)$ social cognitive theory provides useful and relevant insight on analysing the significance of these aspects underpinning 
its selection as the theoretical framework for this study in relation to three major aspects: (1) agency and efficacy; (2) observational learning and social modelling; and (3) environmental influence.

\section{Social cognitive theory}

Social cognitive theory, formerly known as social learning theory, provides a relevant theoretical framework to further understand how cognitive, behavioural, and environmental factors influence learners' self-directed learning. In Bandura's (2001, 1989) social cognitive theory, the interdependence of cognitive, behavioural, and environmental aspects to the process of learning is described within the triadic co-determination process of causation (Figure 1).

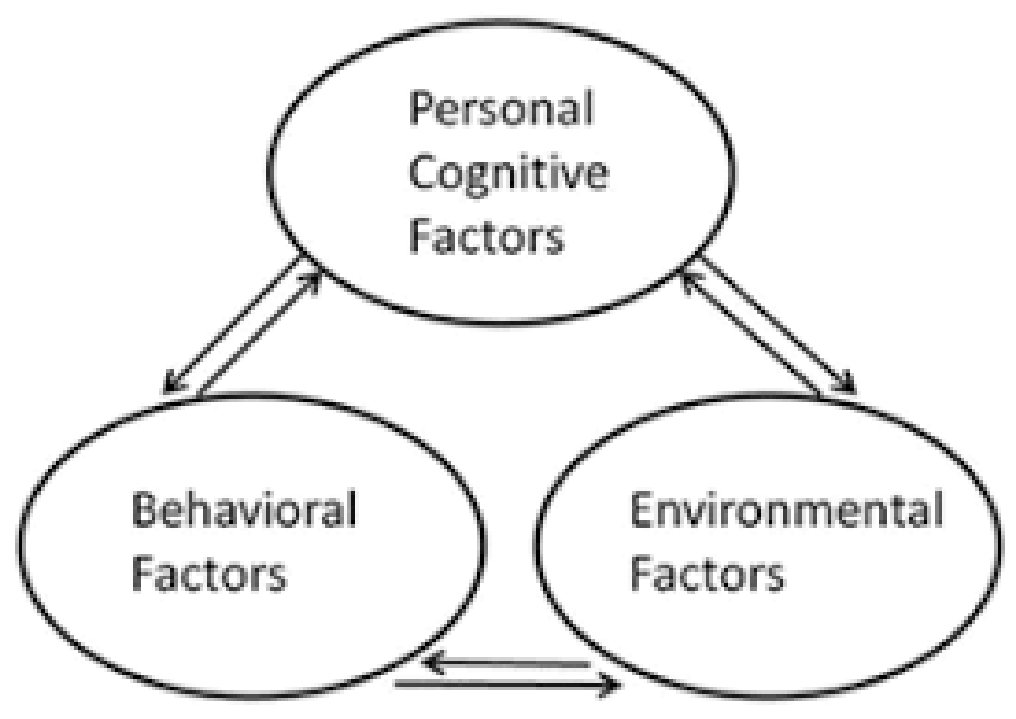

Figure 1. Bandura's triadic reciprocal determinism

Human behaviours can be understood not only by how they are formed through reinforcement, but also through the mutual interaction of cognitive, behavioural, and environmental factors:

"The internal personal factors in the form of cognitive, affective, and biological events; behaviours; and environmental events, all operate as interacting determinants that influence one another bidirectionally" (Bandura, 1986, p.6).

Bandura postulated that there is no fixed pattern in triadic reciprocal determinism, but rather how each aspect in this determinism influences each other depends on activities, environmental conditions, and sociostructural opportunities and challenges (Bandura, 2001). Social cognitive theory argued traditional learning theories situating humans as passive recipients of environmental influences (Thoresen \& Mahoney, 1974). 


\section{Agency and efficacy}

According to Bandura, agency is the capability to exert influence by mindful actions (2009). In the literature of educators' professional learning, researchers have various interpretations on defining agency. Agency is referred to educators' individual capacity to act agentically in a way that it is influenced by the quality of their engagement with their environments:

"The achievement of agency is the result from the interplay of individual efforts, available resources and contextual and structural factors as they come together in particular and, in a sense, always unique situations" (Biesta \& Tedder, 2007, p.137).

Recent literature suggests agency as a means of understanding how teachers might enact practice and engage with policy (e.g. Ketelaar, Beijaard, Boshuizen, \& Den Brok, 2012). Agency is the quality of something that people do rather than people have, which is described as the way "humans are able to be reflexive and creative, acting counter to societal constraints, but also how individuals are enabled and constrained by their social and material environments" (Biesta et al., 2015, p.3). Thus, agency is not about doing anything carelessly just because it can be done. The term agency in this study is drawn more to the individual's capacity to act reflectively responding to a specific situation or context. This suggests that the enactment of human agency is one of the important aspects to consider when understanding the quality of learning as self-directed learners within a specific situation or context.

Recent studies highlighted the significance of educators' agentic capabilities as selfdirected learners to drive their professional growth within which the term of agentic professional learning was first introduced (Goller \& Harteis, 2017; Paloniemi, Eteläpelto, Hökkä, Vähäsantanen, \& Törmäkangas, 2014; Vähäsantanen et al., 2016). Bandura (2002) defined agentic capabilities as the psychosocial systems of self-development or growth. Within the context of professional learning, individual's agentic capabilities is linked to how driven he/she is in constructing new initiatives for learning proactively and reflectively (Goller \& Harteis, 2017). The agentic capabilities influenced by individuals' capacity, behavioural processes, and social context within the profession (Messmann \& Mulder, 2017) in a way that it shapes motivation in learning (Watkins, 2017). Individuals use their agency to not only learn on their own, but also from the practices of others (Bauman, 2013). With agentic capabilities, an individual self-direct his/her own learning (Wenger et al., 2009) and take the ownership of learning through sense-making process (Ketelaar et al., 2012). The individual's capabilities in professional learning were reflected in recent studies of some Indonesian educators' informal learning through potential affordances of Facebook (Patahuddin \& Logan, 2018), social media for local content studies (Pheeney \& Klieve, 2015), and ID Courserian (Firmansyah, 2015). 
These studies suggest an agentic form of professional learning as it is driven by their selfdirectedness and self-motivation as they personalise their learning with support from technology and communities.

Within social cognitive perspective, the enactment of agency occurs within cognitive domain. Human agency is described as intentionally making things by actions to produce different outcomes in response to the perceived environment (Bandura, 2001). There are three core features of human agency in social cognitive theory: forethought, self-reactiveness, and self-reflectiveness (Bandura, 2018). Forethought refers to the outcome expectation; selfreactiveness is the ability to make choices and action plans; and self-reflectiveness emphasises the ability to reflect on one's own thoughts and actions (Bandura, 2001). Three forms of human agency lead to three dimensions of efficacy beliefs in social cognitive theory: personal/individual agency leading to self-efficacy; proxy agency leading to proxy efficacy; and collective agency leading to collective efficacy (Bandura, 2000). Thus, agency and efficacy have similar functions and processing (Bandura, 2006).

Personal agency leads to perceived self-efficacy. Personal agency is defined as "the capacity to exercise control over one's thought processes, motivation, affect, and actions" (Bandura, 1999, p.1). Bandura (2002) explained that in personal agency "people bring their influence to bear directly on themselves and their environment in managing their lives" (p.270). In a study understanding and scaffolding Danish schoolteachers' motivation, Knudsen, Skovgaard, and Bredahl (2018) found that personal agency leads to confidence and selfdetermination fostering motivation, which Bandura (2001) referred to as perceived selfefficacy. Self-efficacy forms the foundation of human agency because "unless people believe that they can produce desired results by their actions, they have little incentive to act or to persevere in the face of difficulties" (Bandura, 1999, p.46). Perceived self-efficacy enables people to "choose what challenges to undertake, how much effort to expend in the endeavour, how long to persevere in the face of obstacles and failures, and whether failures are motivating or demoralizing" (Bandura, 2001, p.10). Personal dispositions such as self-beliefs, aspirations, and outcome expectations regulate behaviour leading to perceived self-efficacy. Individuals with a strong sense of self-efficacy will appear to make more effort, be more diligent, and be more resilient toward reaching their goals, whereas those with a low sense of self-efficacy view are often reluctant in their actions as they doubt at their own self-potentials or intellectual capabilities (Bandura, 2002; Pajares, 2002). Strong self-efficacy enables people to be motivated and optimistic to overcome and achieve things, while people with a lower sense of self-efficacy 
tend to avoid taking risks in overcoming difficult situations due to doubt in their own ability and a low control of negative thoughts (Bandura, 1999).

Proxy agency leads to proxy efficacy. Proxy agency is a sociostructurally influenced and socially-mediated form of agency: an individual could be a proxy agent when he/she helped others or provided support and resources for others. Similarly, an individual needs proxy as he/she seeks his/her well-being, security, and valued outcomes from others, and this is a socially-mediated mode of agency emphasising the mediative efforts of others (Bandura, 2001). The social structures represent acknowledged social practices carried out by human beings to designate their roles leading to proxy efficacy (Ruble, Usher, \& McGrew, 2011). Within a social cognitive perspective, the personal/individual and social dimension has a dynamic interplay that is embedded in nature. As Burns and Dietz (2000) argued:

"It is not a dichotomy between a disembodied social structure and personal agency but a dynamic interplay between individuals and those who preside over the institutionalized operations of social systems. Social structures are created by human activity. The structural practices, in turn, impose constraints and provide resources and opportunity structures for personal development and functioning. Given this dynamic bidirectionality of influence, social cognitive theory rejects a dualism between personal agency and social structure" (p.27).

Within a group context, the proxy efficacy is defined as "an individual's belief in another person's or group's capabilities to organize and execute courses of action on her, his, or its behalf, to produce given levels of attainment" (Alavi \& McCormick, 2016, p.2). By enacting proxy agency "people try by one means or another to get those who have access to resources or expertise or who have influence and power to act on their behalf to achieve the outcomes they desire" (Burns \& Dietz, 2000, p.13). However, Bandura (2001) warned that too much reliance on a proxy can actually reduce the ability to self-regulate, "impede the cultivation of personal competencies" (p.13), and it "reduces the opportunities to build skills needed for efficacious action" (Bandura, 1997, p.17). A study found two kinds of proxy efficacy; lower and higher proxy efficacy, where people who preferred high frequency of contact with others as a proxy had lower self-regulatory efficacy, lower task efficacy, and weaker intentions in a proxy-led exercise context (Shields, 2005).

Collective agency leads to collective efficacy. It extends the scope of personal agency to wider collectives, defined as an emergent group involving the enactment of agency that occurs through socially interdependent efforts, arguably within teams, groups, or in a community context. This leads to collective efficacy where there are "people acting collectively on a shared belief that is doing the cognizing, aspiring, motivating, and regulating" (Bandura, 
1999, p.53). In social cognitive theory, collective efficacy occurs as a form of group attainment that is achieved through social participation, social activism, or collective initiatives:

"Group attainments are the product not only of the shared intentions, knowledge, and skills of its members, but also of the interactive, coordinated, and synergistic dynamics of their transactions" (Bandura, 2001, p.14).

Bandura (2000) also argued that collective efficacy depends on the degree of interdependent effort needed to achieve the desired results:

"Under low system interdependence, members may inspire, motivate, and support each other but the group outcome is the sum of the attainments produced individually rather than by the members working together" (p.76).

Gibson (2003) found that self-efficacy, group affect, and collectivism determined group efficacy in a study of university student groups from the U.S and Hong Kong. Alavi and McCormick (2016) also identified evidence that groups with higher average collectivistic orientation had higher collective efficacy. Thus, collectivistic cultures or collectivism may provide opportunities for the development of higher collective efficacy, which may enhance attachment and cohesiveness within the collective (Jeon, 2017). These studies highlight that collaboration is needed for collective efficacy to occur. However, Bandura noted that the challenge to collaboration is "to meld diverse self-interests in the service of common goals and intentions collectively pursued in concert" (Bandura, 2001, p.6).

\section{Observational learning and modelling}

From social cognitive perspective, observational learning and modelling embody the needs for social connectedness. Observational learning and modelling is a form of social support to one's learning processes and are effective tools of personal agency:

"social supports provide means, resources, and incentive motivation that increases opportunities for individuals to better directions of actions or selection of life choices" (Bandura, 1989, p.8).

Observational learning and modelling can instil motivation and outcome expectations where they believe that similar results can be secured (Bandura, 1999). Cruess, Cruess, and Steinert (2008) found that successful observational learning and modelling can influence behaviour through how teachers consider other colleagues as role models. As learners learn through observing others and modelling influences from others, they cognitively pay attention as well as create behaviour and motivation to expand their knowledge and skills exhibited and authored by others because observational learning could not occur without cognitive processes and the influence of others (Bandura, 2001). Stefanone, Lackaff, and Rosen (2010) found that "the qualities of the individual who is observed or taken as a model, and the qualities of the 
behaviour which is observed or taken as a model are significant to influence one's learning" (p.57). With technological advances in the digital age, learning through observation and modelling influence can be conducted more efficiently from one location to worldwide, and more effectively as the use of technology is pervasive in today's society (Bandura, 2018).

\section{Environmental influence}

There are three characteristics of environmental determinants in social cognitive theory: selected, constructed, and imposed environments.

"Gradations of environmental changeability require the exercise of increasing levels of personal agency. The imposed physical and sociostructural environment is thrust upon people whether they like it or not. Although they have little control over its presence, they have leeway in how they construe it and react to it. Which part of the potential environment becomes the actual experienced environment thus depends on how people behave. The choice of associates, activities and milieus constitutes the selected environment" (Bandura, 1999, p.6-7).

The context of environment can facilitate or hinder the ability to enact agency. For example, the mobility and flexibility in boundaries can enable or prevent agentive practices as "immobility and limited means of actions upon the physical and social environment restrict the domain of influence" (Bandura, 1989, p.61). This suggests that selected environment provides the largest scope of behaviour and therefore, the broadest agentive space (the constructed environment) restricts agentive practice. It also requires concerted efforts to become a viable agentive option, and the imposed environment provides the least option for people to enact agency within this type of environment.

\section{The relevance of social cognitive theory as a theoretical framework}

As explained in the previous chapter, social cognitive theory was considered most relevant and valuable because it provides a theoretical lens allowing in-depth social-cognitive exploration and further understanding of participants' ed-tech professional learning experiences in the GEGs. Accordingly, this study viewed the GEGs from the minds and experiences of individuals as the primary construct in individual learning experiences. As data were obtained from the self-selected group of individuals in the GEGs and their online forum participation rather than the whole population of the groups, findings were interpreted from the individual's perspective of their self-reported ed-tech learning experience and their social interaction within their context in the groups. 


\section{Summary}

This chapter has examined literature related to the shifting paradigm of professional development in education focusing on teacher self-directed professional learning including the use of technology and three current models of teacher self-directed professional learning: (1) teacher informal leadership with technology, (2) personal learning networks (PLN), and (3) informally-organised technology-mediated learning collectives. It has provided insights into the significance of teacher agency and its implications for their self-directed professional learning. The reviewed literature also indicates that teacher agency in self-directed professional learning is influenced by various aspects such as teachers' dispositions, resources, and social connectedness, which determine their decision-making process leading to various actions and activities pertaining to the choices and preferences. It also highlights that teacher self-directed professional learning does not only involve personal factors (e.g. agency, cognition, and motivation) but also their behavioural factors (e.g. leadership, self-efficacy, the needs for social connection), and environmental factors (e.g. access, resources, infrastructural support). For example, not only does a PLN enable learning that is personalised to one's particular needs, but it also enables learning through connected networks of people (Trust et al., 2018). The nature of learning through informally-organised technology-enabled learning collectives is likely similar to a PLN where it is driven by self-motivation and social connection as well as influenced by technological digital environment (e.g. Ranieri et al., 2012). In addition, literature on informal teacher leadership practice demonstrates that in order to enact agency as learning leaders, meaningful connections with others need to be established to effectively influence in a way that it inspires collaboration and creates innovative changes in the environment (e.g. Boylan, 2018). However, the reviewed literature show studies that are predominantly situated within developed-western countries with many similarities in their sociostructural, working life and infrastructural conditions. For example, Carpenter and Linton's (2018) context of study is within United States. Kearney and Maher's (2018) study is within an Australian context. Vescio et al., (2008) examined participation in informal learning communities within American and English context.

Studies in developed non-western countries mainly focus on technological challenges that influences teachers' perception, attitude, and teaching (Wright, 2015) or the ICT and sociocultural facets influencing the formation and operation of online learning communities (Sari, 2012). While these studies provide useful knowledge on teachers' teaching dynamics with technology, they do not focus on their agency and its implications for self-directed professional learning in educational technology. Although studies in the literature review offer diverse 
context of the unique and valuable learning opportunities in teacher self-directed professional learning, social cognitive framework has not yet been used in these studies for further examination of various aspects that may influence such form of professional learning. For example, Danielson (2007) and Boylan (2018) used adaptive leadership framework in his study of teacher informal leadership. Tseng and Kuo (2014) used Community of Practice framework to examine teachers' online social participation and knowledge sharing. Kearney and Maher (2018) used sociocultural theory in examining teacher's use of professional learning networks as a form of self-directed learning. Social cognitive approach is also rarely used within studies on educators' professional learning in Indonesia. For example, a design-based approach (Sari, 2012), a project-based approach (Hyson \& Roesli, 2017), and a technology-acceptance model approach (Pheeney \& Klieve, 2015). As the review of literature shows the gap in understanding the significance of personal-behavioural-environmental aspects that are intertwined in teacher self-directed professional learning, there is a need for further investigation on Indonesian educators' ed-tech professional learning in the GEGs to fill in this gap. This provides persuasive evidence of the need for a social-cognitive study of Indonesian Google Educator Groups, particularly an examination of how Indonesian educators participate in ed-tech professional learning in the groups and how they function to support professional learning. 


\section{Chapter 3}

\section{Methodology}

\section{Introduction}

This chapter begins with a justification of the relevance of social cognitive theory as the theoretical framework in this study followed by an elaboration of why interpretive research paradigm and qualitative research methodology were selected. The collective case study design is described as well as the methods for selecting cases and participants, and collecting data. Following this, data sources, data collection tools, and data analysis are described and explained. Finally, processes that ensure the trustworthiness of the study, ethical considerations, limitations, and delimitations of the study are presented.

\section{Interpretive research paradigm}

A research paradigm suggests "a worldview that defines, for its holder, the nature of the 'world', the individual's place in it, and the range of possible relationships to that world and its parts" (Guba \& Lincoln, 1994, p.107). Remenyi, Williams, Money, and Swartz (1998) assert that a research paradigm is needed to underpin the impact and value of the study. Hay (2002) further explains that the theoretical perspective serves as a lens or a frame for the researcher to organise and clarify his/her thoughts and ideas, leading to how he/she selects the methodology and method(s). Willis (2007) argues that the goal of interpretivism is to value subjectivity, and "interpretivists eschew the idea that objective research on human behaviour is possible" (p.110). The goal of the interpretive study is therefore, to "approach the reality from subjects, typically from people who own their experiences and are of a particular group or culture" (Thanh \& Thanh, 2015, p.25). As indicated above, interpretivist researchers understand "the world of human experience" (Cohen \& Manion, 1994, p.36) to discover reality through the participants' views, and their own background and experiences, and this allows them to view the world through the perceptions and experiences of the participants. The acceptance of multiple perspectives in interpretivism often leads to a more comprehensive understanding of the situation, which facilitates in-depth insight and information from the population, rather than through statistics (Klein \& Myers, 1999; Morehouse, 2012). This suggest that interpretive research is more subjective than objective. Within this paradigm, I drew from Indonesian educators' GEG experiences and online forum to construct and interpret my understanding of their professional learning. 


\section{Qualitative research methodology}

Qualitative research is described as "...a multi-method in focus, involving an interpretive, naturalistic approach to its subject matter. This means that qualitative researchers study things in their natural settings, attempting to make sense of, or interpret phenomena in terms of the meanings people bring to them" (Denzin \& Lincoln, 2001, p.2). Willis (2007) contends that "interpretivists tend to favour qualitative methods such as case studies" (p.90) because the interpretive paradigm "portrays a world in which reality is socially constructed, complex, and ever changing..." (Thomas, 2003, p.6). The qualitative data captured needs to be rich with in-depth description derived from the process of deep attentiveness and empathetic understanding (Punch \& Oancea, 2014), for my study was unlikely that quantitative data that emphasises the worldview using numbers and statistics measures. Lodico (2010) presents the following characteristics of qualitative research that aptly describe my study:

"Studies are carried out in a naturalistic setting. Researchers ask broad research questions designed to explore, interpret, or understand the social context. Participants are selected through non-random methods based on whether the individuals have information vital to the questions being asked. Data collection techniques involve observation and interviews that bring the researcher in close contact with the participants. The researcher is likely to take an interactive role where she or he gets to know the participants and the social context in which they live. Hypotheses are formed after the researcher begins data collection and are modified throughout the study as new data are collected and analysed. The study reports data in narrative form" (p.21).

Qualitative research therefore enables the experiences, views, and perspectives of the participants in a study to be represented by their "lives, behaviour, and interactions" (Strauss \& Corbin, 1990, p.17). The selection of qualitative methodology for this study aligns with my interpretive standing in trying to make sense of what is perceived as reality through capturing the meaning of the narratives from these experiences, views, and perspectives as subjective, relative, and bound by context.

\section{Collective case study design}

An interpretive paradigm and qualitative research methodology align with the exploratory nature and salient features of collective case study design (Stake, 1994, 1995). However, there is currently no research into Indonesian GEGs using such methodology. To that end, a case study is particularly useful (Chetty, 1996; Stake, 1995) when exploring problems where existing theoretical and conceptual frameworks are inadequate, enabling further exploration and investigation within the context understudy (Sarantakos, 2012). 
Within a specific context, the selection and examination of cases as subjects of study is often applied to a small geographical region or a very limited number of individuals (Zainal, 2007). However, greater variation across the cases "can strengthen the precision, validity, and the stability of the findings" (Miles, Huberman, \& Saldaña, 2014, p.33). According to Stake (1995, 2008), evidence from multiple or collective cases, is often considered more compelling, reliable, and robust because it allows the researcher to analyse within each case and across cases to understand the similarities and differences between them. The collective case study provides a substantial opportunity to explore cross-case comparisons and draw generalisations from the entire collection of data that show within-case patterns and cross-case syntheses. It enables the researcher to understand the phenomenon deeply, from a variety of perspectives. By investigating Indonesian educators' participation in three GEGs with different geographical, social, and cultural characteristics, their ed-tech informal professional learning using web-based tools was explored, examined, observed, and analysed in detail and in-depth through a collective case study design. Since my focus is particularly on Indonesian educators' perceptions and experiences, a narrative approach is complementary to the study design where I systematically gathered, analysed, and represented people's stories of lived experience as told by them. Therefore, narratives from these stories are seen as transmitters of reality (Heikkinen, 2002) and "the social reality of the narrator" (Etherington, 2004, p.81), which are situated within the qualitative or interpretive research method (Gudmundsdottir, 2001). Therefore, I selected qualitative collective case study as an appropriate methodology to develop an in-depth understanding towards participants' views of their GEG experiences that I considered individually unique within their natural settings within their own regions.

\section{The design of the study}

The selection of cases and participants followed a non-probability sampling technique in order to capture the essence of this qualitative study (Sharan B Merriam, 1998), where the individuals/participants or cases were selected not because they represented their population (generalisability issue) but more for their relevance to the research topic (Flick, 2009). In doing so, non-probability sampling technique reflects salient features within the sampled population:

"Non-probability sampling technique is not intended to be statistically representative: the chance of selection for each member of the population is unknown but, instead, the characteristics of the population are used as the basis of the selection" (Ritchie, Lewis, Nicholls, \& Ormston, 2013, p.113). 
According to Moser and Korstjens (2018), the use of non-probability sampling technique aims to provide a broad overview in an effort to answer the research question. Purposeful sampling refers to "a specifically qualitative approach to case selection" Patton (2015, p.265), where only samples (cases and/or participants) that plausibly fulfil certain criteria are selected as the provider of the information-rich and information-thick experiences. Purposeful sampling involves "selecting cases that meet some pre-determined criterion of importance" (Patton, 2002, p.238). Merriam (1998) emphasises the aim of purposeful sampling is to gain insights through discovery and understanding from a diverse context of samples from "which one can learn the most" (p.48) and in a way that has the potential to "strengthen the description" (Brink, 1993, p.38). Thus, purposeful sampling is recommended for two principal aims:

"The first is to ensure that all the key constituencies of relevance to the subject matter are covered. The second is to ensure that, within each of the key criteria, enough diversity is included so that the impact of the characteristic concerned can be explored" (Ritchie et al., 2013, p.113).

In this study, purposeful sampling technique was implemented based on the specific criteria to select three Indonesian GEGs and twelve participants consisting of three GEG leaders and nine GEG members. Purposeful sampling is considered beneficial to yield: "(1) high-quality, detailed descriptions of each case, which are useful for documenting uniqueness, and (2) important shared patterns that cut across cases and derive their significance from having emerged out of heterogeneity" (Patton, 2002, p.235). Therefore, using purposeful sampling can support the aim of data collection in a qualitative study, such as from the interviews, observations, and documents, which is rich and meaningful in details involving various contexts and experiences from participants (Patton, 2015). Figure 2 outlines the overall study design. 


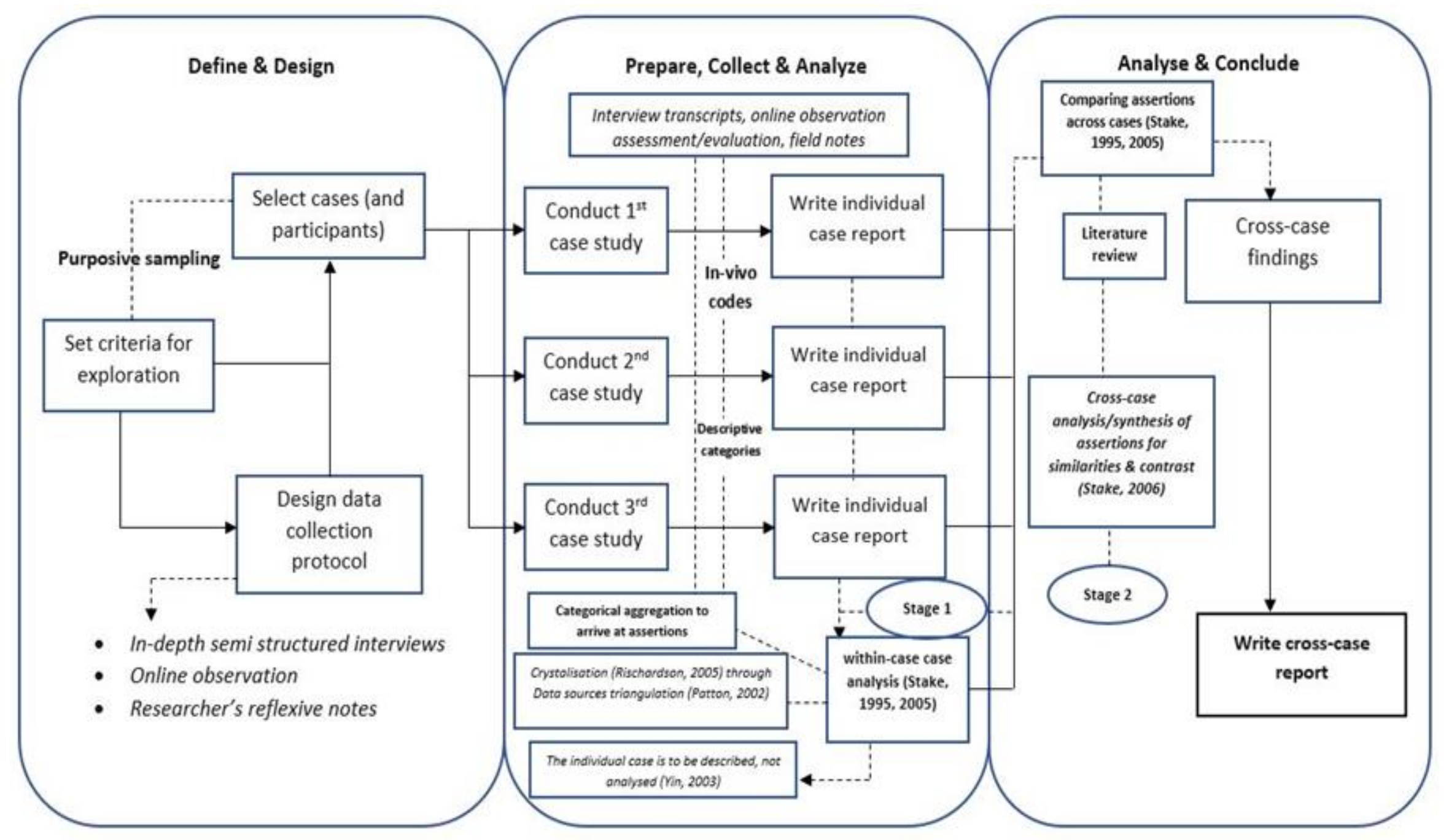

Figure 2. The study design 


\section{Data collection protocols/procedures}

Data were collected through interviews and online observation. They were analysed according to a three-stage procedure. Stage one was preparing for data collection. Stage two was collecting and analysing data, and stage three was interpreting and representing data (Creswell \& Creswell, 2017; Miles et al., 2014). Figure 3 shows data collection protocols/procedures. 


\section{(1)}

Created a dedicated research Wix-website, G+ account, \& conducted an Internet search for

Indonesian GEGs through global GEG website

\section{(2)}

Selected cases and participants (purposeful sampling technique)

- Purposely selected three GEGs: Metropolitan, Urban, and Rural GEGs

- Purposely selected twelve participants: three GEG leaders, three high level participants, three mid-level participants, three lowlevel participants
(3)

- Approached, recruited selected participants (sent introductory email and link to research website to all participants), and obtained their informed consents

- Requested all GEG leaders to publicly post the notification about the research and the researcher in the GEG forums

- Checked any further expressed objection or request from any member in all GEG forums within two weeks postnotification

- Informed consents from all selected participants were obtained before conducting interviews

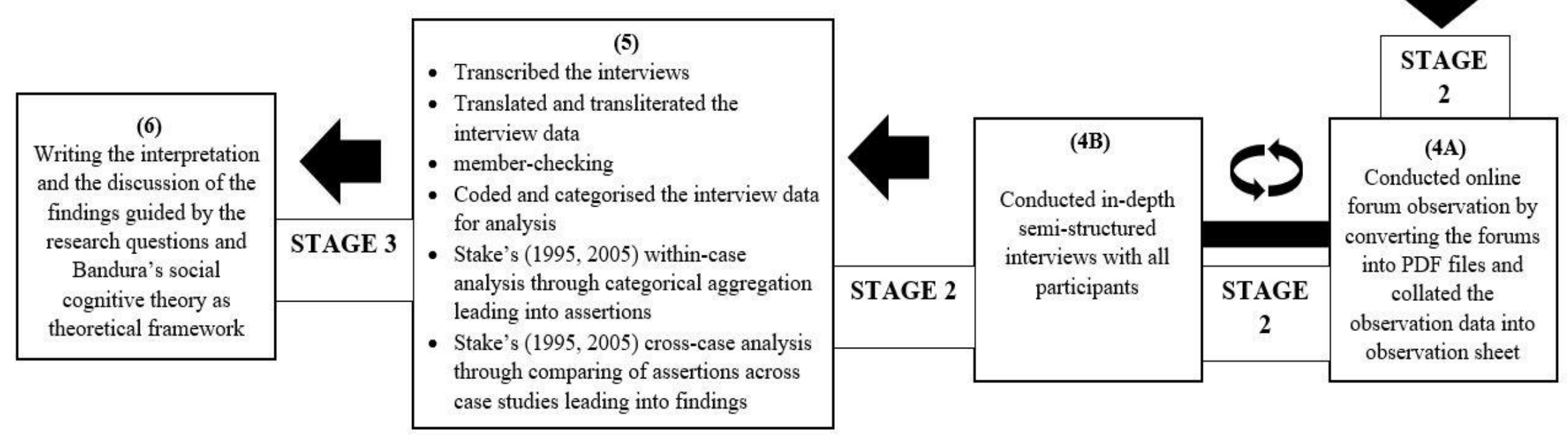

Figure 3. Data collection protocol/procedure 


\section{Preparing for data collection (stage 1)}

After creating a research-dedicated website and $G+$ account, I conducted a public Internet search of Indonesian GEGs on the GEG global website. From several Indonesian GEGs, three Indonesian GEGs were purposely selected based on certain criteria developed for this study. As an Indonesian born citizen, I was able to access and collect data more conveniently and efficiently than a non-Indonesian researcher. Furthermore, my contextual knowledge of geographical, social, and cultural characteristics and features of the cases, as well as my fluency in Bahasa Indonesia (Indonesian language) supported my selection of the Indonesian GEGs through purposeful sampling. These were my strengths in conducting this study.

\section{The criteria developed for purposely selecting cases}

Three GEGs (along with their leaders) were purposely selected based on criteria that aimed to capture information-rich and information-thick insights from the emerging practice of Indonesian educators' ed-tech professional learning, as follows:

1. Public visibility and accessibility on global GEG public website (not in a private mode).

2. More than a year of online posting of GEG Google Plus Communities pages (from the first posting to the moment when this study was commenced (8 December 2016).

3. The most recent posting/online activity of not older than a year on GEG Google Plus Communities pages (from the first posting to the moment when this study was commenced on 8 December 2016).

4. The population of the regions where leaders initiated their GEGs varied in size and geographical location.

5. Leaders of the GEGs that met criterion 1 to 4 gave positive responses and signed informed consent via email for further interviews.

The rationale of the criteria presented in Table 1. 


\begin{tabular}{|c|c|c|c|c|}
\hline \multicolumn{5}{|c|}{$\begin{array}{l}\text { Criteria for case selection } \\
\end{array}$} \\
\hline $\begin{array}{c}\text { Criterion 1 } \\
\text { Public Visibility and } \\
\text { Accessibility on global } \\
\text { GEG public website } \\
\text { (not in a private mode). }\end{array}$ & $\begin{array}{c}\text { Criterion } 2 \\
\text { More than a year of } \\
\text { online forum posting } \\
\text { (from the first posting } \\
\text { to when this study was } \\
\text { commenced). }\end{array}$ & $\begin{array}{c}\text { Criterion } 3 \\
\text { The most recent } \\
\text { posting/online } \\
\text { activity of not older } \\
\text { than a year on } \\
\text { Google Plus online } \\
\text { forum (from the first } \\
\text { posting to when this } \\
\text { study was } \\
\text { commenced). }\end{array}$ & $\begin{array}{l}\text { Criterion } 4 \\
\text { The population of the } \\
\text { regions where leaders } \\
\text { initiated their GEGs } \\
\text { varied in size and } \\
\text { geographical location. }\end{array}$ & $\begin{array}{c}\text { Criterion } 5 \\
\text { Leaders of the GEGs } \\
\text { that met criterion } 1 \text { to } \\
4 \text { gave positive } \\
\text { responses and signed } \\
\text { informed consent via } \\
\text { email for further } \\
\text { interviews. }\end{array}$ \\
\hline $\begin{array}{l}\text { - Active Indonesian } \\
\text { GEGs indicated by } \\
\text { the acknowledgement } \\
\text { of their public } \\
\text { visibility and } \\
\text { accessibility (not in } \\
\text { the private mode) on } \\
\text { global GEG public } \\
\text { website at } \\
\text { https://www.google.c } \\
\text { om/landing/geg/group } \\
\text { s/. The GEGs with } \\
\text { this criterion were } \\
\text { purposely selected } \\
\text { and provisionally } \\
\text { listed. }\end{array}$ & $\begin{array}{l}\text { Based on the duration } \\
\text { of the online posting } \\
\text { period from the first } \\
\text { posting, GEGs with } \\
\text { more than a year of } \\
\text { online posting were } \\
\text { purposely selected } \\
\text { and provisionally } \\
\text { listed. The duration of } \\
\text { online communities } \\
\text { formed over more } \\
\text { than a year enabled a } \\
\text { learning stage } \\
\text { (Haythornthwaite, } \\
\text { Kazmer, Robins, \& } \\
\text { Shoemaker, 2000; } \\
\text { Palloff \& Pratt, 1999). }\end{array}$ & $\begin{array}{l}\text { - The recency of } \\
\text { posting/online } \\
\text { activities of the } \\
\text { active GEGs was } \\
\text { established within a } \\
\text { year of online } \\
\text { posting (not older } \\
\text { than } 8 \text { December } \\
\text { 2016). } \\
\text { - GEGs with } \\
\text { posting/online } \\
\text { activities that were } \\
\text { older than } 8 \\
\text { December } 2016 \\
\text { were not } \\
\text { considered because } \\
\text { they had less }\end{array}$ & $\begin{array}{l}\text { The population of the } \\
\text { regions where leaders } \\
\text { independently initiated } \\
\text { their GEGs varied in size } \\
\text { (metropolitan, urban, } \\
\text { rural) and geographical } \\
\text { location (across three } \\
\text { different islands in } \\
\text { Indonesia) and were } \\
\text { purposely selected and } \\
\text { provisionally listed. } \\
\text { Various population size } \\
\text { and geographical } \\
\text { locations aimed to obtain } \\
\text { data that was more } \\
\text { diverse, representing } \\
\text { various socio-cultural } \\
\text { nuances of Indonesian }\end{array}$ & $\begin{array}{l}\text { - Indonesian GEGs } \\
\text { with leaders who } \\
\text { gave positive } \\
\text { responses and } \\
\text { signed the informed } \\
\text { consent were } \\
\text { purposely selected } \\
\text { and provisionally } \\
\text { listed. This criterion } \\
\text { was crucial due to } \\
\text { the ethical } \\
\text { considerations in } \\
\text { conducting this } \\
\text { study. } \\
\text { The GEG leaders' } \\
\text { positive responses } \\
\text { and signed informed } \\
\text { consent were }\end{array}$ \\
\hline
\end{tabular}




\begin{tabular}{|c|c|c|c|c|}
\hline $\begin{array}{l}\text { Indonesian GEGs that } \\
\text { were not mapped and } \\
\text { acknowledged on } \\
\text { global GEG public } \\
\text { website at } \\
\text { https://www.google.c } \\
\text { om/landing/geg/group } \\
\text { s/ might also have } \\
\text { existed, but were not } \\
\text { provisionally listed } \\
\text { for case selection } \\
\text { because they were no } \\
\text { longer active, as well } \\
\text { being not publicly } \\
\text { available and } \\
\text { accessible (in private } \\
\text { mode). }\end{array}$ & $\begin{array}{l}\text { It takes time for } \\
\text { groups to develop and } \\
\text { shape the learning } \\
\text { culture of a } \\
\text { community through } \\
\text { learning activities } \\
\text { (Wilson \& Ryder, } \\
\text { 1996). Therefore, } \\
\text { Indonesian GEGs } \\
\text { with less than a year } \\
\text { of online posting were } \\
\text { not provisionally } \\
\text { listed because there } \\
\text { was not much online } \\
\text { dynamic to be } \\
\text { observed and analysed } \\
\text { within less than a year } \\
\text { of posting, especially } \\
\text { when there was a long } \\
\text { pause of } \\
\text { posting/online } \\
\text { activities. }\end{array}$ & $\begin{array}{l}\text { updated interaction } \\
\text { and were lacking } \\
\text { recent data for } \\
\text { observation online. }\end{array}$ & $\begin{array}{l}\text { educators' informal } \\
\text { professional learning on } \\
\text { a small scale. } \\
\text { - The diversity of } \\
\text { Indonesian GEGs was } \\
\text { considered as a } \\
\text { significant factor } \\
\text { contributing to the } \\
\text { richness of data. } \\
\text { - The reference for } \\
\text { determining different } \\
\text { categories for the regions } \\
\text { on the characteristics of } \\
\text { their population - } \\
\text { metropolitan, urban, and } \\
\text { rural - was based on } \\
\text { Code and Data } \\
\text { Administration -(The } \\
\text { regulation/law of the } \\
\text { Minister of Home } \\
\text { Affairs Republic of } \\
\text { Indonesia No 56, 2015), } \\
\text { available at } \\
\text { http://www.kemendagri. } \\
\text { go.id/pages/data-wilayah }\end{array}$ & $\begin{array}{l}\text { obtained for further } \\
\text { initial and follow-up } \\
\text { in-depth semi- } \\
\text { structured } \\
\text { interviews. } \\
\text { - Should any of the } \\
\text { approached GEG } \\
\text { leaders give } \\
\text { negative responses, } \\
\text { and not give their } \\
\text { informed consent, } \\
\text { the researcher would } \\
\text { conduct another } \\
\text { approach to a } \\
\text { different GEG under } \\
\text { the same size of the } \\
\text { population-based } \\
\text { network as an } \\
\text { alternative. }\end{array}$ \\
\hline
\end{tabular}




\section{The process of selecting cases}

- Sixteen GEGs were publicly visible and accessible (mapped and acknowledged) on the global GEG public website (https://www.google.com/landing/geg/groups).

- Thirteen GEGs had posting/online activity period for more than one year by the time this study was commenced (and therefore were assumed as having been initiated more than a year after the first posting/online activity from the moment of their online initiation/establishment using criterion 1).

- Thirteen GEGs were identified and ranked in order based on their most recent posting/online activities that were no older than a year from the commencement of this study (between 1 February to 8 December 2016 at the latest).

- Three population categories of metro (metropolitan), urban, and rural were drawn from Code and Data Administration - The regulation/law of the Minister of Home Affairs Republic of Indonesia No 56, 2015.

- The geographical location of the Metro, Urban, and Rural GEGs were selected in a way that it represented the different characteristics of population in Indonesia.

- Three GEGs were finally selected based on which leaders gave positive responses and signed the informed consent via email.

\section{The criteria developed for purposely selecting participants.}

The leaders of the selected GEGs were the participants in this study along with nine GEG members. Participants were recruited through a purposive sampling strategy (Punch \& Oancea, 2014) with some elements of randomness based on their participation on the GEG's online forum. According to the Human Ethics Guidelines of Victoria University of Wellington, section 4 about the use of electronic media, the public nature of the groups' online forum can be used without seeking further permission (HEC VUW, 2016, p.5b). The public nature of the GEGs' online forum enabled me to openly and freely access data and information from participants without authorisation. The selection of participants was conducted using the combination of prospective and retrospective data in the online forum. Hur and Brush's (2009) study of teachers' online participation in an online forum and Mayfield's (2006) power law of participation: high-level, mid-level, and 
low-level participant enabled me to identify diverse types of individual engagement in online activity. The criteria of online forum participation in this study was developed based on the combination of the qualitative and quantitative nature of online activities to capture the significance (substantial nuance) of the interaction (Table 2). The purpose of this table is to illustrate the qualitative nuance of participants' online participation in the forum as the selection criteria. For example, posting ed-tech content is considered more significant/substantial than socialising or having small talk or the quality of post or discussions related to ed-tech or professional learning content/topics and their frequency in the online forum (Table 2).

Table 2. The category of participants' online participation

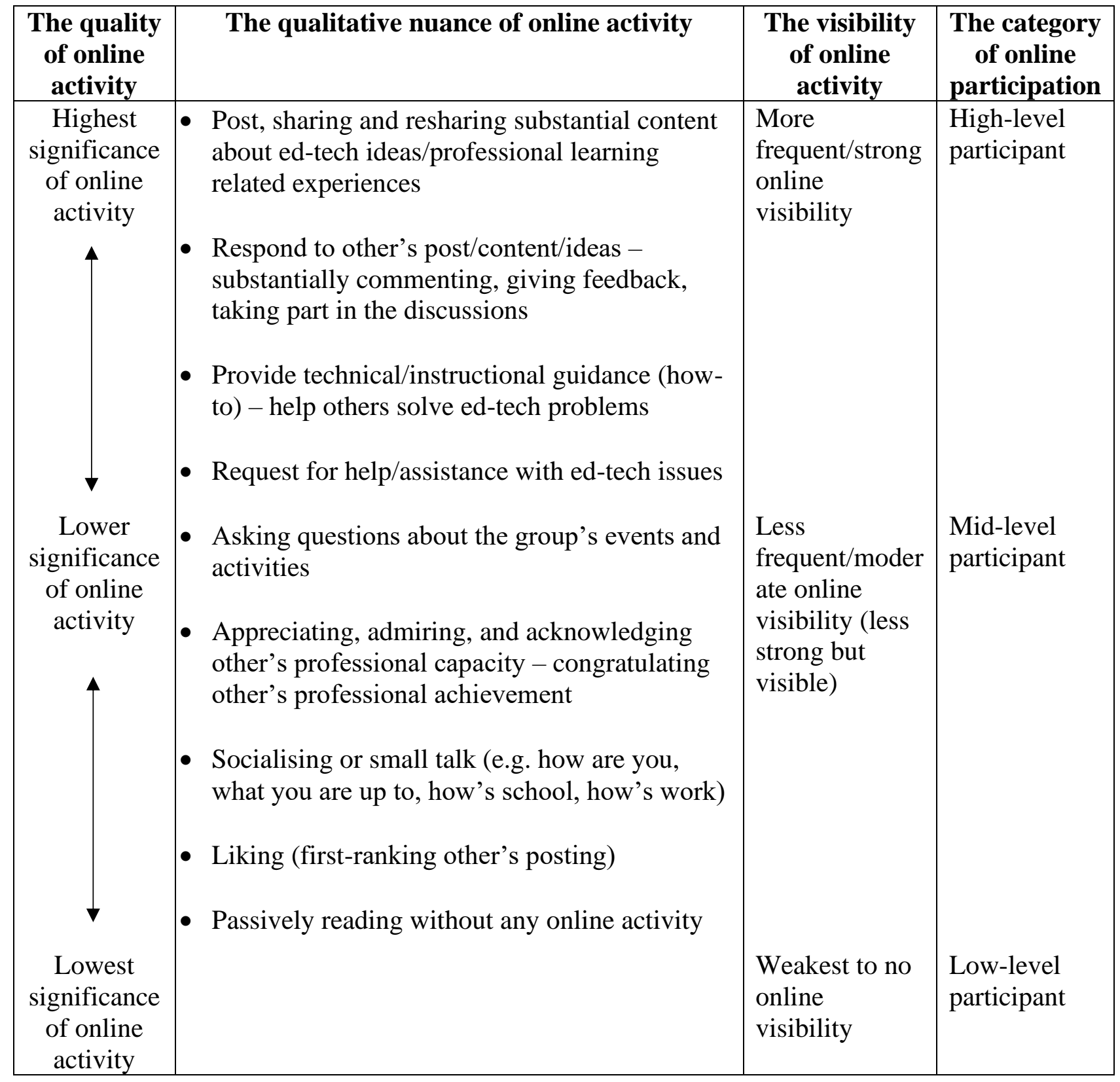




\section{The process of selecting participants}

Participants were identified as being high, mid, or low-level participants. Highlevel participants had highest significance of online activities with strong visibility in the online forum. Mid-level participants had lower significance of online activities with moderate visibility in the online forum, and low-level participants had the lowest significance of online activities with weak to no visibility in the online forum.

A prospective list of participants within each of the category was compiled. I then made a personal approach and invited them to participate in the study. Once they had given their consent, they were then selected. When an invited potential candidate (via email) did not respond, refused, or withdrew within two weeks, then I moved to the next on the list within the same category (high-level, mid-level, or low-level). Potential candidates were listed randomly under the same category, which made selection to some extent, random.

All participants were education professionals. Two of the Metro participants (the leader and mid-level participant) were all teachers; one participant (high-level participant) was an English as a Foreign Language (EFL) lecturer, and the other one (low-level participant) was both a teacher and a lecturer. Three of the Urban participants were teachers (the leader, high-level participant, and low-level participant) and one urban participant was a school principal. One Rural participant (high-level participant) was both a teacher and a school principal in different schools. Three other participants (the leader, mid-level participant, and low-level participant) were all teachers and school data administrators/operators. Further information about the selected participants, the method of selection, data sources, the objective of data collection, and the result of the selection was appended.

\section{Collecting data (stage 2)}

It is recommended to obtain data from various sources in a qualitative case study including interviews, observations, and documents (Stake, 1995). I collected data from participants' interviews and the observation of their activities in the groups' online forum for in-depth exploration of their perspectives, experiences, and activities. The study employed a 'crystallisation' method (Richardson, 2003) in order to allow significant insights to emerge (Klein \& Myers, 1999). All collected data were crystallised through coding and analysis within cases and across cases to obtain a more complete in-depth and 
more coherent picture of Indonesian educators' ed-tech professional learning in the GEGs. The use of interviews and online forum observations aimed to verify and validate data by minimising inadequacies and inconsistencies from each source for a rich, detailed description, more comprehensible data, and in-depth insights. This allows access to the subtleties of changing and diverse interpretations and point of views (Walsham, 1995). I then conducted interview testing to fine-tune the interview guidelines, as well as online observation sheet testing to fine-tune the rubrics. The following sections describe the process of conducting interviews and online forum observation.

\section{In-depth semi-structured interview}

In a qualitative study, semi-structured interviews "help to define the areas to be explored, but also allows the interviewer or interviewee to diverge to pursue an idea or response in more detail" (Gill, Stewart, Treasure, \& Chadwick, 2008, p.291-292). Prior to conducting interviews, DiCicco-Bloom and Crabtree (2006) suggest that designing interview guides can assist researchers to achieve the optimum use of interview time, by guiding them to effectively navigate the exploration of the interview questions being answered by the participants more systematically and comprehensively, as well as to keep the interview focused on the desired line of action. In doing so, this study follows an interview protocols refinement framework (Jones, Torres, \& Arminio, 2013) consisting of four phases:

Phase 1: Ensuring interview questions align with research questions

Phase 2: Constructing an inquiry-based conversation

Phase 3: Receiving feedback on interview protocols

Phase 4: Piloting the interview protocol.

First, an interview guideline was designed with questions that were carefully selected pertaining to the research questions to collect data from three leaders and nine members of the case study of GEGs. The design of every question was underpinned by the research questions, so that I could explore participants' perspectives, experiences, and practices in their social media use for informal professional learning. In addition, every question was arranged under topics of interest to support effective coding. The follow-up questions of every main question were designed to clarify specific information, details, and narratives from the eight core questions, while prompts were utilised to help elicit more detailed information. 
Secondly, I developed an inquiry-based conversation through an interview protocol based on four primary elements:

1. Interview questions were written differently from the research questions (Brinkmann \& Kvale, 2015);

2. An organisation following "social rules of ordinary conversation" (Rubin \& Rubin, 2011, p.96);

3. A variety of questions (R. A. Krueger \& Casey, 2009); and

4. A script with likely follow-up and prompt questions (Brinkmann \& Kvale, 2015).

Thirdly, I then shared the interview protocols and questions in the interview with my supervisors. I also shared them with two of my $\mathrm{PhD}$ colleagues (one who studied in New Zealand and another one who studied in the United States) via Skype video discussion. This sharing aimed to obtain feedback in order to enhance its reliability and trustworthiness as a research instrument (Patton, 2015).

Fourthly, I piloted two semi-structured interviews to test the interview protocols and interview questions in the interview guidelines. The pilot testing of the interviews was conducted with Indonesian educators who were not part of the selection of cases and participants via Skype video calls. According to Creswell \& Creswell (2017), the pilot testing of the interview guide is essential to improve the core question and many associated questions related to the central question. In this regard, the interview testing aimed to improve the interview protocols and refine questions in the interview guidelines by evaluating and avoiding questions that were ineffective, too overwhelming, and too overlapping. Based on the interview testing, the researcher was able to identify that some of the follow-up questions overlapped. Further details about the design of interview questions in the interview guideline for leaders and members of GEGs, along with the protocols, are appended (Appendix 1).

The purpose of in-depth semi-structured interviewing is neither to simply get answers to questions, nor to test hypotheses, but as a point of interest in understanding the experience of other people and the meaning they make of their experience. This then provides access to their context of behaviour and provides insights into the meaning of that behaviour (Seidman, 2006). I conducted the interviews as a series of friendly conversations rather than viewing them as tools for mere information gathering. In so 
doing, I slowly introduced new elements in order to build rapport with the interviewees and jointly construct meanings (Mishler, 1986).

After conducting the four phases above, the guideline was ready to be implemented. The GEG leaders were interviewed twice (initial and follow-up interviews) and nine GEG members were interviewed once. The initial interviews of the Urban GEG and Rural GEG leaders were conducted via audio-recorded Skype, while the Metro GEG leader's initial interview was conducted via recorded Google Hangout (video). The follow-up audio-recorded interviews of all three leaders were conducted in Indonesia. All participants gave consent for the interviews to be recorded. The interviews occurred approximately 1 to 1.5 hours. Participants were given an option to choose the language they felt most comfortable using in the interview. Almost all participants used Bahasa Indonesia in the interview, except the leader of the Metro GEG who chose to use English.

\section{Transcription, translation, and transliteration}

In qualitative studies, data from interviews and conversation, either in the form of audio and/or audio-visual recordings, are further transformed to transcribed texts. This transformation of verbal conversation into textual form, which is accessible for multiple reading by multiple readers, is a multi-layered process, which transforms the format and functionality of data (Lambert, 1997). It involves making decisions and choices along the way in order to enact the theories influencing analysis and interpretation (Lapadat \& Lindsay, 1999). This process is more complex when data are bilingual or multilingual, as in the case of this study. As the interviews were conducted in Bahasa Indonesia and English, the interview data were considered bilingual. Eleven participants chose to use Bahasa Indonesia and one chose to use English in the interview. All participants told me that the reason for using the aforementioned languages was due to their most comfortable preference in expressing their thoughts and ideas.

I imported all interview transcripts into the qualitative data analysis software I utilised for this study, NVivo 11, along with all of the recorded audio and video files of the interviews. The interviews were digitally recorded and transcribed verbatim in Bahasa Indonesia (for participants who used Bahasa Indonesia) or English (for participants who used English). I personally transcribed all interviews in order to better familiarise and immerse myself with the subtleties in my data. The only interview I transcribed in English was that of the leader of the Metropolitan GEG's. 
The transcribing process was also a cultural experience for me as the researcher because it involved converting ideas expressed in one language (for one social group) to another language (for another social group), entailing cultural decoding (Torop, 2002). Besides the language aspect, the participant's culture is also embedded in the interview, and therefore I needed to keep the target social group/reader in mind. Although one participant chose to use English, the context he used to describe his thoughts and ideas in English was nevertheless Indonesian. In this case, I had the advantage as I belonged to the same culture as my participants. Hence, it enabled me to relate to the culture of all participants with ease, as well as preserve the essence of the interview data as close as possible to the participants' cultural context. As I proceeded with the transcription, I continued to formulate such rules for myself to help remain consistent in this process. Once the transcribing of all the interviews was done, I read again the transcribed interviews along with their audio-video files so that I could check for errors and inaccuracies.

The most common errors identified within a transcription process are gaps, omissions, misspelt words, misunderstood words, and missing paralinguistic communication, which includes all variations in volume, pitch, and quality of voice, as well as the pacing of speech and length of silences (Foucault \& Gordon, 1980). As I was reading all of my transcribed interviews one by one, I found that non-verbal cues such as deep sighing, long pauses/gaps, soft laughing, laughing aloud, fillers, and the intensity of tonal voice helped me further in making sense of the interview. However, due to participants' high speed in speaking and their uses of too many fillers, some parts of their utterances were hard to grasp. I overcame this issue by using the slower speed feature provided by NVivo 11. From this transcribing experience, I have come to understand that the figures of speech and writing expressions have different nuances, and transcribing is not just converting speech into text, but involves a transformation process of thoughts, ideas, context, and culture.

Following transcription, the next step was repeatedly reading and taking notes of all the interview transcripts. I made notes in a journal in order to observe and reflect on my own interpretation while managing data. Sutton and Austin (2015) describe how making notes in journals are relevant as a reminder for the researcher to reflect on situational factors that may provide an important context to the interpretation of data. In doing so, I took notes of the challenges I had, initial notions, and changes in the decision- 
making I made in the process. The journal enabled me to put forth my thinking, values, and experiences behind my decision-making process and made them visible throughout the entire process of the study. Consequently, I was able to reflect on my own subjectivity as a reminder to maintain a level of transparency in the way I interpreted my data to reduce my own bias. While repeatedly reading and taking notes of all the interview transcripts, I edited and corrected the structure of the utterances and added the non-verbal cues wherever I found them to be essential for a better understanding of the text without losing substantial meaning. I chose not to take unsubstantial utterances such as a laugh, sigh, pause, or filler into consideration as I was more focused on trying to understand the main ideas expressed

I both translated and transliterated the interview transcripts and the online observation sheet. Translation is a process where "the meaning and expression in one language (source) is tuned with the meaning of another (target) whether the medium is spoken, written or signed" (p. 346). The translation was conducted only for post-memberchecked transcripts in Bahasa Indonesia, while transliteration was conducted for the transcript in English when necessary to describe and present the identified codes and emerging themes. The online content on Google Plus platform pages had also undergone a translation process.

Transliteration referred to a process of "replacing or complementing the words or meanings of one language with meanings of another as sometimes the exact equivalence or exact meaning might not exist" (Regmi, Naidoo, \& Pilkington, 2010, p.18). The transliteration process was undertaken as part of the translation process because some words in Bahasa Indonesia were not contextually available and equivalently available in English. I, therefore, had to find words/sentences in English, which could best provide the best nuance to capture their meanings from Bahasa Indonesia. I tried to keep the number of words/phrases in Bahasa Indonesia used in the research report to as few as possible, so as not to hamper the flow and readability of the text.

\section{Online forum observation}

The online forum observation was conducted as one of the sources for data collection to generate qualitative findings. An online observation sheet was designed to organise the data and served as a confirmation tool about what participants did online, compared to what they said they did online. All content in the group's online forum was 
publicly accessible by anyone with an Internet connection without any passwordprotected environment and without restriction of authorisation such as in a closed group or like those in Facebook.

In an offline environment, observation refers to "fieldwork descriptions of activities, behaviour, actions, conversations, interpersonal interactions, organizational or community processes, or any other aspect of observable human experience" (Patton, 2002, p.4). This is also applicable to the online environment where the Internet represents a different kind of space for the online interaction of communities that can appear and exist beyond the limits of time and space (Szmigin \& Reppel, 2004). As the Internet is interactive by nature (Tsoukas, 1997), observation in an Internet-based environment allows the researcher to study a multiplicity of social dynamics through a variety of online communication media (Nørskov \& Rask, 2011). It can also provide opportunities for viewing or participating in unscheduled events (De Munck \& Sobo, 1998).

I conducted the online forum observation without interfering the group's activities as peripheral member researcher who seeks to develop an insider's perspective without directly participating in group activities (Adler \& Adler, 1994, as cited in Denzin \& Lincoln, 2008). In this regard, I provided general information about the study to let leaders and GEG members know about the online observation without any further participation and interaction for me in the forum. The leaders then posted this information publicly on their groups' online forums.

I conducted several steps for online forum observation. First, a Fireshot plugin to the Chrome browser was used to generate and capture the online forums, converting them into PDF files. The online observation was conducted simultaneously within a 12 month period to allow a sufficient window for more data from dynamic online activities to be observed. I observed participants' online activities/contents/postings after they signed their informed consents. The observation included the group's participation, communication, interaction, collaboration, discussion, and networking. The practical guideline of the online observation sheet and the design of the online observation sheet are appended (Appendix 2 and 3). 


\section{Analysing data (stage 2)}

Two forms of data analysis were conducted in this study. I followed Stake's (2006) multiple case study analysis where analysis within-case and across-cases. For within-case analysis, I conducted an initial coding for each case and aggregated the codes into broader categories as a basis for making within-case assertions.

\section{Within-case analysis}

As I examined all data sources by reading and re-reading interview transcripts and online observation along with my notes, I conducted initial coding by reducing the data into meaningful segments (issue-relevant meanings) and assigning names to the segments as the initial codes. Table 3 shows the process of initial coding from participants' interview transcripts and online observation evaluation. Data from these sources were considered to ensure systematic and consistent process for generating initial codes. I generated 40 initial codes from Metropolitan GEG case study; 67 initial codes from Urban GEG case study; and 45 initial codes from Rural GEG case study (Table 3 ).

Table 3. Examples of generating initial codes from the Rural GEG case study

\begin{tabular}{|c|c|c|}
\hline $\begin{array}{c}\text { Example of phrases/excerpts from the } \\
\text { data corpus }\end{array}$ & $\begin{array}{c}\text { Initial code } \\
\text { (nodes in NVivo) }\end{array}$ & Sources of data \\
\hline $\begin{array}{l}\text { I recruited a co-leader to assist me in } \\
\text { organising and managing the group's F2F } \\
\text { free and open events and activities, but I } \\
\text { managed the online forum and the site by } \\
\text { myself. I administer the forum... }\end{array}$ & Leader's roles & \multirow{4}{*}{$\begin{array}{l}\text { Rural participants' } \\
\text { interview } \\
\text { transcripts and } \\
\text { Rural GEG's } \\
\text { online forum }\end{array}$} \\
\hline $\begin{array}{l}\text { I want to contribute to improving the } \\
\text { quality of teachers and educators' teaching } \\
\text { and learning practices with technology in } \\
\text { my region. }\end{array}$ & Leader's aspirations & \\
\hline $\begin{array}{l}\text { My school is still struggling for now, but I } \\
\text { do not want to give up. I learned a lot from } \\
\text { colleagues who shared similar challenges } \\
\text { with me, and it made me feel that I was not } \\
\text { alone in this. }\end{array}$ & $\begin{array}{l}\text { Motivation } \\
\text { Connected through } \\
\text { similar challenges }\end{array}$ & \\
\hline $\begin{array}{l}\text { It has brief discourse and no display of } \\
\text { negative discourse. No display of } \\
\text { discussions, collaborative activities, or } \\
\text { problem-solving activities. No detailed } \\
\text { feedback. No display of ed-tech } \\
\text { experience-sharing No affective } \\
\text { expression/emotion... }\end{array}$ & $\begin{array}{l}\text { The forum is driven } \\
\text { by sharing and } \\
\text { finding information } \\
\text { The forum as an } \\
\text { information } \\
\text { platform }\end{array}$ & \\
\hline
\end{tabular}


This study implemented Stake's (2006) categorical aggregation. I conducted the categorical aggregation process manually with the evidence from data that had been initially coded, bearing in mind that a combination of both manual and computer-assisted methods is likely to achieve the best result (Welsh, 2002). I reduced the initial codes by establishing patterns and aggregating them under similar, but broader, categories. I also looked for a correspondence between two or more categories. Throughout this process, two or more categories were assigned accordingly when they shared similar relevance or had similar categorical patterns.

All categories were examined and refined until the final categories were aggregated. Throughout this process, the initial codes were aggregated into larger and wider categories leading to final categories in each individual case study. Assertions were then made based on the final aggregation of categories in each individual case study inductively (Stake, 1995). Thus, following Stake, the assertions were formulated from the examination and refinement of the final categories leading into the final interpretation of each of the final category. The purpose of the assertions is to build an understanding based on the evidence-based findings that captured the temporal truth within the context of the data (Miles et al., 2014). In the process of formulating assertions, I involved participants in checking and clarifying the assertions via email aiming to increase the robustness of my within-case findings, which referred to as member-checking (Creswell \& Miller, 2000). I also made a form of mind-mapping illustration to visualise data from within-case analysis, which helped me in the process of understanding how participants' ed-tech professional learning in each case of GEG occurred (See an example of figure 4 for the mind-mapping of the Metropolitan GEG). 


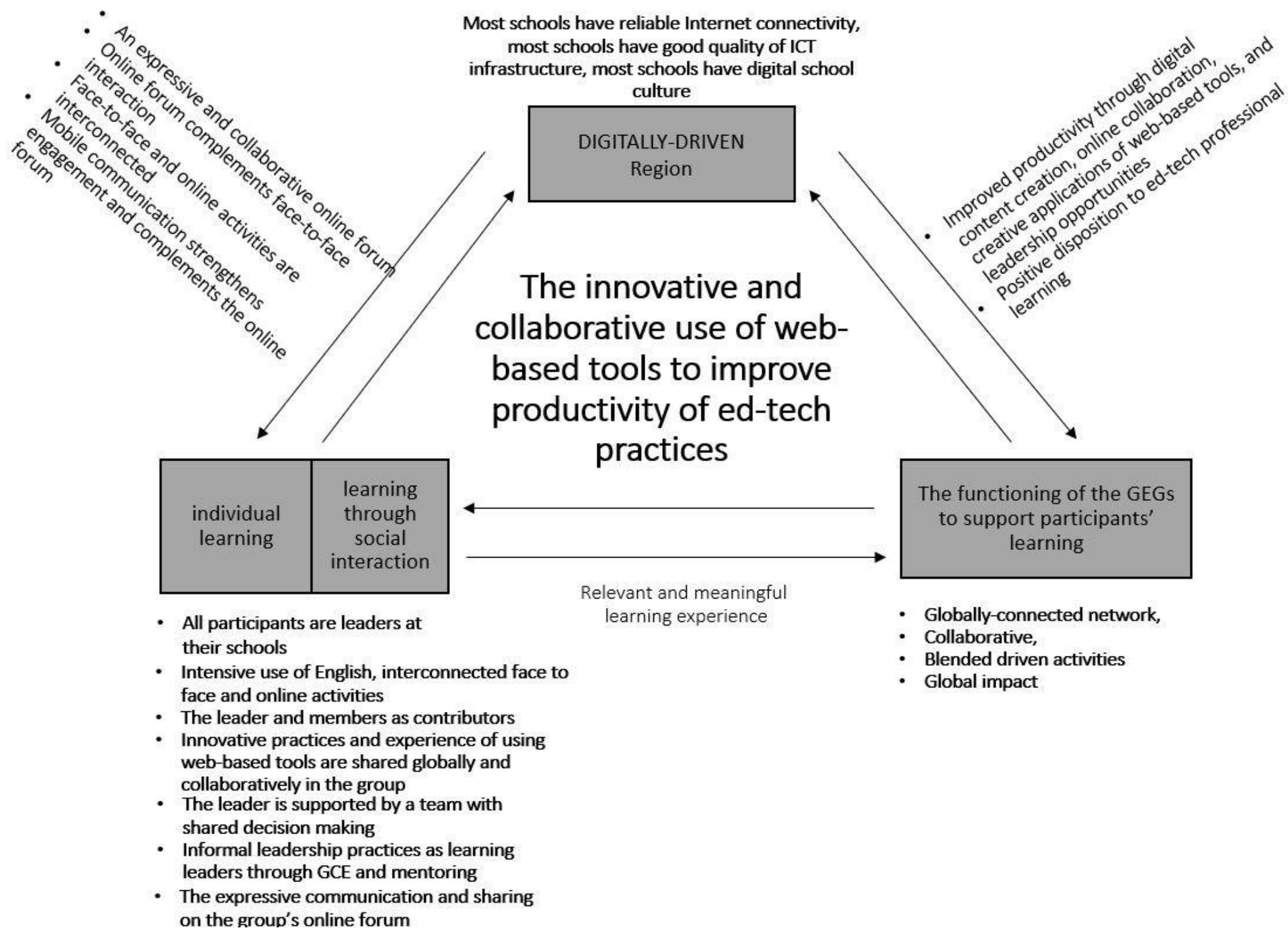

Figure 4. An illustrative example of the mind-mapping of the Metropolitan GEG 
Figure 4 shows my thought process visually in analysing the individual case study of the Metropolitan GEG through categorical aggregation, which was further processed into refined categories leading to assertions. For example, I put the category of digitally driven region as I analysed the ICT infrastructure influencing participants' learning and digital practices in the Metropolitan GEG. I then went along to visualise how participants learned in the group through the category of their individual learning, learning through social interaction, and the functioning of the group to support their learning.

At the final stage of within-case analysis, the refined categories (main categories) were presented along with relevant quotes and evidence supporting them in both the narrative account of individual experiences and the collective description of the group in the online forum, were described in contextually rich details (Stake, 1995). Assertions were then formulated and presented as the result of how each of the main category led into final interpretation following the evidence, which also served as the basis for conducting the cross-case analysis.

\section{Cross-case analysis/synthesis}

The assertions from individual case studies were collated and displayed as a colour-coded table for comparison across cases. This is where Stake's (2006) cross-case analysis was conducted to reveal the emerging themes from the entirety of the data analysed. Following Stake's cross-case analysis guideline, I used this table to begin my cross-case analysis by comparing each assertion across the cases to probe for any similar and contrasting features that were significant, relevant, and contradictory. The colours and codes helped me identifying these similarities and contrasts more efficiently. Three themes were identified in the process of cross-case analysis: (1) the regionaltechnological environment, (2) group functions, and (3) the informal leadership practices. Table 4 displays an example of the comparison of assertions under the theme of the regional-technological environment. The complete table of the comparison of assertions across cases is appended (Appendix 4) 
Table 4. An example of the comparison of assertions

\begin{tabular}{|c|c|c|c|c|c|}
\hline \multicolumn{3}{|r|}{ Assertions } & \multirow{2}{*}{$\begin{array}{l}\text { M GEG } \\
\text { S }\end{array}$} & \multirow{2}{*}{$\begin{array}{l}\mathbf{U} \mathbf{G E G} \\
\mathrm{C}\end{array}$} & \multirow{2}{*}{$\begin{array}{l}\text { R GEG } \\
\text { C }\end{array}$} \\
\hline \multirow{5}{*}{\multicolumn{2}{|c|}{ 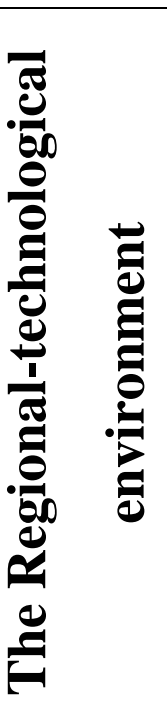 }} & $\begin{array}{l}\text { The conducive ed-tech learning environment in the GEG supported participants' ed-tech } \\
\text { collaboration and encouraged them to explore leadership opportunities (M1) }\end{array}$ & & & \\
\hline & & $\begin{array}{l}\text { Global networks with collaborative events and activities provided diverse face to face and } \\
\text { online activities enabling a range of learning opportunities (M2) }\end{array}$ & $\mathbf{S}$ & $\mathbf{C}$ & $\mathbf{C}$ \\
\hline & & $\begin{array}{l}\text { GEG participants were professionally challenged by a regional disparity in Internet access } \\
\text { and a pervading emphasis on the use of hard copy, rather than digital resources (U1) }\end{array}$ & $\mathbf{C}$ & $\mathbf{S}$ & $\mathbf{R}$ \\
\hline & & $\begin{array}{l}\text { With constrained digital resources and Internet connectivity, motivating and facilitating } \\
\text { learning using web-based technologies in the group became challenging (R1) }\end{array}$ & $\mathrm{C}$ & $\mathbf{R}$ & $\mathbf{S}$ \\
\hline & & $\begin{array}{l}\text { As participants struggled with a lack of resources, they formed strong friendship and } \\
\text { collegiality through face-to-face and Telegram communication (R3) }\end{array}$ & C & $\mathbf{R}$ & $\mathbf{S}$ \\
\hline
\end{tabular}

\section{Significant (S)}

Relevant (R)

Contradictory (C) 
From the example above, it can be seen that an assertion was deemed significant (in green) when it reflected the case from which it emerged. A relevant assertion (in blue) also reflected plausibility of occurrence in another case study. An assertion was contradictory (in red) when it was in contrast with another case. Through analysing the significance, relevance, and contradictory across cases using this table, I could see clearly the commonalities and contrasting features that were significantly interlinked across case studies beyond individual cases (Stake, 1995, 2006). Evidence from the relevant quotes from participants and online observation data supporting these findings were also examined, reviewed, and cross-checked. At the final stage of cross-case analysis, I wrote the analytical report of the cross-case analysis/synthesis in Chapter 7.

\section{Interpreting and representing data (stage 3)}

The interpretation of findings was represented with the evidence from data analysis of the online forum observation and participants' interviews following the writing of every chapter in the form of texts and illustrations (figures, tables, and diagrams). The discussion chapter was written with the guidance from the research questions and Bandura's social cognitive theory as theoretical framework. Two significant aspects needed to be considered in the whole research process through all of these stages are establishing trustworthiness and making sure that everything conforms to the ethics of the research.

\section{Trustworthiness}

The trustworthiness of a qualitative research study is important to evaluate its worth (Guba \& Lincoln, 1994). Trustworthiness seeks authenticity as a quality in the crystallising approach instead of absolute truth (Polsa, 2013), which requires credibility, dependability, transferability, and confirmability (e.g. Elo et al., 2014). Credibility refers to the "confidence in the truth of the findings, including an accurate understanding of the context" (Ulin, Robinson, \& Tolley, 2005, p.25). Dependability refers to how consistent and reliable the research findings are based on how well the researcher documents the research procedures enabling the external party to follow, audit, and criticise the research process (Streubert-Speziale, 2007). Transferability refers to the results of the qualitative research that can be transferred to other contexts in a certain degree, settings, or respondents by readers (Bitsch, 2005; Tobin \& Begley, 2004). Confirmability refers to 
the degree to which another researcher can confirm or corroborate the results of the research inquiry (Baxter \& Eyles, 1997).

To establish trustworthiness of this study, I provided a detailed description of the findings consisting of meaningful information and an in-depth interpretation of my participants' experiences. The detailed and thick description of the study depends on the richness of the data, rather than its amount, to demonstrate the truth of the research study's findings; hence its credibility (Graneheim \& Lundman, 2004). I documented my biases, dispositions, and assumptions from data collection to data analysis through notes in a journal. Merriam and Tisdell (2009) point out researcher reflexivity as another tactic for establishing the credibility of a qualitative study by "explaining their biases, dispositions, and assumptions regarding the research to be undertaken where it allows the reader to understand how the researcher might have arrived at the particular interpretation of the data" (p.219). I then conducted member-checking to confirm the accuracy of the reality of my interpretation of the transcripts and online observations, which is considered as "the most critical technique for establishing credibility" of a qualitative study (Lincoln, Guba, \& Pilotta, 1985, p.314).

I provided a detailed description of my situation as a researcher and the methods in a way that may provide guidance for other researchers to conduct other studies that have similar conditions in other contexts or settings. I described the selection of cases and participants based on the specific criteria in details. I created a trail of evidence through systematic documentation of the data collection, data compiling, and data analysis. The articulated trail gathered from the chain of evidence develops trustworthiness and credibility to build rigor through a clear chain of evidence, which allows the reader to follow a logical path from the research question through to the conclusion (Gibbert, Ruigrok, \& Wicki, 2008).

\section{Ethical considerations}

I adhered to Victoria University of Wellington Human Ethics Committee's guidelines in every process of how the study was carried out to align with the ethics of the research. I also made sure that my research conforms to the New Zealand Association for Research in Education. All the research-related work from the conception, design, process, reporting, and dissemination of the research was conducted and reported transparently, objectively, and based on evidence. I treated my participants with respect. 
I ensured that the rights and interests of the selected leaders and members of GEG as my participants were carefully and thoughtfully respected, cared for, served, facilitated, and accommodated, including the provision of consent forms for permission to conduct an interview and record it electronically, permission to observe the public group pages/sites, agreement for the group leaders to be informed about my research and share it in the group's online forum, confidentiality about the actual identity of the selected GEGs and their leaders and members, the avoidance of unnecessary harm to participants, providing a comfortable environment for the participants throughout the research process, and respecting property rights (including intellectual property) for any use of online materials from the Google Plus platform pages. I also consulted with the participants about any issues that needed to be clarified during the interview and online observation.

A research-dedicated website contained further information, and detail about my research was provided along with an embedded link for opting out from the study to enable them to withdraw from it at any time with ease. Any member from the selected GEGs who did not wish to participate in the study could directly inform the researcher through an automatic online form. In so doing, should no members of GEGs opt out, they were all automatically included in the online observation. Over the period of data collection, I visited the research-dedicated website regularly to see whether there were any opting out notifications from participants. However, when I finished collecting my data, I found no opting out notifications from any of the participants from the three selected GEGs. Therefore, all participants who had agreed to participate in this study kept their commitments without any objection (voluntarily). The information about my research and the link to the research-dedicated website was also posted by all GEG leaders in their online forums to inform all GEG members about my position as a passive observer.

This study was not anonymous, but confidential, and signed informed consent was obtained from all participants in this study. All participants and GEGs were allocated codes to preserve confidentiality. All participants were given opportunities to read their transcripts and verify the information and offer comments and clarifications via email. All data from multiple sources of responses, comments, and information had been reported in an aggregated form in such a way that the actual individuals with their GEGs were not identifiable. I used a direct quotation from the interview transcripts or individual online contributions/postings without breaching confidentiality. The Bahasa-English 
translation and transliteration process was conducted in such a way that it did not identify the actual identity of all participants. All data were stored on a password-protected NVivo 11 cloud server and will be destroyed two years after the completion of the study.

\section{Limitations and delimitations of the study}

There are a number of potential design limitations in this study need to be considered. This study is focused on a specific setting of Indonesian educators' participation in the GEG for ed-tech informal professional learning and leadership with web-based tools and, therefore, the generalisability to broader groups as a form of ed-tech informal professional learning and leadership is limited. Instead, this study provides a rich narrative of how Indonesian educators participated in the GEG as a form of their edtech informal professional learning and leadership with web-based tools that readers can learn from. In addition, this study has a small, purposeful sampling that limits its ability to make broad statements based on the specificity of sampling. The year and the 12-month timeline of how data were collected is also part of the limitations of this study. Data were collected in 2017, which did not account for any recent updates of activities in 2019. This study is also limited because I single-handedly collected and analysed the data and, therefore, my bias could not be omitted; it occurred naturally and could only be minimised. As a delimitation of this study, it is not only delimited by the criteria of the selection but also by the positive responses of the participants and willingness to sign the informed consent via email.

\section{Summary}

This chapter began with theoretical framework and its relevance for the study underpinning the methodology: the interpretive research paradigm and qualitative research methodology. Then, the collective case study design and the detailed methods in selecting cases and participants were outlined and explained. The particularity of the process of within-case and cross-case data analysis was explained and trustworthiness of this study justified. Lastly, this chapter presented the limitations and delimitations of the methodology as well as the ethical considerations following the selected methodology. Findings from the individual case study of Metropolitan GEG, Urban GEG, and Rural GEG case study are presented further in chapter 4,5, and 6 . 


\section{Chapter 4}

\section{The Metropolitan GEG case study}

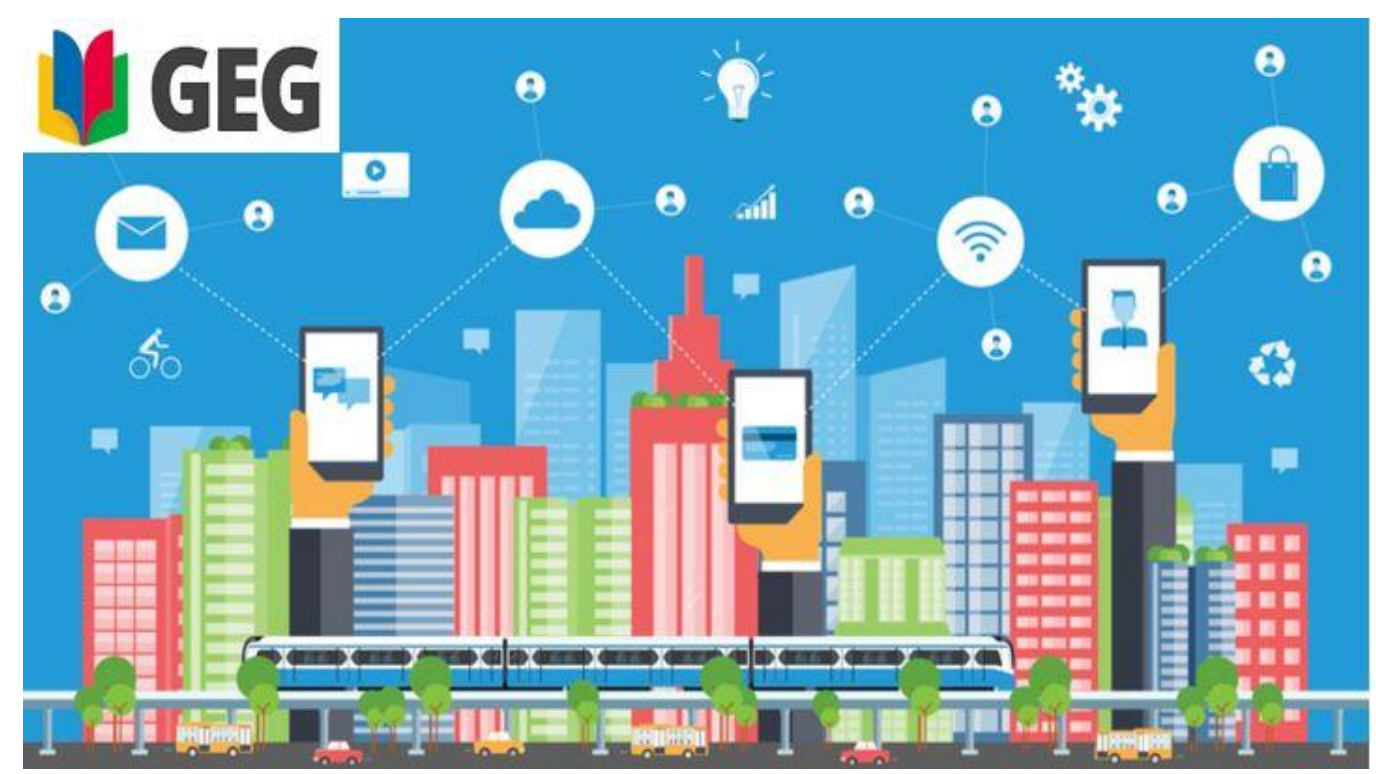

(Source: Image taken from Harvard's future cities programme at https://www.planetizen.com/node/94488)

"There is more to technology in education than just tools, technicalities, and functionalities for educators to teach lessons to their students. With technology such as web-based tools, educators can empower others to lead with confidence, globally and locally collaborate with passion, and create supportive and innovative networks" (Metropolitan GEG leader).

\section{Introduction}

This chapter presents findings from the study of a Metropolitan GEG, an informal group voluntarily initiated and organised by an educator in a digitally driven, large, and densely populated Indonesian Metropolitan region. It begins with a description of the context, the GEG itself, an analysis of GEG online forum observation data, and four key participants: the leader; a high-level; a mid-level; and a low-level participant. It is then followed by an examination of the main categories and assertions (Table 5) and ends with a summary: 
Table 5. The main categories and assertions in the Metropolitan GEG case study

\begin{tabular}{|l|l|}
\hline \multicolumn{1}{|c|}{ Main categories } & \multicolumn{1}{c|}{ Assertions } \\
\hline $\begin{array}{l}\text { Conducive ed-tech learning } \\
\text { environment }\end{array}$ & $\begin{array}{l}\text { The conducive ed-tech learning environment } \\
\text { in the GEG supported participants' ed-tech } \\
\text { collaboration and encouraged them to explore } \\
\text { leadership opportunities (M1) }\end{array}$ \\
\hline $\begin{array}{l}\text { A range of learning } \\
\text { opportunities through global } \\
\text { networks }\end{array}$ & $\begin{array}{l}\text { Global networks with collaborative events } \\
\text { and activities provided diverse face to face } \\
\text { and online activities enabling a range of } \\
\text { learning opportunities (M2) }\end{array}$ \\
\hline $\begin{array}{l}\text { The value of participants' } \\
\text { learning experiences in the } \\
\text { group }\end{array}$ & $\begin{array}{l}\text { Participants valued their learning experiences } \\
\text { as they gain benefit from being part of the } \\
\text { group (M3) }\end{array}$ \\
\hline $\begin{array}{l}\text { Innovative and collaborative } \\
\text { use of web-based tools }\end{array}$ & $\begin{array}{l}\text { Participating in the group enabled } \\
\text { participants to improve productivity of ed- } \\
\text { tech practices and experiences (M4) }\end{array}$ \\
\hline $\begin{array}{l}\text { Mobile communication with } \\
\text { WhatsApp }\end{array}$ & $\begin{array}{l}\text { WhatsApp was used as a popular and } \\
\text { practical mobile communication tool to } \\
\text { extend interaction and connectedness in the } \\
\text { group (M5) }\end{array}$ \\
\hline Intensive use of English & $\begin{array}{l}\text { The intensive use of English in the group's } \\
\text { online forum enabled the group to facilitate } \\
\text { global interaction and gained global } \\
\text { recognition (M6) }\end{array}$ \\
\hline $\begin{array}{l}\text { The interconnectivity of face- } \\
\text { to-face and online activities }\end{array}$ & $\begin{array}{l}\text { Participants' interaction and communication } \\
\text { were interconnected as the group blended } \\
\text { face-to-face and online activities (M7) }\end{array}$ \\
\hline
\end{tabular}

\section{The context of the Metropolitan GEG}

\section{The regional context}

As in participants' description of their regional condition, the metropolitan region is located in one of the largest, most-populated islands in Indonesia. Most regions on this island have the highest level of economic development of any other island in the country. With more developed infrastructure, facilities such as Internet connection are relatively reliable and extensively available, with various options ranging from ultra-fast to standard connectivity through Digital Subscriber Line (DSL), cable, or fibre optics. Many Base Transceiver Stations (BTS) from telecommunications service providers/companies have also been built to facilitate wireless communication. Mobile Internet connection is therefore considered affordable as one of the important things people need in their daily lives. 
From the way Metropolitan GEG participants' informed, the metropolitan region reflects a digitally-driven environment. Access to free public Internet connection at schools and outside of schools is abundant. Wireless Internet access points or Wi-Fi connection are widely available for free in many public places in the region such as airports, public libraries, shopping centres, cafes, restaurants, public parks, and schools. Most schools in the metropolitan region have relatively reliable Internet connection and accessible Wi-Fi areas supported by good quality of ICT infrastructure with prevalent digital teaching and learning practices and school administration. There is also a high exposure to global communities of educators as there are many international schools and globally private academies, international religious-based schools, or international boarding schools. In addition, the rise of ed-tech start-up companies in the metropolitan regions provide participants with various options of affluent ed-tech web-based resources, including professional learning opportunities.

\section{The Metropolitan GEG}

The group was informally initiated by an educator who became the leader in 2014 . By January 2018, there were over 800 members, both local and international, recorded in the group's online forum. The group's membership is open and free whose members include variety of educators, such as teachers, school principals, school staffs, school technology coordinators, superintendents, ed-tech consultants, and media specialists. The group ranked at the top of Google Educator Group Asia Pacific Professional Development Leader Board due to the highest amount of PD activities being organised and implemented in Indonesia and are recognised as a leading group. The group had one leader, supported by his colleagues from various schools, who were not participants in this study. They led the group as a team who collaborated and shared roles, responsibilities, and made decisions together to independently managed and organised the group's online forum, virtual activities, mobile communication forum, and face-toface activities.

The group used Google Plus Communities as the platform for online forum and mobile instant messaging application WhatsApp as the platform for mobile forum. Google Plus is a Google-based online forum platform allowing users to connect, interact, share ideas, links, videos (e.g. YouTube), pictures and messages. WhatsApp is a cross-platform messaging applications and Voice over IP service owned by Facebook, which enables people to the send text messages and voice calls, as well as video calls, images and other 
media, documents, and user locations. The group's WhatsApp forum was created by the leader to allow direct contact and communication between him and members as well as amongst members.

A variety of events and activities were organised by the group, such as face-toface study groups and online study groups (virtual learning sessions), as well as outreach support for various institutions and organisations that request mentoring, coaching, and facilitating. One of the most prevalent learning events and activities in the group is Google Certified Trainer (GCT) and Google Certified Educators (GCE). The GCT is the next level of certification that requires passing of the GCE exam levels 1 and 2. Other types of activities are free and open workshops-seminars-summits and meet-ups (virtually via Google Hangout and physical), the GCE coaching programme, the Google Classroom training series, and Photowalk (exploring the city together and taking pictures of places in the city to add to Google maps).

The group also facilitated international events and activities such as a collaboration event featuring cloud-based class creation. In these events, participants learned about Google sites training and Google Classroom with a special presenter from abroad via Google Hangout on Air. Such events and activities provided participants with not only knowledge and information about the educational use of various web-based tools and resources, but also how to use them for developing creative and collaborative projects and activities. Among various web-based tools that were introduced and used are Google slides, forms, docs, drive, Google expedition, Google street view, Google tool builder, and Google Suites/Classroom, Flipgrid, Kahoot, ClassDojo, Story bird, Canva, Write to Learn, YouTube, Apple-apps, Android apps, and many others. The leader and members actively shared examples and model from their own teaching and classroom practices such as the implementation of ClassDojo apps. The group incorporated virtual activities within the face-to-face events and immerse face-to-face activities with virtual activities.

\section{The Metropolitan GEG's online forum}

Although there were 800 registered members in the forum, online activities from 176 members were documented in the form of posts, comments, and likes. Thus, the rest of the registered members' online activities in the forum were not visible suggesting lurking or passive online reading activities. 
The forum captured various ed-tech topics, diverse content/activities, and communicative interaction. Among these topics are the use of web-based tools for creating educational contents, teaching, and learning strategies, leadership practices through GCT and GCE, networking, collaboration, mentoring, and study groups. The online activities were diverse, frequently posted, and responsive, such as online discussion, sharing ideas and practices, which signifies no issues of staying connected to each other or participate in the forum.

The group's online forum was highly communicative, appreciative, and supportive (Table 6). The leader and members communicated with each other, shared information, discussed ideas/thoughts, expressed appreciation, acknowledgement, encouragement/reinforcement, shared experiences, and practices, asked, and gave feedback, and collaborated for support in the online forum. The leader said that having no Internet issues enabled members to share and learn from diverse range of ed-tech practices and experiences with web-based tools on the online forum. He also said that he was grateful to have a reliable digital environment where it provided the group with diverse opportunities and resources for ed-tech learning that are available online.

Table 6. Examples of highly communicative, appreciative, and supportive posts in the group's online forum

\begin{tabular}{|c|c|c|}
\hline & Description & Posted by \\
\hline \multirow[t]{5}{*}{ Appreciation: } & $\begin{array}{l}\text { "Thank you for taking the time to share } \\
\text { with the GEG. Excellent ideas! Now I } \\
\text { encourage all of us GEG educators to } \\
\text { record themselves with ideas of how } \\
\text { Google for Education (GAFE) can be } \\
\text { integrated into students' learning } \\
\text { experiences in a video and share it with } \\
\text { each other here. You can use either } \\
\text { Bahasa Indonesia or English" }\end{array}$ & $\begin{array}{l}\text { The leader to } \\
\text { members }\end{array}$ \\
\hline & $\begin{array}{l}\text { "Thank you for the leader and the team } \\
\text { for giving me inspiration!" }\end{array}$ & $\begin{array}{l}\text { Member to the } \\
\text { leader and the } \\
\text { lead team }\end{array}$ \\
\hline & $\begin{array}{l}\text { "Thank to the leader for encouraging me } \\
\text { to be more active using my } G+"\end{array}$ & $\begin{array}{l}\text { Member to the } \\
\text { leader }\end{array}$ \\
\hline & $\begin{array}{l}\text { "Wishing you guys awesome } \\
\text { presentation. I will attend your talks next } \\
\text { time! }\end{array}$ & $\begin{array}{l}\text { Member to the } \\
\text { leader and the } \\
\text { lead team }\end{array}$ \\
\hline & $\begin{array}{l}\text { "Thank you for the awesome feedback. } \\
\text { This is such a really great support ed-tech } \\
\text { network!" }\end{array}$ & $\begin{array}{l}\text { Member to } \\
\text { another member }\end{array}$ \\
\hline
\end{tabular}




\begin{tabular}{|c|c|c|}
\hline & $\begin{array}{l}\text { "That's fantastic! Keep up the good } \\
\text { work. Looking forward to reading your } \\
\text { next review of ed-tech books. Your } \\
\text { review is very useful!" }\end{array}$ & $\begin{array}{l}\text { Member to } \\
\text { another member }\end{array}$ \\
\hline $\begin{array}{l}\text { Congratulating } \\
\text { others }\end{array}$ & $\begin{array}{l}\text { "Please welcome the candidate of Google } \\
\text { Certified Educator from...." }\end{array}$ & $\begin{array}{l}\text { The leader to } \\
\text { members }\end{array}$ \\
\hline \multirow{6}{*}{$\begin{array}{l}\text { Positive } \\
\text { affirmation and } \\
\text { encouragement }\end{array}$} & $\begin{array}{l}\text { "Start your first day of school with these } \\
\text { coolest apps!" }\end{array}$ & $\begin{array}{l}\text { The leader to } \\
\text { members }\end{array}$ \\
\hline & $\begin{array}{l}\text { "Here are several great updates on } \\
\text { Google Classroom!" }\end{array}$ & $\begin{array}{l}\text { The lead team to } \\
\text { members }\end{array}$ \\
\hline & $\begin{array}{l}\text { "Watch my golden moments with the } \\
\text { most inspiring educators through my new } \\
\text { vlog! I am grateful to the people who } \\
\text { have been inspiring mentors and coaches } \\
\text { to me. Now I get to help educators to } \\
\text { empower and inspire more educators and } \\
\text { students. That's gold!" }\end{array}$ & $\begin{array}{l}\text { The leader to } \\
\text { members }\end{array}$ \\
\hline & $\begin{array}{l}\text { "Google Classroom saves you time, } \\
\text { keeps you organised and helps you } \\
\text { communicate with your students" }\end{array}$ & $\begin{array}{l}\text { The leader to } \\
\text { members }\end{array}$ \\
\hline & $\begin{array}{l}\text { "This is just the beginning of our journey } \\
\text { to be GCE! Let us support our incredible } \\
\text { educators to be the changemakers!" }\end{array}$ & $\begin{array}{l}\text { The leader to } \\
\text { members, } \\
\text { referring them } \\
\text { who passed the } \\
\text { GCE program }\end{array}$ \\
\hline & "Well done on accepting the challenge" & $\begin{array}{l}\text { The lead team to } \\
\text { a member }\end{array}$ \\
\hline \multirow{2}{*}{$\begin{array}{l}\text { Expressing } \\
\text { thought/idea and } \\
\text { feeling }\end{array}$} & $\begin{array}{l}\text { "I love the idea of being a connected } \\
\text { educator" }\end{array}$ & $\begin{array}{l}\text { Member to } \\
\text { member }\end{array}$ \\
\hline & $\begin{array}{l}\text { "I will be looking out for people who } \\
\text { share my interest and connect with them } \\
\text { to share and learn" }\end{array}$ & $\begin{array}{l}\text { Member to } \\
\text { member }\end{array}$ \\
\hline
\end{tabular}

Through highly communicative, appreciative, and supportive online interactions, the leader and the lead team appeared to try initiating conversations by creating a friendly environment for members to engage in. Positive affirmation, encouragement and expressions of appreciation were strongly shown in the leader and the team lead's posts as well as members. The leaders, the lead team, and members were attentive and appreciative towards each other, which appeared to create a positive, supportive, and encouraging environment as no criticism and negative expression such as disappointment, anger, dispute, or sarcasm found in the forum, which could encourage participants to further engage and contribute to the online forum. 
The leader and the lead team were not the only contributors in the online forum. Although the leader and the lead team had a strong visibility of online activities, they did not seem to dominate the forum. Most members also contributed to the forum through their posts such as contributing to online discussions, sharing ideas and content, asking questions, responding/commenting to others' posts, giving likes, and resharing links of ed-tech resources.

From the online observation, it was evident that the leader and the lead team managed to take turns in keeping the forum active and updated. Data from the observation showed that the forum remained active and updated regularly in a month. It was never stagnant for more than a month (Table 7).

Table 7. Examples of diverse content posted by the leader and the lead team within an actively updated timeline

\begin{tabular}{|l|l|}
\hline \multicolumn{1}{|c|}{ Posting/content } & \multicolumn{1}{c|}{ Time of posting } \\
\hline Deeper learning infographic & 17 Jan 2017 \\
\hline Apply Google certified Trainer & 20 Jan 2017 \\
\hline Google returns the reference citation option to Google Docs & 4 Feb 2017 \\
\hline Differentiate Questions with Google forms & 22 March 2017 \\
\hline Workshop on educators' and school operators' favourite apps & 27 March 2017 \\
\hline How to become Google Certified Educator & 9 April 2017 \\
\hline Join Google forum discussion on teacher WhatsApp group & 27 May 017 \\
\hline Google lens turns your camera into a search box & 8 June 2017 \\
\hline Free access to attending digital conference online in Singapore & 12 June 2017 \\
\hline 7 creative activities using cool apps for first day at school & 18 July 2017 \\
\hline Updates on Google classroom & 2 August 2017 \\
\hline
\end{tabular}

Whenever the leader and the lead team posted in the forum, it was always responded by members, be it with likes, comments, or questions, which appeared to encourage members to post in the forum (Table 8). 
Table 8. Examples of diverse content posted by members within an actively updated timeline

\begin{tabular}{|l|l|}
\hline \multicolumn{1}{|c|}{ Posting/content } & Time of posting \\
\hline Maximising Google Search - Understanding what you read & 8 Jan 2017 \\
\hline Break down your classroom walls with this ground-breaking app & 19 Jan 2017 \\
\hline Power searching with Google online course & 7 Feb 2017 \\
\hline $\begin{array}{l}\text { Information about the national conference for educators: education } \\
\text { transparency, accountability, and participation }\end{array}$ & 10 Feb 2017 \\
\hline Create a simple and beautiful video using Adobe Premiere Clip & 13 March 2017 \\
\hline Google Autodraw & 26 March 2017 \\
\hline Blended learning and Flipped classroom & 6 April 2017 \\
\hline Tutorial on Google Map & 20 April 2017 \\
\hline Folders for Google Photo backs up & 14 May 2017 \\
\hline Strategies for collaborative practices and learning: working with text & 23 May 2017 \\
\hline Google Geo Outreach workshop & 4 June 2017 \\
\hline Project GeoBlitz & 11 June 2017 \\
\hline Updating new Google Calendar & 15 July 2017 \\
\hline Universal design: a guide for educators & 28 July 2017 \\
\hline Tutorial to create a hyperlapse video with Microsoft & 5 August 2017 \\
\hline Google slide superhero training & 9 August 2017 \\
\hline Book review: All teachers can teach code - code in every class & 12 August 2017 \\
\hline
\end{tabular}

The online forum also displayed diverse and frequent posts from members. As members responded to the leader and the team lead's posts, they also posted their own ed-tech content/ideas and substantially responded to each other's posts. For example, sharing experiences on using Adobe premiere Clip, sharing thoughts on blended learning, and flipped classroom, etc. This nature of interactive posts from the leader, the team lead, and members appeared to consistently keep the forum active and updated.

The forum also reflected a global network and discourse as English was predominantly used for the interaction and communication involving members who were not only Indonesians or Indonesian-based but also from other countries such as from Malaysia, Tokyo, and South Korea (Figure 5). 


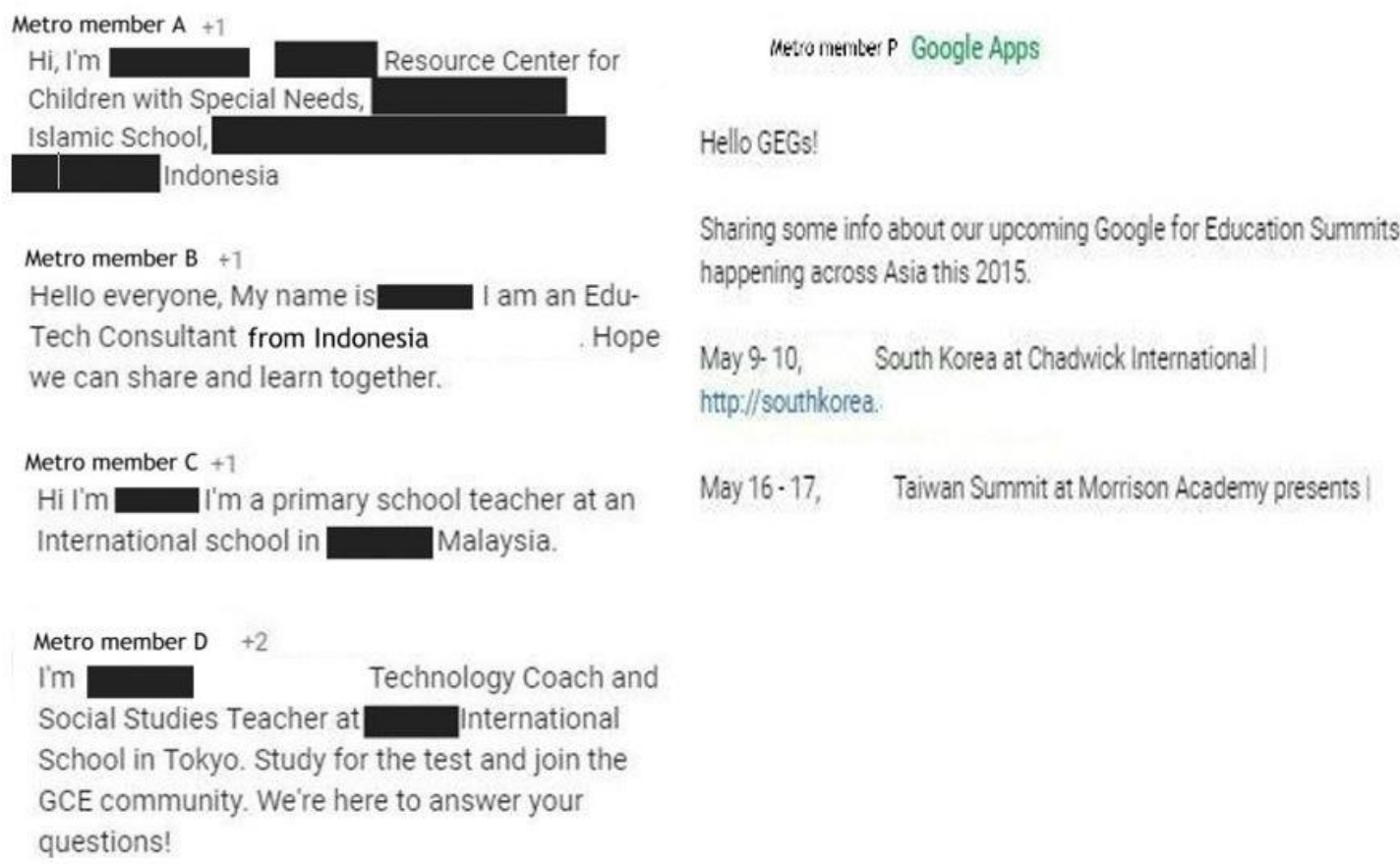

Figure 5. Examples of the group's global network and interaction

Members from Indonesia and other countries introduced themselves to each other and share information using English. The group also comprised of not only local members but also international members such as from Malaysia and Japan. There were also a number of international events shared in the forum, such as a summit in South Korea. These examples indicate the group's global network and interaction.

\section{The Metropolitan GEG's participants}

The four selected participants in this study are all educators with various professional backgrounds and practices. They all live and teach within the Metropolitan region, are leaders at their schools, and have incorporated digital teaching and learning practices at their schools. Although they live within the same region, they have different teaching experiences and teach in different types of school, grade, and teaching subject. They also have their own way of participating in the group, face-to-face, online or both. The following section describes each of the participants' professional background and the way they participate in the group's face-to-face activities and in the group's online forum. 


\section{The Metropolitan leader}

\section{Professional background}

The Metropolitan leader is the initiator and the leader of the group. He is a teacher at a private cluster school and has taught social studies and ICT subjects for grade 7 to 11 students for more than three years. Besides leading the group, he is also the co-founder of other informal learning communities and is active in book clubs. He has a Bachelor's degree in science, economics, education, family, and consumer science. He also studied educational technology, $21^{\text {st }}$ century learning, and blended learning from online courses. He fluently speaks both Bahasa Indonesia and English, but he mostly uses English in speaking, writing, and creating educational content.

\section{Prior Digital Practice and Experience}

The Metropolitan leader has a wide range of digital practice and experiences. He gained international certification from the Google Education Trainer Network and Google Innovator Academy and maintained a partnership with Google Indonesia. He also gained certifications as an Apple teacher and TED-Ed Innovative Educator. He is also an active education technology blogger and social media user. He said that he is passionate about education technology (ed-tech) leadership and ed-tech professional learning since his first encounter with the Internet, computers, and web. Among his content creation are blog, educational sketch notes, educational video blogs (vlogs), and video tutorials, which he actively shares on his blog, social media account, and YouTube account.

\section{Participation in the group}

The Metropolitan leader led and managed the group with a small team of colleagues who supported his vision. It was started when he had an informal gathering with his colleagues whom he shared his vision of the group with. His colleagues were interested to be part of his vision and offered to collaborate with him as a team in leading and managing the group together, which he thought as a great idea as he believed in the power of collaboration.

The Metropolitan leader organised the group's free events and activities in various forms with the support of his lead-team of colleagues. This included organising face-toface study groups and online study groups (virtual learning sessions), outreach support for various institutions and organisations that requested mentoring, coaching, facilitating, free and open workshops-seminars-summits and meet-ups (both virtual and face-to-face), 
GCE coaching programme, Google Classroom training series, and Photowalk. The leadership team has facilitated international events and activities such as a collaboration event featuring class creation on a cloud where participants learned about Google sites training and Google Classroom with a special presenter from abroad via Google Hangout on Air. The Metropolitan leader also provided examples and models from his own practices, sharing them as references to motivate others, such as the implementation of ClassDojo apps in his classroom and using Kahoot as an effective learning tool.

He actively collaborated with Google in organising ed-tech online and face-toface events and activities for educators. He also did projects with Google in creating edtech content and promoting GCT and GCE. He also actively explored collaborative opportunities with various institutions and organisations (such as public, private, and religious-based schools including Islamic schools, non-profit organisations, universities, government institutions, and companies with their corporate social responsibility programmes) to organised local ed-tech events. He used all the support from these collaborative efforts to facilitate teachers and educators who were interested in coming to these events and activities such as light snacks and beverages, venue and logistics, resource person, certificates of attendance/appreciation, and souvenirs. For the Metropolitan leader, having face-to-face group events and activities was important to enrich the online dynamic of the group. He said that he often incorporated virtual activities within the face-to-face events such as classroom-to-classroom meetings with other educators abroad. He believed that immersing face-to-face activities with virtual activities had been fruitful to improve participation and spark excitement.

The Metropolitan leader encouraged members to share their ed-tech experiences and practices:

"Other than providing information, I like to encourage members to openly share their experiences and practices in the forum. My team and I also take turns in our posting activities to trigger members to be more expressive online. When members start to express themselves and openly share their experiences, issues, problems, and reach out to others in the forum, it triggers other members to respond and help" (The Metropolitan leader).

When there were issues or problems that he was not familiar with, or could not find the solution for, the Metropolitan leader would initiate a conversation with his team to encourage any member to also share experiences dealing with such issues or problems. He also responded to members' comments and answering their questions, welcomed, and 
introduced new members, congratulated members for their ed-tech achievements, and conducted virtual learning activities. He managed to allocate times for managing the forum in a way he felt was flexible such as after teaching hours when he had free time at home, or during the weekend. Since the leader also handled his own social media, blog, and YouTube, he managed his time in such a way that he could stay connected with the group's online forum on a daily basis. For example, he routinely posted in the group's online forum and actively encouraged members to participate online. When unavailable, the leader's team would take turns in posting, updating, and managing the forum, thereby supporting his leadership. The leader also moderated the forum by filtering any content that did not align with the group's ed-tech vision, such as commercial ads, links to gossips, or politics news. He said that forum moderation was important to maintain the focus of the group's learning.

\section{The Metropolitan high-level participant}

\section{Professional background}

The Metropolitan high-level participant is a lecturer in English as a Foreign Language (EFL) institute. He teaches English as a Foreign Language (TEFL) at an institute. He is a social media user and publicly shares his research and articles on TEFL using various web-based tools. He also actively presents his TEFL research and works at local and national-level seminars and workshops.

\section{Prior Digital Practice and Experience}

The Metropolitan high-level participant informed that experimenting with webbased and video-editing tools has always been his passion since before becoming an educator and joining the GEG. He reported that he used such tools to create educational content such as podcasts and video tutorial, which he referred to as content creator. He has been using various web-based tools in his teaching practices and to record his classroom activities to help his students learn speaking English through critical and reflective evaluation.

\section{Participation in the group}

The Metropolitan high-level participant's online activities were strongly visible where he actively shared his experiences and practices using open-sourced video-editing software as well as supporting members who needed help in using the software. He occasionally attended the group's face-to-face events. He said that when he had time to 
do so, he would participate. He found the group's face-to-face workshop events very useful for his practices in creating mainly video-based educational content.

He also informed that he applied what he learned from the group to his teaching practices and educational content creation (video tutorials, video podcasts, etc). $\mathrm{He}$ learned from other educators in the group on how to use a video tutorial and video podcast in his TEFL classes, which he believed to have a significant impact on his students in mastering the lesson. As he engaged more with the group, he used Google tools more intensively such as Quiz, Google forms, and Google sites for his classroom practices because of their convenient but effective features; they were free, user-friendly, and easy to use.

He actively and intensively used English in the group's online forum discussions, asking and giving feedback, or explaining about his practices with video-editing tools to other international members in the forum. He valued the group's global network and resources and promoted it to his colleagues to join in and participate.

The Metropolitan high-level participant regularly visited the forum, which he said to find information, engage in discussions, ask questions, share and reshare content and practices, and give feedback/comments/responses/likes to other members.

"It is always great to create content about Teaching English as Foreign Language (TEFL) and sharing them with others in the forum. Some of the responses I get makes me realise that there is still less variety of TEFL content that is in Indonesian-context. In the group's online discussions, I also share my experience using a variety of video editing free software, and I am glad that can help them. Some members also often asked about issues they experience when they use certain tools for video editing and I understand what they are going through, I have been there before, and sometimes it can get very confusing. I am glad that my experience can help" (The Metropolitan high-level participant).

He considered the group's online forum a great platform upon which to share his practices, especially in relation to video editing. He observed that some colleagues in the group tried to reach out for help to overcome their confusion or problems in using tools for video editing and he understood what that felt like. Therefore, he was glad that his experiences and practice could help others: "Some of the members in the group have personally contacted me to further explain about certain functionalities in editing videos. I am glad that my video-editing experiences can help others" (The Metropolitan highlevel participant). Keeping up with the group online by participating and engaging in 
conversation and discussion made him feel "meaningful" because he felt that he could contribute to the group.

\section{The Metropolitan mid-level participant}

\section{Professional background}

The Metropolitan mid-level participant has a professional background as a school administrator at a public high school and now is an ICT teacher. He does not have formal educational background in IT and is self-taught. However, he informed that joining the GEG has opened up a valuable opportunity to become a Google Certified Educator level 1, which has been the result of his intensive learning in the group. He believed that his current teaching job has pushed him out of his comfort zone to seek active networking, browsing, searching more information about education technology and leadership. He also reported that he wanted to improve his ed-tech leadership because he was inspired by an ed-tech teacher leader can do to lead, empower, and collaborate beyond the classroom, not only for the students but also for other educators.

\section{Prior Digital Practice and Experience}

Among the Metropolitan mid-level participant's digital experiences were helping to facilitate students at his school to prepare for the computer Olympics at the national level while also working as a school ICT administrator. He also explored and experimented with education technology software and hardware, programming, hardware installation, and free and open-sourced web-based tools. His prior digital practice and experience also include practical ed-tech knowledge such as tips and strategies for using technology particularly for teaching, learning and professional purposes.

\section{Participation in the group}

The Metropolitan mid-level participant had frequent interaction with the group face-to-face. He allocated his time to attend the group's face-to-face (offline) events and activities. Along the course of his membership with the group, he also made friends with the leader and frequently communicated with him.

"I realise that most face-to-face activities in Metropolitan GEG such as meet-up, workshops and study groups were conducted quite far away from where I live. I live within the Metropolitan region but more to the sub-region of it. However, I am willing to take trains or buses to get there because I find their events and activities valuable. I made friends with some new colleagues and the leader. Being able to be with people who understand you and understand what I am going 
through is awesome. They know it is not easy but also not impossible. They give me motivation" (The Mid-level participant).

It appeared that the mid-level participant's effort to attend the group's face-to-face events and activities, as well as his friendship with some members and the leader, became the source of his motivation to participate in the group more actively.

The mid-level participant regularly visited the group's online forum to follow updates on the group's activities online and download resources. His online activities in the forum included posting content and commenting on other postings. He also included a link to various resources to the content he posted and shared in the forum:

"My experiences with the group have been amazing, and I like to share them with others in the forum. Some of the members who have similar experience contact me further, and we discuss more. I learn more by sharing what I experience more publicly and openly in the forum because it makes it easier for others who share a similar experience with you to reach out to you" (The Mid-level participant).

He shared his experiences attending the group's face-to-face events and activities in the forum and participated in the discussions. It appears that his further engagement with the group has encouraged him to be more active in expressing his ideas and practice more openly in the group. As he was more engaged, openly expressed himself in the group, and shared information and experiences with others in the group, he said that he had learned more.

\section{The Metropolitan low-level participant}

\section{Professional background}

The Metropolitan low-level participant is an ICT teacher at a public secondary school near the Metro city. He is also a guest lecturer who teaches human resources management in a government-owned university. In addition, he has written books on ICT for students and ICT training materials and learning modules for teachers. He has been learning to actively integrate various free and open-sourced web-based and Android tools in his teaching practices and professional activities. He is also keen on experimenting with web-based technologies and modifies the use of such tools in his ICT lesson plans at school. 


\section{Prior Digital Practice and Experience}

The Metropolitan low-level participant has professional experience as an ICT trainer for teachers and education/school personnel since 2005 . He is involved as the leader of the formal regional subject-matter teacher organisation (MGMP) in his school region. He is also a local-regional chief of the regional ICT teacher association. He is a social media user and a respected leader at his own school and in regional communities and organisations.

\section{Participation in the group}

The Metropolitan low-level participant did not always follow the group's interaction online or attend their face-to-face events and activities due to his activities at school and other professional responsibilities he had to do after school, but he volunteered for mentoring other educators around his school area.

The Metropolitan low-level participant visited the group's online forum whenever he can without any scheduled timeline. He did not always check up in the forum daily, but only a few times a month.

"Reading through others' shared experiences in the forum is enough for me. Sometimes I give likes too but that is it, but I just like reading the forum. There is a lot of information I can learn just by reading it. If I have further questions or need further explanation from colleagues in the group, I'd rather email or message them directly" (The Metropolitan low-level participant).

He said that he chose to observe the forum rather than actively participated because it was more comfortable for him to learn by observing. He went in the forum for checking up on the updates of the latest tools and resources which he downloaded when available. He also did not feel the need to post in the forum, but he gave 'likes' to certain articles about tools and resources from others that he found interesting.

The Metropolitan low-level participant said that he used the group's online forum as a reference for any creative idea to use web-based tools mainly for collaborative classroom activities. He believed that he has learned a lot from other members' experiences on being a GCE. He said that he wanted to participate in the GCE study group programme, but he could not yet find a suitable time to do so. However, he informed that communicating with other GCE educators in the group has provided him with opportunities to learn about it in outside of the study programme. 


\section{Main categories}

The following sections pertain to the main categories as the results of data analysis from the participants' interviews and the group's online forum. They are conducive edtech learning environment, a range of learning opportunities through global networks, the value of participants' learning experiences in the group, innovative and collaborative use of web-based tools, mobile communication with WhatsApp, intensive use of English, and the interconnectivity of face-to-face and online activities (see Table 5). Assertions are then presented as the result of how each of the main category lead into final interpretation following the evidence in the case of the Metropolitan GEG.

\section{Conducive ed-tech learning environment}

Metro participants believed that the conducive ed-tech learning environment, online and offline supported them to collaborate with each other and engaged in leadership practices as they help other educators in using web-based tools in various contexts. For example, The Metropolitan high-level participant suggested to other educators in the group's online forum that they combine free web-based video editing with the mobile platform:

"To the best of my knowledge... either you use Mac and get iMovie or use Windows and get Movie Makers. Adobe once released Adobe Premier Clip (free) but it only runs for Windows 10. Now it is not offered anymore. My suggestion is to use Premiere Clip (free for Android and iOS). Tell your students to export their video clips into their mobile and do editing in it. It's a workaround" (High-level participant's post in the group's online forum).

The diversity of ed-tech knowledge and complex experiences and practices that were openly shared in the forum showed that the majority of members appeared to be active, confident, and conversant, possibly from their ed-tech practices or leadership roles and activities at schools and outside of schools. In the group, participants engaged in discussing various topics/content (Table 9).

Table 9. Examples of topics in the group's online forum

\begin{tabular}{|l|l|l|}
\hline \multicolumn{1}{|c|}{ Topics } & \multicolumn{1}{c|}{ Content/Posts } & Linked resources \\
\hline \multirow{2}{*}{$\begin{array}{l}\text { Ed-tech } \\
\text { philosophy } \\
\text { and }\end{array}$} & Helping kids navigate digital lives & Link to blog post \\
\cline { 2 - 3 } pedagogical & A fun way to improve teacher skills & Photo \\
\cline { 2 - 3 } knowledge & Feedback for the creative academy & Websites \\
\cline { 2 - 3 } & Amplifying student's voice & YouTube \\
\cline { 2 - 3 } & Video blog \\
\cline { 2 - 3 } & Textand education & Text-based \\
\cline { 2 - 3 } & Technology curriculum & \\
\cline { 2 - 3 } & Deeper learning & \\
\hline
\end{tabular}




\begin{tabular}{|c|c|}
\hline & Collaborative practices and learning \\
\hline \multirow{14}{*}{$\begin{array}{l}\text { Practical } \\
\text { ed-tech } \\
\text { knowledge }\end{array}$} & $\begin{array}{l}\text { Google apps add a feature on Gmail, YouTube, use } \\
\text { by teachers }\end{array}$ \\
\hline & How to become GCE \\
\hline & Digital tools to carry out research \\
\hline & Explore millions of doodles with quickdraw \\
\hline & Flip it, Flipgrid, Quizalize \\
\hline & Benefits and barriers using Google Classroom \\
\hline & Explore cultural resources with Google Classroom \\
\hline & $\begin{array}{l}\text { Tutorial on Google Classroom, Google analytics, } \\
\text { Google apps, Google autodraw, Google forms or } \\
\text { survey }\end{array}$ \\
\hline & $\begin{array}{l}\text { Google Computer Science (CS) first, coding in the } \\
\text { classroom }\end{array}$ \\
\hline & Google doc tips and adds on for teachers \\
\hline & $\begin{array}{l}\text { Google maps, Google power searching, Google } \\
\text { street view }\end{array}$ \\
\hline & Maximising Google search part 1 \\
\hline & New Google earth, New Google sites \\
\hline & $\begin{array}{l}\text { Tips for using Google forms, updated differentiation } \\
\text { with Google forms }\end{array}$ \\
\hline
\end{tabular}

There was no evidence of any issues related to the Internet connectivity and therefore, participants had no issues in exploring wide variety of digital tools in their daily ed-tech practices. They also did not have any difficulties in sharing variety of digital resources with the group in the online forum. A reliable digital environment enabled participants to implement digitally driven teaching and learning practices and sharing them publicly with other educators from Indonesia and other countries. This contributed to the group's global networks and diverse range of ed-tech resources and created a conducive, ed-tech learning environment.

The leader said that he initiated the group because he aspired to make a difference to educators' learning and practices using web-based tools to create, empower, collaborate, and lead beyond the classroom. He had observed that most educators in the Metropolitan region were relatively active users of web-based technology and some of them were leaders at their schools. However, he noticed that there was still not enough support for their leadership practices and collaboration initiatives from their school communities. Responding to this issue, he wanted to help and support other educators by providing a platform for them to learn, leading with confidence, and empowering each other through collaboration with technology. He said that members' interest in attending the group's activities about expanding the impact of ed-tech leadership practices increased as he shared his own experiences with various ed-tech leadership members in 
local and international events. He reported that one of the group's most intensive ed-tech leadership activities were the GCE programs and events because there was a growing interest from the majority of members towards it:

"Educators have shown great interest in participating in GCE intensive programme that I organise with my team for free in the group. I have also been receiving significant number of requests to mentor teachers and educators from variety of schools" (The Metropolitan leader).

The GCE-related events were also significantly posted in the online forum. For example, the leader organised a free workshop, seminar, virtual study group sessions, virtual meetup with Google Hangout, school outreach, mentoring, tutorial resources (text-based and video), and informal gathering in nearby cafes or public venues to facilitate members and anyone with an interest to learn to be a certified educator. In addition, he often gave appreciation and acknowledgement to members' achievement as they passed the exam through the study group and became a certified educator. For example, the following were among the examples of things he often posted in the group's online forum to promote being a certified educator and to congratulate members from various educational institutions who passed its exam (Figure 6).

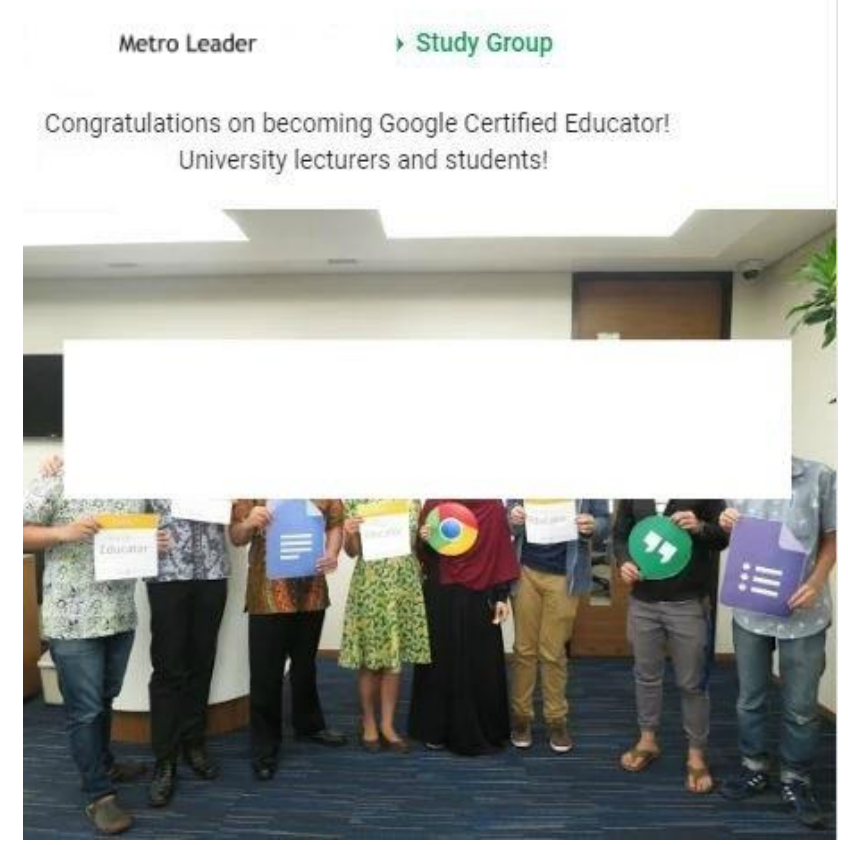

Figure 6. An example of a post about GCE activities posted by the leader 
Members often contacted the Metropolitan leader to thank him for his help and support in the preparation of the GCE exam. He said that more members were interested in certification because they wanted to enrich their knowledge and skill in order to help other educators in their school with web-based technologies and explored collaboration with others in the group. For example:

"I am so grateful to have the opportunity to become a GCE. The biggest support comes from the leader. He encouraged me to be certified and he believed in my leadership potential. Since I have been certified, my colleagues at school often came to me for help. I also helped the school principal to create a more effective school administration system. I collaborate with colleagues from other institution to help them innovate their programming project with Google tools. Being a certified educator is more than just being able to use technology. I can also be a leader and make positive changes with technology" (The Metropolitan mid-level participant).

The Metropolitan mid-level participant said that being certified had provided him with more opportunities in extending impacts of ed-tech practices. For example, being requested to assist colleagues at school, being involved in local government projects doing programming, and being acknowledged by Google. He valued the GCE programme as a tool for inspiration, a professional bonus and professional credential enabling wider opportunities for leadership practice and expanded global networks with GCE educators from various countries.

The Metropolitan high and low-level participants were also interested in becoming certified educators, but they had not yet found a time do so due to their current professional workload. However, they both said that they looked up information about the certification programs and events or the tutorials from the leader and other members.

"I find GCE provides opportunity to advance professional branding and expertise. However, not all teachers are aware of this opportunity depending on their mindset, awareness, passion, and experiences'. I am interested to be one and hopefully can find time to prepare for the exam" (The Metropolitan low-level participant).

The Metropolitan high-level participant thought that educators who pursued the certification had stronger characters and were more progressive, independent, motivated, determined, and passionate despite the limited resources and infrastructure. Although the high-level participant and the low-level participant were not yet certified, they learned from other members' ed-tech practices and experiences as a certified educator such as designing classroom activities with various Google tools, applying collaboration, 
creativity, communication and critical thinking in designing classroom projects, and teaching digital citizenship to their students. This diverse ed-tech resources indicates the group's conducive ed-tech learning environment, which seemed to strengthen participants' engagement with the group for support.

Within a digitally driven environment, it was conducive to support participant's ed-tech practices and collaboration in the group encouraging them to explore leadership opportunities, particularly being a certified educator. The GCE program provided an added value as it was considered as a tool for inspiration, a professional bonus and professional credential enabling wider opportunities for leadership practice and expanded global networks. Members who were GCEs also inspired and motivated other members to learn from their shared experiences in the group.

Assertion: The conducive ed-tech learning environment in the GEG supported participants' ed-tech collaboration and encouraged them to explore leadership opportunities.

\section{A range of learning opportunities through global networks}

A range of learning opportunities that was enabled by global networks were identified. Participation from local and international members brought about diverse and collaborative learning experiences into the group, which aligned to the analysis in the group's online forum. Although all participants valued the group's online forum, each participant had a different engagement with the group, depending on their preferences to use the forum. They did not describe any issues with Internet access to connect to the group's online forum.

The observation data showed that a variety of free online activities involving collaboration with local and international members had been conducted, shared, and posted in the forum since 2014. These activities included virtual meet-ups (via Google Hangout), virtual coaching and mentoring, and global online collaborative events involving online conferencing with schools from abroad. With seemingly no Internet connectivity issues, participants could participate and engage in these virtual activities in real time and they could access the recorded sessions later. Local and international collaborative events and activities such as online conferencing or virtual study groups were also conducted smoothly without connectivity issues, providing a variety of learning 
opportunities that participants could choose from that suited to their preferences and needs.

The leader was not the only one who provided and shared information, knowledge, and professional learning opportunities in the group's online forum. Members also engaged in providing information, sharing informal professional learning opportunities and events such as free face-to-face and virtual ed-tech events, gatherings, conferences, seminars, meet-up or Hangout sessions. These opportunities and events were organised locally and internationally. The leader's collaboration with global networks of educators added to the variety of face-to-face and virtual professional learning activities that he could share with members. Likewise, members and their networks also contributed to the group's diverse activities.

The leader described his experiences on the affordances of global networks to enable various opportunities for professional learning:

"It is amazing how these educators empower each other by sharing resources and opportunities for learning together. I am grateful that the members of our group are so collaborative. So many interesting professional learning events are up for grab at any time and from anywhere. Thanks to members from abroad who share great free virtual ed-tech PD events, Indonesian educators could join and learn with them as well so that they can develop global understanding and expand edtech perspective" (The Metropolitan leader).

Furthermore, all three participants (high-level, mid-level, and low-level) explained about accessing interesting informal professional learning opportunities that were shared by the leader and other members in the group.

"The group has incredible members with wide networks who have access to various ed-tech professional learning which I, as a local educator, would not have known if it was not because of joining this group" (The Metropolitan mid-level participant).

The high-level participant highlighted the leader's ability to develop the group's network and gather all of the members to be collaborative in sharing resources:

"It is important to learn that the leader who is an educator like me is able to pull this out; to develop the group's global networks and encourages all these incredible members to share, learn, and support each other by sharing great resources" (The Metropolitan high-level participant). 
The low-level participant also pointed out the flexibility of participating in these local and international free professional learning activities such as free ed-tech events, gatherings, conferences and meet-ups with other educators, either virtually or face-toface.

“The group's online forum has been my go-to ed-tech resources. Not only does the leader share incredible resources and informal learning opportunities but members also do too. We can join or participate in a flexible manner, either it is virtually or face-to-face. It is not only local but also international. I had joined free some of these local and international events and I had great experiences with all of them. It inspires me to write training modules with various use of web-based tools for teachers" (The Metropolitan low-level participant).

The low-level participant believed that the learning resources and opportunities shared in the group's online forum provided him with references and inspiration for his teaching practices, classroom activities, and writing training modules for teachers, which reflected ed-tech support he obtained from the group. Various professional learning activities and opportunities were shared in the group's online forum (Figure 7). The leader shared about free international event in the form of online conference "Education on Air" where members can access through GEG Watch party. Member $\mathrm{C}$ shared an information about Google for Education Global Summit. Member B shared about special invitation for members to participate in certified international training program with Hootsuite on managing social media. Member A posted an invitation to join the Connected Classroom focusing on teaching good health lessons to year 5 students. 
Join us for a free online conference. You have the best seat in the house (your own!) or you can join GEG

Feel free to mention me if Vatch Party to learn with other educators.

Originally shared by Google Educator Groups Indonesia

Education on Air Sessions include:

- Improving the writing process with Google Docs.

Speakers and sessions for Education on Air

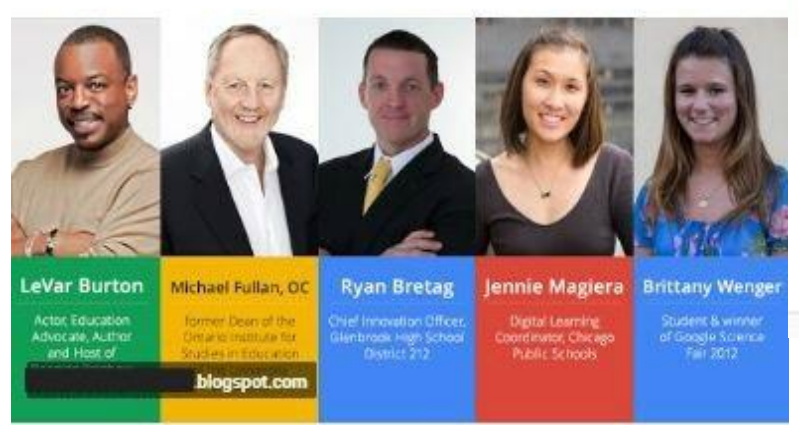

member A Others

Hi, anyone interested to join the Connecte Classroom with us on 20ct 10:30AM teaching the "Good Health" lesson to year 5 students.

Originally shared by

Ma aysia is joining the World Largest Lesson movement, this movement consists out of $17 \mathrm{Globa} / 60$ ols to achieve 3 extraordinary things in the world: End extreme poverty, Fight inequality \& injustice and Fix climate change. All 17 Global Goals can achieve these 3 things but some help is needed, that is why the World's Largest Lesson will start The ambition of the Worid's Larges Le ...

\section{Figure 7. Examples of various professional learning activities} and opportunities in the group's online forum

It was evident that global networks with collaborative events and activities involving local and international members in the group provided diverse face-to-face and online activities enabling a range of learning opportunities for participants to explore in the group. The leader was not the only contributor to the group's professional learning activities, but both local and international members also contributed by sharing information and accesses to variety of professional learning events providing the group with various options and alternatives of learning activities and flexible forms of engagement and participation. The majority of participants also felt that they were part of a global network through how they engaged globally in the group such as communicating and having discussion with international members or observing/reading what local and international participation in the forum.

Assertion: Global networks with collaborative events and activities provided diverse face to face and online activities enabling a range of learning opportunities. 


\section{The value of participants' learning experiences in the group}

As participants shared what motivated them to join and participate in the group, the value of their learning experiences in the group were identified. All participants responded positively when asked about their learning experiences in the group. They regarded the group was relevant to their learning interest and needs and had provided them with benefits such as useful ed-tech resources.

Participants expressed how they valued their ed-tech learning in the group, how they were inspired by the leader, and how they felt connected with each other in the group. When asked about their initial experiences, The Metropolitan high-level participant outlined his experience of joining:

"When I opened the group's online forum for the first time and read through everything there, I instantly felt connected. These educators are awesome, knowledgeable, and creative and that is why I joined the group. I hope I can contribute to the group through my ed-tech experience and practices. I also hope that my video tutorial can be useful for others in the group. I am hoping to get constructive feedback from them to improve my ed-tech practices" (The Metropolitan high-level participant).

Similarly, the Metropolitan mid-level participant felt that the leader's experience-sharing and activities with the group inspired him. He felt connected to how some people in the group shared similar challenges and difficulties to which he could relate. He wanted to be more productive as an educator by participating in the group. In the similar fashion, the low-level participant believed that learning and sharing from the leader had inspired him to improve his own leadership skills and helped him to be more optimistic in overcoming professional challenges, leading to him expanding his own informal leadership practices outside of school.

The way participants described the value of their learning experiences, access to the ed-tech resources, expanded networks, the inspiration from others, and the connectedness they felt with others reflected the positive values, reflected the relevance of the group and its support to their learning. Thus, it was evident that group had significance to participants learning experiences as they gained benefits as being part of the group.

Assertion: Participants valued their learning experiences as they gain benefit from being part of the group. 


\section{Innovative and collaborative use of web-based tools}

All participants felt confident of using web-based tools in their ed-tech practices. They reported the feeling of enjoyment using, exploring, and experimenting with various web-based tools and technologies to create content, to help other educators using webbased technology by mentoring, and to collaborate with others at school and outside of school.

The Metropolitan leader actively created innovative digital content including textual and audio-visual content. He used various web-based tools such as Google slides, slides, forms, docs, drive, Google expedition, Google street view, Google tool builder, Google Suites/Classroom, Flipgrid, Kahoot, ClassDojo, Story bird, Canva, Write to Learn, YouTube, Apple-apps, and Android apps to innovate his classroom activities, particularly in to improve his students' learning engagement. The leader believed that he developed confidence by taking chances, exploring opportunities, learning something new, and doing various professional activities besides his regular teaching duty. He also said that helping other colleagues to use web-based tools enabled him to learn how to overcome challenges in a more positive way and see beyond the comfort zone, while also extending his networks.

Not only did the leader actively engaged in collaborative projects with Google, but he also actively explored opportunities to collaborate with various institutions and organisations:

"I like sharing about my own teaching practices and professional learning activities and collaborate with others to provide support for educators in need. Besides collaborating with others, I am also willing to allocate time, energy, and resources outside of school to give technical assistance, coaching, mentoring, or giving a workshop for non-commercial purposes to help to find a solution to others' ed-tech issues at school or classroom activities. I feel awesome with what I am doing now knowing that I can do something good by sharing motivation inspiration about innovative teaching practices with other educators" (The Metropolitan leader).

With the experience of leading the group, the leader had explored opportunities to be a motivator, trainer, coach, facilitator, networker/connector, collaborator, initiator, content creator, and many more roles. 
The Metropolitan high-level participant's confidence about the way he used various technologies underpinned his passion in creating educational content. He highlighted the digital instinct that naturally helped him in learning to use various types of technologies innovatively.

"I would say that I have a natural digital instinct that enables me to have a quick grasp with the use of technology and I am grateful for that. I like creating content and explore innovative use with various technology. I would like to think of myself of not only teaching or lecturing but also creating, innovating, and producing" (The Metropolitan high-level participant).

The Metropolitan high-level participant considered the exploration of all kinds of webbased technologies as an outlet to get creative with content creation to innovate his practices. He used social media as a media for cataloguing multiplatform tools in his professional practices (video tutorial, video podcast, video editing).

"I consider creating and sharing my educational video content such as video podcast and a video tutorial as part of my social project because I find it professionally fulfilling and through it, I can reflect on my teaching practice and learning process" (The Metropolitan high-level participant).

He believed that creating educational video content and sharing it on YouTube provided him with interesting and innovative ideas to get creative with his own content creation such as making a video podcast with slide show software.

He expressed his preference in using all kinds of web-based tools, including Google quiz, Google forms, and Google sites. However, he said that he needed more than just using web-based tools.

"I used all kinds of free web-based tools such as Google quiz, Google forms, and Google sites extensively, but I need more than that. That is why I created and shared educational contents through video podcast, video tutorial aside from my teaching jobs. I also look forward to the opportunity to present my teaching research and work in seminars or workshops as a social project. I enjoyed doing all of these to channel my passion and interest" (The Metropolitan high-level participant).

The Metropolitan high-level participant referred to his activities in creating content and sharing them in a seminar or workshop as a social project, which he enjoyed doing to channel his passion and interest. 
The Metropolitan mid-level participant described his programming skills, which encouraged him to learn more about innovative use of other tools and applications. He aspired to be more productive as an innovative educator by using social media and YouTube for sharing his educational video content, class-related, training, workshop, and informal learning activities. He also said that he learned more about technical problem solving by helping other educators with his programming skills in overcoming technological issues to do the administrative tasks.

The Metropolitan low-level participant shared what he aimed to do as he engaged with the group, particularly writing ICT books. He combined the use of free web-based tools and apps to design various classroom activities for his students. However, he said it could be difficult sometimes to allocate more time to experiment with such tools and apps due to his responsibilities at school. However, he was grateful that he could help others with his technology skills at school and outside of school. He considered his experience in training teachers to use ICT in their teaching practice to be very rewarding. He felt good that he could use his skills and expertise to help other teachers and educators to improve theirs.

All participants reported that they gained more acknowledgement and appreciation at school and outside of school by taking up ed-tech leadership roles. They felt more productive as they gained more requests for mentoring colleagues from a variety of institutions and schools to use Google Classroom and Google tools

“There are great ideas I have obtained from the group's online forum that I applied to my sketch notes, vlogs and wrote in my blog. I create more content and design more classroom activities with interesting tools that I have known from the group. I also have received more requests for mentoring from various institutions and schools, which has extended my repertoire of mentoring experiences" (The Metropolitan leader).

High level of confidence was expressed by participants in their activities and practices using web-based tools, especially when they said that they wanted to help others with the skills they had. The Metropolitan high-level participant said that he helped other educators in the forum by referring to his own problem-solving using video-editing tools. The positive responses and feedback that he received made him discover new things he could do with those tools. In a similar fashion, the Metropolitan mid-level participant also said that he took examples from some of the educators' blogs and vlogs to create his own stories of ed-tech learning journey with the group. He had received messages from various 
educators asking questions and information, and even been requested to coach other educators from different schools and institutions. Furthermore, the Metropolitan lowlevel participant also showed confidence in the way he was asked by his school principal and colleagues at his school to teach them using various Google tools and Google Classroom.

Looking at participants' experiences engaging with the group, it was evident how they felt that their productivity had improved. For example, teachers and educators from various schools asked them questions for further information regarding their ed-tech experiences through personal messages, WhatsApp, or emails. It then leads to seminar invitations, workshop invitations, offers to collaborate on ed-tech projects, referrals to enter competition/contests, or extended repertoire of mentoring experiences.

Assertion: Participants considered their productivity of ed-tech practices improved as they engage in the group.

\section{Mobile communication with WhatsApp}

All participants used WhatsApp as a mobile communication tool for both collective and personal extended interaction in the group because of its popularity and practicality as expressed by participants. The leader created a WhatsApp group forum to make it easier and more flexible for members when they needed to reach out directly to the group, to him, or other members in the group more personally. He realised that there were some members who needed to seek certain information they might not feel comfortable sharing publicly. With the ubiquity of digital technologies, such as smartphones and free Wi-Fi areas at public places available, WhatsApp gained popularity in the group as a practical mobile communication tool in the group, both personally and collectively.

The group leader used WhatsApp as an extended platform of interaction with the team leaders and some of the very active members of the group. He enabled all members to contact him by publicly sharing his WhatsApp number in the forum.

"I use all kinds of channels to make the group more open to everyone, including with WhatsApp. This way, I can facilitate certain members who prefer to communicate and interact with WhatsApp because not all members have similar preferences in communication and interacting. The more variety of communication tools I use, the more members I can facilitate" (The Metropolitan leader). 
To this end, his WhatsApp was never off, and he said that there were always membereducators, leaders from other Indonesian GEGs and other colleague-members from international GEGs who contacted him at odd hours to ask questions, stay in touch, get acquainted, request a meet and greet, request workshops and facilitation, or even only to say hello. He was online and actively mobile as all his social media accounts were integrated on his smartphone. He felt that both online and offline were inseparable in his daily activities.

The high-level participant used WhatsApp quite extensively for more direct communication with the group, including with the leader and other members in the group who he knew well. The WhatsApp was primarily used for personal communication, group forum, and multimedia file-sharing. He said that using WhatsApp was very useful because it was efficiently mobile. He also considered WhatsApp to be as real-time and responsive as the online forum because he integrated the online forum to be mobile and the current notification from the forum would appear instantly on his mobile phone. However, the WhatsApp enabled the communication to be more private when he needed to, while the online forum was more public and transparent to all.

The mid-level participant often used the WhatsApp forum to extend communication with the group, including maintaining communication with the leader, the team leaders of the group and some members in the group who he knew well. He used the WhatsApp group for further discussion, communication, and information-sharing about a variety of topics which sometimes overcrowded his mobile phone. To him, WhatsApp gave him quicker responses, and it had significantly impacted his communication dynamic and connectivity.

The low-level participant actively used WhatsApp for personal and professional communication, including interacting with some members of the group. He said that WhatsApp helped him to stay connected with the group more. He felt that using WhatsApp made him feel closer to the group as he could reach out to it anytime when he needed to. He said that the leader and the team of leaders, as well as some of the active members in the group, had been very responsive in responding to and facilitating him. 
It was evident that WhatsApp was used as a popular platform for extending interaction and both personal and professional communication, engaging in further discussion and information-sharing in the group. WhatsApp was used extensively as it was considered more practical for communicating with each other. The ubiquity of WhatsApp enabled participants to feel closer with each other in the group, which reflected the need to feel supported and stay connected.

Assertion: WhatsApp was used as a popular and practical mobile communication tool to extend interaction and connectedness in the group.

\section{Intensive use of English}

The group's global network and resources were strongly visible in the group's online forum as English is predominantly used for communicating in the forum. When a member apologised for his English, the leader responded:

"It is okay. You can choose to speak using either Bahasa or English and even both and get the help you need. You can also practice speaking English if you want to, with some of our international members who I believe will be supportive and helpful" (The Metropolitan leader).

By using English as the primary language of discourse in the group's online forum, the group's participation and recognition were expanded, gaining recognition and acknowledgement from abroad. International members were able to join and participate alongside local members. For example, an international member posted an information about the group's achievement in the top place for impactful ICTPD with Google Apps reflecting the pride as part of the group's members. In the announcement, appreciation is also openly expressed to the whole group while also providing motivational notes about making an impact for better future as educators (Figure 8). 


\begin{abstract}
and I are delighted to announce that our GEG received top place for impactful ICTPD with Google Apps for all of 2015. Thank you to and the many enthusiastic contributors who have led sessions, organised and facilitated. It is a privilege to work with all of you and see that what we do, impacts teaching and learning. Let us make 2016 even better.

Do note we delivered more PD than Japan, New Zealand, India and and other countries - the scores reflect the number of activities and also the study group programme championed by Google rates the Study Groups with higher scores.

So thank you all for fully participating, growing your skills and changing the lives of students. YOU are valuable. YOU are the change-maker. YOU are the reason that students reach their DESTINY, POTENTIAL and FUTURE because of your commitment to this profession we have - TEACHING.
\end{abstract}

\title{
Figure 8. An example of a post regarding International recognition towards the group
}

The extensive use of English in the group's online forum was also demonstrated by the leader's online discourse. For example, most of the leader's posts in the online forum were expressed in English, be it when he shared information, interacted with members, congratulated members' achievements, motivated members, or gave feedback as in the following (see, for example, Figure $9 \& 10$ ).

Metro high-level and mid-level participants also intensively used English in their online posts. The international and local members' participation in the group's online forum was also strongly evident. It was clearly shown that the group was not only known in Indonesia but also abroad. With the use of English, participation in the group's online forum was not limited to local members but had expanded to international members. Participants also shared their experiences using English to communicate with both local and international members in the group.

The high-level participant highlighted using English to communicate with each other in the group as part of his daily professional practice teaching English as a foreign language for years before joining the group. He said that one of the things that made the group appeal to his interests was learning from other educators from the group's online forum global networks, interaction, and collaboration:

"Speaking English has been part of my daily professional practices and I find the group's online forum global networks, interaction, and collaboration to be beneficial because I could learn a lot from what they do" (High-level participant). 
The mid-level participant also often used English to communicate with the leader and to engage in the group's online forum discussion.

“The group's online forum is an amazing platform for me to improve my English because there are also international members joining and engaging in the discussions. At first, I was not that confident of using English but the longer I observe and start to exercise using English by participating in the group's online discussions, I feel more comfortable because I am not judged. Instead, they are really appreciative and supportive. I still use Bahasa Indonesia to communicate with most local educators, but I also more frequently use English to communicate with some international members that I personally communicate with" (The Metropolitan mid-level participant).

The Metropolitan mid-level participant considered practising English in the group was fun because the group was supportive and not judgemental. He was never criticised for his English, which made him feel more supported to learn from his own mistakes.

The Metropolitan leader believed that using English had benefits in terms of obtaining and learning from ed-tech resources, which were predominantly English-based. He also considered using English would open doors to many fruitful global collaborations and expand the ed-tech learning experiences.

"Nowadays, it is important that we do not limit our learning experience within a local context only. We need to learn to widen our perspective and practices and also collaborate with others, especially when it is about ed-tech leadership. Most ed-tech leadership resources are in English and English language skill will surely help a lot in learning these resources. That is why I encourage members to communicate in English so that they have more opportunities to learn and collaborate" (The Metropolitan leader).

However, to make it more communicative to educators who preferred learning in Bahasa Indonesia, he translated and transliterated some of the resources into Bahasa Indonesia. For example, he made the Bahasa Indonesia version of the GCE preparatory guidelines for educators (modules, handouts, presentation, booklet, etc).

The low-level participant believed that learning English was necessary to keep up with the global context of education technology and it was part of his efforts in expanding opportunities for learning about it. He said that his reading ability in English improved as he learned from members' interaction and discussions in English in the group's online forum.

"I am grateful to have found the group and being its member. Although I am not actively participated in the group's online forum discussions, I actively seek information and observe the forum. I have been able to find great references and 
resources about teacherpreneurship, digital citizenship, Google Certified Educator, among others that I found interesting but not yet written in Bahasa Indonesia. I have learned so much by observing the way international members exchanged ideas and practice with Indonesian educators here. Being in the group with a global network such as this group opens up to cutting edge topics which resources are not easily found in Bahasa Indonesia" (The Metropolitan low-level participant).

He valued the variety of ed-tech leadership resources in the group, although they were mostly in English. He also found that observing interactions between international members and Indonesian educators in exchanging ideas and practices was beneficial. He preferred to use these resources as useful and valuable references to explore more on his own, as he often found interesting topics that were not yet available in Bahasa Indonesia such as teacherpreneurship, digital citizenship, GCE, etc.

It was evident that the intensive use of English as the language for interaction and communication in the group enabled wider participation and engagement leading to global interaction and recognition. Accordingly, the group was recognised globally as educators from Indonesia and outside of Indonesia joined, participated, networked, and collaborated in the group. It was the global scope of the group that enabled facilitation of ed-tech learning and resources within global context.

Assertion: The intensive use of English in the group's online forum enabled the group to facilitate global interaction and gain global recognition.

\section{The interconnectivity of face-to-face and online activities}

The group's face-to-face and online activities were interconnected. The leader and members frequently engaged in both platforms (face-to-face and virtual). Their interaction and communication on both platforms appeared to be interconnected where they treated the group's online forum as the extension of face-to-face interaction and vice versa instead of a stand-alone platform. Follow-up posts, comments, and responses from the previous face-to-face events and activities by the leader and members appear to be interconnected. For example, one of the members said thank you to the leader and his team's facilitation on the face-to-face forum he attended (Figure 9). Member Q and the leader could have just texted them or sent a thank you email but they chose to openly express and communicate gratitude with each other in the forum. 


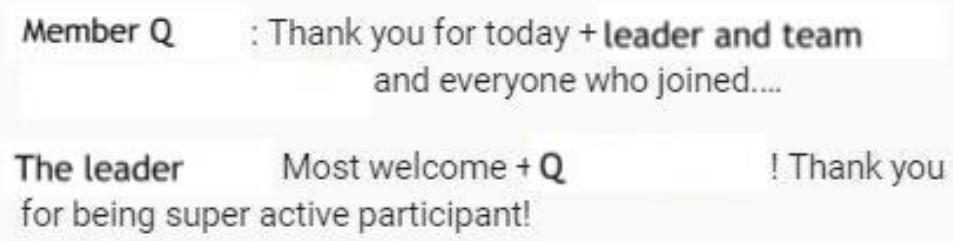

Figure 9. Interconnected face-to-face and online activities (1)

The face-to-face and online activities seemingly occurred because the leader and members had a strong willingness to keep in touch both face-to-face and online. In so doing, both the leader and members felt that they could count on each other and that they could communicate at any time and from anywhere (Figure 10).

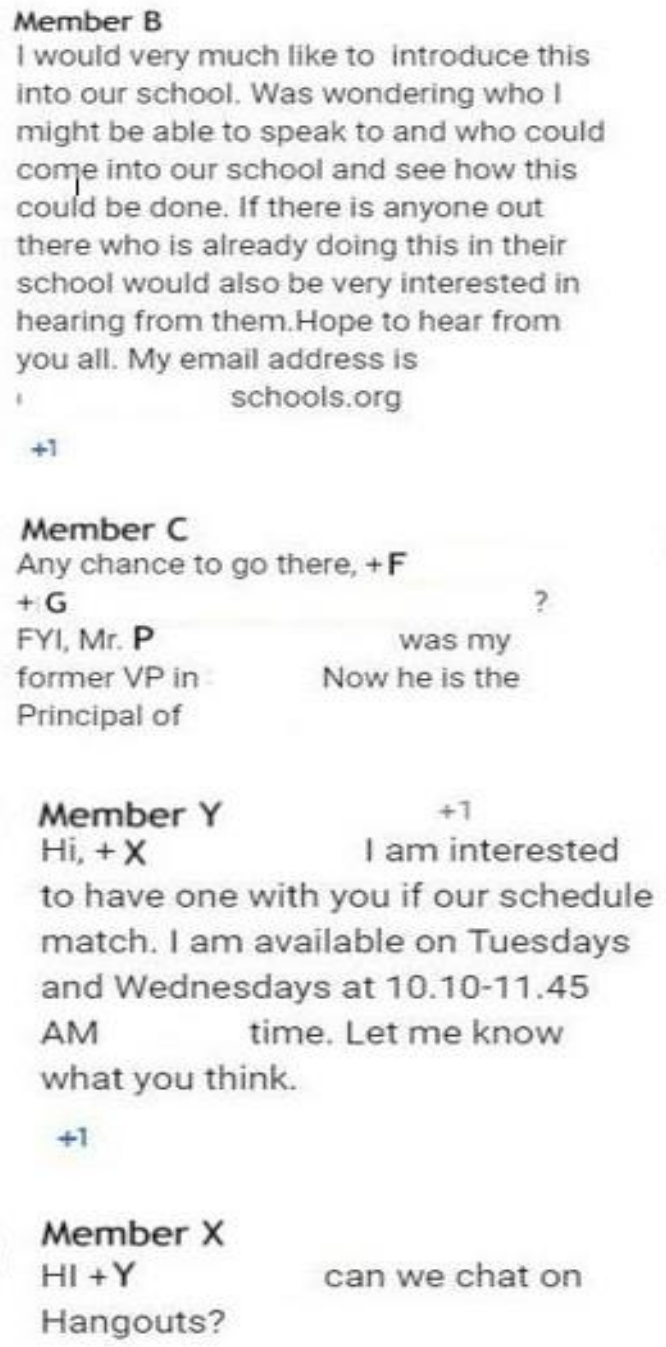

Figure 10. Interconnected face-to-face and online activities (2) 
These two examples of the interaction showed that member $\mathrm{B}$, member $\mathrm{C}$, member $\mathrm{Y}$, member $\mathrm{X}$, member $\mathrm{F}$, member $\mathrm{Q}$, and the leader seemed to bring out what they experienced in their face-to-face activities and share it publicly in the online forum. This described how their face-to-face and online activities with each other in the group were interconnected as part of the group's blended communication and interaction, from faceto-face to online and from online to face-to-face (Figure $9 \& 10$ ).

The examples above show how the Metropolitan leader and members gave each other support, in the physical (face-to-face) and online context, which then created personal or professional relationships to be further developed into an interconnected engagement. Whenever a member, for example, needed assistance and was not able to communicate face-to-face, the virtual presence serves as a meeting point. This could make a member feel that there was always an option to connect to the group in every situation because each member had a different capacity for face-to-face interaction and communication. When they could not, for some reason, engaged with the group face-toface, if this interconnectivity was there, members would not likely feel that they were missing out on something by not being able to interact and communicate with the group face-to-face. In the same fashion, members could feel supported when they knew that they could count on each other's physical (face-to-face) presence. For example, a member could request for someone who he/she could contact for further support, and if any member in the group happened to know someone of interest, it might lead to them meeting each other or developing further professional relationships. In other words, the interconnectivity between face-to-face and online activities created a sense of reality of existence (of being there for each other) rather than superficiality or formality, where the feeling of being supported, encouraged, and appreciated was openly shared as part of the group's daily activities.

Assertion: Participants' interaction and communication were interconnected as the group blended face-to-face and online activities. 


\section{Summary}

The emphasis in the Metropolitan GEG case study is that participants were able to explore diverse opportunities for ed-tech professional learning in group within a digitally-driven region. Participants in this group were confident educators actively using web-based tools in a conducive ed-tech learning environment, supported by relatively reliable Internet connectivity, digital school culture, and global networks. Participants were also leaders at their schools, content creators, and collaborators. They used the group's online forum for discussions, resource-sharing, and collaborations. The group's global network and its intensive use of English played an important role in enabling a range of learning opportunities and collaborations as well as diverse ed-tech resources. The leader and his lead team were not the only contributor to the group's online forum. Members also contributed to the forum by sharing information and access to professional learning events and activities. The flexibility of participation enabled members with various options to participate and engage with the group through blended activities: faceto-face, online, or both enabling them to stay connected to each other in the group without difficulties. The use of the mobile instant messaging application of WhatsApp was considered important by all participants to strengthen both collective and personal connectedness in the group, which appear to complement the group's online forum. All participants reported positive learning experiences and disposition in the group as they were more engaged with the group. They also personalised their individual ways of learning based on their own preferences and situation. Participants considered their productivity improved after joining the group through digital content creation, online collaboration, creative applications of web-based tools, and informal leadership practices at school and outside of school. The digitally-driven environment in the group enabled participants to have access to global network as well as collaborative and blended driven activities where they engaged in innovative and collaborative use of web-based tools to improve the productivity of ed-tech practices 


\section{Chapter 5}

\section{The Urban GEG case study}

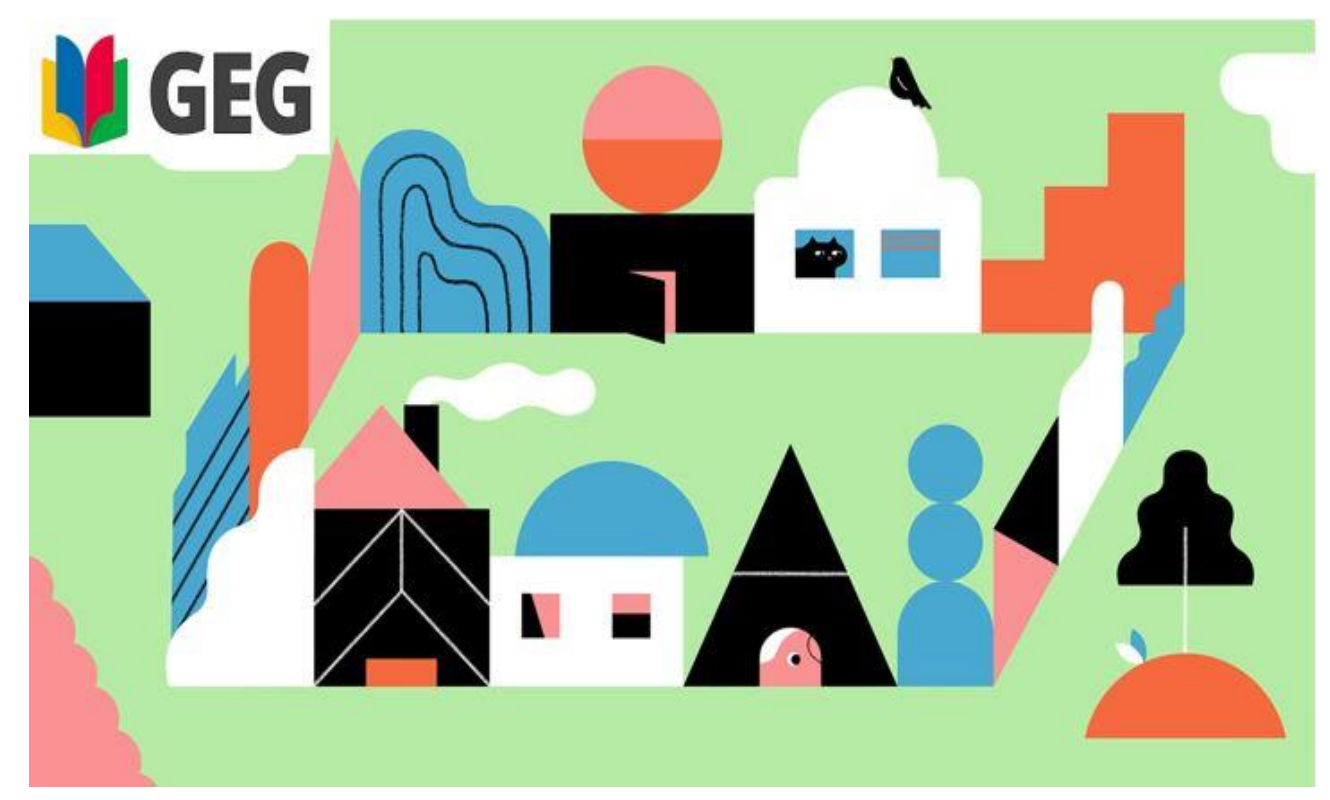

(Source: Image taken from https://helpx.adobe.com/nz/illustrator/how-to/draw-

\section{buildings.html)}

"All educators should have equal access to a good Internet connection and ongoing support to use digital resources anytime and anywhere to successfully improve practice with implementing digital teaching and learning”(Urban GEG leader).

\section{Introduction}

This chapter presents findings from the study of an Urban GEG, an informal group voluntarily initiated and organised by an educator in a digitally diverse, moderately populated Indonesian urban region. It begins with a description of the context, the GEG itself, an analysis of GEG online forum observation data, and four key participants: the leader; a high-level; a mid-level; and a low-level participant. It is then followed by an examination of the main categories and assertions (Table 10) and ends with a summary: 
Table 10. The main categories and assertions in the Urban GEG case study

\begin{tabular}{|l|l|}
\hline Main categories & Assertions \\
\hline $\begin{array}{l}\text { Unreliable Internet access } \\
\text { with pervading emphasis on } \\
\text { the paper-based education }\end{array}$ & $\begin{array}{l}\text { GEG participants were professionally } \\
\text { challenged by a regional disparity in Internet } \\
\text { access and a pervading emphasis on the use } \\
\text { of hard copy, rather than digital resources } \\
\text { (U1) }\end{array}$ \\
\hline The leader's influence & $\begin{array}{l}\text { Participants joined the group because they } \\
\text { admired its leader and shared his vision of } \\
\text { optimising the use of web-based tools for } \\
\text { paperless classroom practices and school } \\
\text { administration (U2) }\end{array}$ \\
\hline $\begin{array}{l}\text { Mobile communication with } \\
\text { Telegram }\end{array}$ & $\begin{array}{l}\text { Participants with minimal experience, } \\
\text { practice, and confidence in sharing in the } \\
\text { group's online forum preferred Telegram as a } \\
\text { more practical tool for collective and personal } \\
\text { communication in the group. }\end{array}$ \\
\hline The need for connectedness & $\begin{array}{l}\text { Personal connectedness encouraged } \\
\text { participants to actively seek support and be } \\
\text { more open in sharing experiences and } \\
\text { practices (U4) }\end{array}$ \\
\hline $\begin{array}{l}\text { Participants' mentoring } \\
\text { activities }\end{array}$ & $\begin{array}{l}\text { As participants gained confidence in the } \\
\text { mastery of web-based skills and practices, } \\
\text { they became mentors in-school and outside of } \\
\text { school (U5) }\end{array}$ \\
\hline $\begin{array}{l}\text { The group's stagnant online } \\
\text { praperless professional } \\
\text { tools. }\end{array}$ & $\begin{array}{l}\text { When the group's face-to-face activities were } \\
\text { paused by the leader, the group's online } \\
\text { forum became stagnant (U6). }\end{array}$ \\
$\begin{array}{l}\text { Participants reported improved professional } \\
\text { practices when they spent more time on } \\
\text { learning with the leader or more } \\
\text { knowledgeable and confident members (U7). }\end{array}$ \\
\hline
\end{tabular}

\section{The context of the Urban GEG}

\section{The regional context}

The Urban GEG was initiated by an educator who lives in a region located on an island where he said that religious values were highly respected and cultural norms infused education philosophy. This educator felt committed to be the leader of Urban GEG and dedicated his time to manage the group. According to him, 'silaturahim' (gettogether/kinship) and respect for elders were among values prominently nurtured as part of the important educational values within urban region. However, he explained that regional disparity in Internet connectivity, non-digital school culture and a pervading 
emphasis on the use of non-digital materials in the classroom and at schools were among the professional challenges that urban educators face in the region.

The Urban leader explained that a regional disparity in Internet access exists, creating a gap of access where the Internet connection was not equally provided or accessible. Some areas had relatively good Internet connection, while in others, Internet connection varied, ranging from good, minimum, to very limited. The Urban leader believed that although the central government had allocated grants for the Internet procurements grants at schools to help to overcome the disparity of the Internet connectivity in urban region, the improvement of the Internet connectivity is mainly prioritised in central business and government administrative areas. As a result, he believed that the rest of the local government's regional budget revenue and expenditure were limited to help support the technological infrastructure for school areas. He then continued to express his concern that the Internet connection at some schools can sometimes be unstable, which makes it less reliable.

The Urban leader believed that most educators in the region had relatively nondigital professional practices. Formal mandatory PD programmes from the government or schools did not seem to make an impact on creating a digital culture for educators' professional practices. From his experience attending these PD programmes, he found them to be mainly policy-related such as general teacher certification, new curriculum socialisation, or non-digital lesson plans. Although personal computers, laptops, and Internet access were used in some of these PD programmes, their uses were not integrated into learning sessions, evaluation, or monitoring. He believed that educators mainly used them to deliver, store and retrieve learning materials (upload and download) rather than transforming practice.

The leader explained about his perception of the school culture in urban region. First, most urban educators seemed to know how to use technology but not all of them knew how to optimise it to improve their practices. In most schools, the pervading emphasis on the use of non-digital materials in the classroom and at schools seemed to be the main norm of educational practice. Second, most educators were still overwhelmed with paper-based grading and evaluation, such as having piles of paper-based administrative work, with the risk of misplacing or missing the paper files adding to stress and frustration. Third, most classrooms and schools were still highly paper-based. Printer 
and photocopy machines were utilised to produce teaching and learning materials. Fourth, most schools required their students to use (school-printed) papers for daily and weekly quizzes and tests. The exams at most school were still conducted within paper-based system. The Urban leader further described that although few schools had shifted to a computer-based exam, the daily teaching and learning activities were paper-based. He believed that this predominant paper-based system is no longer effective for $21^{\text {st }}$ century teaching and learning. Given this condition, he then joined the Urban GEG as he wanted to transform his school into a paperless school and classrooms. He concurred that being paperless aligned with his education technology values and the conception of improving professional practices to being more efficient in doing, organising, and managing. He believed that when educators could save their time doing work, they could save energy and have more time to focus on more important things such as their professional learning with technology.

\section{The Urban GEG}

The group was informally initiated in 2015 by the leader who had been nominated by other Indonesian GEG leaders with the endorsement of Google Indonesia. He had three main reasons for initiating the group. First, he concerned about the unequal access of Internet among schools and the inefficiency of teaching practices and classroom activities in most schools in the region. Second, he wanted to help educators in the region to use certain web-based tools effectively so that they could work more effectively. Third, he also wanted to provide support for educators in less resourceful regions who needed to learn how to use web-based tools. In January 2018, there were approximately 400 members joining the group's online forum.

The group had open, free, and voluntary membership. A colleague was recruited by the leader as a co-leader to assist in managing and organising the group. The group uses the Google Plus Communities online forum, face-to-face interaction, and the Telegram group forum. Telegram is a mobile instant messaging application similar to WhatsApp, but it has larger coverage for a group forum. Telegram enables users to send messages and exchange photos, videos, stickers, audio, and files of any type and seamlessly move conversations between a smartphone, tablet, and desktop computer. The group uses the Telegram group forum extensively to extend communication and interaction, which may lead to a sub-group forum. The leader believed that face-to-face meeting is a preferable form of interaction in the group because the majority of members 
did not participate in the group's online learning activities such as using Google Hangout or Skype. Face-to-face mentoring and study group were the most frequently conducted face-to-face activities.

The Urban leader recruited a younger colleague at his school who was willing to assist him in organising and conducting the group's events and activities as a co-leader. The co-leader is the high-level participant in this case study. By recruiting him, not only did the leader want to transfer knowledge about web-based tools and resources such as Google Classroom and Google tools, but also to train him to teach other teachers and educators at the nearest schools. With the co-leader assisting him, the leader conducted mainly free face-to-face events and activities such as an inaugural meet-up, free workshops, photo walk, seminars, free training, and free teachers' workshops. Such events and activities provided participants with practical knowledge and hands-on guidance on using web-based tools and resources, including Google tools and Google for paperless professional practices.

In the first year of initiation, the group obtained financial incentive from Google to run its activities. Urban leader made use of this support to organise many free Google PD programmes to socialise the conception of paperless classrooms and schools in the region and teach them how web-based tools, mainly Google tools and Google Classroom, to help educators to transform their classrooms into a paperless classroom. He also approached school principals to advocate the use of various web-based tools to transform their schools into paperless schools. He said that this has not been an easy or smooth journey as most educators were still attached to paper-based ways of doing things such as massive printing and copying. However, his leadership came to fruition when educators started to do digital quizzes and tests, conduct digital grading and evaluation, and shift to digitising their administrative files and digitally managing them in virtual storage. Some educators became models of practice, whom he recruited to exemplify paperless teaching and learning at schools at the group events and activities (e.g. seminars, workshops, mentoring), in order to encourage other teachers and educators to follow their footsteps. 
In the group, participants socialised, sought, and shared information from the group's online forum, but preferred to share their experiences and expressed themselves more openly outside of the online forum in the face-to-face manner or via the Telegram group forum. There were four types of participation:

- leading the group, managing, and organising the group's face-to-face events and activities,

- finding information, sharing content, practiced, experienced in the group's online forum, and co-leading the group

- finding information without conducting any online activity in the group's online forum, and occasionally attending the group's face-to-face events and activities when he had the time, and

- regularly observing the group's online forum, but not attending the group's faceto-face events and activities.

\section{The Urban GEG's online forum}

Although there were 400 registered members in the forum, online activities from 34 members were documented in the form of posts, comments, and likes. Thus, the rest of the registered members' online activities in the forum were not visible suggesting lurking or passive online reading activities.

The content of the group's online forum was dominated by the Urban leader's online posting, mainly about the information of the group's locally organised face-to-face activities such as Google paperless workshops, a few updates on Google tools, and the leader's mentoring activities in various schools. Although there was no tension or conflicting discourse, engaging interaction rarely occurred among members and there were not many members who shared their ideas, experiences, and practices. The forum was rarely updated as the leader visited and posted in the forum when he felt necessary. As a result, the forum had no new updates or be stagnant for weeks. Although some posts related to ed-tech content, not all topics were about education technology. Few topics of posts were or religious-related. Below are examples of the stagnant timeline of posting activities in the forum from September 2016 onward (Table 11) with a religious-related content posted in 2 October 2017 and a politics-related content posted in 24 January 2018. (Figure 11). 
Table 11. Examples of the stagnant timeline of postings activities in the group's online forum

\begin{tabular}{|l|l|}
\hline \multicolumn{1}{|c|}{ Posting/content } & Time of \\
\hline $\begin{array}{l}\text { Being a paperless school (posted by the } \\
\text { leader) }\end{array}$ & 3 July 2016 \\
\hline $\begin{array}{l}\text { Introducing Google Classroom for } \\
\text { paperless school (posted by the leader) }\end{array}$ & 9 September \\
\hline $\begin{array}{l}\text { The power of Google forms in the } \\
\text { Classroom (posted by the leader) }\end{array}$ & 2016 September \\
\hline $\begin{array}{l}\text { A question about the group: "is there any } \\
\text { GEG available in X region?" (posted by } \\
\text { one of the members referring to one of } \\
\text { the remote regions). The leader } \\
\text { responded: "Unfortunately there is not } \\
\text { one yet" }\end{array}$ \\
\hline $\begin{array}{l}\text { Workshop G-Suite for Education (posted } \\
\text { by the leader) }\end{array}$ \\
\hline $\begin{array}{l}\text { Going to Paperless school using Google } \\
\text { forms, Sheets, and Calendar at one of the } \\
\text { high schools in the region (posted by the } \\
\text { leader) }\end{array}$
\end{tabular}




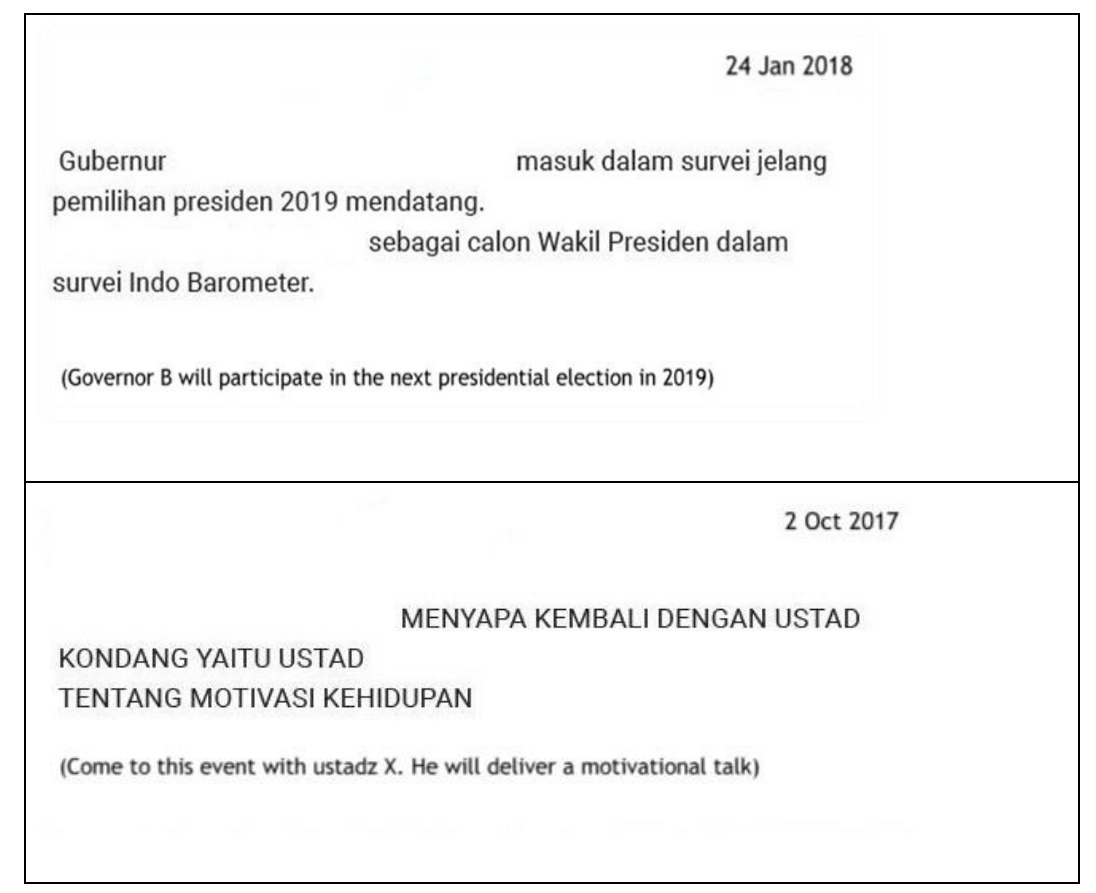

Figure 11. Examples of members' politics and religious-related posts (non ed-tech posts)

The group's online forum primarily used Bahasa Indonesia as the main language of discourse and interaction that prominently displays local discourse. There was no evidence of humour, fun, or relaxed discourse identified in the forum and posting activities displaying social activities such as introductions and greetings were limited. There was also not much dynamic in the interaction because members rarely used the forum to engage in a substantial discussion, seek technical assistance or give ed-tech feedback. Observation of the online forum revealed that members did not publicly express their ideas or did not publicly share their experiences and practices in teaching and learning with technology. 


\section{The Urban GEG's participants}

The four selected participants in this study come from various professional backgrounds with differing ed-tech experiences. The following section describes the participants' professional background and their participation in the group.

\section{The Urban leader}

\section{Professional background}

The Urban leader is the initiator and the leader of the group. He is a teacher at a public high school and a private vocational school in a medium city. He teaches an ICT subject with more than 15 years of teaching experience. Leading the group has given him an opportunity to become a GCE level 1 .

\section{Prior Digital Practice and Experience}

He has been a chief of one of teacher associations in Indonesia before leading the Urban GEG. He is among the few educators in the region who was selected as one of the ambassadors (senior trainers) from an USA-based microprocessor company's corporate social responsibility teaching-with-ICT programme in Indonesia. With an academic background in Information Technology (IT), his digital practice and experience include actively advocating the use of various web-based tools to optimise efficiency in educators' teaching practice, classroom activities, and school administration.

\section{Participation in the group}

The Urban leader voluntarily organised the group's face-to-face events and activities with the co-leader. He recruited a younger colleague at his school who was willing to assist him in organising and conducting the group's events and activities as a co-leader. However, he said that he was the one who made decisions related to the group such as deciding which school, institution, or organisation to collaborate with. By recruiting a co-leader, not only did he want to transfer knowledge about web-based tools and resources such as Google Classroom and Google tools, but he also trained him to teach other teachers and educators at the nearest schools.

The Urban leader mainly organised free face-to-face events and activities such as an inaugural meet-up, free workshops, photo walk, seminars, free training, and free teachers' workshops. Such events and activities provided participants with practical knowledge and hands-on guidance on using web-based tools and resources, including Google tools and Google Classroom to improve efficiency at school such as applying 
them to students' feedback, evaluation and assessment or doing more efficient school administration. He said that participation in the group's face-to-face events was more engaging than in the online forum or virtual. Therefore, he concurred that most members and most educators in the urban region preferred learning from face-to-face interaction.

The Urban leader also recruited model teachers from various schools in the medium city as part of his efforts in involving them in participating in the group as a role model teacher to encourage other teachers and educators to join the group. According to him, having model teachers and their teaching practices using tools and resources from Google as examples and models for paperless teaching and learning at schools was more effective for motivating them to follow their footsteps. This was because it felt more real, concrete, and contextually related to their day-to-day teaching practices.

The Urban leader made efforts in socialising and promoting the group and approached school principals and other teacher groups and organisation, such as asking an MGMP and the Indonesian ICT teacher association to collaborate. He aimed to explore this potential collaboration to reach out to more teachers and schools in the medium city and gather more of their attention and participation through collaborative events about using Google tools for paperless teaching and learning at schools.

He also volunteered for mentoring other educators in need of support. While being part of the GEG events and activities, they were also conducted at the request of some school principals, teachers, and educators who invited him to their schools for face-toface mentoring. He also created video tutorials that could be used offline to help educators implement Google classroom and Google tools step by step, which they could pause and replay as needed.

The Urban leader said that he did not always spend much time in the group's online forum due to his schoolwork and other professional activities. As the sole administrator and moderator for the group's online forum, he did not have any dedicated role to evaluate the forum. He tried his best to connect to the forum and moderate it whenever he had the time. Regarding moderation, he said that commercial ads, political campaign, or religious events ads were the kinds of content that he filtered out from appearing in the forum, which he called as "spam". Although the appearance of this spam content, he said, were not concerning, it was still necessary to be filtered so that the forum can be clean from spam. 
Besides moderation, he used the online forum to deliver and distribute information about the group's events and activities. His posts were mostly about the group's activities with various schools that 'had gone Google' He also posted information about events and activities, including face-to-face and a virtual event, through Hangout on Air. There was one virtual activity through Hangout that he remembered sharing on the online platform, which only a few members participated. He said that most members preferred face-toface activities or communicating through mobile instant messaging applications due to the limited bandwidth and unstable Internet connection in most areas in the region. Besides that, he also answered questions and responded to comments from members. He said that he preferred answering questions and responded to any members' comments as efficiently and briefly as possible, because in his experience giving further explanation or instruction was easier done face-to-face or through mobile communication than in the online forum.

\section{The Urban high-level participant}

\section{Professional background}

The Urban high-level participant teaches computer and network engineering at a private vocational school as well as teaches robotics at a private Islamic elementary school. He is also the head of the ICT school subject department at this school. Joining the group has given him an opportunity to be a GCE level 1.

\section{Prior Digital Practice and Experience}

The Urban high-level participant's academic background in ICT has provided him with skills and experiences with technology prior to his teaching job. He was involved in robotics projects when he was undergraduate student. To that end, experimenting with coding, programming, and web-based tools has become part of his daily routine and digital practice.

\section{Participation in the group}

Besides doing his co-leading roles to assist the leader, the Urban high-level participant also volunteered for mentoring educators at his school to help them use Google Classroom and Google tools outside of his regular school hours. He regularly visited the group's online forum to check on new updates about the tools and resources from Google, shared things and expressed himself. He posted one content about teaching material (mathematics) and shared about his co-leading activities and GCE experiences. For 
example, the Urban high-level participant's posted one content about teaching material (mathematics) using Google forms, and also shared about his co-leading activities and experiences including GCE experiences (Figure 12). He also gave ' +1 ' (likes) to certain postings from other members. He reported that members of the group seldom publicly shared their practices, discussed ideas for creatively using web-based tools and resources in various school contexts, or gave feedback about each other's practices in the online forum. He believed that most of the forum posts were from Urban leader or were questions and comments from members about how to join these. The forum was less appealing to him because the unstable Internet connection did not enable a smooth process of sharing certain media files or videos that he wanted to share with others online. He said that sharing files with USB or portable hard drive while having face-to-face meeting is more convenient. He also said that sharing links and documents with Telegram and email was more practical than using the group's online forum. He would rather connect with some members of the group outside of the online forum.

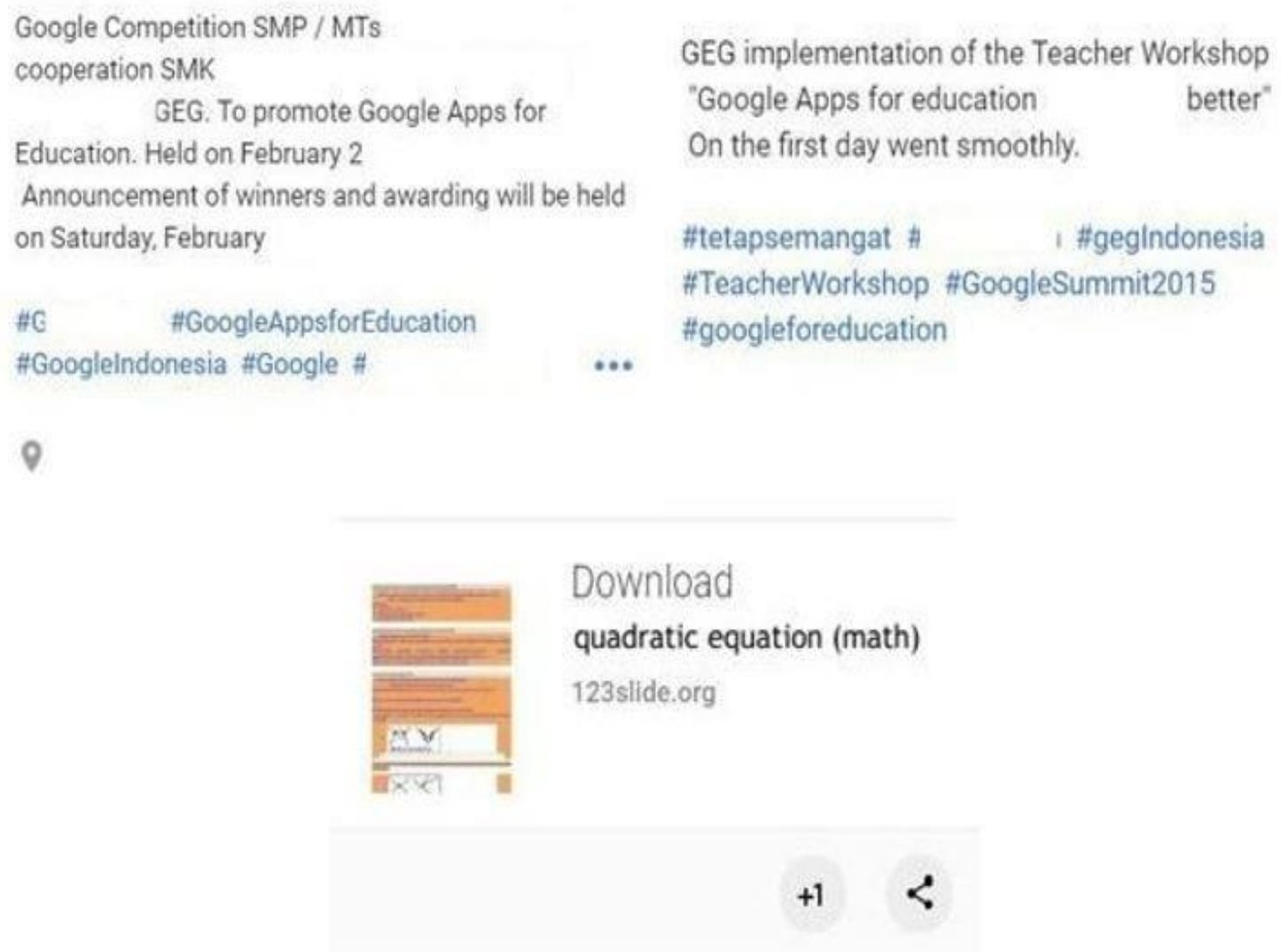

Figure 12. examples of the Urban high-level participant's online activities in the group's forum 


\section{The Urban mid-level participant}

\section{Professional background}

The Urban mid-level participant is a school principal at a private vocational school who teaches about character building and motivation with religious values, as well as entrepreneurial skills. As a school principal, he used technology to help him do school administrative tasks and uses emails, social media, a few Google tools, virtual storage, and school financial report software. Outside of school, he was active in religious-based entrepreneurial activities.

\section{Prior Digital Practice and Experience}

Although the Urban mid-level participant said that he did not have a specific ICTrelated academic background, he liked to experiment with technology, particularly mobile-based applications to which its exploration has been implemented into both of his professional activities at school and entrepreneurial activities outside of school. Prior to joining the group, he had been familiar with the use of Google tools or web-based tools such as email, for his own personal and professional digital practices.

\section{Participation in the group}

As a busy school principal who also had various responsibilities outside of school, he said that he could not always able to participate in or could not always attend the group's face-to-face events and activities, but he would come by whenever possible. As he realised the affordances of technology to improve efficiency at school, he actively promoted the group to other school principals, encouraged them to join the group and use Google Classroom and Google tools, as well as gave them advice about paperless teaching and learning based on its implementation at his school. He also supported the leader and the high-level participant's voluntarily mentoring and training activities at the school to use Google Classroom and Google tools across various teaching subjects.

The Urban mid-level participant did not regularly visit the group's online forum as he did find the forum to provide the information he needed. He also did not post anything or socialise in the forum other than few brief comments and gave 'likes' to other members' posts. He said that he did not feel the need to engage with other members in the forum because he felt that obtaining the information about the group along with its activities directly from the leader was enough. He said that he expected more important discussions and more sharing to occur in the forum from more members besides the 
leader. He felt that it was not always easy to have Internet access to get connected to the group's online forum when travelling within the region and thus, it was more practical for him to reach out to the leader or other members in the group through mobile communication, such as Telegram, short message service (text), or by phone. He also said that he could not find many school principals in the region joining the group yet. Therefore, he preferred communicating and interacting with a few of the members who were school principals on the mobile instant messaging application of Telegram or faceto-face. He also said that he never participated in the forum posting, commenting, liking, or responding other than browsing and looking for information because he did not feel the need to do so.

\section{The Urban low-level participant}

\section{Professional background}

The Urban low-level participant is an ICT teacher at a public secondary school outside of the medium city. He is keen on exploring ways to use technology to create an effective and efficient system of classroom planning activities, students' evaluation, and school administration with using free, open source, and simple web-based or software.

\section{Prior Digital Practice and Experience}

Besides teaching and joining the group, the Urban low-level participant is also a member in various teacher communities and associations such as the ICT teacher association, ICT teacher learning communities, and other GEGs in various regions. He has an academic background in ICT as well as a teacher-trainer at his school.

\section{Participation in the group}

The Urban low-level participant did not attend the group's face-to-face events and activities due to limited financial capacity, distance, and time. However, he hoped that the group could improve its online events and activities besides face-to-face and mobile. With his inactivity about participating in the group's face-to-face events, he applied what he had learned through his observation in the group's online forum to his practice.

The Urban low-level participant volunteered for mentoring educators in his school area to help them use Google Classroom and Google tools across teaching subjects, outside of the school hours and sometimes on the weekend, which he enjoyed doing. In his mentoring activities, he also shared resources that he obtained from the group. He said that he learned best by helping others learn. 
While regularly visited the forum, The Urban low-level participant did not feel the need to engage with its members because he did not feel the need to do so. He used the forum to keep in touch with the updates from the leader about the group's events and activities or to seek information and checking updates from other members. He felt that there were no discussions in the forum that were interesting enough for him to participate in:

"I visit the forum to keep up with the group's updates but not regularly. I do not see any interesting discussions regarding teaching practices in the forum for me to participate in" (The Urban low-level participant).

He said that he had difficulties to get a stable connection to the Internet and thus, although he regularly visited the forum, he found it troublesome to share certain digital resources with others in the forum, such as large video files or power point due to the unstable bandwidth. To him, observing what was happening in the forum had already given him enough ideas about things he wanted to explore further by himself. However, he was grateful that the leader always documented the events and activities and shared them with the group in the forum. In that way, he could get information about how they went and things that happened at the events and activities.

\section{Main categories}

The following sections describe the main categories as the results of the data analysis from all participants and the group's online forum: unreliable Internet access with pervading emphasis on the paper-based education, the leader's influence, mobile communication with Telegram, the need for connectedness, participants' mentoring activities, the group's stagnant online forum, and improved efficiency through paperless professional practice with web-based tools (see Table 9). Assertions are then presented as the result of how each of the main category lead into final interpretation following the evidence in the case of the Urban GEG.

\section{Unreliable Internet access with pervading emphasis on the paper-based education}

Participants shared similar experiences with unequal and insufficent access to the Internet at schools in the urban region. Issues that were expressed by all participants reflected the unstable Internet connection at some schools that was often reliable to use for the whole school. Some other schools had a limited capacity for Internet connection, and there were more schools in rural areas that had few ICT tools but did not have Internet 
access. An additional concern regarding Internet access was the limited school budget that did not allow for improving Internet capacity.

Participants said that the regional disparity of ed-tech resources seemed to influence most school's paper-based educational practices. Urban mid-level participant interacted with other members who knew how to browse on the Internet and use emails but who still relied on massive printing and copying teaching materials (besides hard copy books). For example, manual grading, paper-based quizzes and tests, and manual filing of students' data. He said:

"They did not seem to be interested with using these web-based tools to transform their classroom as the Internet connection at their schools were barely reliable" (The Urban mid-level participant).

Therefore, it was not always easy for him to motivate other colleagues to be paperless when their school principals or school culture still highly emphasised the use of nondigital resources. Similarly, the leader's experiences in mentoring provided him with the knowledge that it was not always easy for educators who were already used to doing paper-based practices to change into paperless practice. He said that these educators were worried about not being able to access the tools when the Internet connection was down. The high-level participant's experience in assisting the leader as the facilitator in the group's face-to-face hands-on free workshops also confirmed that many senior educators who joined the workshop still felt comfortable using papers-based practices. He said, "They felt that using web-based tools with unstable Internet access was quite a hassle as they often encountered buffering that made it less efficient" (The Urban high-level participant).

It was evident in this category that infrastructural challenges of unequal and insufficient access to the Internet as schools within the region had made the connectivity is unreliable. In addition, some schools in the rural areas were not connected to the Internet. As a result, participants felt that these challenges are one of the reasons of the pervading emphasis on the paper-based education. The participants said that moving from paper-based education to paperless school requires significant improvement and infrastructural support on the quality of the Internet connectivity that is more reliable for digital-based education. 
Assertion: GEG participants were professionally challenged by a regional disparity in Internet access and a pervading emphasis on the use of hard copy, rather than digital resources.

\section{The leader's influence}

The Urban high, mid, and low-level participants joined the group because they admired the leader and wanted to support his vision about technology. They considered the leader as a role model with his ICT organisational and training experience, his modelling practices with technology, and his charisma and reputable role in the ICT teacher communities.

The Urban high-level participant's admiration of the Urban leader's vision about paperless schools, curiosity about Google Classroom and Google tools, and an offer to be the co-leader of the group motivated him to participate further.

"I do admire the leader's innovative vision about paperless school. I wanted to support it. I also find Google Classroom and Google tools fascinating. I can use such tools for safe and systematic storing and database, easier repository and searching, more economical, more detailed, and more precise data retrieval. They are free and easy to use, not too many complex interfaces I have to learn" (The Urban high-level participant).

He wanted to support the leader's vision of the paperless school and paperless teaching and learning when he agreed to the co-leading roles. The more he went along with his coleading roles, the more his interest and curiosity grew about how to use web-based tools and resources, particularly Google Classroom and Google tools.

Urban mid-level participant also admired the leader and the things he had done for the group. He also said that he wanted to support Urban leader's vision of the paperless school and digital teaching and learning.

"I admire what the leader had done with the group and I support him in any way possible. As a good start, I wanted my school to take part in the vision of the paperless school. The idea of paperless may be trivial for others, but the impact can be significant for school budget efficiency because it can minimise the use of papers and allocate that cost for papers to something else that is more important such as improving the quality of the Internet at school" (The Urban mid-level participant).

He also encouraged other teachers and educators at his school to join the group and use Google Classroom and Google tools, and he wanted to implement them to improve his school's efficiency by conducting more paperless teaching and learning activities. 
The Urban low-level participant's main reason for engaging with the group was because he wanted to support the leader's vision of educating schools in the region to go paperless.

"I admire the leader for initiating this GEG. I know it can be very challenging as not all teachers in this region are aware of how beneficial this group can be. But I still want to be part of it. To me, a community-based platform like the GEG is an innovative approach to how teachers and educators can come together to collaborate" (The Urban low-level participant).

He felt that this initiative could innovate the school culture in an urban region, and he wanted to be part of it. He also believed that being paperless was also a positive effort to conserve nature. He wanted to take part in the rising awareness about maximising the use of web-based tools and resources for paperless teaching and learning.

It was evident that the Urban leader has significant role in influencing high, mid, and low-level participants to join the group. These participants consider the Urban leader's ed-tech vision, practices, professional activities, and approach to them has inspired them. The admiration towards what the Urban leader has done for the group is also one of the reasons why they joined the group as they feel that they share his paperless school vision.

Assertion: Participants joined the group because they admired its leader and shared his vision of optimising the use of web-based tools for paperless classroom practices and school administration.

\section{Mobile communication with Telegram}

Participants used Telegram as a practical tool for collective and personal communication in the group. The Telegram group forum was created to overcome the group's lack of online forum engagement. Although the Urban leader had the dominant posting activities providing members with information and documentation about his mentoring activities, there were not many members responding to his posts. If any, there were usually brief and short comments such as "excellent", "awesome", or "great". The Urban high-level participant also made several posts about the group's face-to-face activities, his GCE experiences, and Google tools updates and teaching material (mathematics) using Google forms, but it did not trigger other members' responses. After the Telegram forum was created, some members started to personally communicate with the leader for consultation or discussions. Some of these members invited him to give 
training and facilitation at their schools. The Urban leader felt that the communication with members on Telegram was more engaging than in the group's online forum. $\mathrm{He}$ added that sometimes he met with some members outside of school hours for socialising or having a further face-to-face discussion in a friendlier way.

The Urban high-level participant said that being friends with colleagues who understood his struggles made him feel and think more positively. He also met with them occasionally to discuss about current ed-tech trends over lunch or for doing their hobbies together. He created sub-forums with these colleagues, and he considered it to be very useful to reach out and approach some other colleagues. He also felt the group's interaction and communication was more practical than in the online forum due to its ease of use with a mobile phone/smartphone.

The Urban mid-level participant said that he used Telegram more often than the group's online forum, including group Telegram forums with other school principals. He said that important discussions were done by using mobile instant messaging applications such as Telegram for faster and practical decision-making. He also said that most school principals he knew in the group did not favour discussions on the virtual platform, such as the group's online forum, due to the fully public nature of the conversation. He considered that private topics pertaining to the private nature of the school condition should stay private, and therefore it was not suitable to be discussed in the group's online forum. He considered Telegram as a more practical platform for communication and interaction, which can be adjusted accordingly regarding the privacy issues.

The Urban low-level participant used Telegram and other mobile-based applications extensively to reach out to the leader and some members more personally in the group. He said that connecting to some colleagues in the group who shared similar experiences and made similar efforts of using technology in the same context, made him feel that there were always ways to overcome challenges and problems. He felt that most of the members were more active and responsive than those in the group's online forum. Whenever he had questions or wanted to find out more about a certain posting in the forum, he reached out to the leader or some of the members he knew well on the Telegram forum and sub-group forums. To him, Telegram was more useful than the group's online forum. 
It clearly shows the ubiquity of Telegram as a practical mobile communication tool to strengthen both personal and collective communication in the group. It appears that using Telegram as a means of sharing is preferable to using the group's online forum as the majority of participants find it more convenient and use it more often. Telegram is also considered a useful communication tool for sub-group forums.

Assertion: Participants with minimal experience, practice, and confidence in sharing in the group's online forum preferred Telegram as a more practical tool for collective and personal communication in the group.

\section{The need for connectedness}

Participants developed further needs for connectedness through friendship or closer collegiality while being in the group. Reflecting on their friendship in the group, participants said: "I understand what they are going through" (The Urban leader), "They know what I mean" (The Urban low-level participant), "They know it is not easy but also not impossible" (The Urban mid-level participant), or "It never occurred me to do it like what they did" (The Urban high-level participant). The examples of these phrases reflected the impact of friendship on encouraging sharing without the feeling of being patronised and allowing for direct reflection on each other's experiences. This friendship was usually nurtured and maintained by regular face-to-face interaction where they grew closer and bonded more deeply. Through this kind of interaction, participants also allocated time to meet and have an informal discussion over relaxing activities such as lunch and dinner or recreational/hobby-based activities.

"I have made a friendship with this one educator from school ' $\mathrm{X}$ '. We have a similar philosophy in making the most of technology to make our work easier without destroying the environment. Now, we find ourselves helping each other on a project on the students grading system. If this works, we would like to implement it at own schools" (The Urban high-level participant).

It appeared that the closer the friendship was, the more comfortable participants were to seek support and be open to sharing experiences and practices. When participants had developed a friendship and grew closer with one another, they did not seem to hesitate to ask for help, seek support, or work together, which shows how participants developed further connectedness while being in the group.

Assertion: Personal connectedness encouraged participants to actively seek support and be more open in sharing experiences and practices. 


\section{Participants' mentoring activities}

Participants' confidence was reflected through their skills and practices using web-based tools for paperless school activities. For example, the leader used Google Classroom and Google tools to make his students more engaged. "My students are more proactive in submitting tasks and assignments without delaying it as they used to do" (The leader). High-level participant conducted a paperless exam and it had encouraged his students to avoid cheating by designing the test materials to be randomly done, where one student can have a random list of material that is different from other students. He used Google docs for classroom activities to encourage collaborative learning and he also used Google forms mobile for a semester exam. Similarly, the low-level participant also shared his strategies with web-based tools.

"I use Google Classroom, Google forms, and Google drives mainly for daily teaching and classroom activities. Google forms has made my teaching practice more efficient but more effective" (The Urban low-level participant).

It seemed that all participants were confident and enjoyed using various web-based tools in their teaching practices. They believed that they had been able to improve efficiency in their practices and were proud of the impact they believed had on their students, which motivated them to help and facilitate other educators to use web-based tools for paperless school activities through mentoring.

Participants' experiences as mentors made them felt good about being able to contribute to help other teachers learn. All three participants (the Urban leader, the Urban high-level participant, and the Urban low-level participant) shared their mentoring experiences. The leader's mentored other educators from various schools to use Google tools for classroom activities:

"School principals and/or teachers from various types of school in this region have contacted me to come for mentoring, facilitation, and asked for advice and guidance" (The Urban leader).

The Urban low-level participant mentored his fellow colleagues from various schools to use Google Classroom and Google tools across teaching subjects:

"I am grateful for the opportunities to share my skills and expertise through mentoring other teachers from various schools about using Google Classroom and Google tools for their teaching and classroom practices. I am happy to see their excitement in using such tools across different teaching subjects" (The Urban lowlevel participant). 
Like the Urban leader and low-level participant, the Urban high-level participant also enjoyed being a mentor for others while also being a co-leader. He said that mentoring had given him valuable learning opportunities:

"I learn more by being a mentor, especially about what others have felt and experienced when it comes to using web-based tools. The process of mentoring others has made me understand that implementing technology in the classroom is a challenging and complex endeavour" (The Urban high-level participant)

It was evident that participants' mentoring experiences are a strong indicator of confidence. Their confidence appeared to also be driven by how perception that mentoring activities were a form of self-actualisation enabling motivation and valuable learning experiences.

Assertion: As participants gained confidence in the mastery of web-based skills and practices, they became mentors in-school and outside of school.

\section{The group's stagnant online forum}

The group's online forum ground to a halt when its face-to-face activities were paused by the Urban leader. Although he was assisted by a co-leader in managing and organising the group's face-to-face activities, he was the only decision-maker and provider of professional learning in the group. In the first year and a half, Google provided financial grants to help GEG become settled and independent. Then, Google withdrew the financial support stating that all Indonesian GEGs should have been able to be independent by then. The Urban leader was aware of the extra challenges he faced and the extra efforts he had made to support the group on his own. For example, he approached to school principals and other teacher groups and organisations such as the MGMP and the Indonesian ICT teacher association to collaborate in organising the group's learning activities.

When the group's face-to-face activities were organised and combined with other group's activities, such as the MGMP or the ICT teacher association, the participation increased as more educators joined the activities all at once.

"I am currently immersing/merging GEG activities into subject matter teacher mandatory working group (MGMP) and Indonesian ICT teacher association's activities to keep the group running. We usually had to organise these teachers in a series of activities to accommodate them due to the limitation of the venue. It is not always easy though. When there is not enough support, or I do not have extra free time, I usually took a pause in organising any free group activity for a while" (The Urban leader). 
However, due a lack of sponsorship or other professional responsibilities, it was not always easy to support the group and to keep it running on his own. He was therefore obliged to pause group activities until further notice. This created a timeline lag or a gap from the last online interaction and the current online interaction, which directly impacted the flow of timeline or updates in the group's online forum leading to a stagnated online forum (see, for example, Table 10).

Assertion: When the group's face-to-face activities were paused by the leader, the group's online forum became stagnant.

\section{Improved efficiency through paperless professional practice with web-based tools}

Participants' said that their classroom activities and school administration has become more efficient as they learned more to use web-based tools in the group. They said that by spending more time to frequently learn with the group, particularly with the leader or some members who were deemed more knowledgeable and confident with webbased tools helped improve their practices. Three participants (high-level participant, mid-level participant, and low-level participant) reported having more personal interactions and communications with the leader, and some members whom they had made friendships with outside of the group's face-to-face activities, in order to continue learning. As two of the three participants (The Urban high and mid-level participants) were within close physical proximity of the leader, they continued to personally interact and communicate directly or via mobile instant messaging applications. Although one participant, the Urban low-level participant, was not in close physical proximity with the leader his friendship with the leader enabled him to interact and communicate often for friendly consultation or asking technical guidance.

All participants shared one-to-one and within small group learning experiences with the leader, and some members said it provided them with more time for personal reflection, more motivation, and a more effective way of learning compared to when they attended one-to-many group learning events. They said that learning with many educators in a group setting with too many people could be distracting as there was limited handson activity and there were only two facilitators available (the Urban leader and the Urban high-level participant) to facilitate many educators. 
Each participant spent time with the leader and some members of the group outside of the group's activities, particularly in using web-based tools to improve efficiency through paperless classroom activities and school administration. For example, The Urban high-level participant consulted with the Urban leader more frequently. With the leader's help and feedback, he could manage to have paperless database and more systematic storage with certain web-based tools such as Google forms and Google drive.

'With Google forms and Google drive, I can manage my students' database to be paperless. It is also more practical and efficient to store and retrieve various forms of database. My students' grading and evaluation are now all digital. No paperbased grading and evaluation and the risk of misplacing them is very minimal to none" (The Urban high-level participant).

Similarly, the Urban mid-level participant said that the Urban leader helped him to use Google tools to efficiently manage all of his work files. When he had free time and was available, he asked the leader to come to his house to teach him. Google docs, Gmail, and Google drive were among the web-based tools he used very often because they were very convenient and practical for him.

"I can also work on any Google documents on my smartphone with other school principals. I no longer have to carry around thick paperwork or paper files with me. I find these tools help me to be more efficient" (The Urban mid-level participant).

When the Urban low-level participant had problems in figuring out about Google Classroom, he contacted the leader for help through Skype or a web-based video call. To him, the leader was a virtual mentor.

"Although we no longer live on the same island, I can always reach out to him. I may not yet fully implement Google Classroom in my class, but I have been using Google tools for classroom activities and students' grading and evaluation more efficiently. Daily and weekly quizzes are all now digital and my students seem to enjoy it more" (The Urban low-level participant).

By having more frequent learning sessions, with the leader or some members outside of the group's setting, whether directly, face-to-face or via mobile communication. Participants believed that using web-based tools in the classroom and for school administration improved efficiency. For example, using Google Docs to manage school paperwork more efficiently; using Google tools for more efficient grading and evaluation of students' works; and using Google forms and Google drive for more practical and quicker storing and retrieving database. 
Assertion: Participants reported improved professional practices when they spent more time on learning with the leader or more knowledgeable and confident members.

\section{Summary}

What was pertinent in the Urban GEG case study is how participants learned using web-based tools to improve efficiency through paperless classroom activities and school administration in the group within digitally-diverse region. Regardless the unreliable Internet connectivity and pervading emphasis on the paper-based education, the Urban leader socialised his vision of paperless school by educating and helping others using web-based tools as a practical tool to make practices more efficient through paperless activities at school. The leader's vision was predominantly reflected in the group's activities, which suggests that using technology for efficiency is one of the indicators of improved educators' practices, particularly efficiency in classroom activities and school administration in the urban region. For example, making the students' grading and evaluation more efficient and more practical or doing more efficient input of data regarding students or teacher administration at school. The leader had a central role in facilitating learning in the group and becomes 'the face of the group' who was admired and respected, which was significant in influencing others to join the group. The group's professional learning activities were primarily organised through face-to-face interaction with local network where some members in the group developed friendships and formed smaller groups (subgroups within the group). Participants considered Telegram as a more familiar and practical tool for extending communication and strengthening the need for social connectedness in the group. Bahasa Indonesia was predominantly used as the main language of online discourse in the forum. The group's online forum was used more as a tool to deliver information than a platform for discussion and communication, mainly displaying the leaders' posts about the group's activities. Only a few members' posts and responses identified in the forum as the leader's posts dominated the forum. Nevertheless, participants appreciated the leader for updating them with information about the group's activities. The group's online forum appeared to be stagnated when the leader paused the group's face-to-face activities. Participants believed that their ed-tech practices had improved as they shared about their experiences using web-based tools to improve efficiency through classroom activities and school administration. 


\section{Chapter 6}

\section{The Rural GEG case study}

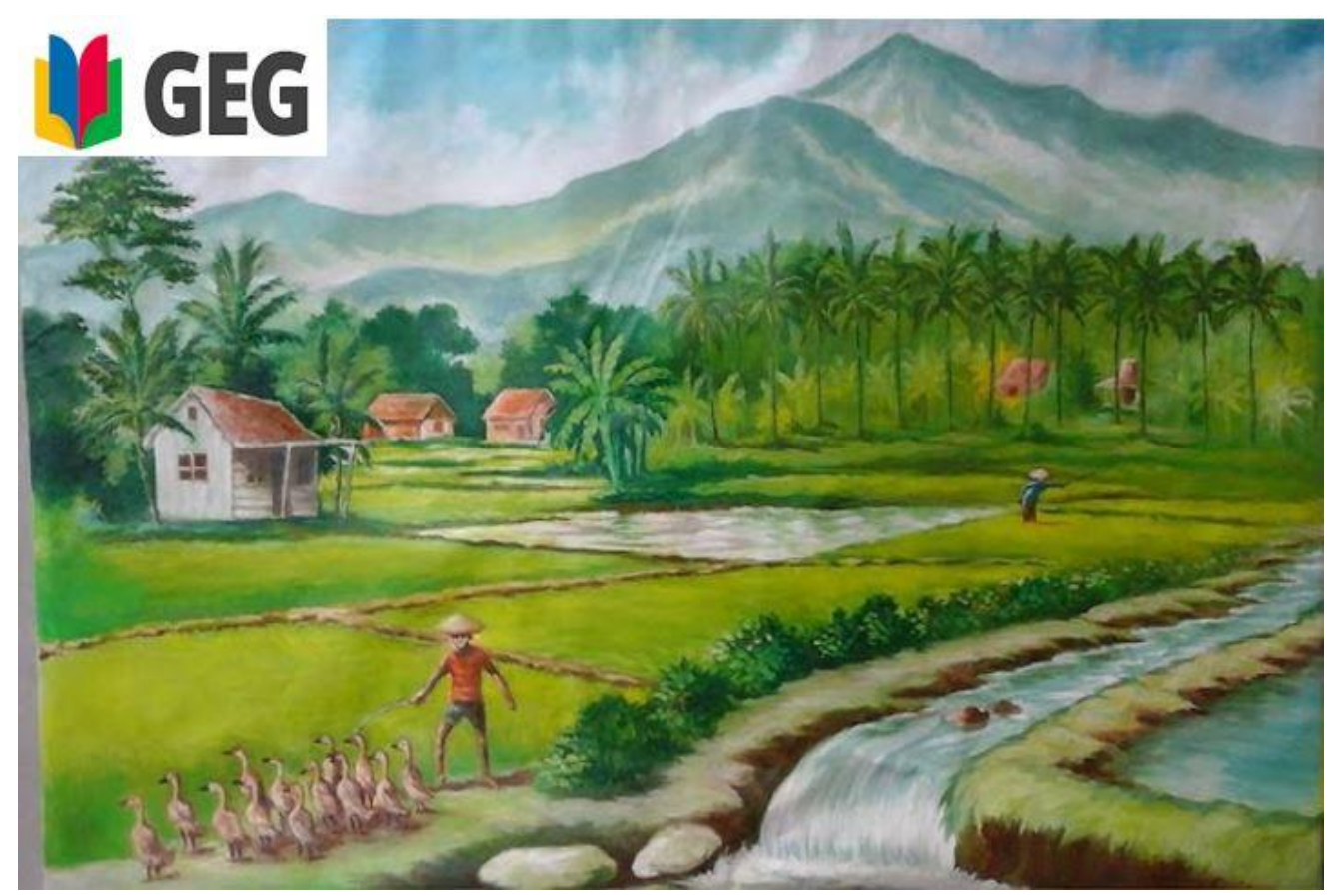

(Source: Image taken from http://bagoes-desain.blogspot.com/2016/01/oil-painting-fororder-buy.html)

"As an educator, it is important to be aware of how far technology has advanced out there and the possibilities that it brings such as reliable Internet connection, continuous

ICT and motivational support, and access to various ed-tech learning opportunities. Instead of using expensive technology, free and simple technology can be powerful if we know how to use it properly and be creative with it" (Rural GEG leader).

\section{Introduction}

This chapter presents findings from the study of a Rural GEG, a newly established group, initiated and organised by an educator in a digitally constrained region. It begins with a description of the context, the GEG itself, an analysis of GEG online forum observation data, and four key participants: the leader; a high-level; a mid-level; and a low-level participant. It is then followed by an examination of the main categories and assertions (Table 12) and ends with a summary. 
Table 12. The main categories and assertions in the Rural GEG case study

\begin{tabular}{|l|l|}
\hline Main categories & Assertions \\
\hline $\begin{array}{l}\text { Constrained digital resources } \\
\text { and Internet connectivity }\end{array}$ & $\begin{array}{l}\text { With constrained digital resources and } \\
\text { Internet connectivity, motivating and } \\
\text { facilitating learning using web-based } \\
\text { technologies in the group became challenging } \\
\text { (R1) }\end{array}$ \\
\hline $\begin{array}{l}\text { Limited resources and } \\
\text { support for the group }\end{array}$ & $\begin{array}{l}\text { When Google withdrew the financial } \\
\text { incentive and the leader did not have the } \\
\text { necessary resources to support the group, its } \\
\text { activities were reduced (R2). }\end{array}$ \\
\hline $\begin{array}{l}\text { Preference to face-to-face and } \\
\text { Telegram communication }\end{array}$ & $\begin{array}{l}\text { As participants struggled with a lack of } \\
\text { resources, they formed strong friendship and } \\
\text { collegiality through face-to-face and } \\
\text { Telegram communication (R3) }\end{array}$ \\
\hline $\begin{array}{l}\text { The leader's role and } \\
\text { influence, }\end{array}$ & $\begin{array}{l}\text { Participants' engagement with the group was } \\
\text { highly influenced by the leader and his } \\
\text { leadership could be the primary driver for } \\
\text { participants to join the group (R4) }\end{array}$ \\
\hline $\begin{array}{l}\text { Positive changes in } \\
\text { professional learning }\end{array}$ & $\begin{array}{l}\text { Participants experienced positive changes in } \\
\text { learning to use web-based tools with low } \\
\text { bandwidth and limited ICT infrastructure for } \\
\text { simple teaching and learning practices (R5) }\end{array}$ \\
\hline $\begin{array}{l}\text { Limited online forum } \\
\text { engagement } \\
\text { through mentoring. }\end{array}$ & $\begin{array}{l}\text { Lack of sharing experiences and practices in } \\
\text { the online forum limited participants' } \\
\text { professional learning activities and, therefore, } \\
\text { was dependent on the face-to-face activities } \\
\text { (R6). }\end{array}$ \\
$\begin{array}{l}\text { Mentoring provided participants with } \\
\text { meaningful learning experiences as they } \\
\text { helped other educators at their school (R7) }\end{array}$ \\
\hline
\end{tabular}

\section{The context of the Rural GEG}

\section{The regional context}

The Rural GEG was initiated by its leader. He lives in a digitally-constrained region located in one of small, less-populated islands in Indonesia where he considered the quality of the Internet connection was very low and access to technological resources was scarce and limited. The leader said that the people on this region lived within a community where traditional culture, values, norms, and wisdom about ancestors and elders were respected and nurtured. He estimated that it would take approximately 1,5 hours from the regional airport to reach the centre of the region, which was a small town, 
comprised of predominantly mountain regions and coastal areas. The leader explained that the closer it was to mountains; the less populated the region was compared to more populated coastal areas and the regional centre. To him, living in this region presented a complex challenge in the way technology was used, especially in the education sector. The leader said that the infrastructure on this island was considered under-resourced compared to more populated and more developed islands in Indonesia. For example, although few base transceiver station (BTS) for wireless communication had been built to facilitate communications, the leader believed that it was not yet enough to fulfil the need of the entire population on the island. One of the leader's major concerns was that there were still larger areas in the region with no electricity, no telecommunication infrastructure, and no Internet connection.

According to participants in this study, the local government prioritised building and strengthening its hard infrastructure such as building bridges, the government's central business district, or tourism management, so the education sector came as the last priority within their local development short-term plan. They considered that rural educators faced complex challenges in using technology for teaching and learning process, as they were relatively constrained with no access to an Internet connection, let alone using technology at school.

Participants said that there was a significant difference when it came to technological support and human resources capacity for support in the rural region. For example, educators who lived near the centre of the region had more support in connectivity to the Internet, public facilities, and easier access to attend local government PD programmes compared to those who lived outside the centre or in a more isolated area. Although Internet connection was accessible, there were few free public Wi-Fi areas, and the quality of connection or speed was minimal where both public and private schools had to allocate certain budget in their school funding to support their own Internet connection and ICT infrastructure. Therefore, with only a few BTS, mobile Internet access became an alternative, although considered expensive and less cost-effective.

Participants also described that schools in more remote areas, were not yet connected to the Internet and did not have computer labs. Other components of ICT infrastructure such as laptops, tablets, LCD projectors, automatic boards, or even smartphones were also low in quality and limited in quantity. Therefore, traditional paper- 
based teaching, learning, and school administration are central to educators' professional practice in these more remote rural regions. Schools and local government-based PD programmes focused on teacher policy implementation, teacher certification, and curriculum or traditional lesson plan content based on the form of the one-to-many lecture platform such as a seminar. The government-based PD programmes and ICT school grants were mainly allocated for educators from public schools and therefore, educators from private schools had less support for professional learning and ICT infrastructure.

The Rural leader described that the existing Internet and ICT infrastructure in the rural region was relatively insufficient to fully support a digital school culture. Educators mostly relied on non-Internet connected technology such as an LCD projector, Word Processor, Excel, and PowerPoint, but not often. Based on the experiences that Urban leader had in facilitating trainings for educators at rural schools, the use of technology in education was not yet considered important or significant. He also observed that there were not many of rural educators who were aware of improving their digital skills and ICT competency and knowledge of web-based technologies, which was part of the reasons why the leader initiated the Rural GEG. By initiating the group, he wanted to help raise awareness about the importance of digital skills, ICT competency, and web-based knowledge in their professional practice to educators in the region, including rural educators.

\section{The Rural GEG}

The group was informally initiated by an educator as the leader in early 2016 and is considered among the newest Indonesian GEGs. Through the nomination of another Indonesian GEG leader and the endorsement from Google Indonesia, the Rural leader led the group with the assistance of a colleague he recruited as a co-leader to assist him in managing and organising the group. The group had voluntary membership and was open to anyone who shared a similar interest in education technology including teachers, a school principal, a school data administrator, and a teacher trainer. Seventy-five members were recorded as joining the group's online forum as at January 2018.

The Rural leader obtained financial incentive from Google from 2016 to 2017, which he used to organise the group's learning events and activities where educators in the region could join and participate for free. He was then notified that Google withdrew their financial support by the end of 2016 as they decided that it was about time for 
Indonesian GEGs to be independent on running their group events and activities on their own. After Google's withdrawal of financial incentive, the leader continued to individually explore other forms of support through collaborating with various institutions for organising the group's events and activities. He collaborated with various institutions and organisations to organise the GEG events and activities though schools, a university, an ICT volunteer regional branch, an ICT foundation, a photographic company, an open source company, a local government (provincial education unit). This collaborative effort aimed at sharing logistical resources to facilitate participants of the events such as through using food and light beverages, a venue and its infrastructure (Internet connection, chairs, tables, LCD projector, stationery, banners, and posters), a resource person, hard copy certificates, and souvenirs.

The Rural leader said that he initiated the group because he wanted to contribute to the development of educators' digital literacy in the region by using web-based tools for simple teaching and learning practices in his region. In doing so, he started raising their awareness towards the importance of digital literacy and the affordances of digital technology to improve the quality of teaching and learning practices of educators in the region aiming to change their pragmatic mindset towards the use of technology. He also wanted to support educators' ed-tech practices by helping them to learn to familiarise themselves with using web-based tools as the traditional paper-based system was still prevalent in their teaching and learning practices. Among the support that the Rural leader provided through GEG was mentoring activities and technical facilitation, which he voluntarily did with the help of a co-leader and the permission from the school principal. Due to the unreliable Internet connectivity and lack of ICT infrastructure in most of educators' schools in the region, the leader focused on helping them to use free and opensourced web-based tools for simple teaching and learning, particularly in an underresourced environment, which became his main agenda in leading the group.

The group's main learning activities were informal and locally organised face-toface with the leader as the main facilitator of learning along with a younger colleague he had recruited as co-leader to help him manage and organise the group. The Rural leader said that the face-to-face meetings became the most preferred form of professional learning due to unreliable Internet connectivity. Activities began with an inaugural meet up and included a free workshop of computational thinking part 1 and 2, free training on Open Source BTS, free other workshop that introduced variety of free web-based tools 
for simple teaching and learning practices such as Google tools, Gmail, or Android-based applications. By-request informal training, informal mentoring and facilitation for educators, school principals, and school data administrator were also conducted based on the leader's availability. Such events and activities provided entry-level practical knowledge and hands-on opportunities for using various web-based tools and resources for educational purposes, such as Google tools (e.g. Gmail, drive, calendar, doc, sheets, slides, Classroom, Hangout, etc) or non-Google tools (e.g. Android-based tools, and social media), and computational thinking in a digital age. The group uses Google Plus Communities online forum and Telegram for communication and sharing information.

\section{The Rural GEG's online forum}

Although there were 75 registered members in the forum, online activities from 19 members were documented in the form of posts, comments, and likes. Thus, the rest of the registered members' online activities in the forum were not visible suggesting lurking or passive online reading activities.

The group's online forum interactions were local within rural network and primary use of Bahasa Indonesia. Rural leader's post were dominant and primarily about the group's face-to-face activities. Besides that, he also responded to members' postings, requests, and comments, and answered questions briefly. He said that he rarely saw members exchanging experiences or discussing issues about teaching and learning practices online.

"My focus is sharing information about the group's face-to-face events and activities so that members could share this information with others and come to attend. I also shared a few educational technology articles in the online forum but only a few members respond, and mostly there is no response at all" (The Rural leader).

Therefore, it appeared that the group's online forum was mainly used as a form of an online noticeboard, while face-to-face meetings and Telegram were used as preferable platforms for further communication, sharing experiences and practices, exchanging ideas, or discussing problems. No substantial discussion, brainstorming activities, or detailed instructional feedback occurred. The leader said that the unstable Internet access or the lack of Internet connectivity in more remote Rural areas seem to discourage members from connecting to the group's online forum. The other three participants confirmed the leader's concern on the lack of Internet connectivity that affected how the 
group's online forum was used. The high-level participant said that sharing certain media files to the forum was difficult when there was no sufficient bandwidth to support. The mid-level participant explained that the majority of members preferred to share or discuss with each other outside of the online forum using Telegram of meeting face-to-face as it was more practical and did not require high-quality Internet connection. Similarly, the low-level participant said that the low-quality of Internet connection did not enable the use of the group's online forum for any virtual learning activities, such as using Google Hangout or Skype video call. According to all participants, the interaction and communication in the group's online forum were "basic and simple". This was in contrast to Telegram, which they considered more practical, dynamic, and did not require a highquality Internet connection.

The characteristics of the interaction in the forum are brief and no conflicting comments or responses identified in the forum. The online interaction is expressed in a less formal discourse within brief sentences. Responses and comments were brief: "nice", "good", "awesome", "thank you", "super", "agree", "okay", "excellent", and "keep the spirit" were common responses to the leader's postings. Questions such as "can I join the event?" and "how to join or register an event" are also common.

\section{The Rural GEG's participants}

The four selected participants are educators with differing ed-tech practices and experiences. The participants do not only teach in the classroom but also have other responsibilities such as being a school data operator/administrator. According to participants, it is common for rural educators in the region to have more tasks and responsibilities than they should have due to a shortage of educators at schools. The following section describes each of the participant's professional background and the way they participated in the group's face-to-face activities and in the group's online forum.

\section{The Rural leader}

\section{Professional background}

The Rural leader is an educator who initiated and led the Rural GEG. He is an ICT teacher as well as a school data operator at one of public high schools in the region. Besides having an academic background in information technology (IT), he is also skilful in graphic design and has an interest in the educational use of technology. 


\section{Prior Digital Practice and Experience}

Before leading the group, he has been actively exploring the use of ICT (mainly web 2.0 technologies in the classroom), manages the school data system, and facilitates informal training through mentoring other teachers, educators, and IT school administrators in order to help them use technology for teaching, learning, technical and administrative purposes. Prior to his role as GEG leader, he had an experience to get involved as an ICT volunteer of a programme at regional level supported by the Ministry of Communication and Informatics in Indonesia aimed at accelerating Internet penetration across the country.

\section{Participation in the group}

The Rural leader organised all events and activities to be open and free to those interested such as meet-ups, free teachers' workshops, training, and seminars about the educational use of web-based tools and resources. He said that face-to-face interaction was still the most preferable interaction because most teachers and educators in his region did not have reliable access to and support for Internet connectivity.

The Rural leader was also a resource person (speaker, presenter, and trainer) for the events and activities he organised. He modelled his practices to provide participants more concrete models of various free web-based tools and resources for teaching and learning.

"I use my practices as examples and models for other teachers, educators, even school principals to show them about the potential of web-based tools and resources for teaching, learning, and education. For example, using Google tools for the administrative process of new students' admission at my school which most schools have not done yet. Teachers here mostly prefer something concrete to relate to and can look up to, and it is part of my strategy to show them the benefits and values of using such technology through examples from my own practices" (The Rural leader).

The Rural leader approached younger people outside of the school environment through various rural youth organisations to introduce Google tools and other technology, aiming to motivate them to use such tools to explore further opportunities. He supported educators who were interested in group mentoring but had lack of technology resources such as laptops, computer, and Internet access (for those who lived outside of the city without support). 
The Rural leader collaborated with various institutions and organisations and also education leaders and stakeholders to encourage them to join and participate in the group.

"I approached the school principal, education leaders and stakeholders for greater influence to reach out to more teachers, and then I encouraged teachers who have successful teaching practices experiences with Google tools to get involved in modelling their practices and inspiring others. Hopefully, this will make the group more appealing to more teachers and educators in this region to join and participate" (The Rural leader).

He said that the collaboration initiatives are important ways to keep the group's events and activities running, particularly from the end of 2016 onward when Google withdrew financial incentive. He also said that by having these school principals, educational leaders, and stakeholders vouching for the group would be more appealing for educators to join in.

The Rural leader did not post regularly, and he had no targeted or dedicated timeline for postings.

"I post content in the group's online forum when I can or need to. I do not do regularly though as most of my members are more engaged on the Telegram forum. I also do not have any certain schedule of posting. Many of members did not reach out to me online. They often make a contact to me personally for questions or consultation by phone or on Telegram. The group's Telegram forum is more dynamic than the online forum" (The Rural leader).

He observed that members rarely exchanged experiences or used the online forum for discussion or problem solving ed-tech practices. Instead, they communicated and interacted more often through Telegram. For example, for consultation, asking technical assistance, exchanging ed-tech practices and challenging experiences with using webbased tools, or providing solution to certain technological problems at schools. He also informed that the level of moderation he did for the forum was low as members rarely posted in the forum. Therefore, his main posting activities in the forum aimed to encourage members to be more active in the forum.

\section{The Rural high-level participant}

\section{Professional background}

The Rural high-level participant is a school principal, an ICT administrator, and a school data operator at a clustered private senior high and secondary school. He studied Indonesian language and literature at the local university. He is currently a teacher at a public senior high school, teaching Bahasa Indonesia and art craft. Although he does not 
have a formal education background in IT, he said that he has always been a self-taught when it comes to technology. Although his school does not have an Internet connection and few laptops and personal computers are available to use, it does not stop him from using technology in his professional practice and trying to bring technology into his school.

\section{Prior Digital Practice and Experience}

Before joining the group, the Rural high-level participant has been actively using email, Word Processor, and Excel Spreadsheet, PowerPoint, search engine tools, and virtual storage in his professional activities. His prior digital practice and experience include using social media and watching instructional videos on YouTube, especially on using simple and free ICT and web-based tools for teaching. Prior to joining the group, he has been actively connected with communities of ICT teachers to find information about using technology, applications and tools and troubleshooting issues.

\section{Participation in the group}

The Rural high-level participant attended the GEG's face-to-face activities whenever he could, which he regarded as very important and beneficial to him. He valued the group's events and activities as refreshing alternatives to the government PD programs as he considered the content of the group's free learning events and activities was more relevant to his needs of learning about using technology in education. He has attended the group's free workshops and meet-up events. He said that he has learned a lot about the information about computational thinking in the digital age, as well as practical skills to use Google Apps for Education (e.g. Gmail, drive, calendar, doc, sheets, slides, Classroom, Hangout, etc), Android tools, and social media for educational purposes. He said that learning in the group has helped him improve his ed-tech knowledge and skills in using web-based tools and resources at his school.

The Rural high-level participant volunteered his time outside of school hours to help other rural educators use Google tools. He did this through group and one-on-one mentoring at school using Internet-mobile tethering, or at the nearest local community centre where there is free access to the Internet (with limited bandwidth). He spent his own money on additional mobile data package so that he could tether it for Internet access at schools. He said that although he did not get paid for doing this, he did not mind doing it. He was willing to lend his laptops to other teachers to help them learn to use Google 
tools effectively, such as Gmail which had not been used. He felt happy to give educators in the rural region the opportunity to use technology and learn together despite the limitations they experienced. He believed that motivating other educators to learn about using technology through informal mentoring enabled him to learn more about finding ways to creatively address various issues with web-based tools in a constrained access context.

The Rural high-level participant only went to the group's online forum to see what was happening with the group recently, such as the latest content in the forum or the latest notification or information that the leader posted. His online activities were visible than other members. Not only did he regularly visit the group's online forum but also followed information updates on the group.

“Although a few times I comment on the leader's post in the forum, I don't think that it is necessary to share my struggles with technology at school in the forum. It's more convenient to connect directly to the leader or some of my colleagues in the group" (The Rural high-level participant).

He responded to the leader's online post and made social comments such as "it's ok" and "thank you for your confirmation", and "long live ICT". He gave "likes" to the leader and other members' posts by using the Google Plus feature of ' +1 ' to respond to the latest content he liked. However, as observed earlier, he neither shared his experience nor expressed any ideas or thoughts related to teaching practice in the forum. He also said that sharing certain media files to the forum was difficult when there was no sufficient bandwidth to support.

\section{The Rural mid-level participant}

\section{Professional background}

The Rural mid-level participant is a teacher and a school data administrator at a private secondary school. She teaches Christianity and has also taught sport and health at a public elementary school. She does not have any formal education background in ICT, but she said that loves to learn and explore new technologies, tools, and applications on her own. 


\section{Prior Digital Practice and Experience}

Prior to joining the group, the Rural mid-level participant has been regularly using a Word Processor, Excel Spreadsheet, and PowerPoint with simple ICT tools such as a laptop and LCD projector in her classroom activities to engage her students more in the classroom. She said that she is trying her best to make use of technology that is suitable to her school environment where the ICT infrastructure and Internet connectivity are not conducive. She has also been using social media for personal purposes and leisure activities through her mobile phone. She is incorporating a Facebook closed group page as a tool of communication with her students to provide extended learning support outside of school hours to prepare for exams. She believed that the best technology is not necessarily the most expensive but the one that can be used effectively within the current context to solve problems.

\section{Participation in the group}

The Rural mid-level participant had limited face-to-face interaction with the group because she had never attended any face-to-face events and activities that the leader had conducted. However, she said that she promoted the group to her colleagues at school and other schools, as well as through social media networking.

"I also told my colleagues at school about the group, Google Classroom, Google tools and so forth and encouraged them to join the group because there are valuable knowledge and information about using web-based tools and resources that I can learn from, and I want to share it with them. It is just my way of letting them know that there is the GEG where they can be part of the outside of the school-mandatory teacher working group/MGMP. Few of them have joined, some of them are still considering, and the rest probably does not think it is necessary" (The Rural mid-level participant).

With no experience of attending the group's face-to-face events and activities, what she shared mostly was promoting the group to others so that they would join.

The Rural mid-level participant used the group's online forum to stay current on any activity and information updates. She said that the forum helped her to stay connected with the group because she felt she was missing out on not being able to participate in its face-to-face events and activities. However, she rarely used the group's online forum to express herself or to share her experience with others.

"I don't feel the need to share my experiences with technology in the forum. I am more comfortable to just read from others' posts. No one seems to share about his/her experience in the forum, though" (The Rural mid-level participant). 
She followed through the leader's postings in the group's online forum and asked questions whenever she needed. Other than posting questions, she said that she did not feel the need to post comments or give likes. However, she appreciated the leader for responding to her questions and updating her about the group's upcoming face-to-face events and activities. The way the Rural leader did not stop updating her with the group's events and activities, although she had not yet been able to attend one of them, made her feel that they did not take her for granted so she felt welcomed and included as a meaningful part of the group. She also explained that most members preferred to share or discuss with each other outside of the online forum. Using Telegram for meeting face-toface was found to be more practical and did not require a high-quality Internet connection

\section{The Rural low-level participant}

\section{Professional background}

The Rural low-level participant is ICT teacher at a public senior high school. He was recruited by the leader as the co-leader of the group. He actively assists the leader in managing and organizing the group's face-to-face activities and often assists the leader in facilitating hands-on Google workshops.

\section{Prior Digital Practice and Experience}

Prior to joining the group, he has been actively engaging in ICT community/ICT teacher organisation as well as a teacher-trainer at his own school. To that end, he has experiences in helping his colleagues use Google Classroom and other technology-related skills for teaching and administrative purposes. He said that having an academic background in IT enabling him to explore and experiment with various technologies for teaching and learning at ease. He is grateful that his school supports his ed-tech practices by procuring the Internet connection at school. Although the Internet connection at his school still needs improving, he is grateful that he can use it to engage his students more in the classroom: "I am aware that the Internet connection at my school needs more improvement, but it does not stop me from using technology such as web-based tools in my classroom" (The Rural low-level participant). 


\section{Participation in the group}

The Rural Low-level participant's online presence in the group's online forum is not visible as high and midlevel participants, but he was among the inactively online members who offered to participate in this study and agreed to be interviewed. Although he does not use the group's online forum to post or communicate with others in the group, he attends the group's face-to-face events and activities and directly contributes to the group through his co-leading role. Besides assisting the Rural leader to manage and organise the group's face-to-face activities, such as workshops and seminars, he also allocated his spare time to experiment using Google Classroom and Google tools for various classroom activities across school subjects. Whenever he comes up with ideas on certain kinds of models to implement them, he consulted with the leader and the school principal for a try-out. When it was successful, together with the leader, he then invited educators from across school subjects at the school to help them to learn using it for in their practices.

The Rural low-level participant volunteered outside of school teaching hours to help other educators use Google Classroom and Google tools at school through mentoring them and giving them technical guidance. He said that helping other teachers was always an exciting experience, because he felt that he had learned more by doing more and he wanted to motivate them to creatively use the tools for their classroom activities. According to his mentoring observation, most teachers at the school needed some time to adjust with using Google Classroom and Google tools, but once they got used to it, they found it more practical and efficient, especially for students' evaluations, task assignments, and grading.

The Rural low-level participant did not actively participate in the group's online forum, and he did not feel the need to post content or give likes:

"As I observe, there is not much going on in the forum. I do not see members exchanging ideas or discussing their practice there. It was mainly information from the leader. Although the information is useful for me, I do not feel the need to express myself in the forum" (The Rural low-level participant).

He also said, "I only go to the forum for observation just in case there are questions that the leader misses to answer, I can let him know". He only visited the forum to observe, to check up, or to read for new information from the leader or other members. He noted that although the online forum has a good and user-friendly platform, he felt that it was 
less engaging for him. He concerned about the low-quality of Internet connection, which did not enable the use of the group's online forum for any virtual learning activities, such as using Google Hangout or Skype video call.

\section{Main categories}

The following sections describe the main categories as the results of the data analysis from all participants and the group's online forum: constrained digital resources and Internet connectivity, limited resources and support for the group, preference to faceto-face and Telegram communication, the leader's role and influence, positive changes in professional learning, limited online forum engagement, and meaningful learning experiences through mentoring (see Table 12). Assertions are then presented as the result of how each of the main category lead into final interpretation following the evidence in the case of the Rural GEG.

\section{Constrained digital resources and Internet connectivity}

Participants described the constrained digital resources and Internet connectivity in the region, which they believed to contribute to the lack of awareness and a pragmatic mindset about the use of technology among rural educators. Without access to good quality of Internet connection and sufficient access to digital resources, participants considered that it is hard to improve the quality of teaching and learning in the region using web-based technologies.

The Rural leader observed that most schools in the rural region were not yet connected to the Internet. For the schools with an Internet connection, it was often limited in bandwidth, had low quality or connection, and was often unstable for a few hours before it got back to normal again. He reported that the amount of cell tower coverage from telecommunication providers was very limited, particularly in more remote rural areas. Most often the case is that many schools in these areas did not have adequate ICT tools or even a computer laboratory.

The cost of a mobile Internet package was also considered expensive. In addition, he saw that most classrooms were still conventional where educators relied on using pens, paper, chalk, and blackboards to teach but students did not seem engaged. He explained that the main part of his volunteer work was helping school principals to find ways to procure Internet access by giving them guidance to apply for Internet and ICT funding/grants from local government and non-government organisations. However, as 
the funding for grants was also limited there were not many schools that could obtain them.

The predominant issue of limited to no access to Internet connection is evident. Participants said it is their most challenging situation when trying to implement what they learned from the group using technology at school.

"Only one cell tower is built for now, and the location is so far away from this village. We have no other option but using the only existing telecommunication provider and the mobile data package is expensive for almost all of us here. Most of them (rural teachers) told me that they prioritised to buy gasoline or grocery shopping than mobile data package" (The Rural high-level participant).

It appeared that educators in the rural region preferred to put aside an Internet connection as less important and prioritise more on primary expenses such as gasoline, groceries, and household necessities.

The Rural mid-level participant acknowledged the insufficient and unsupportive infrastructure at school as being the most challenging to her when she wanted to fully implement Google Classroom. The ICT resources were extremely limited in her school, and the quality of the Internet connection was poor. The school also did not have any computer laboratory and there were not enough personal computers or laptops for all teachers and students to use. She used non-Internet technology to help with her teaching practices such as using slides (PowerPoint presentation) from her own laptop. When trying out web-based tools such as Google tools or Gmail at school, she used mobile broadband to connect to the Internet as there was no Wi-fi available at school.

The Rural low-level participant considered the low and unstable quality of the Internet connection at school as challenging because it was not conducive when trying to implement Google Classroom. It could be unstable sometimes or was even off momentarily. He also felt that access to free Wi-Fi in his region was lacking and its bandwidth needed improvement. To him, the cost of mobile Internet access was also quite expensive, and there were not many Internet kiosks available, which was also challenging to his motivation, especially when he had trouble connecting to the Internet.

The Rural leader expressed his concern about this and aspired to provide more support for educators by initiating the GEG. He was aware that although he could give guidance for school principals to apply for Internet and ICT funding/grants, he felt that he could not do much with the procurement as it was entirely up to local government or 
non-government organisations to decide. Based on his ICT volunteer experience, supporting educators and their schools to use technology for teaching and learning where there was no Internet access at all or no ICT equipment available did not create any significant changes. This was because conventional teaching and learning was the only viable option. However, by initiating the GEG, he believed that he could do more in providing support for educators and their schools where there was at least some Internet access and a few pieces of ICT equipment available, although he felt that it could still be a very challenging thing to do.

"Most of the time, it can be very challenging to encourage school principals and teachers in schools with very limited access and few ICT tools because most of them are not aware of or familiar with using web-based tools for teaching and learning and are sort of afraid to explore the way these technologies can be used properly for teaching and classroom practices. If there was not enough motivation and support, it is understandable if they refrain to go conventional again" (The Rural leader).

The Rural leader said that it was hard to motivate rural educators to learn how to use webbased tools when there was limited Internet access and poor quality of ICT tools at their schools as they never seem to have opportunities to use such tools and experiment with them for classroom activities. They also appeared to be hesitant to continue learning new tools because they did not see any relevance in their daily teaching practices. Some educators with higher motivation tried to make experiments with certain tools and use them in their teaching and classroom activities but did not know how to do it properly as they were not familiar with it. This was when he felt he could do more with the GEG by raising these educators' awareness, changing their mindset, and helping them to be more digital-literate in using free and simple web-based tools with a limited Internet connection and few ICT tools available.

Reflecting on his ICT volunteer experience in a digitally-constrained environment had motivated the Rural leader to focus on providing resources to support rural educators learn to use web-based technologies in a technology-limited environment through the GEG. In doing so, he focused on introducing and promoting the benefits of using free and open-sourced web-based tools and teaching them how to use them properly within limited access and poor quality of ICT infrastructure such as using web-based tools that can be used with limited bandwidth and few ICT tools. 
The free workshops for rural educators were also adjusted within a digitallyconstrained environment to be more relevant in applying it to practice. For example, in the introductory workshop on computational thinking, the leader first introduced the concept of the thinking before showing them how it could be applied across teaching subjects. The Rural leader realised that not many educators in the region were aware of the computational thinking concept as the foundation of effective ways for problemsolving with critical thinking. He believed that understanding this concept before implementing it with any tool would yield a deeper understanding beyond technicalities. He was glad that many members had come to him to say that the knowledge they obtained from the group was new, relevant, useful, and beneficial, which they did not get from school or formal PD programmes. He highlighted that he did not want them to just use the technology without understanding the bigger picture of using it wisely and effectively.

The issues of Internet connection, low quality of connectivity/bandwidth, poor quality of ICT infrastructure, no available Wi-fi areas, and expensive cost of mobile Internet access are clearly identified as participants described their experiences and efforts in overcoming technological issues and limitations, which indicate constrained digital resources and Internet connectivity in the region.

Assertion: With constrained digital resources and Internet connectivity, motivating and facilitating learning using web-based technologies in the group became challenging.

\section{Limited resources and support for the group}

The resources were limited to support the group, especially after Google withdrew their financial incentive to Indonesian GEGs in the end of 2016 including Rural GEG. Starting from 2017, the Rural leader have explored ways to continue supporting the group's events and activities. Using his own networks and resources, the Rural leader reported that he made efforts to explore opportunities for collaboration initiatives and sponsorship for the group's activities. In doing so, he managed to obtain support from several parties such as small ed-tech start-ups, private universities, and small computer companies. He also approached people from the local government, his ICT network, and school principals from various schools to collaborate and share resources to organise the group's face-to-face activities. However, as the Rural leader became the only facilitator of learning in the group, he found it challenging at times to find time for managing the group's activities, particularly when he was preoccupied with other tasks and 
responsibilities. For example, when he no longer had time or the necessary resources to support the group, the group's activities were reduced until he returned. He reported that he also helps other educators in his own personal time until he is able to reactivate the group's activities. With limited ed-tech resources such as constrained Internet access, limited ICT infrastructure, and the scarcity of references and examples of ed-tech practices that educators can use to learn from at their schools added to the challenges the leader face to facilitate learning in the group. Thus, these challenges indicate that it had not always been easy to support the group as the only facilitator due to limited resources and support available for the group.

Assertion: When Google withdrew the financial incentive and the leader did not have the necessary resources to support the group, its activities were reduced.

\section{Preference to face-to-face and Telegram communication}

Participants described the significance of face-to-face interaction and Telegram to strengthen the connectedness with each other in the group and for further support. All participants expressed the need to feel connected through friendships or collegial relationships to avoid the stress of struggling with a lack of resources and the feeling of isolation in the profession. They said that educators in the region had limited opportunities to connect with each other within professional capacity as not all educators had access to attend government PD programmes. In the rural region, the opportunity to connect with each other was through attending these programmes. Even then, it could still be quite difficult for them to find a connection and relate to other colleagues who had similar aspirations and interests about education technology as most government PD programmes focused on the policy implementation rather than ed-tech related topics or trainings. Therefore, they appreciated what the leader had done with the group by providing opportunities to meet and find a connection with colleagues who shared professional similarities in education technology, which they had not experienced from attending government PD programmes.

Since access to free $\mathrm{Wi}-\mathrm{Fi}$ areas were rarely available in most of the regions, participants relied on using the mobile instant messaging applications of Telegram and face-to-face interaction to connect to each other personally and collectively in the group. The leader created a Telegram group because the group's online forum was lacking engagement. Telegram was also popular and preferable among members in the group 
because of its practicality and ease of use in a bundle with a mobile Internet connection, through mobile phones (smartphones). Telegram also allowed them to get connected in real-time communication and send the various type of files which they regarded as simpler than using emails. Participants used the Telegram to connect to the leader and some members in the group. The more they felt connected to the leader and certain members in the group, the more they personally developed a professional relationship. When it grew stronger, they engaged further in experience and practice-sharing or even allocated time to meet with one another outside of work to socialise, do hobbies together, help each other, or do certain projects together. Participants then felt more open in seeking support with technology at school when they felt that they had a strong professional relationship with the leader and some members in the group, which he referred to as close friends or close colleagues.

The need to be connected to each other in the group through friendship and collegiality is highlighted as participants shared their preference for face to face interaction and Telegram communication. It appears that the impact of face to face interaction and the ubiquity of Telegram as a mobile communication tool encourage sharing and enable opportunities to form strong friendship and collegiality.

Assertion: As participants struggled with a lack of resources, they formed strong friendship and collegiality through face-to-face and Telegram communication.

\section{The leader's role and influence}

The Rural leader had a significant impact on the group. Members expressed their admiration for him and were grateful that he provided them with access and opportunities to learn about the use of web-based technologies for teaching and learning, which they had not had before. Because the group was underpinned by the leader's philosophy of technology in education, every topic was educational-technology related. For example, Google Apps for Education (Google Classroom and Google tools), ICT-based learning resources for teacher professionalism, building teacher's ICT literacy and writing skills in the $21^{\text {st }}$ century, and the use of Google forms for creating classroom quizzes. Participants said that it sparked their interest and curiosity as they felt connected to the Rural leader. His leadership appeared to have had a strong influence on participants' interest about the group and their decision to join it. 
The Rural mid-level participant's curiosity about the Rural leader and his activities with the group sparked an interest to learn more about using those tools for her classroom activities. She also admired the leader for initiating the group and felt connected with his vision about it, which she considered inspirational. Through her own research that she conducted in the group's online forum and website, she found its domain knowledge interesting and wanted to explore further. She also thought of the GEG as being the first group in the region that was not only virtually reachable, but also physically within reach. She felt connected and supported in learning to use a variety of web-based tools and resources for her students.

The Rural high-level participant shared the Rural leader's vision of the group and wanted to support it. He felt the group's interest in knowledge aligned with what he was interested in learning further - updating his knowledge and skills about using Google Classroom, Google tools, and other web-based tools and resources for teaching and classroom practices. He also wanted to share what he learned from the group with other teachers and educators in his rural area by teaching them how to use mainly free and simple Google tools for teaching and learning. He found such tools and resources beneficial to him and he wanted them to experience it as well. By doing so, he aimed to raise more awareness among teachers and educators in his rural area about the potential of such tools and resources to improve students' interest to learn at school.

The co-leading role had sparked his curiosity and interest to further explore the use of web-based tools and resources, particularly Google Classroom and Google tools, for his teaching and learning practices. He admired the leader's effort to initiate the group in the region and wanted to support the leader's vision by assisting him in managing the group's activities.

"When the leader approached me and offered me to help him manage the group, I did not know at all about it, but I went along with it because I support his vision about initiating the group which I think is great. The more I help him manage the group's activities, the more I know about the educational use of web 2.0 tools and resources. I find that Google Classroom and Google tools are very appealing to me that I want to explore further. I also want to support him and the group because I think it offers a positive opportunity for teachers and educators in this region to learn more about web 2.0 tools and resources" (The Rural low-level participant). 
He did not know at all about the group at first when the leader initially approached him to offer the co-leading role, but when the more low-level participant got involved in assisting the leader to manage the group's activities, his interest in using web-based tools and resources grew.

As Rural high, mid, and low-level participants shared how they engaged with the group, the leader's role and influence are significantly revealed. The admiration towards the Rural leader, the appreciation towards what the leader had done in the group, and the Rural leader's ed-tech vision that they shared described the significant impact of the leader in the group.

Assertion: Participants' engagement with the group was highly influenced by the leader and his leadership could be the primary driver for participants to join the group.

\section{Positive changes in professional learning}

Participants shared the positive changes in their professional learning, particularly with the use of web-based tools. Participants reported that they experienced positive changes in the way they think, feel, and do things with technology. Their experiences varied depending on what they gained and learned from the group. They considered the group's support in providing them with access to web-based tools, and motivation through networks of friendships, and facilitation, enabled them to learn and experience positive changes.

The Rural leader felt that leading the group changed the way he learned through cultivating his networking with other GEG leaders in Indonesia for resource-sharing. He felt that he was no longer dependent on the local government or local education unit for any information about education-related information, resources, and PD activities.

The mentoring activities also changed the leader's approaches to find various strategies of facilitating various types of educators. He said that mentoring senior and young teachers to introduce the use of technology for teaching and learning requires different approaches because their exposure, characteristics, and habits were completely different. To him, effective mentoring involved understanding the situation and condition of the mentee, and it was not merely about transferring knowledge but how that knowledge was transformed into consistent practice. 
Improved optimism through developing supportive networks was also among the positive changes that the leader experienced. Through experience-sharing with some members in the group and other GEG leaders in his networks, it helped him to be more optimistic and positive in overcoming professional challenges. By doing so, it enabled him to be more reflexive and critical about his own practices as an educator. Although most of the issues and challenges in a wider context had not yet resolved, such as the limited Internet access, low quality of Internet connection, or limited support from local government, he felt more confident in exploring ways to find solutions.

The Rural high-level participant was grateful for the opportunity to get to know other educators who shared similar challenges, giving him courage and hope.

"Joining and participating in the group enabled me to get to know other members with similar challenges. I learned a lot from sharing experiences with them and it gives me the courage to keep on doing what I am doing. I know that there is hope and ways if we keep looking and never stop trying to do good things" (The Rural high-level participant).

Learning from other members' experiences of simple use of web-based tools and getting to know them better changed the way he addressed professional challenges. He said he felt more optimistic and motivated knowing that he was not the only one who struggled with challenges and limitations in the profession.

The Rural mid-level participant said that being in the group expanded her views and knowledge about things she could do with web-based tools and made her more motivated and optimistic. She was able to meet with other educators in her region who she never had a chance to meet before. To her, it was not only for a small talk meeting but also for connecting and sharing experiences, which she found to be beneficial to keep her motivation intact. She knew that other teachers and educators in the region shared similar issues and challenges at school as hers, which she could relate to and learn from. She learned that it was not wise to dwell on the negativity because it could drain her positivity as an educator.

"Learning from other teachers and educators in the group who have a similar condition with mine but still eager to use Google tools in their practices have inspired me. I think it is important for me as a teacher to use tools that are suitable in my school context. I have been learning a lot from other teachers and educators in the GEG about this. Not many, but there are few who I think are inspiring" (The Rural mid-level participant). 
She felt that sharing experiences with other educators with professional similarities made her feel less distress and be more optimistic in facing professional challenges.

The Rural low-level participant regarded that being in the group had not improved his knowledge and skill to use web-based tools in a low-bandwidth environment but also made him more optimistic in overcoming technological challenges. Using Google Classroom and Google tools for simple practices and activities at school helped him to facilitate his students' need for more engaging and interesting learning processes in the classroom. Through support from the Rural leader and some members in the group, he was able to solve problems in various technological contexts and he felt more confident to explore and experiment with web-based tools.

Being a co-leader made the Rural low-level participant felt more skilful and knowledgeable in using web-based tools and resources, which enabled him to help other teachers and educators, particularly about the implementation of Google Classroom and Google tools for teaching and learning in an environment with limited resources. For example, finding more creative and efficient ways for the facilitation method and strategies to use various tools and resources for simple classroom activities despite the unstable Internet capacity, managing mentoring sessions, and designing more effective instruction that various types of teachers could follow. Through mentoring, he found ways to effectively mentor senior and younger teachers in a way that they would not feel undermined. He also felt that his leadership and trouble-shooting skills improved as he helped other educators with using web-based tools with low bandwidth and limited ICT infrastructure for simple teaching and learning practice.

The participants' positive changes in learning to use web-based tools in a technology-limited environment were evident as they shared about their learning experiences. The more they were engaged in the group, participants reported positive changes such as their cultivation of networks for resource-sharing, learning from informal leadership practices, their learning dispositions, and improved ed-tech knowledge and skills.

Assertion: Participants experienced positive changes in learning to use web-based tools with low bandwidth and limited ICT infrastructure for simple teaching and learning practices. 


\section{Limited online forum engagement}

The limited online forum engagement was clearly identified as a category, which reflected the group's online forum lack of engagement, lack of interaction, and limited online activities. Participants' options for professional learning in the group were limited to face-to-face activities because there were not enough learning resources available on its online forum due to a lack of sharing activities among members in the group. As a result, participants were highly dependent on the group's face-to-face activities as a form of professional learning. They were also dependent on the leader's face-to-face facilitation to learn web-based technologies with hands-on technical practices and activities. The Rural leader stated that when he tried to guide participants through giving instruction by phone or indirectly through textual communication, the instructions he gave did not seem to be well-received and often caused confusion leading to ineffective result. Therefore, he had to be physically present when participants needed instructional guidance or technical consultation or facilitation in using web-based tools.

The high-level participant neither shared his experience, nor expressed any ideas or thoughts related to teaching practice, in the group's online forum because he did not feel that it was necessary.

"I do not think that it is necessary to share my struggles with technology at school in the forum. I only go there to find information from the leader about the group's upcoming activities that I can attend to. I always make the time for it. I have attended several group activities and they are very motivating" (The Rural highlevel participant).

He preferred to allocate his time to attend the group's face-to-face activities such as an inaugural meet-up, free workshops, free training, and free teachers' workshops that were organised by the group. He was grateful and regarded the group activities as motivating. He considered such activities to be more refreshing compared to government PD programs he had attended. He said that attending the group's activities allowed him to be more connected with other educators in the region. He felt that it improved his ed-tech knowledge and skills using web-based tools. 
Both mid and low-level participants also preferred to engage with the group through face to face interaction. Mid-level participant rarely used the group's online forum to express herself or share the experience with others.

"I don't feel the need to share my experiences with technology in the forum. I am more comfortable to just reading from others' posts. No one seems to share about his/her experience in the forum, though" (The Rural mid-level participant).

She wanted to attend the group's face-to-face activities but could not allocate time to attend one because she felt overwhelmed by the tasks, assignments, and roles at school that she viewed as too demanding. She also felt that the timing of these events and activities always conflicted with her mandatory teacher meeting at school. Although she could connect to the leader and other members in the group to ask for help when using Google tools, she felt she was missing out by not being able to attend the group's faceto-face activities. Similarly, the group's online forum was also not the choice for lowlevel participant to engage with the group. He did not actively participate in the group's forum and he did not feel the need to post content or give likes. His face-to-face interaction with the group is more evident as he further engaged in his co-leading roles.

The limited and rather static dynamics of online interaction made the group's faceto-face activities more dependable and favourable to members' interest as a form of professional learning. The leader also informed that the group's face-to-face activities were attended by relatively more participants than the number of members joining or interacting in the group's online forum. This suggested that the lack of members' interaction in sharing experiences and practices in the online forum limits participants' options for professional learning activities and, therefore, they were dependent on the face-to-face activities.

Assertion: Lack of sharing experiences and practices in the online forum limited participants' professional learning activities and, therefore, was dependent on the faceto-face activities.

\section{Meaningful learning experiences through mentoring}

The majority of participants considered their learning experiences through mentoring to be meaningful because they were able to help other educators. When asked why they became mentors, they said that they wanted to share what they had learned about using various web-based technologies with other colleagues at school. For example, how to use Google forms and Google Classroom for managing simple classroom 
activities. However, they also reported that not all colleagues were interested in learning to use web-based tools. Consequently, they only mentored and provided coaching to those colleagues who were interested to learn. They usually allocated their time outside of school to do the mentoring.

The Rural leader's mentoring activities provided simple and practical knowledge and hands-on activities using various web-based tools and resources for educational purposes, for example, Google tools (e.g. Gmail, drive, calendar, doc, sheets, slides, Classroom, Hangout, etc) or non-Google tools (e.g. GSM mobile phone, Android tools, and social media). With the support from his school principal, the Rural leader helped other educators who lived in rural areas through his mentoring activity, which provided him with meaningful learning experiences. However, with no Internet connection at rural schools and not enough mobile Internet connection available, there was not much he could technically do in practice other than providing consultation on Internet procurement and trying to provide motivation.

The Rural high-level participant volunteered to help other educators in the rural region to introduce the use of Google tools in the classroom. He did this through group and one-on-one mentoring at school using Internet-mobile tethering, or at the nearest local community centre for free access to the Internet but with limited bandwidth. He was willing to lend his laptops to other teachers at schools to help them learn to use Google tools effectively, such as Gmail, which not many were aware of and they had not used it before. He regarded his mentoring activities provided him with meaningful learning experiences as he was able to help other educators in learning, which he felt enlightening and fulfilling. He wanted other colleagues at his school to experience the benefits of using technology such as web-based tools in order to be motivated in using technology. Through mentoring, he was able to learn more about finding ways to address various technological issues.

The Rural low-level participant also volunteered to help teachers and educators with the simple and practical use of Google Classroom and Google tools at school through mentoring.

"It is always an exciting experience for me to help with mentoring and giving technical guidance to other teachers about simple practices and activities using Google Classroom and Google tools whenever I can. It is not always easy, and by the way, I am not being paid for mentoring them, but I am always up for it because I learn more by doing more. I hope to motivate them to create an engaging 
atmosphere for their own classroom with simple and efficient web-based tools" (The Rural low-level participant).

He said that helping other teachers was always an exciting and meaningful experience because he felt that he had learned more by doing more and he found satisfaction as he saw other educators was able to use web-based tools within their own context of practice to create an engaging atmosphere for their classroom activities.

Participants' meaningful learning experiences were evident as they described how mentoring enabling them to feel meaningful, fulfilled, and satisfied by helping other educators to use web-based tools. It also appeared that these meaningful learning experiences enabled them to stay motivated to learn engaged more in learning in the group.

Assertion: Mentoring provided participants with meaningful learning experiences as they helped other educators at their school.

\section{Summary}

The Rural GEG case study highlights the Rural leader's efforts in supporting and facilitating participants and members' learning in the group to use web-based tools. This occurred in a technology limited environment within a digitally-constrained region where participants considered access to the Internet and digital resources were extremely limited; traditional teaching and learning practice with paper-based system was predominant; awareness of using technology in teaching and learning was low; and a pragmatic mindset towards technology in education was common. These were referred to as complex challenges by all participants. The leader had a preference to lead the group with a colleague as a co-leader, and the decision-making was made by the leader. The group's events and activities were leader-driven where the role of the leader was significant in influencing the way participants interacted with each other in the group. For example, participants joined the group because they were primarily influenced by what the Rural leader did in the group. Although not all participants were leaders at their schools, they shared a similar ed-tech vision and interest in the group. The group's events and activities were predominantly face-to-face enabling participants to connect with each other within a localised network. Telegram was favoured as the main platform to extend communication and strengthen social connectedness in the group compared to the group's online forum. The group's lack of online engagement confined the options for online 
learning activities and, therefore, their learning seemed to be highly dependent on the leader's efforts as the main facilitator. Bahasa Indonesia was primary used as the language of communication and interaction in the group's online forum. The online forum was used mainly for information distribution rather than discussion and collaboration. The leaderdriven online forum reflected the presence of social activities in the interaction, but no ed-tech related discussion and collaboration were identified. Mentoring activities occurred as participants grew confidence engaging in the group as learning leaders. All participants seemingly shared positive learning experiences with the group. Among those were the way they cultivated networks for resource-sharing; the way some of them learned through leadership practices, the way they expressed their learning dispositions, and the way they believed that their ed-tech knowledge and skills improved. Despite the limitations and lack of resource, the group appeared to enable participants to have meaningful learning experiences as they were more engaged in the group learning to use web-based tools in a technology-limited environment, particularly with low bandwidth and limited ICT infrastructure. 


\section{Chapter 7}

\section{Cross-case analysis}

\section{Introduction}

This chapter presents findings from the cross-case analysis. It compares withincase assertions across the three case studies. Each assertion was compared across cases to probe for similarities and contrasts and assigned as significant, relevant, or contradictory (see appendix 4). Three cross-case themes emerged from this analysis: (1) the regional-technological environment, (2) leadership practice, and (3) group functions. The cross-case findings will show how the interplay of these themes has significantly influenced participants in all three GEGs.

\section{The regional-technological environment}

The regional-technological environment emerged as the first theme prominently reflecting a contrast in each group. Three different types of regional-technological environment were identified: (1) digitally-driven region, (2) digitally-diverse region, and (3) digitally-constrained region, which significantly influenced he groups' digital environment, online forum's networks, activities, and resources, and the use of mobile communication. Depending on the type of regional-technological environment, a group could have a reliable or challenging digital environment. The groups' online forum's networks, activities, and resources could also be global or local and the way mobile communication used could be complementary or substitutive. Both Urban and Rural GEGs shared similar challenges that did not seem to be present in the Metropolitan group.

\section{Internet access and school culture: reliable and challenging digital environment}

The Metropolitan GEG's digitally-driven region provided a more reliable digital environment enabling diverse ed-tech practices than the Urban GEG's digitally-diverse and the Rural GEG's digitally-constrained regions. In the Metropolitan's digitally-driven region, participants had reliable Internet connectivity, good quality ICT infrastructure and, as a result, digitally driven school cultures:

"I have been using various web-based tools such as Google Quiz, Google forms, and Google sites in my EFL classroom for quite some time now with more systematic grading, feedback, and evaluation. I also enjoy making video podcast 
and video tutorial, not only for own teaching or classroom activities but also for sharing them with others. I love to make experiments to create content such as using Camtasia or Apple keynote. Part of my hobbies is exploring ed-tech blogs such as $t, T E D-E d$ videos or $y t 6$ as references for my EFL classroom. I use YouTube to share my content creation" (The Metropolitan high-level participant).

In the Urban GEG's digitally-diverse region, there were challenges arising from the unequal access of medium to low quality of Internet connection. Not all schools had an Internet connection, some schools had unstable and unreliable connections, and there was pervading emphasis upon paper-based school culture:

"It is so unfortunate that unstable Internet connection at my school can be problematic when I use web-based tools in my classroom. The technical ups and downs of access can be distracting and need improvement" (The Urban low-level participant)

In strong contrast to the Metropolitan and Urban GEGs, the Rural GEG had the most challenging regional-technological environment. Most schools had either low quality of Internet access and ICT infrastructure or no Internet connection at all, particularly in more remote rural areas. Not surprisingly, traditional teaching and learning practices within a largely paper-based school culture was prevalent in most schools.

"Only one cell tower is built for now, and the location is so far away from this village. We have no other option but using the only existing telecommunication provider and the mobile data package is expensive for almost all of us here. Most of them (rural teachers) told me that they prioritised to buy gasoline or grocery shopping than mobile data package" (The Rural high-level participant).

It was evident that both Urban and Rural GEGs shared similar challenges with the Internet connection. The unequal access to good quality Internet connection in the Urban GEG was as unreliable as the low quality of Internet connection in the Rural GEG leading to the prevalence of paper-based teaching and learning practices, which became challenging for participants' ed-tech practices in both groups. Participants' ed-tech practices in the Metropolitan group, on the other hand, did not seem to be interfered by either unequal access to the Internet or low-quality of the Internet connection as they seemed to have no issues in accessing a wide variety of digital technologies and using them in their practices. Respectively, Metropolitan participants' experiences with digital technologies suggest a digitally-driven group whereas Urban and Rural participants' experiences are similar in terms of being a group with a challenging digital environment. Therefore, the Metropolitan GEG's regional-technological environment reflects a reliable digital environment whereas both Urban and Rural's contexts reflect a challenging digital 
environment. This shows that certain aspects of regional-technological environment such as Internet access and school culture can either be reliable or challenging for the exploring learning with digital technologies.

\section{The online forum's global and local networks, activities, resources}

The group with digitally-driven environment had different online forum's networks, activities, and resources compared to the groups with digitally-challenging environment. It appears that the digitally-reliable environment enabled the online forum's networks, activities, and resources to be collaborative and globally connected with diverse range of learning opportunities whereas the online forum's networks, activities, and resources in the groups with digitally-challenging environment were shown to be more locally-connected with lack of online engagement and driven by the leader (leaderoriented forum).

It appears that the use of English in the group's interaction and communication and digitally-reliable environment could create an online forum environment where participants were globally networked and collaboratively engaged in blended learning activities as shown in the Metropolitan GEG's online forum. In Metropolitan group's online forum, both local and international members participated, engaged, and contributed to the group's online forum enabling the group to have a global range of edtech resources. The content of the group's online forum demonstrated participants' diverse knowledge of the use of educational technology within global context:

"The group's online forum has been my go-to ed-tech resources. Not only does the leader share incredible resources and informal learning opportunities but members also do too. The great thing is that we can join or participate in a flexible manner, either it is virtually or face-to-face. The next great thing is that they are not only local but also international. I had joined free some of these local and international events and I had great experiences with all of them" (The Metropolitan low-level participant).

The local and international members collaboratively engaged online through communication, information-sharing, discussions, and problem solving in a highly communicative, appreciative, and supportive atmosphere, which indicates the reliability and convenience of the online forum as a platform for group interaction and communication. With this kind of atmosphere and blended learning activities, the faceto-face and online interaction in the group were interconnected in a way that it supports collaboration. The Metropolitan leader also said that having no Internet issues enabled 
members to share a wide range of digital resources and learn from diverse range of edtech practices and experiences with web-based tools on the online forum. The other three participants also shared how they used the group's online forum to share various digital resources and explored how to use them in diverse contexts.

In contrast, the predominant use of Bahasa and a challenging digital environment could lead to an online forum environment that was lacking engagement where participants were locally networked and mostly engaged in face-to-face driven learning activities as shown in both Urban and Rural GEGs' online forums. Two participants described similar experiences reflecting the lack of engagement and contribution from members in the online forum: "I do not see any interesting discussions regarding teaching practices in the forum for me to participate in" (The Urban low-level participant). "No one seems to share about his/her experience in the forum, though" (The Rural mid-level participant). With no online participation from International members and the lack of online engagement where few members responded but not substantially contributed, the leaders' dominant online activities became the major contributors in the forum. This resulted in a locally-networked online forum and a local context of ed-tech resources where face-to-face driven learning activities were most dominant in the group. Although all forums provided supportive environment with no dispute and negative criticism, both Urban and Rural's online forums were not as communicative and appreciative as the Metropolitan's. This indicates that all groups' online forums provided supportive atmosphere but were different in the way it was used to express communication and appreciation.

The challenging digital environment in both Urban and Rural GEGs also limited the use of the group's online forum for learning. The Urban leader said that most members preferred face-to-face activities or communicating through mobile instant messaging applications due to the limited bandwidth and unstable Internet connection in most areas in the region. To Urban high-level participant, the unstable Internet connection did not enable a smooth process of sharing certain media files or videos that he wanted to share with others online whereas the Urban mid-level participant concurred that it was not always easy to have Internet access to get connected to the group's online forum when travelling within the region. The Urban low-level participant shared his experiences on how difficult it could be sometimes to get a stable connection to the Internet and thus, although he regularly visited the forum, he found it troublesome to share certain digital 
resources with others in the forum, such as large video files or power point due to the unstable bandwidth. Similarly, the Rural leader said that the unstable Internet access or the lack of Internet connectivity in more remote Rural areas seem to discourage members from connecting to the group's online forum. The Rural high-level participant informed that that sharing certain media files to the forum was difficult when there was no sufficient bandwidth to support. The Rural mid-level participant explained that the majority of members preferred to share or discuss with each other outside of the online forum using Telegram of meeting face-to-face as it was more practical and did not require high-quality Internet connection. The Rural low-level participant concerned about the low-quality of Internet connection, which did not enable the use of the group's online forum for any virtual learning activities, such as using Google Hangout or Skype video call. This shows the influence of a challenging digital environment to the use of the group's online forum.

Unlike the Metropolitan's collaborative online forum, both Urban and Rural's online forums were used more as the leader's information distribution and socialising platform rather than discussion and collaboration. Accordingly, participants in both Urban and Rural primarily used online forums for seeking information from the leader and socialise with each other instead of having substantial discussion and collaboration as in Metropolitan group. This indicates that within a challenging digital environment, the online forum can be informative and social but is not necessarily collaborative and educational compared to how a reliable digital environment can enable the online forum to be informative, social, collaborative, and educational.

It was evident that although all groups used online forums for learning resources, not all forums supported learning from online collaboration. The Metropolitan group's globally networked and collaborative online forum was shown to provide participants with diverse resources and therefore, support opportunities for learning from online collaboration The Metropolitan leader also said that having no Internet issues enabled members to share a wide range of digital resources and learn from diverse range of edtech practices and experiences with web-based tools on the online forum. The other three participants also shared how they used the group's online forum to share various digital resources and explored how to use them in diverse contexts. In contrast, although participants in both the Urban and Rural GEGs valued the locally networked and leaderoriented online forum, both forums did not seem to provide resources that support learning from online collaboration. 


\section{The complementary and substitutive use of mobile communication}

Interestingly, despite having a reliable or challenging digital environment, all GEGs used mobile communication such as WhatsApp and Telegram to strengthen personal and group communication and face-to-face interaction. The role of mobile communication could be complementary or substitutive, depending on the dynamics of the group's online forum.

Two mobile instant message applications were primarily used across cases: WhatsApp and Telegram. The Metropolitan GEG used WhatsApp for mobile communication:

"I use all kinds of channels to make the group more open to everyone, including with WhatsApp. This way, I can facilitate certain members who prefer to communicate and interact with WhatsApp because not all members have similar preferences in communication and interacting. The more variety of communication tools I use, the more members I can facilitate" (The Metro leader).

The Metropolitan GEG's collaborative and globally-connected online forum enabled the group to have diverse learning activities and resources along with interconnected face-toface and online interaction. The role of mobile communication appeared to be complementary to the online forum. It also became optional when needed because the groups' online forum already provided a variety of options and flexibility for members' engagement, participation, and communication.

Both Urban and Rural GEG members used Telegram for mobile communication. The Urban leader felt that Telegram was more engaging than in the group's online forum. The Urban high-level participant also felt that using Telegram for interaction and communication was more practical and convenient compared to using the group's online forum. Similarly, the Rural low-level participant considered Telegram as his favourite tool for interactive communication rather than the online forum. The Rural mid-level participant created a Telegram sub-group forum to stay in touch with some members more often, such as for socialising face-to-face, sharing resources and school-related experiences or challenges, and giving information and support. Both Urban and Rural GEGs' online forums lacked engagement and provided a limited range of activities and resources. Therefore, face-to-face groups' events and activities were more dominant. Unlike the Metropolitan GEG's complementary use of WhatsApp, the use of Telegram in both Urban and Rural GEGs were more prevalent than their group's online forum to make up for the lack of online forum engagement. Thus, the Metropolitan GEG's use of 
WhatsApp complemented the group's online forum whereas both Urban and Rural GEGs' use of Telegram substituted the lack of the groups' online forum engagement.

Thus, differences in the groups' digital environment, online forum's networks, activities, and resources, and the use of mobile communication suggest that certain aspects of regional-technological environment can either support or limit opportunities for learning from online collaboration. A reliable digital environment with global online forum's networks, activities, and resources, and complementary use of mobile communication can support opportunities for learning from online collaboration. In contrast, a challenging digital environment with local online forum's networks, activities, and resources, and substitutive use of mobile communication can limit opportunities for learning from online collaboration.

\section{Leadership practice}

The second theme is leadership practice drawn from data relating to participants' leadership experiences. Two important aspects reflecting this practice are (1) "sharing the leadership" versus "delegating tasks" and altruism and volunteering through mentoring.

\section{"Leading by sharing the leadership" versus "leading by delegating tasks"}

The differences in the way the leader led and managed the groups were significantly shown within two styles of leadership practice: leading by sharing the leadership versus leading by delegating tasks. Leading by sharing the leadership was demonstrated by the Metropolitan leader whereas both Urban and Rural leaders led the group by delegating tasks. The Metropolitan leader led and managed the group with support from a small group of colleagues who were involved in the shared decisionmaking process whereas both Urban and Rural leaders recruited a colleague within the same school as a co-leader whom they delegated tasks to assist in leading and managing the group, primarily in organising the group's face-to-face activities. The Metropolitan leader's colleagues were interested and wanted to be part of his vision resulting in a collaborative effort of leading the group including discussing and making decision together, which aligned to his belief on the power of collaboration through shared leadership. Both Urban and Rural leaders, on the other hand, preferred co-leadership because it was more convenient to lead the group with someone whom they felt close to within their professional inner circle. It seemed that in a digitally-driven region, collaborative culture and practice is the driving factor for the Metropolitan's shared 
leadership practice whereas leading by delegating task is the common leadership culture and practice in a digitally diverse and constrained regions underpinning Urban and Rural leaders' style of leadership.

It was evident that leading by sharing the leadership enabled a stronger support system to maintain productivity in the group than leading by delegating tasks. For example, when the Metropolitan leader was not available or busy doing other responsibilities outside of the group, the lead-team were there taking turns to help and support him to keep the group's activities running in his absence. In contrast, when both Urban and Rural leaders were busy or unavailable to manage the group, they delegated tasks to assist them in managing the group. However, it became challenging to keep the group's activities running when these co-leaders were also unavailable in the absence of the leaders resulting in a stagnant period where no group's activities were conducted until the leaders were available again.

How leaders led by sharing leadership and delegating tasks was also reflected on how they managed the group's online forum, which seemed to influence the dynamics within the online forum. By sharing the leadership, the roles of administering and moderating online forum were managed interchangeably within the lead-team. Together with the lead-team, the Metropolitan leader collaboratively designed strategies for online forum intervention in order to trigger members' interest and curiosity to participate. This appeared to engender a collaborative atmosphere enabling online forum members to not only socialise and obtain information but also to collaborate through discussions and problem-solving activities. This suggests that by managing the forum together with the lead team enabled the group's online forum to be collaborative.

In contrast, although both Urban and Rural leaders delegated a task to their coleaders to help them monitoring the online forum, they mostly single-handedly managed the online forum. There were few interactions or activities requiring administration and moderation and so they, therefore, did not need to specifically allocate time for this. Both Urban and Rural leaders said that they only went in the forum when they felt it was required and that they mainly used the forums for information distribution rather than discussion and collaboration. Both Urban and Rural leaders' main online activities seemed to concentrate on providing, sharing, and distributing information about the 
group's face to face events and activities. This shows that the tendency of managing the forum single-handedly did not seem to enable online collaboration to occur.

Regardless the differences in the leaders' style of leading and managing the group, the influence of all three GEG leaders were significant. They all both led and manage the group with confidence, and they all shared their ed-tech vision and aspiration to others by helping, supporting, and facilitating other colleagues in the use of educational technology through web-based tools. Furthermore, their ed-tech vision and aspiration became an exemplary practice that participants wanted to follow:

"A potential teacher like him (referring to the leader) should be supported, and I support him in any way possible...I wanted my school to take part in the vision of the paperless school..." (the Urban mid-level participant).

With their commitment and dedication in leading the group, all leaders had become role models for all participants, and highly influential in the use of educational technology in the group.

All leaders' significant influence were also reflected by how they were considered inspirational and supportive by participants. Participants admired all leaders for their edtech vision as well as their commitment and dedication for the group, which encouraged further engagement within the group:

"I admire what he has done as the leader of the group, and I am inspired. I feel connected with what he experienced and what he has done with the group. I can feel the positive energy with things he shares, especially when you know that some teachers and educators also experience difficulties, limitation of resources, and challenges but still do not want to give up which I can relate to..." (the Metropolitan mid-level participant).

All leaders seemed to have the ability to make participants felt connected and motivated:

"...learning and sharing from him gives me more motivation to improve my own leadership skills" (the Metropolitan low-level participant).

Across cases, all participants reported that their leaders made them feel appreciated, acknowledged, and supported reflecting the leaders' dedication and commitment to each group:

"I am actually humbled but also proud when the leader told me in person to ask for my permission mentioning me as an exemplary leadership figure as a school principal for what I have been doing with my teachers at my school..." (the Urban mid-level participant). 
How participants admired, supported, and valued their leaders across the cases suggests that being a GEG leader does not only involve having ed-tech related capabilities but also requires the ability to inspire and motivate others.

\section{Altruism and volunteering through mentoring}

The aspects of altruism and volunteering were significantly shown in participant leadership practice across all case studies where participants engaged as ed-tech mentors to help, support, and facilitate other educators in using digital technologies particularly web-based tools, which seemed to be embedded various leadership roles. For example, all GEG leaders mentored their colleagues. The co-leader participants (Urban high-level participant and the Rural low-level participant) mentored other educators. Some participants also shared their mentoring experiences in guiding their colleagues preparing for GCE exams to expand their ed-tech leadership potentials. All participants voluntary mentored their colleagues and they usually did it after school hours or at their convenient time.

The voluntary nature of their mentoring activity revealed the altruistic aspect as a learning leader and a form of professional contribution:

I am also willing to allocate time, energy, and resources outside of school to give technical assistance, coaching, mentoring, or giving a workshop for noncommercial purposes to help to find a solution to others' ed-tech issues at school or classroom activities. I feel awesome with what I am doing now knowing that I can do something good by sharing motivation inspiration about innovative teaching practices with other educators" (The Metropolitan leader).

Participants believed that their experiences as mentors provided them with meaningful and valuable learning opportunities. For example, the Rural high-level participant was able to help other educators in helping other colleagues in learning to use Google tools for simple classroom practices, which he found both enlightening and fulfilling. He wanted other colleagues at his school to experience the benefits of using technology and be motivated to use it. Through mentoring, he was able to learn more about finding ways to address various technological issues, similar to that of the Urban high-level participant's mentoring experience:

"Being a co-leader enabled me to mentor others to use Google Classroom and Google tools. I learn more by being a mentor, especially about what others have felt and experienced when it comes to using web-based tools. The process of mentoring others has made me understand that implementing technology in the 
classroom is a challenging and complex endeavour" (The Urban high-level participant)

It appeared that not only did participants find mentoring very valuable, but it also reflected participants' confidence on their skills and practice with digital technologies. Such experiences made them feel happy, fulfilled, and satisfied knowing that they were able to help others to use web-based tools underpinning their altruism and volunteering activities as mentors.

\section{Group functions}

The third theme, group functions, relates to sharing, communicating, and learning in the group. Four main aspects were identified across the cases: sharing, online communication, learning, and ed-tech learning orientation.

\section{Sharing: online-public and offline-private}

Online public sharing relates to the group's tendency of publicly sharing in the online forum. Offline private sharing relates to how group members had a tendency of privately sharing outside of the online. Although this occurred in all cases, how it was reflected in the group's online forum was different.

The Metropolitan GEG leader and participants reported that they were enthusiastic about public sharing, which was supported by the contribution from other members in this group.

"Other than providing information, I like to encourage members to openly share their experiences and practices in the forum... I am glad that it works. When members start to express themselves and openly share their experiences, issues, problems, and reach out to others in the forum, it triggers other members to respond and help" (The Metropolitan leader).

It was evident that the leader, participants, and other members felt confident in publicly sharing what they think, have, and do in the online forum resulting in the diverse resources and variety of options for participation in the online forum. In contrast, both Urban and Rural groups' lack of online engagement could be driven by the prevalence of offlineprivate sharing outside the online forum resulting in the lack of dynamic of interaction compared to the Metropolitan's online forum. In both Urban and Rural groups, a majority of online forum members did not publicly share their ideas, experiences, and practices and they rarely used the forum to seek technical assistance or give ed-tech feedback. They also did not communicate and interact with each other frequently. This might be driven 
by the preference of both Urban and Rural members to interact and communicate through face-to-face interaction and Telegram, which they found more convenient and practical.

It seemed that the online-public and offline-private sharing can also be influenced by how collaborative nature of the online forum. The Metropolitan GEG's collaborative online forum showed that members were encouraged to contribute as they engaged with each other in discussions, helped solve ed-tech issues, and gave each other feedback, which seemed to create an active loop of engagement where the leaders and members being both active takers and givers online. In contrast, both Urban and Rural groups' leader-oriented online forums did not seem to encourage members to contribute through discussions or problem solving, which seemed to create a passive course of engagement with the leaders being the main contributors and members being the passive receiving end online.

\section{Online communication: multidirectional versus unidirectional interaction}

The comparison of the groups' online forums across the cases revealed two differing characteristics of online communication: multidirectional and unidirectional interaction. It is important to highlight the different nuance between multidirectional and unidirectional interaction. A multidirectional interaction involves multiple directions of interaction as shown in the Metropolitan GEG's online forum whereas unidirectional interaction emphasises on the one-sided direction of interaction as shown in both Urban and Rural GEGs' online forums.

The Metropolitan GEG's online forum was characterised by multidirectional interactions that were highly communicative, appreciative, and supportive. The online interaction comes from multiple directions where the leader and members' online activities contributed to the online forum. This interaction involved the leader and members' engagement through threads of professional learning conversations and discussions. In the forum, the leader and members' interactions involved communicating with each other; sharing information, experiences, and practices; discussing ideas, issues, and challenges; expressing appreciation, acknowledgement, and encouragement; asking and giving feedback; and engaging in the threaded discussions about collaborating on various projects. The attentiveness of the leader and members appeared to enable frequent expression of appreciation and acknowledgement creating an encouraging and empowering online environment that was valued by its members. Not only were the 
threads of conversation communicative but also interactive. For example, the leader and the lead-team posts were never ignored by members. There were always enthusiastic and attentive responses, be it with likes, comments, or questions, resulting in continuous threaded professional conversations. Although there were also brief social comments found, such as "thank you", "great", "well-done", and "awesome", there were always followed up by more substantial comments that were related to ed-tech practice. It appears that highly communicative, appreciative, and supportive multidirectional interactions encouraged online collaboration, which differentiated the Metropolitan's online forum from both the Urban and Rural GEGs' online forums.

Compared to the multidirectional interactions on the Metropolitan's online forum, both Urban and Rural GEGs' online forums were characterised by unidirectional interactions displaying one-sided direction of interaction where the leaders' prominent posting activities in distributing information about the group's face-to-face events were dominant. This form of unidirectional interaction was mainly related to the leader's distribution of information about the group's activities and did not generate continuous threaded discussions among members. The leaders' online activities of information distribution seemed to dominate the forum as very few members briefly responded but did not lead to creating continuous threaded discussions. The leaders' dominated online posting activities also occurred as most members rarely responded to them. In the forum, members rarely engaged in substantial discussions, asked for technical guidance, and gave feedback. The observation from online forum revealed that members did not communicate their ideas, express feelings, and share their ed-tech experiences and practices. The online interactions were predominantly brief social comments such as introductions, saying thank you, greetings, or asking about the date for the next group face-to-face activity. Compared to the rich display of attentive and communicative expression of feelings in the Metropolitan GEG's online forum, both Urban and Rural GEGs' online forum had very limited to no expression of appreciation, acknowledgement, and encouragement.

Regardless the multidirectional and unidirectional interactions online, all groups' forums enabled collegiality through how socialising occurred with no display or tension, quarrel, dispute, or negative criticism. This shows that the groups' online forum could be used as a platform for maintaining collegiality and potentially extending members' professional networks. 


\section{Learning: individual and collegial}

All groups had similar characteristics in relation to learning. All participants across cases seemed to experience both individual and collegial learning. In individual learning, all participants said that they were able to learn on their own terms. For example, they could freely join the face-to-face events and activities, engage in the group's online forum, or personally reach out to the leader or some members through mobile communication and face-to-face meetings:

"I have made a friendship with this one educator from school ' $X$ '. We have a similar philosophy in making the most of technology to make our work easier without destroying the environment. After we get to know each other for a few weeks, we find ourselves helping each other figuring out things and working together on a project on the students grading system. If this works, we would like to implement it at own schools" (the Urban high-level participant).

They individually downloaded ed-tech resources from the online forum and used them to practice at home or at school. They also personalised access to web-based resources in a way that was beneficial to them, such as reading from website links that were shared in the online forums, reading others' blogs or watching others' vlogs, curating web-based resources, saving them into personal hard drives, and printing them when needed. Furthermore, they were able to individually ask for help and guidance, as well as being the person whom other members could ask for help and assistance. For example, they used WhatsApp or Telegram to consult the leaders or ask questions to other members personally. All participants said that their individual learning experiences were tailored to their own needs and context, indicating the value of the group as a form of personalised learning support.

All participants' collegial learning experiences reflected the need for social connection, which was found to be significant in conjunction with their individual learning experiences. This was an indicative that participants' individual learning experiences also mirrored their social-connectedness. For example, they valued others' experience, practice, and expertise as they found a connection, such as similar challenges and issues, similar professional background, similar ongoing school projects, and similar mutual friends and colleagues. All participants reported that they valued communication and had formed new friendships or collegial relationships with each other. Typical comments reflecting collegial learning experiences were "I understand what they are going through"; "They know what I mean"; "They know it is not easy but also not 
impossible"; and "It never occurred me to do it like what they did". These phrases seemed to be related to some participants' experiences of being inspired, empowered, encouraged, and supported by the leaders or other group members. It seems that this social connectedness strengthened participants' collegiality through formed new friendships, which enabled them to create meaningful learning experiences through do-it-together activities, such as meeting with each other outside of work to socialise, doing hobbies together, helping each other, or collaborating on projects.

Participants' collegial learning through both global and local networks of interpersonal connections was significantly reflected in all cases. Through these networks within the GEGs, all participants appeared to personalise the way they connect with their colleagues to share experiences with some other members in the group that they perceived to be inspiring, knowledgeable, and insightful in their ed-tech knowledge, experiences, and practices through face-to-face interactions, mobile communications and online forums. For example, a sub-group was created as they found stronger connections with few colleagues. They also seemed to develop a personalised network of colleagues whom they referred to in time of needs or whose ed-tech practices were followed as personal references. Some participants even visited each other's schools and invited each other for a study group, attended informal training sessions at schools, or arranged casual meetups. Therefore, it was evident across cases that when participants had strong social connectedness in the group, they were more invested and engaged with the group extending and strengthening their professional networks through personal networks, friendships, or collegial relationships.

\section{Ed-tech learning orientation: collaborative and leader-driven}

The GEGs had differing ed-tech learning orientation pertaining to the use of webbased tools. In the Metropolitan GEG located in a digitally-driven region and with a collaborative online forum, had a conducive learning environment for supporting the innovative use of web-based tools. All Metropolitan participants were leaders at their schools where digital-driven classroom practices using various web-based tools were common, such as Google slides, slides, forms, docs, drive, Google expedition, Google street view, Google tool builder, Google Suites/Classroom, Flipgrid, Kahoot, ClassDojo, Story bird, Canva, Write to Learn, YouTube, Apple-apps, and Android apps. The group's online forum reflected complex and advanced ed-tech experience, practice, and expertise from both local and international members supporting global collaboration, which 
enabling participants to engage in the innovative use of web-based tools to improve productivity of ed-tech practices.

In contrast, the challenges in the Urban GEG's digitally-diverse environment had driven the leader to promote his vision of a paperless school, which was supported by all Urban participants. This seemed to engender a group learning orientation. Both groups' online forum resources were leader-oriented with no display of alternative or different interests or orientations from members. With the leader's vision as the driver of the group's learning orientation, all Urban participants engaged in learning to optimise the use of web-based tools to improve efficiency through paperless classroom practices and school administration:

"I do admire the leader's innovative vision about paperless school and I wanted to support it..." (the Urban high-level participant).

Similarly, the Rural GEG's group learning orientation was also underpinned by the leader's vision of how to use web-based tools with limited technological resource and support, particularly in using web-based tools with low bandwidth and limited ICT infrastructure for simple teaching and learning practices. Therefore, it appears that the Metropolitan GEG's ed-tech learning orientation was driven by the group's collaborative nature, involving the leader and members' activities and contribution in the group. In contrast, both Urban and Rural leaders' ed-tech visions significantly influenced the groups' ed-tech learning orientations within which members seemed to follow and support. This suggests a significant difference between the group's ed-tech learning orientation as the collaborative outcome and the leader's effort.

\section{Summary}

Different regional-technological environment appeared to engender different digital environment, online forum's networks, activities, and resources, and the use of mobile communication. Although all groups used online forums for learning resources, not all forums supported learning from online collaboration. All groups' online forums provided supportive atmosphere but were different in the way it was used to express communication and appreciation. The online forum could be informative and social but was not necessarily collaborative and educational. These differences suggest that certain aspects of regional-technological environment can either support or limit opportunities for learning from online collaboration. Two styles of the leaders' leadership practice 
emerged from the data: leading by sharing the leadership versus leading by delegating tasks. Leading by sharing the leadership enabled a stronger support system to maintain productivity and encouraging online collaboration in the group than leading by delegating tasks. Regardless the differences in the leaders' style of leading and managing the group, not only had all leaders become role models who were considered inspirational and supportive, but they were also highly influential in the use of educational technology in the groups. This suggests that being a GEG leader does not only involve having ed-tech related capabilities but also requires the ability to inspire and motivate others. Altruism and volunteering were significantly shown in participant leadership practice across all case studies where participants engaged as ed-tech mentors to help, support, and facilitate other educators in using digital technologies particularly web-based tools. It appeared that not only did participants find mentoring very valuable, but it also reflected participants' confidence on their skills and practice with digital technologies. The groups functioned differently through sharing, online communication, learning, and ed-tech learning orientation. Online public sharing seemed to create an active loop of engagement whereas offline-private sharing outside of the online forum can create a passive course of engagement. A highly communicative, appreciative, and supportive multidirectional interaction seemed to encourage online collaboration than a unidirectional interaction. All participants experienced both individual and collegial learning. The individual learning experiences were tailored to their own needs and context indicating the value of the group as a form of personalised learning support and mirroring their social-connectedness that seemed to strengthen participants' collegiality by forming new friendships to create meaningful learning experiences. Each group had differing ed-tech learning orientation pertaining to the use of web-based tools. The group ed-tech learning orientation in the Metropolitan GEG reflected a collaborative outcome of the innovative use of web-based tools. The Urban leader's vision of a paperless school seemed to engender a group learning orientation in optimising the use of web-based tools to improve efficiency through paperless classroom practices and school administration. This is similar to the way in which Rural leader's vision influenced the group learning orientation in using web-based tools with low bandwidth and limited ICT infrastructure for simple teaching and learning practices indicating the leader's effort in both groups rather than collaborative outcome. 


\section{Chapter 8}

\section{Discussion}

\section{Introduction}

This chapter is divided into four main sections. The first section discusses the significance of the findings to answering two research questions. It then continues to the next sections focusing on the discussion of the three important aspects in the findings. The second section discusses how participants' enactment of agency is influenced by the regional-technological environment. The third section discusses how the regionaltechnological environment influence the groups' learning behaviour. The fourth section discusses how participants' enactment of agency and the groups' learning behaviour are interdependent. A summary is then provided to end this chapter.

\section{The significance of the findings to answering the research questions}

This first section presents the significance of the interpretation of findings to answering two research questions highlighting on (1) how do Indonesian educators participate in the GEGs for ed-tech professional learning? and (2) how do the GEGs function to enable Indonesian educators' ed-tech professional learning?

\section{How do Indonesian educators participate in the GEGs for ed-tech professional learning?}

Indonesian educators participated as agents of their own learning who enacted their agency in both individual and collegial learning. Participants' enactment of agency in individual learning was reflected through their capabilities in tailoring ways of learning to specifically fit their needs and context, whether it was through face-to face interaction, online forum, mobile communication, or all of the above. For example, they personalised how they wanted to learn, when they wanted to learn, what kind of web-based tools they wanted to use, and with whom they wanted to learn. Not only did participants personalise their networks comprising connections to people, but they also had accesses to digital tools and resources that were beneficial for them. As individual learners, they were selfmotivated to seek opportunities and resources for learning in a way that was personally relevant, meaningful, and empowering, such as learning by sharing ed-tech practices; 
learning by engaging in leadership practices; and learning by creating educational content with digital technologies. Driven by this self-motivation for learning, not only did participants learn on their own but they also learned by helping and supporting others, which indicates the importance of social connection in the process of learning.

Participants' collegial learning in the groups indicates that social-connectedness was influential to their learning process. With social-connectedness, individual experiences were valued and could be considered as authentic learning resources. Being socially-connected through friendships or other forms of collegiality in the groups enables participants to feel supported and empowered. It appears that when participants engaged in collegial learning, they reflected on similar practices, experiences, challenges, and issues that professionally connected them with each other and enabled them to model others' behaviour in the use of educational technology.

Participants' collegial learning took various forms, such as engaging in meaningful conversations, mentoring, and collaborating online. The social connections that were developed and maintained through collegial learning seemed to be a positive influence on participants' learning. Participants felt that their knowledge improved by learning from others' knowledge, experiences, expertise, and practices. They also mentioned the positive influence on their learning disposition as they felt more optimistic, positive, motivated, and empowered in solving problems with digital tools and overcoming ed-tech professional challenges.

All participants in the Metropolitan GEG exercised local leadership as a way to address a need growing out of their exercise of local technology leadership as they expressed needs to "give back" to their local community of educators in the way they could. As a result, all participants considered the GEGs as valuable resources where they could "give back" to their community of educators as they also learn and teach other educators in using technology for teaching and learning, particularly the educational use of web-based tools. For example, participants who were also leaders at their schools considered their participation in the GEGs strengthened their local leadership through being mentors, trainers, or collaborators. In the same manner, they also said that being mentors, trainers, or collaborators provided ways of learning that were more meaningful as they learn from other educators. the altruistic motivation and voluntary nature of their leadership practices and its impact on them and others reflected social-connectedness. 
This suggests that participants did not only learn individually but they also learned by socially-connecting to others, which shows the altruistic motivation and voluntary nature of their leadership practices.

\section{How do the GEGs function to enable Indonesian educators' ed-tech professional learning?}

The GEGs have two different functions which are influenced by two digital learning environments and three ed-tech learning orientations. The functions are, as a globally collaborative ed-tech professional learning support and as a locally leader-driven ed-tech professional learning support. A reliable digital environment reflects the group's digitally-driven regional-technological environment where global online forum's networks, activities, resources, and complementary use of mobile communication provide diverse blended learning opportunities including learning from both face-to-face interaction and online collaboration. In the Metropolitan GEGs, participants did not seem to have any issues related to Internet connectivity, which provide a conducive environment to share a wide range of digital resources and learn from diverse range of ed-tech practices and experiences with web-based tools on the online forum. Local and international members could collaboratively engage online through communication, information-sharing, discussions, and problem solving in a highly communicative, appreciative, and supportive atmosphere, which indicates the reliability and convenience of the online forum as a platform for group interaction and communication. The reliable digital environment also supported the group to have blended learning activities where the face-to-face and online interaction were interconnected in a way that encouraged collaboration. As a result, Metropolitan participants were able to explore diverse opportunities and resources for ed-tech learning through blended learning activities and international networks where they can globally expand social connections. Such an environment contributed to how the Metropolitan GEG functioned as a globally collaborative ed-tech professional learning support where participants engaged in learning to use web-based tools innovatively to improve productivity of ed-tech practices.

In contrast, a challenging digital environment reflected digital diversity and constrained regional-technological environments where local online forum networks, activities, resources, and substitutive use of mobile communication provide face-to-face driven learning opportunities but did not support learning from online collaboration. In both Urban and Rural GEGs, participants shared concerns and experiences related to the 
lack of Internet connectivity and low-quality of Internet connection, which influenced the use of the group's online forum. Several issues related to the limitations of the group's online forum for learning were found in both groups. For example, the Urban leader said that most members preferred face-to-face activities or communicating through mobile instant messaging applications due to the limited bandwidth and unstable Internet connection in most areas in the region. The Rural leader also informed that the unstable Internet access or the lack of Internet connectivity in more remote Rural areas seemed to discourage members from connecting to the group's online forum. The unstable Internet connection and low-quality of bandwidth that did not seem conducive to support sharing diverse media files, such as video or virtual learning activities such as Google Hangout or Skype video call, were also expressed by participants in Urban and Rural GEGs. As a result, these issues and challenges limited the opportunities and resources for ed-tech learning as the groups primarily rely on face-to-face driven learning activities and local networks where they mainly expand their social connections locally.

The challenging environment contributed to how Urban GEG functioned as a locally leader-driven ed-tech professional learning support driven by the leader's efforts in providing participants with opportunities and resources to learn the optimisation of web-based tools to improve efficiency through paperless classroom practices and school administration. Similarly, the Rural GEG's challenging digital environment contributes to how the group functioned as a locally leader-driven ed-tech professional learning support driven by the leader's efforts in providing opportunities and resources to learn using web-based tools with low bandwidth and limited ICT infrastructure for simple teaching and learning practices. This indicates that within a challenging digital environment, the opportunities and resources for ed-tech learning can be more limited as it did not support a wide range of activities to be conducted and a diverse range of digital resources to be shared due to the lack of Internet access and low-quality of Internet connection. 


\section{Three important aspects in Indonesian educators' ed-tech professional learning in the GEGs}

There are three important aspects in Indonesian educators' ed-tech professional learning in the GEGs. These aspects are: (1) the influence of the regional-technological environment to participants' enactment of agency; (2) the influence of the regionaltechnological environment to the group learning behaviour; and (3) the interdependence of participants' enactment of agency and group learning behaviour.

\section{The influence of regional-technological environment on participants' enactment of agency}

The group's regional-technological environment influenced participants' enactment of agency within two aspects: agentive spaces and refrained agency. Different regional-technological environment could either minimise or optimises agentive spaces where participants could refrain their agency due to minimised agentive spaces within the environment.

\section{Agentive space}

Agentive space is the environment, be it a place or location, where agency can be enacted upon (Bergman et al., 2019), which resonates to Bandura's (1999) environmental structures that influence the enactment of agency. Findings from the significant influences of the regional-technological environment in the Metro GEG, Urban GEG, and Rural GEG reflect three types of Bandura's (1999) environmental structures in social-cognitive theory: the selected, constructed, and imposed environment. The selected environment is reflected in the Metro GEG's digitally driven environment, the constructed environment is described by the Urban GEG's digitally diverse, and the imposed environment is reflected on the Rural's digitally constrained environment. The Metropolitan's reliable digital environment enabled participants to explore diverse opportunities and resources for ed-tech learning through blended learning activities and international networks where they could globally expand social connections. Compared to the Metropolitan GEG, both Urban and Rural's challenging digital environments limited the opportunities and resources for ed-tech learning as the groups primarily relied on face-to-face driven learning activities and local networks where they were socially connected within local areas. Thus, the characteristics of a reliable digital environment are similar to a selected environment. In contrast, the characteristics of a challenging digital environment are 
similar to both constructed and imposed environments. An imposed environment limits people's sense of control where they had the greatest limitation to enact agency, whereas the constructed environment presents considerable challenges to enact agency, and the selected environment enables the greatest opportunities to enact agency (Bandura, 1999).

A recent social-cognitive study on Metrorail commuters in the Western Cape, South Africa found that the selected, constructed, and imposed environmental structures influence commuters' agency, motivations and past experiences (Bergman et al., 2019). In their study, the selected environment enabled the broadest agentive space for commuters as individual, proxy, and collective agency, thus having considerable pathways to be interdependent and to achieve maximum mobility. Slightly different, the constructed environment with less desirable conditions and fewer pathways required a concerted effort from commuters to achieve more optimum mobility. In a different manner, the imposed environment created the greatest limitations leading to the least pathways to achieve desirable mobility. Findings from the influence of regionaltechnological environment on participants' agentive spaces in the GEGs show a similar influence with the Metrorail study's selected-constructed-imposed environment (Bergman et al., 2019), where the Metropolitan participants had the broadest agentive spaces compared to Urban and Rural GEGs. This suggests that both constructed and imposed environments can narrow down the space to exercise agency whereas the selected environment can broaden such space as the challenges are minimum, and resources are easily available.

Findings from the influence of the regional-technological environment on participants' agentive spaces corroborate previous studies in the Indonesian context (Sari, 2012; Tanang \& Abu, 2014) highlighting on how the lack of technological infrastructure can limit learners' agentive space in exploration of learning opportunities and resources. It is clearly shown in the Metropolitan GEG that when the digital environment is reliable, participants seemed to have more limitations in exploring learning opportunities and resources, such as using certain web-based tools that required good Internet access and ICT tools, which broaden their agentive spaces. In contrast, the stagnant/reduced group learning activities and lack of online forum engagement in both Urban and Rural GEGs seem to limit participants in exploring opportunities and resources for learning within the group resulting in fewer options to interact, participate, and learn within the group, narrowing down their agentive spaces. 
Different regional-technological environment in the GEGs suggests the inequality of support to educators' professional learning in Indonesia still persists. Many educators were still suffering from a lack of access to the advances of ICT in non-urban areas in Indonesia where they could not be expected to have, or even be exposed to, the same educational resources and opportunities for professional learning than those attained in central city locations (Kusmawan, 2015). Until recently, the Internet and ICT infrastructure are still considered to be a challenging issue for educators' professional learning and development about technology within the Indonesian context, which is perceived as a barrier to innovation (e.g. Cahyono \& Mutiaraningrum, 2015; Relmasira, et al., 2017; Son et al., 2011). Better Internet and ICT infrastructural support are imperative to support educators' professional learning in Indonesia (Tanang \& Abu, 2014). This suggests that in Indonesia, the regional-technological environment has an important role in supporting educators' ed-tech professional learning practices.

\section{Refrained agency}

A challenging digital environment in both Urban and Rural GEGs minimised participants' agentive spaces in ed-tech learning and thus, resulting in their refrained agency in the groups' online forum, which did not occur in the Metropolitan GEG. Both Urban and Rural leaders did not seem to engage in their online forums as the Metropolitan leader did, which reflected their refrained agency:

"I did not always spend much time in the group's online forum and most members informed me that they preferred face-to-face activities or communicated through mobile instant messaging applications" (the Urban GEG leader).

Although the Rural leader shared a few educational technology articles, it was mainly for information distribution rather than threads of discussions. He believed that few responses from members was an indicative of the lack of online engagement where members preferred communicating with him or with others outside of the online forum. With the online forum lacking engagement, it created an online environment where substantial activities or interaction did not seem to occur. Consequently, members refrained their agency to participate and contribute online resulting on the passive use of online forum:

"I did not feel the need to engage with other members on that forum because I felt that obtaining the information about the group along with its activities directly from the leader was enough for me" (the Urban mid-level participant). 
Due to this refrained agency in the online forum in both Urban and Rural GEGs, both leaders became the major online forum contributors where face-to-face interaction and mobile communication became dominant modes for learning activities and communication.

"Although a few times I comment on the leader's post in the forum, I don't think that it is necessary to share my struggles with technology at school in the forum. It's more convenient to connect directly to the leader or some of my colleagues in the group face to face or through Telegram" (the Rural high-level participant).

Findings from Urban and Rural participants' refrained agency in the online forum seems to align with previous studies suggesting that barriers to online participation were related to the online content and how people interacted online (Brandtzæg \& Heim, 2008; Maloney-Krichmar \& Preece, 2005). This suggests that challenging digital environment can impede learning due to minimised agentive spaces and refrained agency.

Findings from the how the Metropolitan GEG's digitally-driven environment broadened participants' agentive spaces in ed-tech learning were consistent with previous studies on how technology-enabled environment supported educators' practices in integrating ed-tech in their teaching activities in diverse contexts (Hermans et al., 2008; Stošić \& Stošić, 2013). In contrast, findings from the refrained agency in the Urban and Rural GEGs align with previous studies on how technology-limited environment and digital divide presented challenges that did not only constrain educator's teaching and learning practice (Guemide \& Benachaiba, 2012) but also their dispositions in using ICT (Wright, 2015). This suggests that broadened agentive spaces enabled more opportunities for ed-tech learning.

\section{The influence of regional-technological environment on the group learning behaviour}

The regional-technological environment influenced how the group functions, which reflected the group learning behaviour through the nature of the interaction, communication, sharing, and activities in the group. The different nature of the GEGs leads to two different types of group behaviours: collaborative and leader-driven group and globally and locally-networked group interaction. 


\section{Collaborative and leader-driven group behaviours}

Findings from the Metropolitan GEG show that a reliable digital environment enabled the group to function collaboratively through online collaboration, blended learning activities, online-public sharing, and multidirectional online communication. Collaborative learning behaviour, such as engaging in online discussions, may determine the success for a collaboration and the diversity of the group's online resources. Members who were highly involved cognitively in online discussions significantly contribute to the collaborative culture of the group (Wang \& Lin, 2007). Grabher and Ibert (2013) provide insights to help explain knowledge production through meaningful online contribution. They argued that for knowledge production to occur in the online environment, variation of ideas may be more evident than the cumulative advancement of ideas and validation of knowledge. This aligns with Metropolitan GEG's collaborative knowledge production online. Not only was the online forum used for distributing information, but it was also used for interactions which stimulated collaboration through the exchange of ideas, feedback, and sharing of ed-tech practices. The Metropolitan GEG's collaborative learning behaviour enabled diverse learning opportunities with a high level of flexibility for participation and engagement.

The Metropolitan group's members' cognitive involvement was reflected in the collaborative learning behaviour which significantly contributed to the creation of diverse opportunities for learning in the group. In contrast, both Urban and Rural leaders primarily provided unidirectional online interaction did not seem to engage members' cognitive involvement. Although Urban and Rural participants were supportive of their leaders' vision and leadership, they were less active in their online participation. What seemed to be significant in both Urban and Rural GEGs were the leaders' efforts to provide resources and facilitate learning for their members. Thus, stimulating a collaborative culture in a group with digitally-diverse and constrained region can be more challenging than in a digitally-driven region.

What seemed to differentiate Metropolitan, Urban, and Rural GEGs' online learning behaviour was how trust and confidence were reflected in their online environments. The Metropolitan group's tendency for online-public sharing and multidirectional online communication indicated the presence of trust and confidence in an online environment, which were not reflected in the Urban and Rural GEGs' online forums. A lack of trust in online sharing may inhibit online communication (Kling \& 
Courtright, 2003), and free-riding (McLure Wasko \& Faraj, 2000), which could lead to members being hesitant in sharing their knowledge in a way that it can impede learning in an online environment (Kling \& Courtright, 2003; Ridings, Gefen, \& Arinze, 2002). Confidence is also shown to affect an individual's engagement in respect of both giving and receiving knowledge online (Tseng \& Kuo, 2014), which may be related to what is referred to as web-specific self-efficacy (Chen et al., 2009). These studies suggest that the process of knowledge-sharing in an online environment involves the elements of trust and confidence in online sharing.

Findings from both Urban and Rural GEGs' online forums indicated the lack of trust and confidence of sharing in an online environment as both groups' online forums demonstrated lack of engagement. This might be driven by the tendency of offline-private sharing outside of the online forum, unidirectional online communication, and the leaders' dominated online activities in distributing information. The majority of participants also said that they did not seem to feel comfortable and convenient sharing things publicly online. However, both groups' tendency of offline-private sharing also implies that a higher level of risk-taking occurs outside the public online forum, within the groups' face-to-face interactions and private mobile communication. A study confirmed that educators were likely to share and express emotions and ask others for help when they felt comfortable and confident (Hur \& Brush, 2009) and therefore, the collaborative learning behaviour in the GEG's public online forum can be driven by participants' trust and confidence in online sharing.

Regardless of the differences in the regional-technological environment, mobile communication was common across the three cases to strengthen both personal and group engagement enabling meaningful learning experiences. This reveals the potential of mobile communication, particularly WhatsApp, among Indonesian educators to support educators' professional learning as they were more familiar to use it and consider it to be more accessible through mobile network than wi-fi network. In the Indonesian context, mobile technology and social media are popular communication platforms among teachers and teacher educators, which can offer potential affordances for professional learning (Sari, 2012). The vast majority of Internet users in Indonesia (85\%) conduct online activities using their mobile phones ("In Indonesia", 2015) and mobile phones are more preferable for teacher training in Indonesia because the price for devices and services were affordable and the coverage area of the mobile network was broad (Yusri 
et al., 2018). The affordability of using mobile technology allows "access to Internet resources, run experiments in the field, capture, store and manage everyday events as images and sounds and communicate and share the material with colleagues and experts around the world" (Sharples, 2002, p.222). In addition, mobile communication is used as a practical and flexible information-sharing mechanism (Hase, 2009; Narayan \& Herrington, 2014). Therefore, mobile communication is accessible in Indonesia and increasingly acknowledged as a flexible, affordable, and popular communication tool that can support learning. However, findings from how the GEGs used mobile communication as either complementary or substitutive to the online forum adds insights to the affordances of mobile communication in conjunction to the educators' learning engagement in the online forum.

\section{Globally and locally-networked group interaction}

Different types of digital environment in the GEGs can lead to different kinds of group interaction. Findings from the Metropolitan GEG's digitally-driven environment displayed prominent use of English within the group's interaction and communication whereas both Urban and Rural groups' interaction and communication were predominantly Bahasa-driven. The predominant use of English and global range of participation in the Metropolitan GEG enabled interactions that was globally-networked compared to the locally-networked interactions in Urban and Rural GEGs. Through global collaboration, new technologies and cultural shifts can drive educators to create change and innovation as global connections and networks provides diverse opportunities for educators to deepen their understanding towards the complexity of learning across different cultures (Nussbaum-Beach \& Hall, 2011). This is reflected in the way the Metropolitan group's online forum was cultivated for global collaboration.

In the Metropolitan GEG's digitally-driven environment, the use of English for interaction and communication contributed to the global collaboration in the group enabling global access to diverse ed-tech learning opportunities. In the Metropolitan GEG's, both local and international members across different cultures such as Malaysia, Japan, Singapore, Indonesia, could connect, communicate, and collaborate through various group learning events. In contrast, both Urban and Rural groups' Bahasa-driven challenging digital environment did not seem to stimulate global collaborations, which contributed to how ed-tech learning opportunities was limited within the local context. This was likely to promote intercultural interaction within the group as members came 
from different cultural professional background and ed-tech environment, which seemed to present a wider-range of ed-tech learning opportunities to improve understanding towards the implementation of ed-tech practices across different cultural context. This is consistent with how intercultural perspectives of individuals promotes deep cross-cultural knowledge and enhances learning capacity (Trust et al., 2016), which reflects how different range of interactions within the groups' network can be beneficial to enrich participants' learning experiences in the GEGs.

Looking at the influence of the regional-technological environment in the GEGs, it is clearly shown, although quite predictable, that the Internet infrastructure plays a significant role in participants' personal learning network as a critical enabler in:

- Providing access to ed-tech resources,

- Supporting opportunities for web-based exploration (for personal and group learning as well as classroom practices), and

- Supporting participants to expand their personal learning network globally and engage in the global communication, collaboration, and professional learning opportunities.

\section{The interdependence of participants' enactment of agency and group learning behaviour}

Participants' enactment of agency and the group learning behaviour are interdependent in the way they generate ed-tech resources in the group. This interdependence is reflected on three aspects that significantly contribute to how the groups function as ed-tech professional learning support: (1) participants as agentic and experiential learners, (2) the social-connectedness in learning, (3) the influence of participants' agency and social connectedness on the group's capacity to support learning

\section{Participants as agentic and experiential learners, but not all reflect on their leadership practice.}

All participants in the GEGs demonstrated the characteristics of agentic and experiential learners, but not all of them reflected on the leadership practice. This suggests that being an agentic and experiential learner does not necessarily make a way for leadership practice as it may depend on the dynamics between the learner and the learning environment, which each participant might have different experiences. From social 
cognitive perspective, being an agentic learner indicates an individual who exercises his/her personal agency (Bandura, 2001). Personal agency is a form of emergent interactive agency where learners become the sentient agents of experiences with the capability of forethought, self-reactiveness, and self-reflectiveness - hence, experiential learners (Bandura, 1999). The forethought capability involves an outcome expectation where learners "motivate themselves and guide their actions anticipatorily providing direction, coherence, and meaning to one's life" (Bandura, 1999, p.35). The selfreactiveness involves the selective capability to "pursue courses of action that give them self-satisfaction and a sense of self-worth" (Bandura, 1999, p.37). Self-reflectiveness is considered the highest level of thought-processing where learners "evaluate their motivation, values, and the meaning of their life pursuits" (Bandura, 2001, p.10). To this end, the enactment of agency is driven by learners' beliefs in their capability to have control over their own functioning and navigate over environmental events, which is referred to as personal agency (Bandura, 1997). Thus, the cognitive process of exercising personal agency does not only involve agency itself but also motivation and experience. All participants' activities in the group reflected their personal agency, motivation, and experiences when they learn as individuals, such as developing personal learning network, participating on the group's online forum, observing others on the group's online forum, asking for help and giving advice when necessary, or sharing experiences both face to face and online. However, the reflection of such learning experiences does not always involve leadership practices as findings indicate that although all participants revealed the characteristics of agentic and experiential learners, not all participants reflected on their leadership practices.

Researchers have explored ways to explain what is happening in the individual's cognitive process. Individuals as agents adjust and regulate their actions through cognitive process involving the activation of sensory stimulation (Sperry, 1993). The sensory, motor and cerebral systems are cognitive tools to accomplish the tasks and goals that give meaning of life and direction to the course of actions (Harré \& Gillett, 1994). Bandura (1999) further explains the cognitive process of agency, motivation, and experiences:

"It is not just exposure to stimulation, but agentic action in exploring, manipulating, and influencing the environment that counts. By regulating their own motivation and the activities they pursue, people produce the experiences that 
form the neurobiological substrate of symbolic, social, psychomotor, and other skills" (p.4).

This shows the role of motivation in the way people pursue activities that they considered relevant, significant, and meaningful. To this end, participants' learning experiences on how they individually undertook different roles and activities in the GEGs are indicative of their individual exercise of agency. Findings from these learning experiences show that they were likely driven by a motivation to learn, particularly in deciding how they wanted to learn, when they wanted to learn, and with whom they wanted to learn. For example, some participants noted that they actively engaged in the online forum while some others said that they prefer to passively observe the online forum and actively attend face-toface activities. This suggests that different cognitive processes contributes to different types of group engagement.

How some participants purposefully enacted their agency for ed-tech professional learning in the GEGs supports previous studies on professional learning agency. Educators act purposefully and constructively in driving their professional growth and contribute to the growth of their colleagues by actively responding to learning opportunities and making learning choices to achieve their goals (Calvert, 2016). Agency focuses more on the actual potential of teachers in developing the capacity to act within the limitations of their profession (Erss, 2018), which reflects how some participants in the GEGs enacted their agency to develop their professionalism in ed-tech practices, creating positive changes within their region, and striving for better ed-tech learning opportunities in the GEGs.

Some participants reflected on how they explored learning in the groups as agentic and experiential learners in the form of leadership practices through mentoring, which they considered an empowering experience. Learning leaders within a community empower other educators and enhance the learning experience of others in a complex and challenging environment (Halsall, Powell, \& Snowden, 2016), which aligns with the sense of empowerment that some participants felt through their leadership practices in the GEGs. A sense of empowerment is often associated with professional activism (Sachs, 2000), which can be used to characterise some of the participants' empowering learning experience in the form of leadership practices in the groups. In the GEGs, some participants reflected their empowering learning experience in the form of leadership activities as mentors for other colleagues from different schools. This aligns with previous 
study on how teacher can extend their leadership practices beyond a concern for their own school and students (Boylan, 2018).

The sense of empowerment that some participants felt from their leadership experiences within the GEGs were evident through their perceptions towards their own personal experiences in incorporating technology in their professional practices and the connections and towards others' experiences including reflecting on various ed-tech challenges. This seemed to influence the altruistic and voluntary nature of their mentoring activities where they did not only inspire others but were also inspired by others. This suggests leadership practice as a form of reflective practice that involves valuing experiences as essential learning resources, which is likely in alignment with the notion of "we share who we are, we learn what we do" (Blaschke et al., 2014, p.112). Through reflection, learners constantly cultivate and reflect on their meaningful learning experiences on their own and in conjunction with colleagues (Hase \& Kenyon, 2001). Moreover, meaningful learning experiences enable learners to extend their influence, improve their learning, or deepen their understandings towards their own learning journey, which others may find beneficial when shared (Blaschke et al., 2014). As learners reflect on the influence of others, new pathways of acquiring information and learning are developed by connecting and creating dialogues, collaborating, and constructing knowledge with others (Conole, 2013; McLoughlin \& Lee, 2010). This also aligns with Bandura's (1989) process of reflection where "learners do not only gain understanding (but also) evaluate and alter their own thinking by this means" (p.58). In the process of reflection, learners internally examine and explore an issue of concern, triggered by an experience, which creates and clarifies meaning in terms of self, and which results in a changed conceptual perspective" (Boyd \& Fales, 1983, p.100). These studies are likely to support findings in my study that suggests the role of valued experiences as an essential element in the meaningful learning process through some participants' reflection of their leadership practices in the GEGs.

\section{The social connectedness in learning}

An interesting aspect related to participants' meaningful learning experiences as agentic and experiential learners is how such experiences also reflect the need for socialconnectedness. The GEGs allowed participants to have personal access to curate resources, making contacts, and developing friendships with the leader or other members in the group. This reflects the affordances of personal learning network to enable access 
to others' thoughts, ideas, and perspectives as well as tools and digital resources (Eun, 2018). Findings showed that participants considered the GEGs as part of their personal learning networks. For example, the GEGs' online forums provided them with information about the group's activities and other members' practices and experiences. It also provided them with access to links for downloading web-based resources and for making contacts with others, such as email addresses, social media links, and WhatsApp numbers. By extending further interaction and communication through their personal learning networks in the GEGs, they could develop friendship or similar form of collegial relationships. The social-connectedness seemed to drive the development of friendships and collegial relationships in the GEGs. This was shown by how participants reported feeling appreciated and acknowledged as well as inspired, motivated, and empowered by others, which was considered valuable form of support and resources for learning. This is consistent with how personal learning network can be used for knowledge sharing, idea exchange, informal learning and collaboration" (Trust, 2012, p.133). Participants in the GEGs did not only demonstrate characteristics as agentic and experiential learners but also have significant needs for social connectedness, which influenced how they learned as both as individuals and as a group.

Participants' collegial learning reflected the significance of social-connectedness in their process of learning. The capability to develop connectedness with others through social interaction in learning is a form of social cognition where individuals become a proxy agent (Bandura, 1999). Proxy agency is exercised on the spectrum between individuals when they influence each other and act on behalf of one another (Bandura, 2001). A proxy agent is a socially-mediated mode of agency where an individual "wield influence and power to act at their behest to secure the outcomes they desire through mediated efforts of others" (Bandura, 2001, p.13). This means that certain individuals can influence others by becoming the provider or enabler of access, resources, and expertise for others. The way individuals influence other individuals as proxy agents through social connections occurs within individuals' personal learning networks in the GEGs. For example, following other educators' references or recommendations of web-based tools or taking member's advice on solving ed-tech issues. However, Bandura (1999) cautioned that reliance on a proxy actually reduces mastery experiences, leading to an inability to self-regulate one's behaviour. This suggests that when an individual relies too much on others, it can be disempowering. This resonates to Nussbaum-Beach and Hall (2011) 
concern that following a lot of people online is not necessarily useful unless it is for learning purposes, which suggests that having a personal learning network is a good investment when the social-connections are cultivated for meaningful learning.

Participants reflection on the need for social-connectedness in the GEGs suggests its potential to develop their self-efficacy as they likely felt supported by experiencesharing with others and felt motivated or inspired by how others learned in the groups. Reflection is fundamental to the concept of perceived self-efficacy (Artzt, ArmourThomas, Curcio, \& Gurl, 2015), which functions as an incentive to persevere in the midst of a challenging condition because "unless people believe that they can produce desired results by their actions, they have little incentive to act or to persevere in the face of difficulties" (Bandura, 1999, p.46). People of high perceived efficacy show greater cognitive resourcefulness, strategic flexibility, and effectiveness in managing their environment (Wood \& Bandura, 1989) as well as focus on the opportunities worth pursuing rather than dwelling on risks (Krueger \& Dickson, 1994). Bandura (1997) asserts that the self-efficacy guides individuals to choose which goal challenges to undertake, how much effort to invest, and how long to persevere in the face of difficulties. In the GEGs, participants' positive and optimistic behaviour in facing and overcoming ed-tech challenges indicates the potential of social connectedness to develop selfefficacy. For example, despite challenges in the inequality of Internet connectivity at schools, some participants in the Urban and Rural GEGs continued to explore alternatives for more practical, effective, and efficient classroom practices such as electronic grading or evaluating their students with Google tools. Similarly, participants in the Metropolitan GEG also support each other through socially connected networks in providing access and information to various resources for digital practices, collaboration, and professional development. This supports previous study on how learners developed efficaciousness by innovatively retrieving knowledge and reproducing the skills in new contexts and new environments (Blaschke et al., 2014).

The concept of social modelling, observational learning, and vicarious experiences can be used to describe the role of social connectedness to individuals' learning process. Social modelling plays a "ubiquitous role as a vehicle for agentic action" (Bandura, 2018, p.134) and observational learning enables the expansion of "knowledge and skills on the basis of information conveyed by modelling influences" (Bandura, 1989, p.20). Through vicarious experiences, "people acquire attitudes, values, and emotional 
dispositions towards persons, places, and things" (Bandura, 1989, p.23). Vicarious experiences also enable learners to observe others' behaviour and its consequences for them:

"Unlike learning by doing, which requires altering the actions of each individual through repeated trial-and-error experiences, in observational learning a single model can transmit new ways of thinking and behaving simultaneously to many people in widely dispersed locales" (Bandura, 1989, p.21-22).

Social modelling, observational learning, and vicarious experiences enable learners to obtain authentic and accurate feedback, which can lead to mastery experiences and verbal persuasion as sources for efficacy because "those who are most experienced and competent provide models of efficacious styles of thinking and behaviour" (Bandura, 1989, p.68). Participants' positive perceptions towards their learning experiences in the GEGs showed that others' knowledge, experiences, expertise, and practices were valued as important resources for learning.

The positive perception influenced learning dispositions as participants reported feeling more optimistic, motivated, and empowered to overcome ed-tech professional challenges, which resonates the impact of modelling influences in the social cognitive perspective:

"Modeling influences can have diverse psychological effects. First, they foster acquisition of new competencies, cognitive skills, and behaviour patterns. Second, they affect level of motivation and restraints over behaviour that has been previously learned. Modeling influences also serve as social prompts that actuate and channel behaviour in social transactions." (Bandura, 1989, p.23).

The modelling influence generates efficacious action and personal satisfaction (Bandura, 1989, p.26-30), which is reflected in the participants' shared-connectedness in the GEGs. Participants identified colleagues with whom they shared professional similarities, such as ed-tech challenges, or ed-tech vision and practices. This shared-connectedness drives the stimulation of mind to which Bandura (1989) referred to as cognitive arousal:

"Cognitive arousal can take two forms: personalising the experience of another, or by taking the perspective of another. In the personalising form, observers get themselves emotionally aroused by imagining things happening to themselves that are either similar to the model's experiences or have been generalised from previous positive and aversive experiences. In the perspective-taking form, observers come to experience the emotional states of others by putting themselves in their place and imagining how they might feel" ( p.31). 
This suggests that cognitive arousal involves emotional and affective experiences that enable learners to gain a better understanding, not only about themselves but also about others.

In the GEGs, participants' collegial learning involved meaningful conversations, which seems to experience cognitive arousal through sharing resources, practices, experiences, challenges, and issues. For example, some participants said that they learned more than just a theory by sharing experiences with other colleagues who managed to overcome professional challenges by creating a solution that was unique and applicable for others to follow. What they shared in the groups directly came from their experiences as an educator and from their daily professional practices in the classroom or outside of schools, along with their efforts in experimenting with the tools and challenges they faced in using them. They also learned from each other's practices, experiences, challenges, and issues, which brings about new perspectives and enables the discovery of new strategies. This suggests that the social connectedness opens up opportunities for participants to reflect upon their experiences that can help them maintain positive disposition in adjusting to changes and overcoming challenges. Positive dispositions derived from emotional processes are considered important alongside cognitive, motivational, and choice processes in the development of learners' efficacy beliefs (Bandura, 2018).

Bandura's concept of efficacy beliefs resonates to the potential of participants' social-connectedness to develop self-efficacy in a way that it enabled them to feel supported and to have a sense of purpose for what they do, which creates positive emotion significant to meaningful learning experiences. Providing support for others so that they can feel supported was also shown in the GEGs' online forums. Findings from the online observation show that all forums had no negative or discouraging interactions in the posts, comments, and responses from leaders or members. There was also no display of explicit expressions of disapproval or harsh disagreement regarding certain topics of posts, comments, or responses in all groups' online forums. In this respect, all leaders were trying to create a supportive type of online environment where they hoped to encourage their members to feel safe in participating. This suggests that social connectedness plays an important role as a form of learning support for participants in the GEGs. 


\section{The influence of participants' agency and social connectedness on the group's capacity to support learning}

The influence of participants' agency and their social connectedness as personal, proxy, and collective agents revealed different group capacities to support learning. Collective agency is exercised by a group of individuals who act in accordance with each other to produce collectively desired outcomes:

"People's shared beliefs in their collective power to produce desired results; not only of shared knowledge and skills of its different members, but also of the interactive, coordinative, and synergistic dynamics of their transactions as an emergent group-level property" (Bandura, 2000, p.75-76).

This highlights the importance of collective agency where individuals function as a unit or a group forming an agentic blend. Bandura (2018) introduces the notion of "the agentic blend" where he defined as a collaborative effort to achieve common goals leading to collective efficacy. Collective efficacy is "a group's shared belief in its conjoint capabilities to organise and execute the courses of action required to produce given levels of attainments" (Bandura, 1997, p.477) and has been used to construct an explanation of the group models of professional learning (Berebitsky \& Salloum, 2017). The higher the perceived collective efficacy, the stronger the collaborative practices, activities, and efforts reflected within the groups (e.g. (Becker, 2017; Mackenzie, 2000).

In social cognitive theory, although personal, proxy, and collective agencies are clearly identified in the construct of human agency, there is no fixed operationalisation of these three types of agencies due to the variability of context. This suggests various interpretations of how personal, proxy, and collective agencies interact. There are various contexts within which different interactions of personal, proxy, and collective agencies can occur in a way that it may not necessarily form a similar agentic blend leading to collective efficacy. For example, in the context of personal learning network, each participant may have different reason to join certain networks or participate in them, and therefore, there may not be a collective goal. However, in the context of mandated professional development program, educators are likely moving towards to similar attainments. As such, attainments such as professional credits or certification could be the driver for a collective effort to successfully participate in the program, which reflects a collective efficacy. 
Although the interaction of personal, proxy, and collective agencies can be different in the groups, all participants' similarly value their learning experiences in the GEGs as positive and meaningful through various forms of participation such as mentoring, problem-solving, altered way of thinking, experience-sharing, or reflecting on their digital practice in the classroom This indicates that participants' agency and social connectedness support experiential learning where they manage to find ways to learn regardless of the quality of the Internet and digital infrastructure.

In the Metropolitan GEG, members' wide-range of ed-tech practices and experiences led to global ed-tech collaboration that contributed to the group's learning activities and resources, which indicated a digitally-driven agentic blend. The global collaboration shown in the Metropolitan group's online forum indicated members' collective agency in making efforts to achieve similar objectives, such as collaborative ed-tech projects or ed-tech professional learning activities. This collective agency stimulated a group effort reflecting its higher perceived collective efficacy compared to Urban and Rural GEGs where the leader's efforts were more dominant. Findings from the Metropolitan group's global collaboration supports previous studies on the positive implication of individuals' personal efficacy in the form of cognitive involvement and interactive user engagement to increase collective efficacy (Halpern, 2017). In contrast, the group's learning activities and resources in both Urban and Rural GEGs were derived from the leaders' dominant efforts in the group, which indicated the absence of agentic blend from the majority of group members. The lack of collaboration in both Urban and Rural's online forums was also an indicative of the dominance of participants as personal and proxy agents than as a collective agent. Therefore, findings from the differences between the Metropolitan GEG as a collaborative group and both Urban and Rural GEGs as leader-driven groups can add insights into such variability, particularly on how personal and proxy agency did not necessarily lead to collective efficacy due to both groups' reliance towards the leader as dominant proxy agent. This suggests that the group's collaborative learning behaviour can be influenced by how collective agency can occur as an agentic blend that leads to collective efficacy.

The interdependence among individuals is indicative of collective efficacy. Within this interdependence, interlocked shared-intention, mutual responsiveness, common knowledge, and interdependence can provide sufficient conditions for collective intentional activity (Bratman, 2013). This notion resonates with Bandura's (1997) theory 
on how "beliefs of collective efficacy serve functions similar to those of personal efficacy beliefs and operate through similar processes" (p.14). Findings from the Metropolitan GEG support Bratman and Bandura's concept of how such collective efficacy may emerge with regard to the role of personal agency. The Metropolitan participants as both personal and proxy agencies formed globally-networked agentive spaces, interdependent towards one another. This allowed public-online sharing to occur, which diversified the experiences and practices as the leader was not the only contributor in the group. A higher degree of interdependence between individuals and others was publicly expressed and shared online is an indication of strong collective efficacy (Bandura, 2000), which corresponds to the Metropolitan GEG's collaborative online forum. However, interdependence did not seem to occur in both Urban and Rural GEGs due to their preference for private-offline sharing contributing to the lack of engagement in the online forum, and thereby minimising opportunities for learning. There was a dominant dependence upon the leader as the proxy agent to provide resources and facilitate of learning for group members. This was shown by a stagnant group learning activity when the leaders were busy. Therefore, when individuals are interdependent, it seems to create a stronger chain of support as there are more people who can be proxy agents compared to the dependence to only one individual as proxy agent.

Findings from the ed-tech learning orientation in each GEG add insight into conditions that support collective efficacy. As all leaders and participants had altruistic motivation and voluntary activities with positive and meaningful learning experiences, they became part of the valuable support system and resources for learning that other members could rely on in the group. All leaders' commitment and efforts to lead the groups were a source of support, motivation, and inspiration for participants in the group. This shows that all GEGs enables a supportive environment for self-directed learning. However, not all groups have similar conditions conducive for collective efficacy to occur. The Metropolitan participants' interdependent globally-connected networks along with their public-online sharing and multidirectional online interaction contributed to global collaboration of diverse ed-tech practices and experience indicating the group's collective efficacy in ed-tech professional learning. In contrast, the Urban and Rural groups' dependence on the leader as the main provider of resources and facilitator of learning, the tendency for offline-private sharing and unidirectional online interaction contributed to the group being driven by the leader's efforts to conduct face-to-face group 
activities, which seemed to limit resources and opportunities for ed-tech professional learning within local context.

As collective efficacy did not occur in all groups, each group has different ed-tech orientations, which leads to different functions of the groups as ed-tech professional learning support: (1) the Metropolitan GEG as globally-collaborative ed-tech professional learning support for innovative use of web-based tools to improve productivity of ed-tech practices; (2) the Urban GEG as locally-leader-driven ed-tech professional learning support for optimising the use of web-based tools to improve efficiency through paperless classroom practice and school administration; and (3) the Rural GEG as locally-leaderdriven ed-tech professional learning support for using web-based tools with low bandwidth and limited ICT infrastructure for simple teaching and learning practice.

The interdependence of these three aspects on participants' ed-tech professional learning was significant in all groups (figure 13), which suggests that Indonesian educators' ed-tech professional learning in the GEGs is three-dimensional and contextspecific.

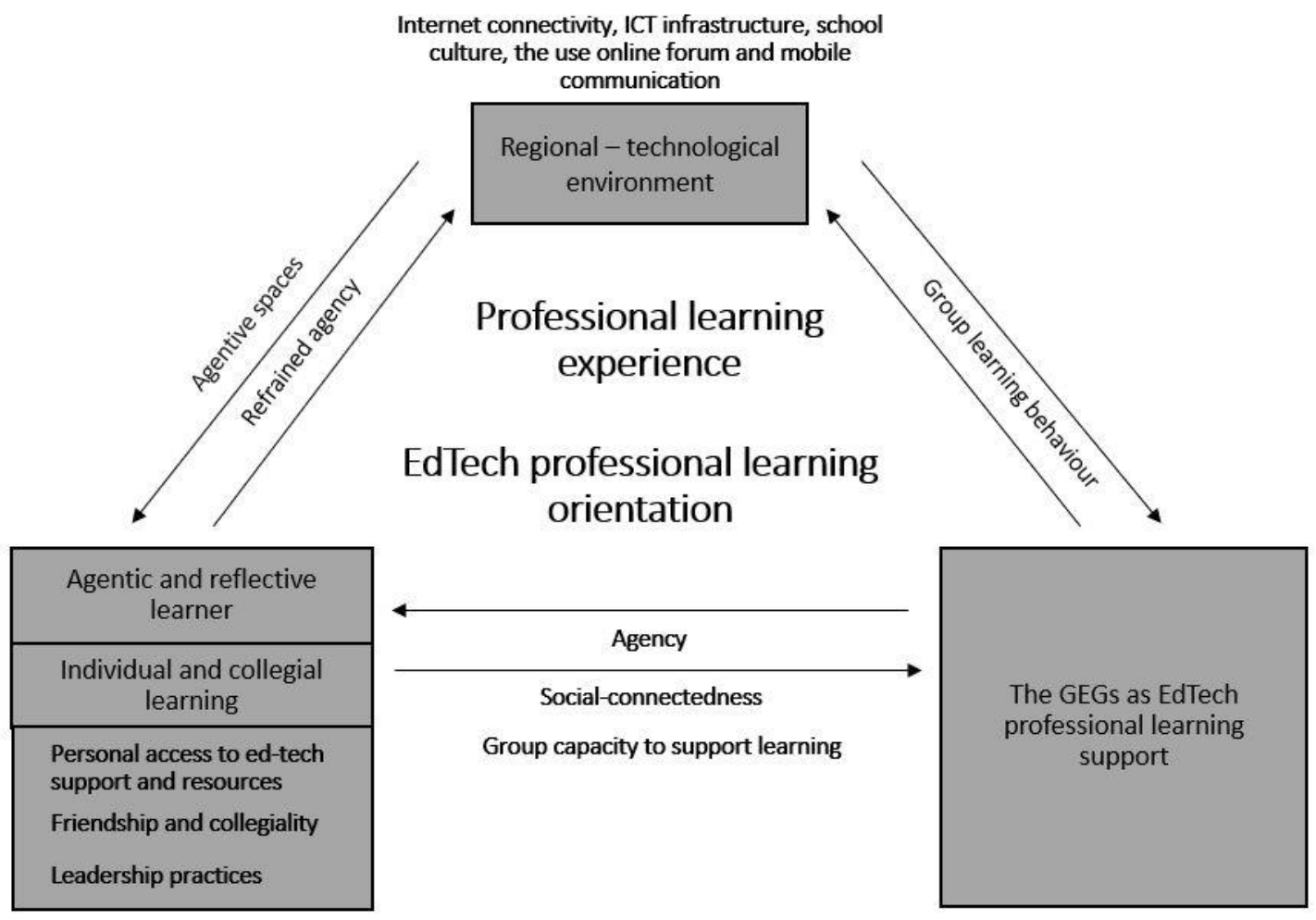

Figure 13. The interdependence of the regional-technological environment, participants' agency, and group learning behaviour 
Not only did the regional-technological environment influence participants' enactment of agency and the group learning behaviour but their enactment of agency and the group learning behaviour were also interdependent resulting in the groups function as ed-tech professional learning support, either it globally-collaborative or locally-leader-driven. As the regional-technological environment influence participants' activities in the online forum, how participants' online activities in the forum also influence the group's dynamics in the online forum. For example, the leaders' enactment of the agency in the online forum through moderation and the capacity of Internet connectivity influence the group's online forum interaction. It is also through moderation that the leaders were trying to encourage their member's online activities as well as maintaining the focus of the group's online forum to be "spam-free". Previous studies provided insightful knowledge about some aspects that influence such practices in various educational contexts, such as the leadership aspect (Brandt \& Laiho, 2013), cultural aspect (Gazi, 2014), technological aspect (Northcote \& Boddey, 2014), individual aspect (Blaschke et al., 2014), and social aspect (Foskey, 2013). However, each study focuses on every aspect independently and does not seem to reveal any interdependence between these aspects, and therefore, does not seem to align with findings in my study. Findings from the interdependence of the regional-technological environment, participants' agency, and the group learning behaviour in the GEGs, thus, consistent with Bandura's theory of triadic reciprocal causation describing how individuals and their environment are reciprocally deterministic (Bandura, 2001, 2018), which also support findings from Shepherd and Marshall's (2005) study that agentive practices are constructed within an interdependent network of individual, social, and environmental factors. This strengthens Albion and Tondeur's (2018) argument that ICT support and collegial support are important for empowering "to explore the possibilities inherent in new ICT and make decisions about whether and how they can enhance learning and teaching in their context" (p. 13) indicating greater agency in professional learning.

\section{Summary}

This study provides essential insights into the opportunities and challenges of educators' ed-tech professional learning within the Indonesian context. This study found that not only did the regional-technological environment influenced participants' enactment of agency and the group learning behaviour, but participants' enactment of agency and the group learning behaviour were also interdependent. The GEGs provided 
a supportive environment for participants as agentic and experiential learners to have positive and meaningful learning experiences, but it did not necessarily enable all participants to reflect on leadership practices. The social connectedness in the GEGs could potentially develop participants' individual self-efficacy. However, this did not necessarily lead to collaborative learning behaviour in the group. Both the Urban and Rural groups had a challenging digital environment and absence of collective efficacy due to the over-dependency towards their leaders as proxy agents, which minimised participants' agentive spaces and limited the opportunities for ed-tech learning. In contrast, the Metropolitan group had a reliable digital environment and collective efficacy, which led to collaborative learning behaviour where the leader and members did not only contribute but also collaborate for learning in the group. In addition, the leadership style of the Metropolitan leader also seemed to contribute to the group's collaborative learning behaviour enabling diverse ed-tech learning resources and opportunities where the group functioned as collaborative ed-tech professional learning support. Thus, understanding how to cultivate these aspects is important as an approach to enhance professional learning opportunities for Indonesian educators. The GEGs provide relevant context on the changing nature of educators' professional learning where it is leaning towards self-directed, often informal, socially connected, and digitally oriented. As agency, digital technology, and interpersonal connections within communities are increasingly acknowledged as essential components to support selfdirected professional learning, participants' learning experiences in the GEGs indicate the significance of agency and social-connectedness to create a supportive environment for ed-tech professional learning. The groups also provided a supportive platform and enabled opportunities for personal and collegial learning using digital technologies, particularly web-based tools. For example, participants could personally access ed-tech resources, took up leadership roles, and connected with others for support. Furthermore, findings from participant leadership practices in the GEGs confirm that being a learning leader is beyond having a positional authority. Rather, it is more about the value of expertise and practices that support, inspire, motivate, and empower others. 


\section{Chapter 9}

\section{Conclusion}

The purpose of this study has been to explore and investigate how Indonesian educators reflected on their experiences in participating in Metropolitan, Urban, and Rural GEGs for ed-tech professional learning. Little is known about how these educators' participation in the GEGs for ed-tech professional learning unfolds, particularly in an environment where the use of digital technology and access to internet varies. Therefore, this study was conducted to further understand the nature of Indonesian educators' learning experiences in the GEGs and its significance to their ed-tech professional learning.

Findings reveal that Indonesian educators participated in the GEGs as agents of their own learning who enacted their agency in both individual and collegial learning. They tailored ways of learning to specifically fit their needs and context. Not only did participants personalise their networks comprising connections to people, but they also had accesses to digital tools and resources that were beneficial for them. They were selfmotivated to seek opportunities and resources for learning in a way that was personally relevant, meaningful, and empowering. Not only did participants learn on their own but they also learned by helping and supporting others through friendships, collegiality, and leadership roles where they valued individual experiences as authentic learning resources.

Findings indicate different functions of the GEGs which influenced by two digital learning environments and three ed-tech learning orientations. The Metropolitan GEG functioned as a globally collaborative ed-tech professional learning support where participants engaged in learning to use web-based tools innovatively to improve productivity of ed-tech practices. The Urban GEG functioned as a locally leader-driven ed-tech professional learning support driven by the leader's efforts in providing participants with opportunities and resources to learn the optimisation of web-based tools to improve efficiency through paperless classroom practices and school administration. The Rural GEG functioned as a locally leader-driven ed-tech professional learning support driven by the leader's efforts in providing opportunities and resources to learn using web-based tools with low bandwidth and limited ICT infrastructure for simple teaching and learning practices. 
The Indonesian educators' experiences of ed-tech professional learning in the GEGs were analysed within a social-cognitive perspective. Bandura's social-cognitive theory was used as a relevant framework to understand the nature of participants' learning experiences within their dynamics of agency and its interdependence to their socialenvironment. Within a social cognitive perspective, three important aspects in Indonesian educators' ed-tech professional learning in the GEGs were identified:

- The influence of the regional-technological environment to participants' enactment of agency

- The influence of the regional-technological environment to the group learning behaviour

- The interdependence of participants' enactment of agency and group learning behaviour

These aspects highlighted the significance of agency, social-connectedness, and the regional-technological environment in participants' learning experiences.

Different roles and activities that participants undertook in the GEGs reflected their enactment of agency to develop their professionalism in ed-tech practices, creating positive changes within their region, and striving for better ed-tech learning opportunities in the GEGs. Participants' social-connectedness was reflected in the collegial learning where they could reflect upon their experiences that could help them maintain positive dispositions to overcome ed-tech challenges indicating self-efficacy. Different characteristics of the groups' regional-technological environment engendered different dynamics of participants' enactment of agency and the group learning behaviour. The Metropolitan group's digitally-driven environment reflected a reliable digital environment with optimised agentive spaces and globally-collaborative nature of the group. Both Urban GEG's digitally-diverse and Rural GEG's digitally-constrained environments reflect a challenging digital environment with minimised agentive spaces, thereby leading to the refrained agency and locally-leader-driven nature of the group. The interdependence of these three aspects suggests that Indonesian educators' ed-tech professional learning in the GEGs is three-dimensional and context-specific, which provides essential insights into the opportunities and challenges of educators' ed-tech professional learning within the Indonesian context 
This study also adds insights into the affordances of mobile communication as flexible, affordable, and popular communication tool that could support learning in conjunction to the educators' learning engagement in the online forum: either it was complementary or substitutive to the online forum. Furthermore, this study identified the driving factors of participants' informal leadership practices as learning leaders in the GEGs: successful experiences in overcoming professional challenges with technology; altruism, empathy, and a sense of purpose to help/support voluntarily; motivation to contribute to the teaching profession; being inspired, empowered, and encouraged by other learning leaders; and confidence in a professional capacity with technology. These findings informed that being a learning leader is not about having a positional authority, but more about the value of expertise and practices that support, inspire, and empower others.

Providing a reliable digital environment, opportunities for ed-tech leadership practice, and fostering social-connectedness for collaborative learning process may be important aspects to consider for meaningful ed-tech professional learning in Indonesia. To that end, it is crucial for the leaders in the education section to create a National policy on strengthening the infrastructure in education, particularly the improving the quality and quantity of the Internet connectivity in the education sector and supporting digital equity in the education sector across regions in Indonesia. This may bridge the gap between what Indonesian educators need in ed-tech professional learning and what they are getting from traditional, mandated PD programmes. It may also help to address current challenges in ed-tech professional learning faced by Indonesian educators.

The rise of teacher's self-directed informal professional learning such as the GEGs is not to ignore the existence of teacher's formal-mandated PD as useless, but rather how to transform the existing a formal-mandated PD into a more flexible and meaningful PD design that does not only provide Indonesian teachers with knowledge and skill on how to solely use ICT in the classroom but also to develop their capacity for learning agency through technology leadership, digital student-centered pedagogy, and global collaboration (as part of global educators' networks). This way, it can be more conducive to create an environment where teachers can feel that their agency is more acknowledged, and their social-connectedness is more cultivated for more effective networking. Thus, ed-tech professional learning in the GEGs is not merely about the technicalities of digital 
technologies but also the importance of how being agentic and experiential learners can lead to meaningful learning experiences with such technologies.

Findings of my study contribute to developing knowledge on the changing nature of educators' professional learning emphasising on the significance of agency and socialconnectedness to support and enable opportunities for experiential learning regardless of the quality of the Internet and digital infrastructure. How participants' value their experiences in the GEGs as positive and meaningful reveal various forms of learning in the groups using variety of digital technologies that are available in their respective environment. Through these experiences, participants' manage to find ways for learning in the groups as both individual and collegial learners, such as mentoring, collaborative learning, experience-sharing, or reflecting on their digital practice in the classroom.

Although all participants reported increased sense of agency for ed-tech professional learning in the GEGs through motivation, inspiration and empowerment from ed-tech practices, the impact on their pedagogy, however, varied depending on their digital practice, ICT skills and background, and the ICT infrastructure in their respective local educational environment such as schools and regions. This finding suggests that there is currently no direct causal link between their agency and student-centred pedagogy identified in the findings of this study.

Finding on the impact of the leaders' moderation show that although the leaders' moderation is beneficial to encourage sharing and collaboration among members in the forum, it may not seem to support critical thinking on the pedagogical practice with digital technology as the posts involving critique on digital learning and the pedagogy in the online forum were not present, which might be moderated by the leaders. This is not to say that the leaders' moderation has no impact on the groups' critical thinking on the pedagogical practice. Rather, developing this type of networked learning in the group seems to require an embedded strategy to introduce a 'safe' type of critical thinking that is culturally and time appropriate. For example, getting participants feel familiar with the platform first and then gently introduce them into constructively critiquing ideas, which takes time to occur. 


\section{Limitations of the study}

The goal of my study was not to generalise the findings to a larger population. Instead, it aimed to examine the unique professional learning experiences of Indonesian educators as participants in this study, in order to yield useful insights for further exploration of how ed-tech professional learning practices take place in different platforms of collectives in Indonesia. However, it is also important to be cautious about applying the results from this study to other contexts or to the broader and larger informally-initiated and self-organised communities. The participants in my study were a specific group of individuals whose involvement in the GEGs seem to exceed other GEG members' experiences. It is likely that they were more motivated to participate in the study and share positive views compared to other GEG members who did not respond or did not give consent to the researcher's invitation to be interviewed. It is unlikely that most members experience the level of willingness, involvement, and intensity of learning that these participants were likely to enjoy. To address this bias, participants were asked to discuss any limitations, challenges, adversities, and barriers throughout their learning journey with the group and describe what changes they would like to happen or what expectations they hoped to achieve to improve their learning experiences with it.

The number of cases and participants were limited, which was challenged by the voluntary response bias, as data were collected from members who were willing to respond to the interviews. Since these members volunteered to participate in the study and willingly participated in the GEGs, it is possible that they were more motivated than other teachers to make changes to their professional practices.

This study was also limited by self-reported data from participants. Participants' self-reported experiences can help to provide a wider range of data that be valuable in obtaining the diversity and richness of perspectives, views, and opinions, but they were inherently bias (Gerald \& George, 2010). As all participants were self-selected and their experiences were self-reported, the enthusiasm in participating in this study influenced the nuance of the data, which tends to be optimistic. To overcome this, participants were informed on the confidentiality of their real identity in the research to allow them to feel safe in sharing challenging experiences such as learning limitations, issues or problems they encountered within the GEGs, which I also included in the data to overcome bias. I also used the observational data from the groups' online forum that allowed me to look into the consistency of what participants said they did in the group with their actual 
participation in the forum. Although there was a high degree of consistency between selfreports and observation data, this study could be strengthened by collecting data from more various sources to examine the validity of the self-reports such as community's face-to-face learning sessions/meet-ups or participants' classroom observation with webbased to explore more depth and richness of learning interaction. In addition, some of the educators shared beyond what was needed in the research, which created an abundance of data that contributed to the overwhelming process of analysis. However, some educators shared less and, therefore, I needed longer time to establish a rapport and create an environment where they could be more open in sharing their thoughts, feelings, and experiences.

The interaction and communication observed in this study were limited to only three forms of communication channels: online observation of publicly open online forum group interaction, self-reported face-to-face interaction at meet-ups organised and the publicly-shared face-to-face interactions in the group's online forum, and self-reported mobile instant messaging application communications (WhatsApp, Telegram). It is possible that there were members in the groups who interacted with each other through other types of communication platforms such as email and private messaging. As a result, the true strength, scope, and nuance of the networks, relationships, and interactions may not be entirely evident/analysed. Whether or not the social connectedness in the GEGs is hindered by the creation of subgroups within the groups is outside the scope of this study, suggesting the need for future research.

\section{Implications for Indonesian educators' ed-tech professional learning experience}

The social-cognitive aspects of Indonesian educators' ed-tech professional learning in the GEGs provides a framework to gain insights on the significance of agency, social-connectedness, and the regional-technological environment for meaningful ed-tech learning experiences. However, it is important to be aware of the challenges to implement self-directed model of ed-tech professional learning as not all educators have similar social-cognitive aspects that could potentially support them, such as individual cognitive capacity, resources, and environment. Some educators may have different challenges in optimising opportunities for self-directed learning depending on the variability of these aspects. Identifying these challenges and how to overcome them is essential to gain understanding towards aspects that contribute to the optimisation of opportunities for selfdirected learning that is effective, meaningful, and empowering. Thus, it is important for 
educators to consider that self-directed professional learning alone would neither suffice in all context nor would it serve as an absolute model that suit all educators' needs but rather a continuously developed-skill for professional growth.

\section{Implications for Indonesian PD policy}

This study has implications for educators, facilitators, school leaders, and administrators who live in the world of teacher professional learning, as well as those who are involved in education policy to support teacher professional learning in education technology. Through reflecting on the learning experiences from participants in this study, educators can become advocates for their own learning while also empowering others. Education leaders, stakeholders, and policymakers whose concerns are related to educators' professional learning with technology can also benefit from this research as they can identify what type of support can be provided to create a conducive learning environment in their education technology context. By gaining insight into Indonesian educators' ed-tech professional learning in the GEGs, these leaders, stakeholders, and policymakers could more informatively implement both national and regional policies to design an empowering and supportive learning environment for PD that can optimise Indonesian educators' potential in learning and leadership to improve practice. For example, a national and regional policies can be implemented to design a PD on ed-tech leadership with certain degree of flexibility to enable relevant and meaningful learning experiences as well as to develop trust and to provide a safe environment. Another example, a national and regional policies can also be implemented to incorporate an agentic, reflective, and supportive method of professional learning about the use of educational technology in Indonesia into the design of government-supported ed-tech PD programmes.

\section{Implications for future research}

With limited number of cases and participants, voluntary response bias, selfreported data, and context, this study provides an initial glimpse into the opportunities and challenges of educators' ed-tech professional learning within the Indonesian context, particularly with web-based tools. Further research is needed within different sampling techniques, number of cases and participants, variety of data resources, diverse contexts of the GEG, and different models of educators' self-directed professional learning, to examine whether these findings can be extended to a broader and more diverse scope and population. 


\section{Final thoughts}

Embarking on every step of the process in completing this thesis has provided me with valuable learning experiences. It has enabled me to reflect on my academic journey, professional practices, and the future goals that I would like to achieve as I implement what I have learned in Indonesia. As an educational technology specialist in the Ministry of Education and Culture in Indonesia, findings in this study will inform my work in facilitating educators' professional learning using information communication technology. Conducting this study also has provided me with opportunities to improve my research skills, which will be essential for my work in the future involving researchrelated projects. The process of collecting data, interviewing participants, and analysing the abundant amount of data allowed me to be more critical in my thinking, in making decisions, and in recognising my own limitations as a researcher with a background as a government official in the field of education. I have learned to address my own biases and subjectivity, embrace new perspectives, and develop an awareness about the issues and challenges I encountered during the process of completing the study. This has enabled me to be more open in expressing my thoughts and seeking support in the midst of difficult situations. Conducting this research has bridged a gap between theoretical and practical knowledge that I never realised existed back in Indonesia. The overall experience of conducting and completing this study has been therefore, valuable for both my personal and professional growth. 


\section{REFERENCES}

Adler, P. A., \& Adler, P. (1994). Observational techniques. In N. K. Denzin \& Y. S. Lincoln (Eds.), Handbook of Qualitative Research (pp. 377-392). Thousand Oaks, CA, US: Sage Publications, Inc.

Alanezi, A. (2016). The relationship between shared leadership and administrative creativity in Kuwaiti schools. Management in Education, 30(2), 50-56. doi:10.1177/0892020616643159

Alavi, S. B., \& McCormick, J. (2016). Implications of proxy efficacy for studies of team leadership in organizational settings. European Psychologist, 21(3), 218-228. doi:10.1027/1016-9040/a000270.

Albion P.R., Tondeur J. (2018) Information and Communication Technology and Education: Meaningful Change through Teacher Agency. In: Voogt J., Knezek G., Christensen R., Lai KW. (eds) Handbook of Information Technology in Primary and Secondary Education. Springer International Handbooks of Education. Springer, Cham.

Allan, B., Hunter, B. and Lewis, D. 2006. Four years on: a longitudinal study assessing the impact of a virtual community of practice. Fifth International Conference on Networked Learning. Lancaster University 10th - 12th April 2006.

Alwasilah, A. C., \& Furqon. (2010). Indonesia. In Peterson, P., Baker, E., \& McGaw, B (Eds), International Encyclopedia of Education (pp. 611-617). doi: 10.1016/B978-0-08044894-7.015688-2.

Ardiansyah, F., Marthen, A. A., \& Amalia, N. (2015). Forest and land-use governance in a decentralized Indonesia: A legal and policy review (Vol. 132). CIFOR. doi:10.17528/cifor/005695.

Artzt, A. F., Armour-Thomas, E., Curcio, F. R., \& Gurl, T. J. (2015). Becoming a reflective mathematics teacher: A guide for observations and self-assessment. Routledge.

Azzizah, Y. (2015). Socio-Economic Factors on Indonesia Education Disparity. International Education Studies, 8(12). doi:10.5539/ies.v8n12p218. 
Bandura, A. (1986). Social foundations of thought and action: A social cognitive theory. Englewood Cliffs, NJ: Prentice-Hall.

Bandura, A. (1989). Regulation of cognitive processes through perceived self-efficacy. Developmental Psychology, 25(5), 729.

Bandura, A. (1997). Self-efficacy: The exercise of control. New York: Freeman

Bandura, A. (1999). A social cognitive theory of personality. In L. Pervin \& John, O. P. (Ed.), Handbook of personality: Theory and research (2nd ed., pp. 154-196). New York: Guilford Publications.

Bandura, A. (2000). Exercise of Human Agency Through Collective Efficacy. Current Directions in Psychological Science, 9(3), 75-78. doi:10.1111/1467-8721.00064.

Bandura, A. (2001). Social cognitive theory: An agentic perspective. Asian Journal of Social Psychology, 2(1), 21-41. doi: 10.1111/1467-839X.00024.

Bandura, A. (2002). Social Cognitive Theory in Cultural Context. Applied Psychology, 51(2), 269-290. doi:10.1111/1464-0597.00092.

Bandura, A. (2006). Toward a Psychology of Human Agency. Perspectives on Psychological Science, 1(2), 164-180. doi:10.1111/j.1745-6916.2006.00011.x.

Bandura, A. (2018). Toward a Psychology of Human Agency: Pathways and Reflections. Perspectives on Psychological Science, 13(2), 130-136. doi:10.1177/1745691617699280.

Banoglu, K. (2011). School Principals' Technology Leadership Competency and Technology Coordinatorship. Educational Sciences: Theory and Practice, 11(1), 208-213.

Barkley, J. M. (2006). Reading education: is self-efficacy important? Reading Improvement, 43(4), 194-211.

Baron, D. (2008). Imagine: Professional development that changes practice. Principal Leadership, Vol. 8, p. 56. Reston, Va. : National Association of Secondary School Principals.

Bauman, Z. (2013). Liquid modernity. NJ: John Wiley \& Sons. 
Baumeister, R. F., Sparks, E. A., Stillman, T. F., \& Vohs, K. D. (2008). Free will in consumer behavior: Self-control, ego depletion, and choice. Journal of Consumer Psychology, 18(1), 4-13. doi:10.1016/j.jcps.2007.10.002.

Bautista, A., Cañadas, M. C., Brizuela, B. M., \& Schliemann, A. D. (2015). Examining How Teachers Use Graphs to Teach Mathematics during a Professional Development Program. Journal of Education and Training Studies, 3(2). doi:10.11114/jets.v3i2.676.

Baxter, J., \& Eyles, J. (1997). Evaluating Qualitative Research in Social Geography: Establishing "Rigour" in Interview Analysis. Transactions of the Institute of British Geographers, 22(4), 505-525. doi:10.1111/j.0020-2754.1997.00505.x.

Baziad, M. (2016). Google says committed to building a 'meaningful Internet' in Indonesia Digital News Asia. Retrieved from Digital News Asia website: https://www.digitalnewsasia.com/digital-economy/google-says-committed-buildingmeaningful-internet-indonesia.

Becker, E. (2017). Strengthening Collective Efficacy through Meaningful Collaboration.(Unpublished master's thesis). Northwestern College, Orange City, Iowa

Berebitsky, D., \& Salloum, S. J. (2017). The relationship between collective efficacy and teachers' social networks in Urban middle schools. AERA Open, 3(4), 233285841774392. doi:10.1177/2332858417743927.

Bergman, Z., Bergman, M. M., \& Thatcher, A. (2019). Agency and Bandura's Model of Triadic Reciprocal Causation: An Exploratory Mobility Study Among Metrorail Commuters in the Western Cape, South Africa. Frontiers in Psychology, 10, 411. doi:10.3389/fpsyg.2019.00411.

Berliner, D. C. (2001). Learning about and learning from expert teachers. International Journal of Educational Research, 35(5), 463-482. doi:10.1016/s0883-0355(02)00004-6.

Bhoyrub, J., Hurley, J., Neilson, G. R., Ramsay, M., \& Smith, M. (2010). Heutagogy: An alternative practice based learning approach. Nurse Education in Practice, 10(6), 322326. doi:10.1016/j.nepr.2010.05.001.

Biesta, G., \& Tedder, M. (2007). Agency and learning in the life course: Towards an ecological perspective. Studies in the Education of Adults, 39(2), 132-149.

doi:10.1080/02660830.2007.11661545. 
Biesta, G., Priestley, M., \& Robinson, S. (2015). The role of beliefs in teacher agency. Teachers and Teaching, 21(6), 624-640. doi:10.1080/13540602.2015.1044325.

Bitsch, V. (2005). Qualitative research: A grounded theory example and evaluation criteria. Journal of Agribusiness, 23(345-2016-15096), 75-91.

Blaschke, L. M. (2014). Using social media to engage and develop the online learner in selfdetermined learning. Research in Learning Technology, 22. doi:10.3402/rlt.v22.21635.

Blaschke, L. M., \& Hase, S. (2015). Heutagogy: A Holistic Framework for Creating TwentyFirst-Century Self-determined Learners. In Maina, M., Gross, B., \& Kinshuk (Eds.), The Future of Ubiquitous Learning (pp. 25-40) Berlin: Springer. doi:10.1007/978-3662-47724-3_2.

Blaschke, L. M., Kenyon, C., \& Hase, S. (2014). Experiences in self-determined learning. Center for Open Education Research (COER), University of Oldenburg: Oldenburg, Germany. Https://Uol. de/Fileadmin/User_upload/Coer/Experiences-in-SelfDetermined-Learning. Pdf.

Bolden, R. (2017). Trends and perspectives in management and leadership development. Business Leadership Review, 4(2).

Borko, H. (2004). Professional Development and Teacher Learning: Mapping the Terrain. Educational Researcher, 33(8), 3-15. doi:10.3102/0013189x033008003.

Borko, H., Jacobs, J., \& Koellner, K. (2010). Contemporary approaches to teacher professional development. In Peterson, P., Baker, E., \& McGaw, B (Eds), International Encyclopedia of Education International Encyclopedia of Education (pp. 548-556). doi:10.1016/b978-0-08-044894-7.00654-0.

Boyd, E. M., \& Fales, A. W. (1983). Reflective Learning. Journal of Humanistic Psychology, 23(2), 99-117. doi:10.1177/0022167883232011.

Boylan, M. (2018). Enabling adaptive system leadership: Teachers leading professional development. Educational Management Administration \& Leadership, 46(1), 86-106.

Bozeman, B., \& Feeney, M. K. (2007). Toward a Useful Theory of Mentoring. Administration \& Society, 39(6), 719-739. doi:10.1177/0095399707304119. 
Brandt, T., \& Laiho, M. (2013). Gender and personality in transformational leadership context. Leadership \& Organization Development Journal, 34(1), 44-66. doi:10.1108/01437731311289965.

Brandtzæg, P. B., \& Heim, J. (2008). User Loyalty and Online Communities: Why Members of Online Communities are not Faithful. In Proceedings of the 2nd International Conference on Intelligent Technologies for Interactive Entertainment. doi:10.4108/icst.intetain2008.2481.

Bratman, M. E. (2013). Shared agency: A planning theory of acting together. New York: Oxford University Press.

Brink, H. I. L. (1993). Validity and reliability in qualitative research. Curationis, 16(2). doi:10.4102/curationis.v16i2.1396.

Brinkmann, S., \& Kvale, S. (2015). InterViews: Learning the craft of qualitative research interviewing. Thousand Oaks, CA: Sage Publications.

Brown, R. (2007). New technologies mean new learning for teachers: Mailring participation and professional development. New England Reading Association Journal, 43(1), 44.

Brown, R., \& Munger, K. (2010). Learning together in cyberspace: Collaborative dialogue in a virtual network of educators. Journal of Technology and Teacher Education, 18(4), $541-571$.

Buchanan, J., Prescott, A., Schuck, S., Aubusson, P., Burke, P., \& Louviere, J. (2013). Teacher Retention and Attrition: Views of Early Career Teachers. Australian Journal of Teacher Education, 38(3). doi:10.14221/ajte.2013v38n3.9.

Burbules, N. C. (2007). Networks as Spaces and Places: Their Importance for Educational Research Collaboration. In Smeyers, P., \& Depaepe, M. (Eds.), Educational Research: Networks and Technologies (pp. 43-54). Dordrecht: Springer. doi:10.1007/978-1-40206613-9_4.

Burns, M., \& Bodrogini, P. W. (2011). The Wisdom of Practice: Web 2.0 as a Cognitive and Community-Building Tool in Indonesia. In Thomas, M (Ed.), Digital Education: Opportunities for Social Collaboration (pp. 167-193). doi:10.1057/9780230118003_9. 
Burns, T. R., \& Dietz, T. (2000). Human agency and evolutionary processes: Institutional dynamics and social revolution. In B. Whittrock. (Ed.), Agency in Social Theory. Thousand Oaks, CA: Sage.

Bush, T., \& Glover, D. (2014). School leadership models: what do we know? School Leadership \& Management, 34(5), 553-571. doi:10.1080/13632434.2014.928680.

Cahyono, B. Y., \& Mutiaraningrum, I. (2015). Indonesian EFL Teachers' Familiarity with and Opinion on the Internet-Based Teaching of Writing. English Language Teaching, 9(1), 199. doi:10.5539/elt.v9n1p199.

Calvert, L. (2016). The power of teacher agency. The Learning Professional, 37(2), 51.

Cansoy, R. (2017). Teachers' Professional Development: The Case of WhatsApp. Journal of Education and Learning, 6(4), 285. doi:10.5539/jel.v6n4p285.

Canţer, M. (2012). E-heutagogy for lifelong e-learning. Procedia Technology, 1, 129-131. doi:10.1016/j.protcy.2012.02.025.

Caron, A. H., \& Caronia, L. (2007). Moving cultures: Mobile communication in everyday life. Montreal: McGill-Queen's Press-MQUP.

Carpenter, J. P., \& Green, T. D. (2017). Mobile instant messaging for professional learning: Educators' perspectives on and uses of Voxer. Teaching and Teacher Education, 68, 53-67. doi:10.1016/j.tate.2017.08.008.

Carpenter, J. P., \& Krutka, D. G. (2014). Engagement through microblogging: educator professional development via Twitter. Professional Development in Education, 41(4), 707-728. doi:10.1080/19415257.2014.939294.

Carpenter, J. P., \& Linton, J. N. (2018). Educators' perspectives on the impact of Edcamp unconference professional learning. Teaching and Teacher Education, 73, 56-69. doi:10.1016/j.tate.2018.03.014.

Carroll, T. (2000). Preparing tomorrow's teachers to use technology. Keynote Presentation at the US Department of Education's Regional Conferences on Evaluating Technology in Education, Atlanta. 
Carver, C. S., Johnson, S. L., Joormann, J., \& Scheier, M. F. (2014). An Evolving View of the Structure of Self-Regulation. In Gendolla, Guido H.E., Tops, Mattie, Koole, Sander. L. (Eds), Handbook of Biobehavioural Approaches to Self-Regulation (pp. 9-23). Amsterdam: Springer. doi:10.1007/978-1-4939-1236-0_2.

Cerit, Y. (2013). Relationship between Teachers' Self-Efficacy Beliefs and Their Willingness to Implement Curriculum Reform. International Journal of Educational Reform, 22(3), 252-270. doi:10.1177/105678791302200304.

Cesareni, D., Martini, F., \& Mancini, I. (2011). Building a community among teachers, researchers and university students. A blended approach to training. International Journal of Computer-Supported Collaborative Learning, 6(4), 625-646. doi:10.1007/s11412-011-9126-8.

Charalambous, C. Y., \& Philippou, G. N. (2010). Teachers' concerns and efficacy beliefs about implementing a mathematics curriculum reform: integrating two lines of inquiry. Educational Studies in Mathematics, 75(1), 1-21. doi:10.1007/s10649-010-9238-5.

Chen, I. Y. L., \& Chen, N. S., \& Kinshuk. (2009). Examining the factors influencing participants' knowledge sharing behavior in virtual learning communities. Journal of Educational Technology \& Society, 12(1), 134-148.

Chetty, S. (1996). The Case Study Method for Research in Small-and Medium-Sized Firms. International Small Business Journal: Researching Entrepreneurship, 15(1), 73-85. doi:10.1177/0266242696151005.

Cho, M.-H., \& Heron, M. L. (2015). Self-regulated learning: the role of motivation, emotion, and use of learning strategies in students' learning experiences in a self-paced online mathematics course. Distance Education, 36(1), 80-99. doi:10.1080/01587919.2015.1019963.

Claxton, G. (2004) Learning is learnable (and we ought to teach it). In S. J. Cassell (ed.), Ten Years On Report (pp. 237-250). Bristol: National Commission for Education

Clements, T. J. (2018). Informal Teacher Leadership for Technology Integration: A Multi-site Case Study of Distributed Leadership. (Unpublished Doctoral Thesis). University of Lexington: Kentucky

Cohen, L., \& Manion, L. (1994). Research methods in education (4th ed.). London: Routledge. 
Collinson, V. (2012). Leading by learning, learning by leading. Professional Development in Education, 38(2), 247-266. doi:10.1080/19415257.2012.657866.

Collinson, V., \& Ono, Y. (2001). The Professional Development of Teachers in the United States and Japan. European Journal of Teacher Education, 24(2), 223-248. doi:10.1080/02619760120095615.

Conole, G. (2014). Designing for Learning in an Open World (Vol. 4). New York, Heidelberg: Springer. doi: 10.1007/978-1-4419-8517-0.

Counts, S., \& Fisher, K. E. (2010). Mobile social networking as information ground: A case study. Library \& Information Science Research, 32(2), 98-115. doi:10.1016/j.lisr.2009.10.003.

Couros, A. (2010). Developing personal learning networks for open and social learning. In G. Veletsianos (Ed.), Emerging Technologies in Distance Education (pp. 109-127). Edmonton: Athabasca University Press

Creswell, J. W., \& Creswell, J. D. (2017). Research design: Qualitative, quantitative, and mixed methods approaches. Thousand Oaks, CA: Sage publications.

Creswell, J. W., \& Miller, D. L. (2000). Determining Validity in Qualitative Inquiry. Theory Into Practice, 39(3), 124-130. doi:10.1207/s15430421tip3903_2.

Crowther, F., Ferguson, M., \& Hann, L. (2009). Developing teacher leaders: How teacher leadership enhances school success. Thousand Oaks, CA: Corwin Press.

Cruess, S. R., Cruess, R. L., \& Steinert, Y. (2008). Role modelling-making the most of a powerful teaching strategy. BMJ, 336(7646), 718-721. doi:10.1136/bmj.39503.757847.be.

Curtis, R. (2013). Finding a new way: Leveraging teacher leadership to meet unprecedented demands. Washington DC: Aspen Institute.

Danielson, C. (2007). The many faces of leadership. Educational Leadership, 65(1), 14-19.

Darling-Hammond, L. (2009). Research review/teacher learning: What matters. Educational Leadership., Vol. 66, p. 46. Alexandria, VA : Association for Supervision and Curriculum Development. 
Darling-Hammond, L., \& McLaughlin, M. W. (2011). Policies That Support Professional Development in an Era of Reform. Phi Delta Kappan, 92(6), 81-92. doi:10.1177/003172171109200622.

Davis, K. (2015). Teachers' perceptions of Twitter for professional development. Disability and Rehabilitation, 37(17), 1551-1558. doi:10.3109/09638288.2015.1052576.

De la Torre Cruz, M. J., \& Casanova Arias, P. F. (2007). Comparative analysis of expectancies of efficacy in in-service and prospective teachers. Teaching and Teacher Education, 23(5), 641-652. doi:10.1016/j.tate.2007.02.005.

De Munck, V. C., \& Sobo, E. J. (Eds.). (1998). Using methods in the field: a practical introduction and casebook. Maryland, US: Rowman Altamira.

Dede, C., Jass Ketelhut, D., Whitehouse, P., Breit, L., \& McCloskey, E. M. (2008). A Research Agenda for Online Teacher Professional Development. Journal of Teacher Education, 60(1), 8-19. doi:10.1177/0022487108327554.

Denzin, N. K., \& Lincoln, Y. S. (Second Ed.). (2001). Handbook of Qualitative Research. Thousand Oaks, CA. Sage Publications.

Desimone, L. M. (2009). Improving Impact Studies of Teachers' Professional Development: Toward Better Conceptualizations and Measures. Educational Researcher, 38(3), 181199. doi:10.3102/0013189x08331140.

Deskins, T. H. (2010). Determining teacher expectations in an urban school environment its implications for affecting student achievement. (Unpublished Doctoral Thesis). Bowie State University, Bowie, Maryland.

Diaz-Maggioli, G. (2004). Teacher-centered professional development. Alexandria, VA: ASCD.

DiCicco-Bloom, B., \& Crabtree, B. F. (2006). The qualitative research interview. Medical Education, 40(4), 314-321. doi:10.1111/j.1365-2929.2006.02418.x.

Dierking, R. C., \& Fox, R. F. (2012). Changing the Way I Teach. Journal of Teacher Education, 64(2), 129-144. doi:10.1177/0022487112462893. 
Duncan-Howell, J. (2010). Teachers making connections: Online communities as a source of professional learning. British Journal of Educational Technology, 41(2), 324-340. doi:10.1111/j.1467-8535.2009.00953.x.

Dunkel Schetter, C., \& Brooks, K. (2009). The nature of social support. In H. T. Reis \& S. Sprecher (Eds.), Encyclopedia of human relationships (pp. 1565-1570)

Earl, L., \& Katz, S. (2007). Leadership in networked learning communities: defining the terrain. School Leadership \& Management, 27(3), 239-258. doi:10.1080/13632430701379503.

Easton, L. B. (2008). From Professional Development to Professional Learning. Phi Delta Kappan, 89(10), 755-761. doi:10.1177/003172170808901014.

Eberle, J. (2009). Heutagogy: What your mother didn't tell you about pedagogy and the conceptual age. In Proceedings of the European Conference on E-Learning, 181-188.

El Miniawi, H., \& Brenjekjy, A. (2015). Educational Technology, Potentials, Expectations and Challenges. Procedia - Social and Behavioural Sciences, 174, 1474-1480. doi:10.1016/j.sbspro.2015.01.777.

Elliott, J., Craft, C., \& Feldon, D. (2010, March). Is informational material shared between K12 professionals on Twitter supported by research? Society for Information Technology \& Teacher Education International Conference, (pp. 444-448). Association for the Advancement of Computing in Education (AACE).

Elo, S., Kääriäinen, M., Kanste, O., Pölkki, T., Utriainen, K., \& Kyngäs, H. (2014). Qualitative Content Analysis: A focus on trustworthiness. SAGE Open, 4(1), 215824401452263. doi: $10.1177 / 2158244014522633$.

Eraut, M. (2000). Non-formal learning and tacit knowledge in professional work. British Journal of Educational Psychology, 70(1), 113-136. doi:10.1348/000709900158001.

Erlangga, M. (2015, May 5). Komunitas EdTech Indonesia Resmi Diinisiasi. Retrieved from https://dailysocial.id/post/edtech-indonesia.

Erss, M. (2018). Complete freedom to choose within limits: teachers' views of curricular autonomy, agency and control in Estonia, Finland and Germany. The Curriculum Journal, 29(2), 238-256. doi:10.1080/09585176.2018.1445514. 
Eteläpelto, A., Vähäsantanen, K., Hökkä, P., \& Paloniemi, S. (2013). What is agency? Conceptualizing professional agency at work. Educational Research Review, 10, 45-65. doi:10.1016/j.edurev.2013.05.001.

Etherington, K. (2004). Becoming a reflexive researcher: Using ourselves in research. London: Jessica Kingsley Publishers.

Eun, B. (2018). Adopting a stance: Bandura and Vygotsky on professional development. Research in Education, 105(1), 74-88. doi:10.1177/0034523718793431.

Evans, K. (2017). Bounded agency in professional lives. In M. Goller \& S. Paloniemi (Eds.), Agency at Work. Professional and Practice-based Learning (pp. 17-36). Cham: Springer. doi: 10.1007/978-3-319-60943-0_2

Fairman, J. C., \& Mackenzie, S. V. (2012). Spheres of teacher leadership action for learning. Professional Development in Education, 38(2), 229-246. doi:10.1080/19415257.2012.657865.

Fairman, J. C., \& Mackenzie, S. V. (2014). How teacher leaders influence others and understand their leadership. International Journal of Leadership in Education, 18(1), 61-87. doi:10.1080/13603124.2014.904002.

Feiman-Nemser, S. (2001). From Preparation to Practice: Designing a Continuum to Strengthen and Sustain Teaching. Teachers College Record, 103(6), 1013-1055. hdoi:10.1111/0161-4681.00141.

Firmansyah, M. (2015, September). Idcourserians, a MOOCs learning community in Indonesia. In Proceedings of Teaching and Education Conferences (No. 2905299). International Institute of Social and Economic Sciences.

Firmansyah, M., \& Timmis, S. (2016). Making MOOCs meaningful and locally relevant? Investigating IDCourserians - an independent, collaborative, community hub in Indonesia. Research and Practice in Technology Enhanced Learning, 11(1). doi:10.1186/s41039-016-0032-6.

Flick, U. (Ed.). (2009). The sage qualitative research kit. London: SAGE Publications Limited. Foskey, R. (2013). Innovations in Community Education. In S. Hase \& C. Kenyon (Eds), SelfDetermined Learning: Heutagogy in Action (pp. 193-206). London: Continuum Press. doi:10.5040/9781472553232.ch-015. 
Foucault, M., \& Gordon, C. (1980). Power/knowledge. Selected Interviews and Other Writings, 1972-1977. New York: Patheon Books.

Frost, D. (2006). The concept of agencyin leadership for learning. Leading and Managing, 12(2), 19-28.

Frost, D., \& Harris, A. (2003). Teacher Leadership: towards a research agenda. Cambridge Journal of Education, 33(3), 479-498. doi:10.1080/0305764032000122078.

Fullan, M. (2001). The New Meaning of Educational Change. London: Routledge. doi:10.4324/9780203986561.

Fullan, M., \& Hargreaves, A. (1996). What's Worth Fighting for in Your School? Revised Edition. New York: Teachers College Press.

Garet, M. S., Porter, A. C., Desimone, L., Birman, B. F., \& Yoon, K. S. (2001). What Makes Professional Development Effective? Results From a National Sample of Teachers. American Educational Research Journal, 38(4), 915-945. doi:10.3102/00028312038004915.

Gavora, P. (2010). Slovak pre-service teacher self-efficacy: Theoretical and research considerations. The New Educational Review, 21(2), 17-30.

Gazi, Y. (2014, June). Issues Surrounding a Heutagogical Approach in Global Engineering Education. Paper presented at 2014 ASEE Annual Conference \& Exposition, Indianapolis, Indiana. Retrieved from https://peer.asee.org/20722.

Gebbie, D. H., Ceglowski, D., Taylor, L. K., \& Miels, J. (2011). The Role of Teacher Efficacy in Strengthening Classroom Support for Preschool Children with Disabilities Who Exhibit Challenging Behaviours. Early Childhood Education Journal, 40(1), 35-46. doi:10.1007/s10643-011-0486-5.

Gee, J. (2005). Semiotic social spaces and affinity spaces: From The Age of Mythology to today's schools. In D. Barton \& K. Trusting (Eds.), Beyond Communities of Practice Language Power and Social Context (Learning in Doing: Social, Cognitive and Computational Perspectives) (pp. 214-232). Cambridge: Cambridge University Press. doi: 10.1017/CBO9780511610554.012.

Gerald, J. H., \& George, S. H. (2010). Self-report: Psychology's four-letter word. American Journal of Psychology, 123(2), 181-188. 
Gibbert, M., Ruigrok, W., \& Wicki, B. (2008). What passes as a rigorous case study? Strategic Management Journal, 29(13), 1465-1474. doi:10.1002/smj.722.

Gibson, C. B. (2003). The Efficacy Advantage: Factors Related to the Formation of Group Efficacy. Journal of Applied Social Psychology, 33(10), 2153-2186. doi:10.1111/j.1559-1816.2003.tb01879.x.

Gill, P., Stewart, K., Treasure, E., \& Chadwick, B. (2008). Methods of data collection in qualitative research: interviews and focus groups. British Dental Journal, 204(6), 291295. doi:10.1038/bdj.2008.192.

Goller M. (2017) Study 3:Work Agency and Its Effect on Expertise Development. In: Human Agency at Work. Wiesbaden: Springer VS. doi:10.1007/978-3-658-18286-1_7.

Goller, M., \& Harteis, C. (2017). Human agency at work: Towards a clarification and operationalisation of the concept. In M. Goller \& S. Paloniemi (Eds.), Professional and practice-based learning: Vol. 20. Agency at work: An agentic perspective on professional learning and development (pp. 85-103). Cham, Switzerland: Springer International Publishing. doi:10.1007/978-3-319-60943-0_5

Goller, M., \& Paloniemi, S. (2017). Agency at work, learning and professional development : An introduction. In M. Goller, \& S. Paloniemi (Eds.), Professional and practice-based learning: Vol. 20. Agency at work: An agentic perspective on professional learning and development (pp. 1-14). Cham, Switzerland: Springer International Publishing. doi:10.1007/978-3-319-60943-0_5

Goria, C., Konstantinidis, A., Kilvinski, B., \& Dogan, B. E. (2019). Personal learning environments and personal learning networks for language teachers' professional development. Professional Development in CALL: A Selection of Papers, pp. 87-99. doi:10.14705/rpnet.2019.28.872.

Grabher, G., \& Ibert, O. (2013). Distance as asset? Knowledge collaboration in hybrid virtual communities. Journal of Economic Geography, 14(1), 97-123. doi:10.1093/jeg/lbt014.

Graneheim, U. H., \& Lundman, B. (2004). Qualitative content analysis in nursing research: concepts, procedures and measures to achieve trustworthiness. Nurse Education Today, 24(2), 105-112. doi:10.1016/j.nedt.2003.10.001. 
Osanloo, A., \& Grant, C. (2016). Understanding, selecting, and integrating a theoretical framework in dissertation research: Creating the blueprint for your "house". Administrative issues journal: connecting education, practice, and research, 4(2), 7. Retrieved from https://files.eric.ed.gov/fulltext/EJ1058505.pdf

Grant, M., \& Hsu, Y. C. (2014). Making personal and professional learning mobile: Blending mobile devices, social media, social networks, and mobile apps to support PLEs, PLNs, \& ProLNs. In A.V. Stavros (Ed.) Advances in communication and media research, Volume 10 (pp. 27-46). New York: Nova Science Publishers.

Grazella, M. (2013, June 18). Facebook has 64m active Indonesian users. Retrieved from http://www.thejakartapost.com/news/2013/06/18/facebook-has-64m-active-indonesianusers.html.

Gronn, P. (2000). Distributed Properties: A New Architecture for Leadership. Educational Management \& Administration, 28(3), 317-338. doi:10.1177/0263211x000283006.

Guba, E. G., \& Lincoln, Y. S. (1994). Competing paradigms in qualitative research. In N.K. Denzin \& Y.S. Lincoln (Eds.), Handbook of qualitative research (pp. 105-117). London: Sage.

Gudmundsdottir, S. (2001). Narrative research in school practice. In V. Richardson (Ed.), Fourth Handbook of Research on Teaching (pp. 226-240). New York: Macmillan.

Guemide, B., \& Benachaiba, C. (2012). Exploiting ICT and e-learning in teacher's professional development in Algeria: The case of English secondary school teachers. Turkish Online Journal of Distance Education-TOJDE, 13(3), 33-49.

Guskey, T. R. (2002). Professional Development and Teacher Change. Teachers and Teaching, 8(3), 381-391. doi:10.1080/135406002100000512.

Guskey, T. R. (2014). Planning professional learning. Educational Leadership, 71(8), 10-16.

Hadfield, M. (2007). Co-leaders and middle leaders: the dynamic between leaders and followers in networks of schools. School Leadership \& Management, 27(3), 259-283. doi:10.1080/13632430701379552.

Halpern, D. (2017). How Does Social Media Trigger Collective Efficacy Through Deliberation? A Field Experiment. International Journal of Communication, 11(20). Retrieved from https://ijoc.org/index.php/ijoc/article/view/5649/2150. 
Halsall, J. P., Powell, J. L., \& Snowden, M. (2016). Determined learning approach:

Implications of heutagogy society based learning. Cogent Social Sciences, 2(1). doi:10.1080/23311886.2016.1223904.

Hamill, S. K. (2003). Resilience and self-efficacy: The importance of efficacy beliefs and coping mechanisms in resilient adolescents. Colgate University Journal of the Sciences, 35(1), 115-146. Retrieved from http://groups.colgate.edu/cjs/student_papers/2003/Hamill.pdf.

Hannay, L., Wideman, R., \& Seller, W. (2010). Professional learning to reshape teaching. Toronto: Elementary Teachers' Federation of Ontario.

Hanraets, I., Hulsebosch, J., \& de Laat, M. (2011). Experiences of pioneers facilitating teacher networks for professional development. Educational Media International, 48(2), 85-99. doi:10.1080/09523987.2011.576513.

Harré, R., \& Gillett, G. (1994). The discursive mind. Thousand Oaks, CA: SAGE Publications, Inc. doi:10.4135/9781452243788.

Harris, A. (2003). Teacher Leadership as Distributed Leadership: Heresy, fantasy or possibility? School Leadership \& Management, 23(3), 313-324. doi:10.1080/1363243032000112801.

Harteis, C., \& Goller, M. (2014). New Skills for New Jobs: Work Agency as a Necessary Condition for Successful Lifelong Learning. In Halttunen et al., (Eds.), Promoting, Assessing, Recognizing and Certifying Lifelong Learning (pp. 37-56). Dordrecht: Springer. doi:10.1007/978-94-017-8694-2_3.

Hase, S. (2009). Heutagogy and e-learning in the workplace: Some challenges and opportunities. Impact: Journal of Applied Research in Workplace E-Learning, 1(1), 4352.

Hase, S., \& Kenyon, C. (2001). From andragogy to heutagogy. ultiBASE Articles (December), 1-10. Retrieved from https://epubs.scu.edu.au/cgi/viewcontent.cgi? article=1147\&context=gcm_pubs

Hase, S., \& Kenyon, C. (2013). Self-determined learning: Heutagogy in action. London: Bloomsbury Publishing Plc. 
Hately, N., \& Schiller, J. (2003). What personal ICT skills do school leaders need. The Practicing Administrator, 4, 5-7.

Hattie, J., \& Timperley, H. (2007). The Power of Feedback. Review of Educational Research, 77(1), 81-112. doi:10.3102/003465430298487.

Hawkins, G. (2001). The ethics of television. International Journal of Cultural Studies, 4(4), 412-426. doi:10.1177/136787790100400403.

Hay, C. (2002). Political analysis: a critical introduction. England, UK: Macmillan International Higher Education.

Haythornthwaite, C., Kazmer, M. M., Robins, J., \& Shoemaker, S. (2000). Community development among distance learners: Temporal and technological dimensions. Journal of Computer-Mediated Communication, 6(1), JCMC615.

HEC VUW. (2016). Human Ethics Guidelines. Retrieved from https://www.victoria.ac.nz/documents/policy/research-policy/appendix-a-human-ethicscommittee-guidelines.pdf.

Heikkinen, H. L. T. (2002). Whatever is narrative research? In Huttunen, R., Heikkinen, H. L. T., Syrjälä, L. (Eds.), Narrative research: Voices from teachers and philosophers (pp. 13-25). Jyväskylä, Finland: SoPhi

Hermans, R., Tondeur, J., van Braak, J., \& Valcke, M. (2008). The impact of primary school teachers' educational beliefs on the classroom use of computers. Computers \& Education, 51(4), 1499-1509. doi:10.1016/j.compedu.2008.02.001.

Hinnant-Crawford, B. (2016). Education Policy Influence Efficacy: Teacher Beliefs in Their Ability to Change Education Policy. International Journal of Teacher Leadership, 7(2), $1-27$.

Hunter, B. (2002). Learning in the Virtual Community Depends upon Changes in Local Communities. In K. Renninger \& W. Shumar (Eds.), Building Virtual Communities: Learning and Change in Cyberspace (Learning in Doing: Social, Cognitive and Computational Perspectives) (pp. 96-126). Cambridge: Cambridge University Press. doi:10.1017/CBO9780511606373.009 
Hur, J. W., \& Brush, T. A. (2009). Teacher Participation in Online Communities. Journal of Research on Technology in Education, 41(3), 279-303.

doi:10.1080/15391523.2009.10782532.

Hyson, M., \& Roesli, R. (2017). Connecting the Dots: Learning Communities for Village Teachers in Rural Indonesia. YC Young Children, 72(4), 35-42. Retrieved from https://www.jstor.org/stable/90013703

Imants, J., \& Van der Wal, M. M. (2019). A model of teacher agency in professional development and school reform. Journal of Curriculum Studies, 1-14. doi:10.1080/00220272.2019.1604809.

In Indonesia: Social Networking Tops List of Digital Activities. (2015, June 9). Retrieved from https://www.emarketer.com/Article/Indonesia-Social-Networking-Tops-List-of-DigitalActivities/1012582.

Indonesia. (2015). Indonesia Digital Education and E-Learning Market Outlook to 2018 Rising Trend of Blended Learning to Drive the Future Growth. Delhi, India: Ken Research Private Ltd. doi:3086087.

Ipnugraha, I. (2013). Pioneering of Schools with International Standard to Respond the Globalization. Journal of Education and Learning, 7(3), 153-158. doi:10.11591/edulearn.v7i3.180.

Jaakkola, M. (2015). Teacher Heutagogy in the Network Society: A Framework for Critical Reflection. In Jandric, P., \& Boras, D, (Eds), Critical Learning in Digital Networks (pp. 163-178). Switzerland: Springer International Publishing. doi:10.1007/978-3-31913752-0_8.

Jamil, F. M., Downer, J. T., \& Pianta, R. C. (2012). Association of pre-service teachers' performance, personality, and beliefs with teacher self-efficacy at program completion. Teacher Education Quarterly, 39(4), 119-138.

Jenkins, H., Purushotma, R., Weigel, M., Clinton, K., \& Robinson, A. J. (2009). Confronting the challenges of participatory culture: Media education for the 21st century. A report for the MacArthur Foundation. Cambridge, MA: MIT Press. 
Jeon, H. (2017). Teacher Efficacy Research in a Global Context. In Akiba, M., \& LeTendre, G. K. (Eds), International Handbook of Teacher Quality and Policy (pp. 414-429). doi:10.4324/9781315710068-27. New York, NY: Routledge.

Jimoyiannis, A., \& Tsiotakis, P. (2016). Self-directed learning in e-portfolios: Analysing students' performance and learning presence. EAI Endorsed Transactions on ELearning, 3(10), 151154. doi:10.4108/eai.11-4-2016.151154.

Jones, S. R., Torres, V., \& Arminio, J. (2013). Negotiating the complexities of qualitative research in higher education: Fundamental elements and issues. New York, NY: Routledge.

Joyce, B. R., \& Showers, B. (2002). Student achievement through staff development (3rd ed.). Alexandria, VA: Association for Supervision \& Curriculum Deve (ASCD)

Katz, S., Earl, L. M. \& Jaafar, S. B. (2009). Building and connecting learning communities: The power of networks for school improvement. Thousand Oaks, CA: Corwin Press doi: $10.4135 / 9781452219196$

Katzenmeyer, M., \& Moller, G. (2009). Awakening the sleeping giant: Helping teachers develop as leaders. Thousand Oaks: Corwin Press.

Kearney, M., \& Maher, D. (2019). Mobile learning in pre-service teacher education: Examining the use of professional learning networks. Australasian Journal of Educational Technology, 35(1). doi:10.14742/ajet.4073

Kellerman, B. (2007). What every leader needs to know about followers. Harvard Business Review, 85(12), 84.

Kelly, N. \& Antonio, A. (2016). Teacher peer support in social network sites. Teaching and Teacher Education: An International Journal of Research and Studies, 56(1), 138-149. Elsevier Ltd. doi:10.1016/j.tate.2016.02.007

Kennedy, A. (2005). Models of Continuing Professional Development: a framework for analysis. Journal of In-Service Education, 31(2), 235-250. doi:10.1080/13674580500200358.

Ketelaar, E., Beijaard, D., Boshuizen, H. P. A., \& Den Brok, P. J. (2012). Teachers' positioning towards an educational innovation in the light of ownership, sense-making and agency. Teaching and Teacher Education, 28(2), 273-282. doi:10.1016/j.tate.2011.10.004. 
Kevin, J. (2012). Google Indonesia Launched, Rudy Ramawy Chosen as Country Head.

Retrieved from TechInAsia. Retrieved from https://www.techinasia.com/googleindonesia-office-2.

Kimmerle, J., Moskaliuk, J., Oeberst, A., \& Cress, U. (2015). Learning and Collective Knowledge Construction With Social Media: A Process-Oriented Perspective. Educational Psychologist, 50(2), 120-137. doi:10.1080/00461520.2015.1036273.

King, F. (2019). Professional learning: empowering teachers? Professional Development in Education, 45(2), 169-172. doi:10.1080/19415257.2019.1580849.

Klein, H. K., \& Myers, M. D. (1999). A Set of Principles for Conducting and Evaluating Interpretive Field Studies in Information Systems. MIS Quarterly, 23(1), 67. doi: $10.2307 / 249410$.

Kling, R., \& Courtright, C. (2003). Group Behavior and Learning in Electronic Forums: A Sociotechnical Approach. The Information Society, 19(3), 221-235. doi:10.1080/01972240309465.

Knight, P. (2002). A systemic approach to professional development: learning as practice. Teaching and Teacher Education, 18(3), 229-241. doi:10.1016/s0742-051x(01)00066$\mathrm{x}$.

Knudsen, L. S., Skovgaard, T., \& Bredahl, T. (2018). Understanding and scaffolding Danish schoolteachers' motivation for using classroom-based physical activity: study protocol for a mixed methods study. BMJ Open, 8(3), e019857. doi:10.1136/bmjopen-2017019857.

Krueger, N., \& Dickson, P. R. (1994). How Believing in Ourselves Increases Risk Taking: Perceived Self-Efficacy and Opportunity Recognition. Decision Sciences, 25(3), 385400. doi:10.1111/j.1540-5915.1994.tb01849.x.

Krueger, R. A., \& Casey, M. A. (2009). Chapter 3: Developing a questioning route. In Focus groups: A practical guide for applied research (4th ed.) (pp. 35-61). Thousand Oaks, CA: SAGE Publications.

Kunter, M., Klusmann, U., Baumert, J., Richter, D., Voss, T., \& Hachfeld, A. (2013). Professional competence of teachers: Effects on instructional quality and student development. Journal of Educational Psychology, 105(3), 805. 
Kusmawan U. (2015). Educating Diverse Teachers in a Diverse Country. In Reynolds R. et al. (Eds), Contesting and Constructing International Perspectives in Global Education (pp. 63-75). Rotterdam: SensePublishers. doi:10.1007/978-94-6209-989-0_6.

Laferrière, T., Lamon, M., \& Chan, C. K. K. (2006). Emerging E-Trends and Models in Teacher Education and Professional Development. Teaching Education, 17(1), 75-90. doi:10.1080/10476210500528087.

Lakhana, A. (2014). What is Educational Technology? An Inquiry into the Meaning, Use, and Reciprocity of Technology. Canadian Journal of Learning and Technology / La revue canadienne de l'apprentissage et de la technologie, 40(3). Canadian Network for Innovation in Education. doi:10.21432/T2H59S.

Lambert, J. (1997). Problems and challenges of translation in an age of new media and competing models. In R. Hodgson., \& P. R. Soukup. (Eds), From One Medium to Another: Basic Issues for Communicating the Scriptures in New Media (pp. 51-65). Kansas City: Sheed and Ward.

Langset, I. D., Jacobsen, D. Y., \& Haugsbakken, H. (2018). Digital professional development: towards a collaborative learning approach for taking higher education into the digitalized age. Nordic Journal of Digital Literacy, 13(01), 24-39. doi:10.18261/issn.1891-943x-2018-01-03.

Lantz-Andersson, A., Lundin, M., \& Selwyn, N. (2018). Twenty years of online teacher communities: A systematic review of formally-organized and informally-developed professional learning groups. Teaching and Teacher Education, 75, 302-315. doi:10.1016/j.tate.2018.07.008.

Lantz-Andersson, A., Peterson, L., Hillman, T., Lundin, M., \& Rensfeldt, A. B. (2017). Sharing repertoires in a teacher professional Facebook group. Learning, Culture and Social Interaction, 100(15), 44-55.

Lapadat, J. C., \& Lindsay, A. C. (1999). Transcription in Research and Practice: From Standardization of Technique to Interpretive Positionings. Qualitative Inquiry, 5(1), 6486. doi:10.1177/107780049900500104.

Latchem, C., \& Jung, I. (2009). Distance and blended learning in Asia. New York/London: Routledge. doi:10.4324/9780203878774. 
Lauder, A. (2008). The status and function of English in Indonesia: A review of key factors. Makara Human Behavior Studies in Asia, 12(1), 9. doi:10.7454/mssh.v12i1.128.

Leithwood, K., \& Azah, V. N. (2016). Characteristics of effective leadership networks. Journal of Educational Administration, 54(4), 409-433. doi:10.1108/jea-08-2015-0068.

Leu, D. J., Kinzer, C. K., Coiro, J. L., \& Cammack, D. W. (2004). Toward a theory of new literacies emerging from the Internet and other information and communication technologies. Theoretical Models and Processes of Reading, 5(1), 1570-1613.

Levenberg, A., \& Caspi, A. (2010). Comparing Perceived Formal and Informal Learning in Face-to-Face versus Online Environments. Interdisciplinary Journal of E-Skills and Lifelong Learning, 6, 323-333. doi:10.28945/1318.

Lie, A. (2017). English and Identity in multicultural context: issues, challenges, and opportunities. TEFLIN Journal, 28(1), 71-92. doi:10.15639/teflinjournal.v28i1/71-92.

Lieberman, A., \& Pointer Mace, D. H. (2009). The role of 'accomplished teachers' in professional learning communities: uncovering practice and enabling leadership. Teachers and Teaching, 15(4), 459-470. doi:10.1080/13540600903057237.

Lin, F., Lin, S., \& Huang, T. (2008). Knowledge sharing and creation in a teachers' professional virtual community. Computers \& Education, 50(3), 742-756.

Lin, M., \& Bates, A. (2014). Who is in my classroom? Teachers preparing to work with culturally diverse students. International Research in Early Childhood Education, 5(1), 27. Retrieved from www.education.monash.edu.au/irecejournal/.

Lincoln, Y. S., Guba, E. G., \& Pilotta, J. J. (1985). Naturalistic inquiry. International Journal of Intercultural Relations, 9(4), 438-439. doi:10.1016/0147-1767(85)90062-8.

Lipponen, L., \& Kumpulainen, K. (2011). Acting as accountable authors: Creating interactional spaces for agency work in teacher education. Teaching and Teacher Education, 27(5), 812-819. doi:10.1016/j.tate.2011.01.001.

Lloyd, M., \& Duncan-Howell, J. (2009). Changing the metaphor the potential of online communities in teacher professional development. In Lindberg, Ola \& Olofsson, Anders (Eds.) Online Learning Communities and Teacher Professional Development: Methods for Improved Education Delivery. Information Science (IGI Global) (pp. 6076). Pennsylvania: Hershey. doi:10.4018/978-1-60566-780-5.ch004. 
Lodico, M. G., Spaulding, D. T., \& Voegtle, K. H. (Eds.). (2006). Methods in educational research: From theory to practice. San Francisco: John Wiley.

López, I. P., Regueiro, B., Ponte, B., Martínez, S. R., Piñeiro, I., \& Valle, A. (2013). Motivación, implicación en los deberes escolares y rendimientos académico. Aula Abierta, 41(3), 13-22.

Macià, M., \& García, I. (2016). Informal online communities and networks as a source of teacher professional development: A review. Teaching and Teacher Education, 55, 291-307. doi:10.1016/j.tate.2016.01.021.

Mackenzie, S. (2000). Collective efficacy and collaborative climate in Maine high schools. (Unpublished Doctoral Thesis). University of Southern Maine, Orono, Maine.

Maloney-Krichmar, D., \& Preece, J. (2005). A multilevel analysis of sociability, usability, and community dynamics in an online health community. ACM Transactions on ComputerHuman Interaction, 12(2), 201-232. doi:10.1145/1067860.1067864.

Mangin, M. M., \& Stoelinga, S. R. (2010). Special Issue: Instructional Teacher Leadership in Action. Journal of Cases in Educational Leadership, 13(2), 1-4. doi:10.1177/1555458910372664.

Martin, S. N. (2019). Science education in Indonesia: past, present, and future. Asia-Pacific Science Education, 5(1), 4. doi: 10.1186/s41029-019-0032-0.

Martindale, T., \& Dowdy, M. (2010). Personal learning environments. Emerging technologies in distance education. In Veletsianos, G. (Ed.), Emerging Technologies in Distance Education (pp. 177-193). Alberta: Athabasca University Press

Marzuki, Y. (2017). Google launches new products and features for Indonesia|Digital News Asia. Retrieved from Digital News Asia website: https://www.digitalnewsasia.com/digital-economy/google-launches-new-products-andfeatures-indonesia.

Matzat, U. (2013). Do blended virtual learning communities enhance teachers' professional development more than purely virtual ones? A large scale empirical comparison. Computers \& Education, 60(1), 40-51. doi:10.1016/j.compedu.2012.08.006.

Mayfield, R. (2006, April 27). Power Law of Participation. Retrived from https://ross.typepad.com/blog/2006/04/power_law_of_pa.html 
Mbodila, M. \& Muhandji, K. (2012). The use of ICT in Education: a comparison of traditional pedagogy and emerging pedagogy enabled by ICT's. In Proceedings of the 11th International Conference on Frontiers in Education (FECS'12).WORLDCOMP (Vol. 12, pp. 16-19). Retrieved July 8, 2014 fromhttp://worldcompproceedings.com/proc/p2012/FEC2651.pdf

McLoughlin, C., \& Lee, M. J. W. (2010). Personalised and self-regulated learning in the Web 2.0 era: International exemplars of innovative pedagogy using social software. Australasian Journal of Educational Technology, 26(1). doi:10.14742/ajet.1100.

McLure Wasko, M., \& Faraj, S. (2000). It is what one does: why people participate and help others in electronic communities of practice. The Journal of Strategic Information Systems, 9(2-3), 155-173. doi:10.1016/s0963-8687(00)00045-7.

Merriam, S. B. (1998). Qualitative Research and Case Study Applications in Education. Revised and Expanded from "Case Study Research in Education.". San Fransisco: Jossey-Bass Publisher..

Merriam, S. B. (2001). Andragogy and Self-Directed Learning: Pillars of Adult Learning Theory. New Directions for Adult and Continuing Education, 89(3). doi:10.1002/ace.3.

Merriam, S. B., \& Tisdell, E. J. (2009). Qualitative research: A guide to design and implementation. San Francisco, CA: John Wiley\& Sons. Inc.

Messmann, G., \& Mulder, R. H. (2017). Proactive Employees: The Relationship Between Work-Related Reflection and Innovative Work Behaviour. In M. Goller \& S. Paloniemi (Eds.), Agency at Work. Professional and Practice-based Learning (pp. 141-159). Cham: Springer. doi: 10.1007/978-3-319-60943-0_8.

Miles, M. B., Huberman, A. M., \& Saldaña, J. (3 ${ }^{\text {rd }}$ ed). (2014). Qualitative data analysis: A methods sourcebook. Thousand Oaks, CA: Sage.

Minott, M. A. (2010). Reflective teaching as self-directed professional development: building practical or work-related knowledge. Professional Development in Education, 36(1-2), 325-338. doi:10.1080/19415250903457547.

Mishler, E. G. (1986). The analysis of interview-narratives. In T. R. Sarbin (Ed.), Narrative psychology: The storied nature of human conduct (pp. 233-255). Westport, CT, US: Praeger Publishers/Greenwood Publishing Group. 
Moffatt, A. (2012). Indonesian culture profile. West End, Queensland: Diversicare.

Januszewski, A., \& Molenda, M. (Eds.). (2008). Educational Technology. New York:

Routledge, https://doi.org/10.4324/9780203054000

Moncada, A. G. (2007). Professional development of EFL teachers in Colombia: Between colonial and local practices. Íkala, Revista de Lenguaje y Cultura, 12(18), 309-332.

Morehouse, R. E. (2012). Beginning Interpretative Inquiry. London: Routledge. doi:10.4324/9780203818244

Moser, A., \& Korstjens, I. (2018). Series: Practical guidance to qualitative research. Part 3: Sampling, data collection and analysis. European Journal of General Practice, 24(1), 9-18.

Mota, R., Ray, T., Francis, B., \& Rodriguez, A. (2010). A descriptive analysis of the impact of leadership styles on teacher job satisfaction (Unpublished Doctoral Thesis). Retrieved from http://search.proquest.com/docview/759244867/.

Muijs, D., \& Harris, A. (2006). Teacher led school improvement: Teacher leadership in the UK. Teaching and Teacher Education, 22(8), 961-972. doi:10.1016/j.tate.2006.04.010.

Mushayikwa, E., \& Lubben, F. (2009). Self-directed professional development - Hope for teachers working in deprived environments? Teaching and Teacher Education, 25(3), 375-382. doi:10.1016/j.tate.2008.12.003.

Mustafina, A. (2016). Teachers' Attitudes toward Technology Integration in a Kazakhstani Secondary School. International Journal of Research in Education and Science, 2(2), 322. doi:10.21890/ijres.67928.

Mutohar, A., \& Hughes, J. E. (2013). Toward Web 2.0 Integration in Indonesian Education: Challenges and planning strategies. In N. Azab (Ed), Cases on Web 2.0 in Developing Countries: Studies on implementation, application, and use (pp. 198-221).PA: Hershey. doi:10.4018/978-1-4666-2515-0.ch008.

Narayan, V., \& Herrington, J. (2014). Towards a theoretical mobile heutagogy framework. In: ASCILITE 2014: Rhetoric and Reality, 23 - 26 November 2014, Dunedin, New Zealand. 
Neubauer, B. J., Hug, R. W., Hamon, K. W., \& Stewart, S. K. (2011). Using Personal Learning Networks to Leverage Communities of Practice in Public Affairs Education. Journal of Public Affairs Education, 17(1), 9-26. doi:10.1080/15236803.2011.12001625.

Neumerski, C. M. (2012). Rethinking Instructional Leadership, a Review. Educational Administration Quarterly, 49(2), 310-347. doi:10.1177/0013161x12456700.

Newman, R. S. (2002). How Self-Regulated Learners Cope with Academic Difficulty: The Role of Adaptive Help Seeking. Theory Into Practice, 41(2), 132-138. doi:10.1207/s15430421tip4102_10.

Newton, P., Riveros, A., \& da Costa, J. (2013). The Influence of Teacher Leadership in the Career Advancement of Schoolteachers: A Case Study. EAF Journal, 23(2).

Nikolaki, E., Koutsouba, M., Lykesas, G., Venetsanou, F., \& Savidou, D. (2017). The support and promotion of self-regulated learning in distance education. European Journal of Open, Distance and E-Learning, 20(1).

Nørskov, S. V., \& Rask, M. (2011). Observation of online communities: A discussion of online and offline observer roles in studying development, cooperation and coordination in an open source software environment. Qualitative Social Research, 12(3).

Northcote, M. T., \& Boddey, C. (2014). Using the self-determined learning principles of heutagogy to support academic staff who are learning to teach online. Rhetoric and Reality: Critical perspectives on educational technology. Paper presented at The Australasian Society for Computers in Learning in Tertiary Education (ASCILITE), Dunedin, New Zealand. Retrieved from http://www.ascilite.org/conferences/dunedin2014/proceedings/.

Nussbaum-Beach, S., \& Hall, L. R. (2011). The connected educator: Learning and leading in a digital age. Indiana: Solution Tree Press.

Pajares, F. (2002). Gender and Perceived Self-Efficacy in Self-Regulated Learning. Theory Into Practice, 41(2), 116-125. doi:10.1207/s15430421tip4102_8.

Palaiologos, G. T. (2011). From Pedagogy to Andragogy and Heutagogy: Thinking Distance Education and Self-Directed Learning. SSRN Electronic Journal. doi:10.2139/ssrn.1967851. 
Palekahelu, D. T., Hunt, J., Thrupp, R. M., \& Relmasira, S. (2016). The Use of Smartphones and Social Media in Schools of Kota Salatiga, Central Java. In Proceedings of the 2016 International Conference on Information, Communication Technologies in Education (pp. 102-111). International Conference on Information, Communication Technologies in Education (ICICTE)

Palloff, R. M., \& Pratt, K. (1999). Building learning communities in cyberspace (Vol. 12). San Francisco: Jossey-Bass.

Paloniemi, S., Eteläpelto, A., Hökkä, P., Vähäsantanen, K., \& Törmäkangas, T. (2014). Theorising and modelling professional agency from a subject centred socio-cultural perspective. In Paperiesitys, EARLI sig conference (Vol. 27, No. 31.8, p. 2014).

Park, S., Steve Oliver, J., Star Johnson, T., Graham, P., \& Oppong, N. K. (2007). Colleagues' roles in the professional development of teachers: Results from a research study of National Board certification. Teaching and Teacher Education, 23(4), 368-389. doi:10.1016/j.tate.2006.12.013.

Pasassung, N. (2003). Teaching English in an "acquisition-poor environment": an ethnographic example of a remote Indonesian EFL classroom. (Unpublished Doctoral thesis), University of Sydney, Australia.

Passey, D., Shonfeld, M., Appleby, L., Judge, M., Saito, T., \& Smits, A. (2018). Digital Agency: Empowering Equity in and through Education. Technology, Knowledge and Learning, 23(3), 425-439. doi:10.1007/s10758-018-9384-x.

Patahuddin, S. M., \& Logan, T. (2018). Facebook as a mechanism for informal teacher professional learning in Indonesia. Teacher Development, 23(1), 101-120. doi:10.1080/13664530.2018.1524787.

Patton, M. Q. (2002). Two decades of developments in qualitative inquiry: A personal, experiential perspective. Qualitative Social Work, 1(3), 261-283.

Patton, M. Q., (2015), Qualitative Research \& Evaluation Methods Integrating Theory and Practice $\left(4^{\text {th }}\right.$ ed.). Thousand Oaks, CA: Sage Publications. Retrieved from: https://study.sagepub.com/patton4e. 
Pheeney, C., \& Klieve, H. (2015). Investigating social media potential for teacher learning in Aceh, Indonesia. In Proceedings of the International HCI and UX Conference in Indonesia on - CHIuXiD '15. doi:10.1145/2742032.2742040.

Poekert, P., Alexandrou, A., \& Shannon, D. (2016). How teachers become leaders: an internationally validated theoretical model of teacher leadership development. Research in Post-Compulsory Education, 21(4), 307-329. doi:10.1080/13596748.2016.1226559.

Polsa, P. (2013). Crystallization and research in Asia. Qualitative Market Research: An International Journal, 16(1), 76-93. doi:10.1108/13522751311289776.

Pounder, J. S. (2006). Transformational Classroom Leadership. Educational Management Administration \& Leadership, 34(4), 533-545. doi:10.1177/1741143206068216.

Priestley, M., Edwards, R., Priestley, A., \& Miller, K. (2012). Teacher Agency in Curriculum Making: Agents of Change and Spaces for Manoeuvre. Curriculum Inquiry, 42(2), 191214. doi:10.1111/j.1467-873x.2012.00588.x.

Punch, K. F., \& Oancea, A. (2014). Introduction to research methods in education. Thoiusand Oaks, CA: Sage Publications.

Putnam, R. T., \& Borko, H. (2000). What Do New Views of Knowledge and Thinking Have to Say About Research on Teacher Learning? Educational Researcher, 29(1), 4-15. doi:10.3102/0013189x029001004.

Rahmi, R. (2016). The development of language policy in Indonesia. Englisia Journal, 3(1), 9. doi:10.22373/ej.v3i1.622.

Ranieri, M., Manca, S., \& Fini, A. (2012). Why (and how) do teachers engage in social networks? An exploratory study of professional use of Facebook and its implications for lifelong learning. British Journal of Educational Technology, 43(5), 754-769. doi:10.1111/j.1467-8535.2012.01356.x.

Reeves, D. B. (2008). Reframing teacher leadership to improve your school. Alexandria, VA: ASCD.

Regmi, K., Naidoo, J., \& Pilkington, P. (2010). Understanding the Processes of Translation and Transliteration in Qualitative Research. International Journal of Qualitative Methods, 9(1), 16-26. doi:10.1177/160940691000900103. 
Reimers, Fernando M., and Connie K. Chung. (Eds). (2018). Preparing Teachers to Educate Whole Students: An International Comparative Study. Cambridge, MA: Harvard Education Press.

Relmasira, S., Thrupp, R. M., \& Hunt, J. (2017). Indonesian Teacher's Use of the Internet for Learning. In Proceedings of the International Conference on Information Communication Technologies in Education 2017 (pp. 296-306). International Conference on Information Communication Technologies in Education (ICICTE).

Remenyi, D., Williams, B., Money, A., \& Swartz, E. (1998). Doing Research in Business and Management: An Introduction to Process and Method. London: Sage. doi:10.4135/9781446280416.

Renandya, W. A., Hamied, F. A., \& Joko, N. (2018). English Language Proficiency in Indonesia : Issues and Prospects. The Journal of AsiaTEFL, 15(3), 618-629. doi:10.18823/asiatefl.2018.15.3.4.618.

Resta, P., \& Laferrière, T. (2015). Digital equity and intercultural education. Education and Information Technologies, 20(4), 743-756. doi:10.1007/s10639-015-9419-z.

Reynolds, R., Bradbery, D., Brown, J., Carroll, K., Donnelly, D., Ferguson-Patrick, K., \& Macqueen, S. (Eds). (2015). Contesting and constructing international perspectives in global education. Amsterdam: Sense Publications. doi:10.1007/978-94-6209-989-0.

Richardson, L.(2003).Writing:A method of inquiry. In Y. S. Lincoln \& N. K. Denzin (Eds.), Turning points in qualitative research:Tying knots in a handkerchief (pp. 379-414). Walnut Creek,CA:AltaMiraPress

Ridings, C. M., Gefen, D., \& Arinze, B. (2002). Some antecedents and effects of trust in virtual communities. The Journal of Strategic Information Systems, 11(3-4), 271-295. doi:10.1016/s0963-8687(02)00021-5.

Ritchie, J., Lewis, J., Nicholls, C. M., \& Ormston, R. (2013). Qualitative research practice: A guide for social science students and researchers. Thousand Oaks, CA: Sage.

Riveros, A., Newton, P., \& Burgess, D. (2012). A Situated Account of Teacher Agency and Learning: Critical Reflections on Professional Learning Communities. Canadian Journal of Education, 35(1), 202-216. 
Robertson, J. (2011). The educational affordances of blogs for self-directed learning. Computers \& Education, 57(2), 1628-1644. doi:10.1016/j.compedu.2011.03.003.

Ross, J., \& Bruce, C. (2007). Professional Development Effects on Teacher Efficacy: Results of Randomized Field Trial. The Journal of Educational Research, 101(1), 50-60. doi:10.3200/joer.101.1.50-60.

Rubin, H. J., \& Rubin, I. S. (2011). Qualitative interviewing: The art of hearing data. Thoiusand Oaks: Sage.

Ruble, L. A., Usher, E. L., \& McGrew, J. H. (2011). Preliminary Investigation of the Sources of Self-Efficacy Among Teachers of Students with Autism. Focus on Autism and Other Developmental Disabilities, 26(2), 67-74. doi:10.1177/1088357610397345.

Sachs, J. (2000). The activist professional. Journal of Educational Change, 1(1), 77-94.

Sarantakos, S. (2012). Social research (4th ed.). New York: Macmillan International Higher Education. doi: 10.1007/978-1-137-29247-6

Sari, E. R. (2012). Online learning community: a case study of teacher professional development in Indonesia. Intercultural Education, 23(1), 63-72. doi:10.1080/14675986.2012.664755.

Schlager, M. S., \& Fusco, J. (2003). Teacher Professional Development, Technology, and Communities of Practice: Are We Putting the Cart Before the Horse? The Information Society, 19(3), 203-220. doi:10.1080/01972240309464.

Schlosser, M. (2015). Agency. In Zalta, Edward N. (ed.), The Stanford Encyclopedia of Philosophy (Summer 2015 Edition). Stanford, CA: The Metaphysics Research Lab. Retrieved from https://plato.stanford.edu/archives/sum2017/entries/agency/.

Schrum, L., \& Levin, B. B. (2009). Leading 21st-century schools: Harnessing technology for engagement and achievement. Thousand Oaks, CA: Corwin Press.

Schunk, D. H., \& Pajares, F. (2009). Self-Efficacy Theory. In Wentzel, K.R., \& Wigfield, A. (Eds.), Handbook of motivation at school (pp. 49-68). London: Routledge. 
Scott, D. E., \& Scott, S. (2010). Innovations in the Use of Technology and Teacher Professional Development. In Lindberg, J. O., \& Olofsson, A. D. (Eds), Online Learning Communities and Teacher Professional Development (pp. 169-189). United States: Hershey. doi:10.4018/978-1-60566-780-5.ch010.

Sebastian, J., Allensworth, E., \& Huang, H. (2016). The Role of Teacher Leadership in How Principals Influence Classroom Instruction and Student Learning. American Journal of Education, 123(1), 69-108. doi:10.1086/688169.

Seely Brown, J., \& Adler, R. P. (2008). Open education, the long tail, and learning 2.0. Educause Review, 43(1), 16-20.

Seidman, I. (2006). Interviewing as qualitative research: A guide for researchers in education and the social sciences. New York: Teachers College Press.

Selwyn, N. (2014). Data entry: towards the critical study of digital data and education. Learning, Media and Technology, 40(1), 64-82. doi:10.1080/17439884.2014.921628.

Sharples, M. (2002). Disruptive devices: mobile technology for conversational learning. International Journal of Continuing Engineering Education and Lifelong Learning, 12(5/6), 504. doi:10.1504/ijceell.2002.002148.

Shepherd, A., \& Marshall, E. (2005). Timeliness and task specification in designing for human factors in railway operations. Applied Ergonomics, 36(6), 719-727. doi:10.1016/j.apergo.2005.05.005.

Sherin, M. G., \& Han, S. Y. (2004). Teacher learning in the context of a video club. Teaching and Teacher Education, 20(2), 163-183. doi:10.1016/j.tate.2003.08.001.

Shields, C. (2005). The dilemma of proxy-agency in exercise: A social-cognitive examination of the balance between reliance and self-regulatory ability (Unpublished Doctoral Thesis). University of Waterloo, Ontario, Canada. Retrieved from http://search.proquest.com/docview/305393800/.

Silva, D. Y., Gimbert, B., \& Nolan, J. (2000). Sliding the Doors: Locking and Unlocking Possibilities for Teacher Leadership. Teachers College Record, 102(4), 779-804. doi:10.1111/0161-4681.00077. 
Simatupang, J. (2017). Communicating Across Borders: How Well Do Indonesians Speak English? | Indonesia Investments. Retrieved from https://www.indonesiainvestments.com/id/news/todays-headlines/communicating-across-borders-how-welldo-indonesians-speak-english/item8072.

Skaalvik, E. M., \& Skaalvik, S. (2007). Dimensions of teacher self-efficacy and relations with strain factors, perceived collective teacher efficacy, and teacher burnout. Journal of Educational Psychology, 99(3), 611-625. doi:10.1037/0022-0663.99.3.611.

Smith, K. (2017). Teachers as Self-directed Learners: Active Positioning through Professional Learning (Vol. 18). Singapore: Springer. Retrieved from https://link.springer.com/content/pdf/10.1007/978-981-10-3587-6.pdf.

Smith, M. K. (2002). Malcolm Knowles, informal adult education, self-direction and andragogy. In The Encyclopaedia of Informal Education. Retrieved from http://www.infed.org/thinkers/et-knowl.htm.

Smulyan, L. (2016). Symposium Introduction: Stepping into Their Power: The Development of a Teacher Leadership Stance. Schools, 13(1), 8-28. doi:10.1086/685800.

Son, J.-B., Robb, T., \& Charismiadji, I. (2011). Computer literacy and competency: a survey of Indonesian teachers of English as a foreign language. Computer-Assisted Language Learning Electronic Journal (CALL-EJ), 12(1).

Southgate, D. (2014). Global Mobile Behaviour. Germany: Millward Brown.

Sperry, R. W. (1993). The impact and promise of the cognitive revolution. American Psychologist, 48(8), 878-885. doi:10.1037//0003-066x.48.8.878.

Spillane, J. P., Halverson, R., \& Diamond, J. B. (2001). Investigating School Leadership Practice: A Distributed Perspective. Educational Researcher, 30(3), 23-28. doi:10.3102/0013189x030003023.

Spruce, R., \& Bol, L. (2014). Teacher beliefs, knowledge, and practice of self-regulated learning. Metacognition and Learning, 10(2), 245-277. doi:10.1007/s11409-014-91240.

Stake, R. E. (1994). Case studies. In N. K. Denzin \& Y. S. Lincoln (Eds.), Handbook of qualitative research (pp. 236-247). Thousand Oaks, CA, US: Sage Publications, Inc. 
Stake, R. E. (1995). The art of case study research. Thousand Oaks, CA: Sage.

Stake, R. E. (2006). Multiple case study analysis. New York, NY. Guilford Press. Strain, PS, \& Bovey, EH (2011). Randomized Controlled Trial of the LEAP Model of Early Intervention for Young Children with Autism Spectrum Disorders. Topics in Early Childhood Special Education, 31, 133-154.

Starkey, L. (2012). Teaching and Learning in the Digital Age. London: Routledge. doi:10.4324/9780203117422.

Starkey, L. (2019). A review of research exploring teacher preparation for the digital age. Cambridge Journal of Education, 1(20). doi:10.1080/0305764x.2019.1625867.

Stefanone, M. A., Lackaff, D., \& Rosen, D. (2010). The Relationship between Traditional Mass Media and "Social Media": Reality Television as a Model for Social Network Site Behavior. Journal of Broadcasting \& Electronic Media, 54(3), 508-525. doi:10.1080/08838151.2010.498851.

Stockton, R. J. (2018). Recultured language in Indonesian English Language Teaching. Indonesian JELT, 13(2), 131-153. doi:10.25170/IJELT.V13I2.1176.

S Stošić, L., \& Stosic, I. (2013). Diffusion of innovation in modern school. International Journal of Cognitive Research in Science, Engineering and Education:(IJCRSEE), 1(1), $5-13$.

Strauss, A., \& Corbin, J. M. (1990). Basics of qualitative research: Grounded theory procedures and techniques. Thousand Oaks, CA, US: Sage Publications, Inc.

Streubert-Speziale, H. J. (2007). Designing data generation and management strategies. Qualitative Research in Nursing: Advancing the Humanistic Imperative, 4, 35-56.

Strucchelli, A. (2009). Inquiry in the classroom: Peer observation as a form of job-embedded professional learning. (Unpublished master's Thesis), Queen's University, Kingston, Canada.

Sulfasyah, S., Haig, Y., \& Barratt-Pugh, C. (2015). Indonesian Teachers' Implementation of New Curriculum Initiatives in Relation to Teaching Writing in Lower Primary School. International Journal of Education, 7(4), 53. doi:10.5296/ije.v7i4.8265. 
Sutton, J., \& Austin, Z. (2015). Qualitative Research: Data Collection, Analysis, and Management. The Canadian Journal of Hospital Pharmacy, 68(3). doi:10.4212/cjhp.v68i3.1456.

Swanson, P. (2012). Second/Foreign Language Teacher Efficacy and its Relationship to Professional Attrition. Canadian Modern Language Review, 68(1), 78-101. doi:10.3138/cmlr.68.1.078.

Sweeney, B. (2005). Management and Leadership in schools. Teacher. The National Education Magazine, (Aug 2005), 48.

Szmigin, I., \& Reppel, A. E. (2004). Internet community bonding: The case of macnews.de. European Journal of Marketing, 38(5/6), 626-640. doi:10.1108/03090560410529259.

Tanang, H., \& Abu, B. (2014). Teacher Professionalism and Professional Development Practices in South Sulawesi, Indonesia. Journal of Curriculum and Teaching, 3(2). doi:10.5430/jct.v3n2p25.

Tang, S. Y. F., \& Choi, P. L. (2009). Teachers' professional lives and continuing professional development in changing times. Educational Review, 61(1), 1-18. doi:10.1080/00131910802684748.

Thanh, N. C., \& Thanh, T. T. (2015). The interconnection between interpretivist paradigm and qualitative methods in education. American Journal of Educational Science, 1(2), 2427.

The Economist Intelligence Unit. (2018). Preparing for disruption Technological Readiness Ranking. Retrieved from https://www.agenceecofin.com/files/31/Hebdo/186/EcofinHebdo-3-2018-06_-_EIU__Preparing_for_disruption_Technological_readiness_ranking.pdf.

The regulation/law of the Minister of Home Affairs Republic of Indonesia No 56, 2015. (2015). Kementerian Dalam Negeri Republik Indonesia. Retrieved from https://www.kemendagri.go.id/index.php.

Thomas, R. (2003). Blending Qualitative \& Quantitative Research Methods in Theses and Dissertations. Thousand Oaks, CA: Corwin Press. doi:10.4135/9781412983525.

Thoresen, C. E., \& Mahoney, M. J. (1974). Behavioural self-control. New York: Holt, Rinehart \& Winston. 
Thorpe, V. (2018). Two conceptual models and their relationship to teaching and assessing group composing. In McPhail, G., Thorpe, V., \& Wise, S. (Eds), Educational Change and the Secondary School Music Curriculum in Aotearoa New Zealand (pp. 95112).London: Routledge. doi:10.4324/9781315109602-7.

Tobin, G. A., \& Begley, C. M. (2004). Methodological rigour within a qualitative framework. Journal of Advanced Nursing, 48(4), 388-396. doi:10.1111/j.1365-2648.2004.03207.x.

Torop, P. (2002). Translation as translating as culture. Sign Systems Studies, 30(2), 593-605.

Tour, E. (2016). Teachers' self-initiated professional learning through Personal Learning Networks. Technology, Pedagogy and Education, 26(2), 179-192. doi:10.1080/1475939x.2016.1196236.

Tripp, D. (2004). Teachers' networks: A new approach to the professional development of teachers in Singapore. In C. Day \& J. Sachs (Eds.), International handbook on the continuing professional development of teachers (pp. 191-214). Maidenhead England: Open University Press

Trust, T. (2012). Professional Learning Networks Designed for Teacher Learning. Journal of Digital Learning in Teacher Education, 28(4), 133-138. doi:10.1080/21532974.2012.10784693.

Trust, T. (2015). Deconstructing an Online Community of Practice: Teachers' Actions in the Edmodo Math Subject Community. Journal of Digital Learning in Teacher Education, 31(2), 73-81. doi:10.1080/21532974.2015.1011293.

Trust, T. (2017). Motivation, Empowerment, and Innovation: Teachers' Beliefs About How Participating in the Edmodo Math Subject Community Shapes Teaching and Learning. Journal of Research on Technology in Education, 49(1-2), 16-30. doi:10.1080/15391523.2017.1291317.

Trust, T., Carpenter, J. P., \& Krutka, D. G. (2018). Leading by learning: exploring the professional learning networks of instructional leaders. Educational Media International, 55(2), 137-152. doi:10.1080/09523987.2018.1484041.

Trust, T., Krutka, D. G., \& Carpenter, J. P. (2016). Together we are better: Professional learning networks for teachers. Computers \& Education, 102, 15-34. doi:10.1016/j.compedu.2016.06.007. 
Tschannen-Moran, M., \& Hoy, A. W. (2001). Teacher efficacy: capturing an elusive construct. Teaching and Teacher Education, 17(7), 783-805. doi:10.1016/s0742-051x(01)000361.

Tseng, F.-C., \& Kuo, F.-Y. (2014). A study of social participation and knowledge sharing in the teachers' online professional community of practice. Computers \& Education, 72, 37 47. doi:10.1016/j.compedu.2013.10.005.

Tsoukas, H. (1997). The tyranny of light. Futures, 29(9), 827-843. doi:10.1016/s00163287(97)00035-9.

Tsvetkova, M. S., \& Kiryukhin, V. M. (2019). Advanced Digital Competence of the Teacher. In Monyai, R. (Ed), Teacher Education in the 21st Century, 13, 237-240. doi:10.5772/intechopen.83788.

Uhl-Bien, M., \& Marion, R. (2009). Complexity leadership in bureaucratic forms of organizing: A meso model. The Leadership Quarterly, 20(4), 631-650. doi:10.1016/j.leaqua.2009.04.007.

Ulin, P. R., Robinson, E. T., \& Tolley, E. E. (2005). Qualitative Methods in Public Health: A Field Guide for Applied Research. Medicine \& Science in Sports \& Exercise, 37(7), 1249. doi:10.1249/01.mss.0000172593.20181.14.

Vähäsantanen, K., Hökkä, P., Paloniemi, S., Herranen, S., \& Eteläpelto, A. (2016). Professional learning and agency in an identity coaching programme. Professional Development in Education, 43(4), 514-536. doi:10.1080/19415257.2016.1231131.

Van Eekelen, I. M., Vermunt, J. D., \& Boshuizen, H. P. A. (2006). Exploring teachers' will to learn. Teaching and Teacher Education, 22(4), 408-423.

Vangrieken, K., Meredith, C., Packer, T., \& Kyndt, E. (2017). Teacher communities as a context for professional development: A systematic review. Teaching and Teacher Education, 61, 47-59. doi:10.1016/j.tate.2016.10.001.

Vaughan, K. (2004). Beyond the age of Aquarius: Reframing alternative education. New Zealand: New Zealand Council for Educational Research.

Vavasseur, C. B., \& Kim MacGregor, S. (2008). Extending Content-Focused Professional Development through Online Communities of Practice. Journal of Research on Technology in Education, 40(4), 517-536. doi:10.1080/15391523.2008.10782519. 
Vescio, V., Ross, D., \& Adams, A. (2008). A review of research on the impact of professional learning communities on teaching practice and student learning. Teaching and Teacher Education, 24(1), 80-91. doi:10.1016/j.tate.2007.01.004.

Villegas-Reimers, E. (2003). Teacher professional development: an international review of the literature. Paris: UNESCO International Institute for Educational Planning. Retrieved from www.unesco.org/iiep.

Visser, R. D., Evering, L. C., \& Barrett, D. E. (2014). \#TwitterforTeachers: The Implications of Twitter as a Self-Directed Professional Development Tool for K-12 Teachers. Journal of Research on Technology in Education, 46(4), 396-413. doi:10.1080/15391523.2014.925694.

Voogt, J., Knezek, G., Christensen, R., \& Lai, K.-W. (Eds). (2018). Springer International Handbooks of Education Second Handbook of Information Technology in Primary and Secondary Education. Retrieved from http://www.springer.com/series/6189.

Walsham, G. (1995). Interpretive case studies in IS research: nature and method. European Journal of Information Systems, 4(2), 74-81. doi:10.1057/ejis.1995.9.

Wang, S.-L., \& Lin, S. S. J. (2007). The application of social cognitive theory to web-based learning through NetPorts. British Journal of Educational Technology, 38(4), 600-612. doi:10.1111/j.1467-8535.2006.00645.x.

Ware, H., \& Kitsantas, A. (2007). Teacher and Collective Efficacy Beliefs as Predictors of Professional Commitment. The Journal of Educational Research, 100(5), 303-310. doi:10.3200/joer.100.5.303-310.

Watkins, C. (2017). Developing Student-Driven Learning: The Patterns, the Context, and the Process. In N. Alias, \& J. Luaran (Eds.), Student-Driven Learning Strategies for the 21st Century Classroom (pp. 1-9). Hershey, PA: IGI Global. doi:10.4018/978-1-52251689-7.ch001.

Webster-Wright, A. (2010). Making a Difference. In Billet, S., Harteis, C., \& Gruber, H. (Eds), Authentic professional learning: Making a Difference through learning at work (Professional and Practice-based Learning) (pp. 231-251). Germany: Springer. doi:10.1007/978-90-481-3947-7_9. 
Welsh, E. (2002). Dealing with data: Using NVivo in the qualitative data analysis process. Forum Qualitative Sozialforschung/Forum: Qualitative Social Research, 3(2).

Wenger, E., White, N., \& Smith, J. (2009). Learning in Communities. In Ehlers, U-D., \& Schenckenberg, D. (Eds.), Changing Cultures in Higher Education (pp. 257-283). Germany: Springer. doi:10.1007/978-3-642-03582-1_20.

Wenner, J. A., \& Campbell, T. (2016). The Theoretical and Empirical Basis of Teacher Leadership. Review of Educational Research, 87(1), 134-171. doi:10.3102/0034654316653478.

Wesely, P. M. (2013). Investigating the Community of Practice of World Language Educators on Twitter. Journal of Teacher Education, 64(4), 305-318. doi:10.1177/0022487113489032.

Widodo, A., \& Riandi. (2013). Dual-mode teacher professional development: challenges and re-visioning future TPD in Indonesia. Teacher Development, 17(3), 380-392. doi:10.1080/13664530.2013.813757.

Willis, J. W. (2007). Foundations of qualitative research: Interpretive and critical approaches. Thousand Oaks, CA: SAGE Publications, Inc. doi: 10.4135/9781452230108

Wilson, B., \& Ryder, M. (1996). Dynamic Learning Communities: An Alternative to Designed Instructional Systems. In Selected Research and Development Presentations at the 1996 National Convention of the Association for Educational Communications and Technology.

Wood, R., \& Bandura, A. (1989). Social Cognitive Theory of Organizational Management. Academy of Management Review, 14(3), 361-384. doi:10.5465/amr.1989.4279067.

Wright, N. (2015). Developing digital smarts in initial teacher education: What motivates new teachers to continue using digital technologies for learning? In N. Wright \& D. L. Forbes (Eds.), Digital Smarts: Enhancing Learning \& Teaching (pp. 104-122). Hamilton, New Zealand: Wilf Malcolm Institute of Educational Research.

Wright, N., \& Forbes, D. (2016). Twitter in Education. E-Learning and Digital Media, 13(1-2), 3-4. doi:10.1177/2042753016666424. 
Xerri, D. (2017). Teachers' Use of Social Networking Sites for Continuing Professional Development. In I. R. M. Association (Ed.), Teacher Education: Concepts, Methodologies, Tools, and Applications (pp. 635-659). PA: Hershey. doi:10.4018/9781-5225-1624-8.ch031.

Xie, B. (2008). The Mutual Shaping of Online and Offline Social Relationships. Information Research: An International Electronic Journal, 13(3).

Yoon, K. S., Duncan, T., Lee, S. W.-Y., Scarloss, B., \& Shapley, K. (2007). Reviewing the evidence on how teacher professional development affects student achievement (Issues \& Answers Report, REL 2007-No. 033). Washington, DC: U.S. Department of Education, Institute of Education Sciences, National Center for Education Evaluation and Regional Assistance, Regional Educational Laboratory Southwest. Retrieved from http://ies.ed.gov/ncee/edlabs

York-Barr, J., \& Duke, K. (2004). What Do We Know About Teacher Leadership? Findings From Two Decades of Scholarship. Review of Educational Research, 74(3), 255-316. doi:10.3102/00346543074003255.

Yusri, I. K., Goodwin, R., \& Mooney, C. (2018). Mobile Learning for Teachers Training in Indonesia: The Potential of Mobile Phones as the Device. In Proceedings of the 8th International Conference of Asian Association of Indigenous and Cultural Psychology (ICAAIP 2017). doi:10.2991/icaaip-17.2018.42.

Zacharias, N. T. (2005). Teachers' Beliefs about Internationally-Published Materials: A Survey of Tertiary English Teachers in Indonesia. RELC Journal, 36(1), 23-37. doi:10.1177/0033688205053480.

Zainal, Z. (2007). Case study as a research method. Jurnal Kemanusiaan, 5(1). Retrieved from https://jurnalkemanusiaan.utm.my/index.php/kemanusiaan/article/view/165/158.

Zuidema, L. A. (2011). Making Space for Informal Inquiry. Journal of Teacher Education, 63(2), 132-146. doi:10.1177/0022487111428326. 


\section{APPENDICES}

\section{Appendix 1. The Interview Protocol and Guideline}

\section{INTERVIEW PROTOCOLS \& GUIDELINE}

\section{Script prior to interview}

I would like to thank you once again for being willing to participate in my study by being the participants in this interview. As I have mentioned to you before, my study seeks to understand how Indonesian educators experience using social media for informal professional learning practices as leaders and members of GEG. My study also seeks to understand how these GEGs facilitate informal professional learning practices among Indonesian educators. Our interview today will last approximately 60 to 90 minutes during which I will also be asking you about your professional background: duration of teaching experience, teaching location, teaching dynamic, leadership/organizational experience, community service experience/volunteer, teaching aspiration, teaching challenges, current hobbies and activities related to professional learning. Since you signed the informed consent already, I need to ask you whether you understand ever information in the informed consent. If you still have any question regarding the informed consent, please let me know before we begin the interview. In the informed consent that you signed, it is also stated that I have your permission (or not) to audio record our conversation. Are you still ok with me recording (or not) our conversation today? Yes _ No. If yes: Thank you! Please let me know if at any point you want me to turn off the recorder or keep something you said off the record. If no: Thank you for letting me know. I will only take notes of our conversation. Before we begin the interview, do you have any questions? [Discuss questions] If any questions (or other questions) arise at any point in this study, you can feel free to ask them at any time. I would be more than happy to answer your questions Ice breaker/warm up question

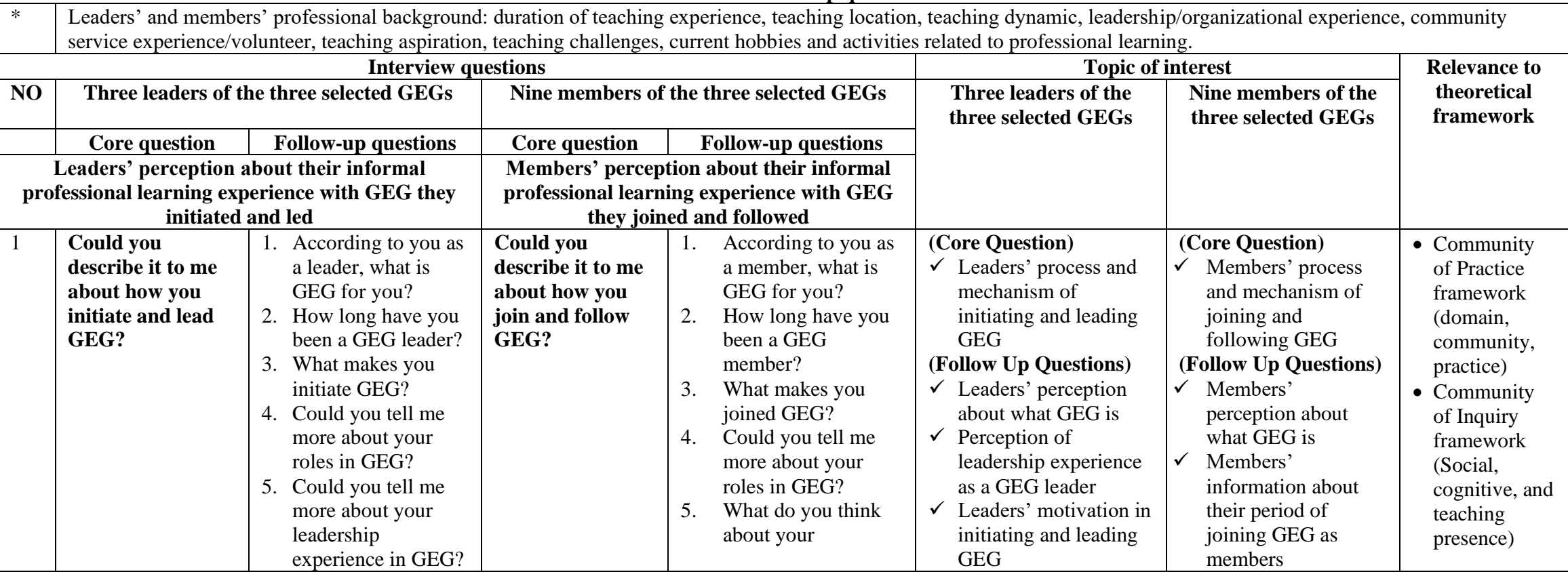




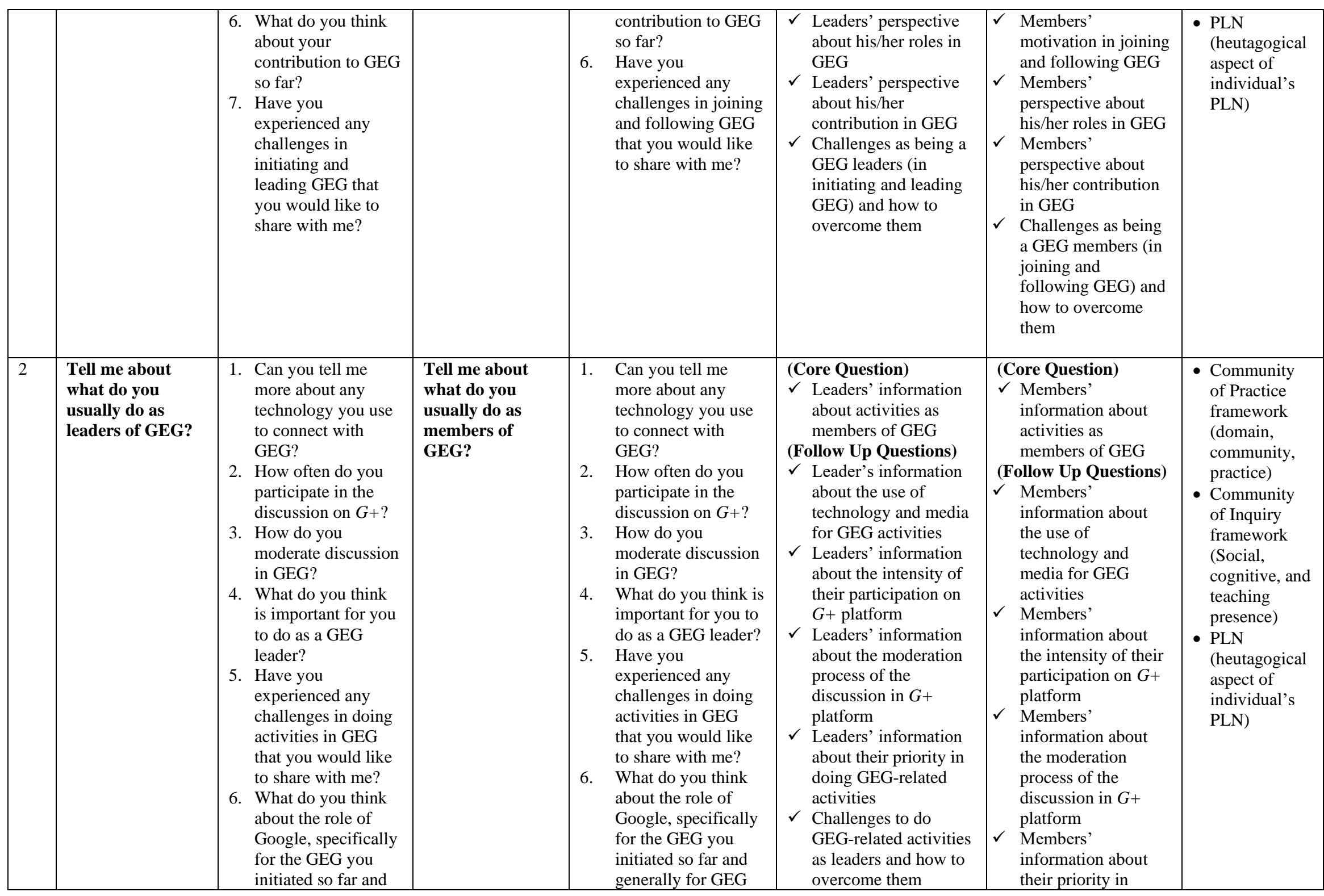




\begin{tabular}{|c|c|c|c|c|c|c|c|c|}
\hline & & $\begin{array}{l}\text { generally for GEG } \\
\text { and teachers in } \\
\text { Indonesia? }\end{array}$ & & & $\begin{array}{l}\text { and teachers in } \\
\text { Indonesia }\end{array}$ & $\begin{array}{l}\checkmark \text { Leaders' perspective } \\
\text { about the role of } \\
\text { Google in GEG they } \\
\text { initiated (specifically) } \\
\text { and the implication of } \\
\text { Google for teachers in } \\
\text { Indonesia }\end{array}$ & $\begin{array}{l}\text { doing GEG-related } \\
\text { activities } \\
\checkmark \text { Challenges to do } \\
\text { GEG-related } \\
\text { activities as } \\
\text { members and how to } \\
\text { overcome them } \\
\checkmark \quad \begin{array}{l}\text { Members' } \\
\text { perspective about the } \\
\text { role of Google in } \\
\text { GEG they joined } \\
\text { (specifically) and the } \\
\text { implication of } \\
\text { Google for teachers } \\
\text { in Indonesia }\end{array} \\
\end{array}$ & \\
\hline 3 & $\begin{array}{l}\text { Could you } \\
\text { describe more } \\
\text { about how you } \\
\text { interact, } \\
\text { communicate, } \\
\text { collaborate, } \\
\text { discuss, and } \\
\text { network with } \\
\text { others in GEG? }\end{array}$ & $\begin{array}{l}\text { 1. How well do you } \\
\text { know other members } \\
\text { in your GEG? } \\
\text { 2. How do you usually } \\
\text { like to discuss, share, } \\
\text { and re-share on } G+\text { ? } \\
\text { 3. Would you like to } \\
\text { tell me more about } \\
\text { tools or resources } \\
\text { that you think is } \\
\text { important for your } \\
\text { GEG-related } \\
\text { interaction, } \\
\text { communication, } \\
\text { discussion, and } \\
\text { networking? } \\
\text { 4. Any collaboration } \\
\text { experience in/with } \\
\text { GEG that you would } \\
\text { like to share with } \\
\text { me? } \\
\text { 5. Have you } \\
\text { experienced any } \\
\text { challenges in your } \\
\text { leadership roles in } \\
\text { GEG that you would } \\
\text { like to share with } \\
\text { me? }\end{array}$ & $\begin{array}{l}\text { Could you } \\
\text { describe more } \\
\text { about how you } \\
\text { interact, } \\
\text { communicate, } \\
\text { collaborate, } \\
\text { discuss, and } \\
\text { network with } \\
\text { others in GEG? }\end{array}$ & $\begin{array}{l}1 . \\
2 . \\
3 . \\
3 . \\
4 .\end{array}$ & $\begin{array}{l}\text { How well do you } \\
\text { know other members } \\
\text { in your GEG? } \\
\text { How do you usually } \\
\text { like to discuss, } \\
\text { share, and re-share } \\
\text { on G+? } \\
\text { Would you like to } \\
\text { tell me more about } \\
\text { tools or resources } \\
\text { that you think is } \\
\text { important for your } \\
\text { GEG-related } \\
\text { interaction, } \\
\text { communication, } \\
\text { discussion, and } \\
\text { networking? } \\
\text { Any collaboration } \\
\text { experience in/with } \\
\text { GEG that you would } \\
\text { like to share with } \\
\text { me? } \\
\text { Have you } \\
\text { experienced any } \\
\text { challenges in your } \\
\text { leadership roles in } \\
\text { GEG that you would }\end{array}$ & $\begin{array}{l}\text { (Core Question) } \\
\checkmark \text { Leader's perspective on } \\
\text { the nature and dynamic } \\
\text { of interaction and } \\
\text { participation in GEG } \\
\text { (Follow Up Questions) } \\
\checkmark \text { Leader's information } \\
\text { about the demography } \\
\text { of GEG members } \\
\checkmark \text { Leaders' information } \\
\text { about preference of } \\
\text { their online activities } \\
\text { on } G+ \\
\checkmark \text { Leaders' information } \\
\text { about their preference } \\
\text { using } \\
\text { technology/tools/resour } \\
\text { ces for GEG-related } \\
\text { activities } \\
\checkmark \text { Leaders' information } \\
\text { about their GEG- } \\
\text { related collaborative } \\
\text { experiences as leaders } \\
\checkmark \text { Challenges in the GEG- } \\
\text { related collaborative } \\
\text { experiences as leaders } \\
\checkmark \text { and how to overcome } \\
\text { them } \\
\end{array}$ & $\begin{array}{l}\text { (Core Question) } \\
\checkmark \text { Members' } \\
\text { perspective on the } \\
\text { nature and dynamic } \\
\text { of interaction and } \\
\text { participation in GEG } \\
\text { (Follow Up Questions) } \\
\checkmark \text { Members } \\
\text { information about the } \\
\text { demography of GEG } \\
\text { members } \\
\checkmark \text { Members' } \\
\text { information about } \\
\text { preference of their } \\
\text { online activities on } \\
\text { G+ } \\
\checkmark \text { Members' } \\
\text { information about } \\
\text { their preference using } \\
\text { technology/tools/reso } \\
\text { urces for GEG- } \\
\text { related activities } \\
\checkmark \text { Members' } \\
\text { information about } \\
\text { their GEG-related } \\
\text { collaborative } \\
\text { experiences as } \\
\text { leaders }\end{array}$ & $\begin{array}{l}\text { - Community } \\
\text { of Practice } \\
\text { framework } \\
\text { (domain, } \\
\text { community, } \\
\text { practice) } \\
\text { - Community } \\
\text { of Inquiry } \\
\text { framework } \\
\text { (Social, } \\
\text { cognitive, and } \\
\text { teaching } \\
\text { presence) } \\
\text { - PLN } \\
\text { (heutagogical } \\
\text { aspect of } \\
\text { individual's } \\
\text { PLN) }\end{array}$ \\
\hline
\end{tabular}




\begin{tabular}{|c|c|c|c|c|c|c|c|c|}
\hline & & & & & $\begin{array}{l}\text { like to share with } \\
\text { me? }\end{array}$ & & $\begin{array}{l}\checkmark \text { Challenges in the } \\
\text { GEG-related } \\
\text { collaborative } \\
\text { experiences as } \\
\text { members } \\
\checkmark \text { and how to overcome } \\
\text { them }\end{array}$ & \\
\hline 4 & $\begin{array}{l}\text { What is your most } \\
\text { rewarding } \\
\text { informal } \\
\text { professional } \\
\text { learning } \\
\text { experience as } \\
\text { GEG leaders so } \\
\text { far and why? }\end{array}$ & $\begin{array}{l}\text { 1. What things do you } \\
\text { learn as GEG } \\
\text { leader? } \\
\text { 2. What is the most } \\
\text { important thing you } \\
\text { value the most } \\
\text { in/from GEG? } \\
\text { 3. What is the most } \\
\text { challenging } \\
\text { experience you } \\
\text { have with GEG? } \\
\text { 4. How do you } \\
\text { implement your } \\
\text { informal } \\
\text { professional } \\
\text { learning experience } \\
\text { as GEG leader to } \\
\text { your own } \\
\text { professional } \\
\text { practices (e.g. in } \\
\text { school, in classes)? } \\
\text { Do you think the } \\
\text { GEG you initiated } \\
\text { brings any } \\
\text { implication to } \\
\text { teachers in your } \\
\text { region? If so, can } \\
\text { you tell me what } \\
\text { and how? } \\
\text { What is your next } \\
\text { goals and } \\
\text { expectation of the } \\
\text { GEG you initiated } \\
\text { so far (specifically) } \\
\text { and Indonesian }\end{array}$ & $\begin{array}{l}\text { What is your } \\
\text { most rewarding } \\
\text { informal } \\
\text { professional } \\
\text { learning } \\
\text { experience as } \\
\text { GEG members so } \\
\text { far and why? }\end{array}$ & 2. & $\begin{array}{l}\text { What things do you } \\
\text { learn as GEG } \\
\text { leader? } \\
\text { What is the most } \\
\text { important thing you } \\
\text { value the most } \\
\text { in/from GEG? } \\
\text { What is the most } \\
\text { challenging } \\
\text { experience you have } \\
\text { with GEG? } \\
\text { How do you } \\
\text { implement your } \\
\text { informal } \\
\text { professional learning } \\
\text { experience as GEG } \\
\text { leader to your own } \\
\text { professional } \\
\text { practices (e.g. in } \\
\text { school, in classes)? } \\
\text { Do you think the } \\
\text { GEG you initiated } \\
\text { brings any } \\
\text { implication to } \\
\text { teachers in your } \\
\text { region? If so, can } \\
\text { you tell me what and } \\
\text { how? } \\
\text { What is your next } \\
\text { goals and } \\
\text { expectation of the } \\
\text { GEG you initiated so } \\
\text { far (specifically) and } \\
\text { Indonesian GEGs (in } \\
\text { general) in the future }\end{array}$ & $\begin{array}{l}\text { (Core Question) } \\
\checkmark \text { Most rewarding } \\
\text { informal professional } \\
\text { learning experience as } \\
\text { GEG leaders (after a } \\
\text { while, initiating and } \\
\text { leading GEG) } \\
\text { (Follow Up Questions) } \\
\checkmark \quad \text { Leaders' information } \\
\text { about things they } \\
\text { learnt as GEG leaders } \\
\checkmark \quad \text { Leaders' information } \\
\text { about the most } \\
\text { important thing they } \\
\text { valued as GEG leader } \\
\checkmark \quad \text { Leaders' information } \\
\text { about their most } \\
\text { challenging } \\
\text { experience as GEG } \\
\text { leaders } \\
\checkmark \text { Leaders' information } \\
\text { about the implication } \\
\text { of informal } \\
\text { professional learning } \\
\text { experience as GEG } \\
\text { leaders to their } \\
\text { professional practices } \\
\text { Leaders' information } \\
\text { about the implication } \\
\text { of the GEGs they } \\
\text { initiated to teachers } \\
\text { in the region where } \\
\text { they initiated their } \\
\text { GEGs }\end{array}$ & $\begin{array}{l}\text { (Core Question) } \\
\checkmark \quad \text { Most rewarding } \\
\text { informal } \\
\text { professional } \\
\text { learning experience } \\
\text { as GEG members } \\
\text { (after a while, } \\
\text { joining GEG and } \\
\text { following GEG- } \\
\text { related activities) } \\
\text { (Follow Up Questions) } \\
\checkmark \text { members' } \\
\text { information about } \\
\text { things they learnt as } \\
\text { GEG members } \\
\checkmark \text { Members' } \\
\text { information about } \\
\text { the most important } \\
\text { thing they valued as } \\
\text { GEG members } \\
\checkmark \text { Members' } \\
\text { information about } \\
\text { their most } \\
\text { challenging } \\
\text { experience as GEG } \\
\text { members } \\
\checkmark \text { Members' } \\
\text { information about } \\
\text { the implication of } \\
\text { informal } \\
\text { professional } \\
\text { learning experience } \\
\text { as GEG members } \\
\text { to their professional } \\
\text { practices }\end{array}$ & $\begin{array}{l}\text { Value-Creation } \\
\text { Framework: } \\
\text { Immediate, } \\
\text { Potential, } \\
\text { Applied, } \\
\text { Realized, } \\
\text { Reframed values }\end{array}$ \\
\hline
\end{tabular}




\begin{tabular}{|c|c|c|c|c|c|c|c|}
\hline & & $\begin{array}{l}\text { GEGs (in general) } \\
\text { in the future }\end{array}$ & & & $\begin{array}{l}\text { Leaders' information } \\
\text { about their future } \\
\text { goals and expectation } \\
\text { of the GEGs they } \\
\text { initiated (specifically) } \\
\text { and Indonesian GEGs } \\
\text { (in general). }\end{array}$ & $\begin{array}{l}\text { Members' } \\
\text { information about } \\
\text { the implication of } \\
\text { the GEGs to } \\
\text { teachers in the } \\
\text { region where they } \\
\text { joined GEGs } \\
\checkmark \text { Members' } \\
\text { information about } \\
\text { their future goals } \\
\text { and expectation of } \\
\text { the GEGs they } \\
\text { joined (specifically) } \\
\text { and Indonesian } \\
\text { GEGs (in general). }\end{array}$ & \\
\hline 5 & $\begin{array}{l}\text { How do you } \\
\text { particularly use } \\
\text { social media on } \\
\text { daily basis? }\end{array}$ & $\begin{array}{l}\text { 1. How many social } \\
\text { media do you } \\
\text { actively use, why? } \\
\text { 2. How often do you } \\
\text { use social media? } \\
\text { 3. What is the } \\
\text { difference between } \\
\text { each of your social } \\
\text { media use/how do } \\
\text { you use each? }\end{array}$ & $\begin{array}{l}\text { How do you } \\
\text { particularly use } \\
\text { social media on } \\
\text { daily basis? }\end{array}$ & $\begin{array}{l}\text { 1. How many social } \\
\text { media do you } \\
\text { actively use, why? } \\
\text { 2. How often do you } \\
\text { use social media? } \\
\text { 3. What is the } \\
\text { difference between } \\
\text { each of your social } \\
\text { media use/how do } \\
\text { you use each? }\end{array}$ & 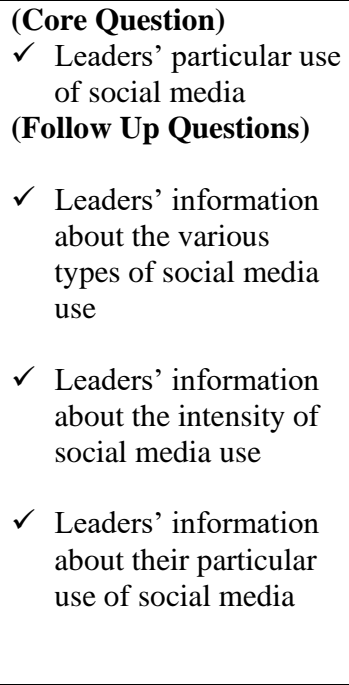 & 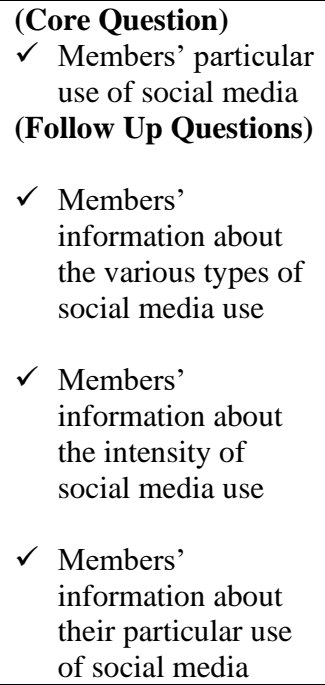 & $\begin{array}{l}\text { Value-Creation } \\
\text { Framework: } \\
\text { Immediate, } \\
\text { Potential, } \\
\text { Applied, } \\
\text { Realized, } \\
\text { Reframed values }\end{array}$ \\
\hline 6 & $\begin{array}{l}\text { What do you } \\
\text { think about the } \\
\text { implication of } \\
\text { your informal } \\
\text { professional } \\
\text { learning using } \\
\text { social media to } \\
\text { your professional } \\
\text { practice (e.g. at }\end{array}$ & $\begin{array}{l}\text { 1. How social media } \\
\text { enables you to } \\
\text { learn? } \\
\text { 2. How does the use } \\
\text { of social media } \\
\text { influence your } \\
\text { professional } \\
\text { practice? }\end{array}$ & $\begin{array}{l}\text { What do you think } \\
\text { about the impact } \\
\text { of your social } \\
\text { media to your } \\
\text { informal } \\
\text { professional } \\
\text { learning and why? }\end{array}$ & $\begin{array}{l}\text { 1. How social media } \\
\text { enables you to learn? } \\
\text { 2. How does the use of } \\
\text { social media } \\
\text { influence your } \\
\text { professional } \\
\text { practice? } \\
\text { 3. What makes you } \\
\text { interested to use }\end{array}$ & $\begin{array}{l}\text { (Core Question) } \\
\checkmark \text { Leaders' information } \\
\text { about the implication } \\
\text { of the use of social } \\
\text { media for informal } \\
\text { professional learning } \\
\text { to their professional } \\
\text { practice }\end{array}$ & $\begin{array}{l}\text { (Core Question) } \\
\checkmark \text { Members' } \\
\text { information about } \\
\text { the implication of } \\
\text { the use of social } \\
\text { media for informal } \\
\text { professional learning } \\
\text { to their professional } \\
\text { practice }\end{array}$ & $\begin{array}{l}\text { Value-Creation } \\
\text { Framework: } \\
\text { Immediate, } \\
\text { Potential, } \\
\text { Applied, } \\
\text { Realized, } \\
\text { Reframed values }\end{array}$ \\
\hline
\end{tabular}




\begin{tabular}{|c|c|c|c|c|c|c|c|c|}
\hline & $\begin{array}{l}\text { school, in the } \\
\text { classroom, etc)? }\end{array}$ & $\begin{array}{l}\text { 3. What makes you } \\
\text { interested to use } \\
\text { social media for } \\
\text { informal } \\
\text { professional } \\
\text { learning and why? }\end{array}$ & & & $\begin{array}{l}\text { social media for } \\
\text { informal professional } \\
\text { learning and why? }\end{array}$ & $\begin{array}{l}\text { (Follow Up Questions) } \\
\checkmark \text { Leaders' information } \\
\text { about the way social } \\
\text { media enables them to } \\
\text { learn } \\
\checkmark \text { Leaders' information } \\
\text { about the implication } \\
\text { of their informal } \\
\text { professional learning } \\
\text { experience using } \\
\text { social media to their } \\
\text { professional practice } \\
\checkmark \text { Leaders' information } \\
\text { about their interest } \\
\text { using social media for } \\
\text { informal professional } \\
\text { learning }\end{array}$ & $\begin{array}{l}\text { (Follow Up Questions) } \\
\checkmark \text { Members' } \\
\text { information about } \\
\text { the way social media } \\
\text { enables them to } \\
\text { learn } \\
\checkmark \text { Members' } \\
\text { information about } \\
\text { the implication of } \\
\text { their informal } \\
\text { professional learning } \\
\text { experience using } \\
\text { social media to their } \\
\text { professional practice } \\
\checkmark \text { Members' } \\
\text { information about } \\
\text { their interest using } \\
\text { social media for } \\
\text { informal } \\
\text { professional learning }\end{array}$ & \\
\hline 7 & $\begin{array}{l}\text { What do you } \\
\text { think about the } \\
\text { use of social } \\
\text { media for } \\
\text { professional } \\
\text { learning of } \\
\text { educators in } \\
\text { Indonesia? }\end{array}$ & $\begin{array}{l}\text { 1. From your } \\
\text { perspective, how } \\
\text { do educators use } \\
\text { social media so far } \\
\text { in Indonesia? }\end{array}$ & $\begin{array}{l}\text { What do you think } \\
\text { about the use of } \\
\text { social media for } \\
\text { professional } \\
\text { learning of } \\
\text { educators in } \\
\text { Indonesia? }\end{array}$ & 1. & $\begin{array}{l}\text { From your } \\
\text { perspective, how do } \\
\text { educators use social } \\
\text { media so far in } \\
\text { Indonesia? }\end{array}$ & $\begin{array}{l}\text { (Core Question) } \\
\checkmark \text { Leaders' information } \\
\text { about their perspective } \\
\text { towards the use of } \\
\text { social media for } \\
\text { professional learning of } \\
\text { educators in Indonesia? } \\
\text { (Follow Up Question) } \\
\checkmark \text { Leaders' information } \\
\text { about the way } \\
\text { educators in Indonesia } \\
\text { use social media so far }\end{array}$ & $\begin{array}{l}\text { (Core Question) } \\
\checkmark \text { Members' } \\
\text { information about the } \\
\text { use of social media } \\
\text { for professional } \\
\text { learning of educators } \\
\text { in Indonesia? } \\
\text { (Follow Up Question) } \\
\checkmark \text { Members' } \\
\text { information about } \\
\text { the way educators } \\
\text { in Indonesia use } \\
\text { social media so far }\end{array}$ & $\begin{array}{l}\text { Value-Creation } \\
\text { Framework: } \\
\text { Immediate, } \\
\text { Potential, } \\
\text { Applied, } \\
\text { Realized, } \\
\text { Reframed values }\end{array}$ \\
\hline 8 & $\begin{array}{l}\text { Do you have } \\
\text { anything more to } \\
\text { say about your } \\
\text { informal } \\
\text { professional } \\
\text { learning } \\
\text { experience (with } \\
\text { GEG or with } \\
\text { social media) }\end{array}$ & $\begin{array}{l}\text { 1. Do you feel any } \\
\text { similarities and/or } \\
\text { differences from } \\
\text { your learning } \\
\text { experience with } \\
\text { social media, } \\
\text { including GEG and } \\
\text { from your learning } \\
\text { experience with } \\
\end{array}$ & $\begin{array}{l}\text { Do you have } \\
\text { anything more to } \\
\text { say about your } \\
\text { informal } \\
\text { professional } \\
\text { learning } \\
\text { experience (with } \\
\text { GEG or with } \\
\text { social media) }\end{array}$ & & $\begin{array}{l}\text { Do you feel any } \\
\text { similarities or } \\
\text { differences from } \\
\text { your learning } \\
\text { experience with } \\
\text { social media, } \\
\text { including GEG and } \\
\text { from your learning } \\
\text { experience with } \\
\end{array}$ & $\begin{array}{l}\text { (Core Question) } \\
\checkmark \quad \text { Leaders' information } \\
\text { about reflecting on } \\
\text { their informal } \\
\text { professional learning } \\
\text { with social media, } \\
\text { including GEG } \\
\text { compared to the } \\
\text { formal and }\end{array}$ & $\begin{array}{l}\text { (Core Question) } \\
\checkmark \quad \text { Members' } \\
\text { information about } \\
\text { reflecting on their } \\
\text { informal } \\
\text { professional } \\
\text { learning with social } \\
\text { media, including } \\
\text { GEG compared to } \\
\end{array}$ & $\begin{array}{l}\text { Value-Creation } \\
\text { Framework: } \\
\text { Immediate, } \\
\text { Potential, } \\
\text { Applied, } \\
\text { Realized, } \\
\text { Reframed values }\end{array}$ \\
\hline
\end{tabular}




\begin{tabular}{|c|c|c|c|c|c|}
\hline $\begin{array}{l}\text { compared to your } \\
\text { formal and } \\
\text { conventional } \\
\text { professional } \\
\text { development } \\
\text { programs (e.g. } \\
\text { assigned by school } \\
\text { or government)? }\end{array}$ & $\begin{array}{l}\text { formal and } \\
\text { conventional } \\
\text { professional } \\
\text { development } \\
\text { programs? }\end{array}$ & $\begin{array}{l}\text { compared to your } \\
\text { formal and } \\
\text { conventional } \\
\text { professional } \\
\text { development } \\
\text { programs (e.g. } \\
\text { assigned by school } \\
\text { or government)? }\end{array}$ & $\begin{array}{l}\text { formal and } \\
\text { conventional } \\
\text { professional } \\
\text { development } \\
\text { programs? }\end{array}$ & $\begin{array}{l}\text { conventional ones in } \\
\text { Indonesia } \\
\\
\text { (Follow Up Question) } \\
\checkmark \text { Leaders' information } \\
\text { about the similarities } \\
\text { and/or differences } \\
\text { between their own } \\
\text { learning experience } \\
\text { with social media, } \\
\text { including GEG and } \\
\text { from their learning } \\
\text { experience with } \\
\text { formal and } \\
\text { conventional } \\
\text { professional } \\
\text { development } \\
\text { programs. }\end{array}$ & $\begin{array}{l}\text { the formal and } \\
\text { conventional ones } \\
\text { in Indonesia } \\
\\
\\
\text { (Follow Up Question) } \\
\text { Members } \\
\text { information about } \\
\text { the similarities } \\
\text { and/or differences } \\
\text { between their own } \\
\text { learning experience } \\
\text { with social media, } \\
\text { including GEG and } \\
\text { from their learning } \\
\text { experience with } \\
\text { formal and } \\
\text { conventional } \\
\text { professional } \\
\text { development } \\
\text { programs. }\end{array}$ \\
\hline \multicolumn{6}{|c|}{ Prompts/Probes to stimulate wider scope of responses for more in-depth information } \\
\hline \multicolumn{6}{|c|}{$\begin{array}{l}\text { - Why? } \\
\text { - Who? } \\
\text { - Howt? } \\
\text { - } \text { Could you.... give me some examples of.... } \\
\text { - Some people say that.... what about you? What do you think about...? } \\
\text { - Tell me more about.... } \\
\text { - Would you mind sharing about...? } \\
\text { - Would you like to elaborate more? } \\
\text { - Would you mind explaining about.... } \\
\text { - } \text { If I am not mistaken, you said that...am I understanding it correctly? }\end{array}$} \\
\hline
\end{tabular}


Interview protocols

- Beforehand, I discussed with each of them about the date, time, and location to meet for the interview. A specific date, time, and location for the interviews was set with each of the participant.

- I conducted the interview with them one by one on different date, time, and location where they lived nearby. Few rescheduling among some of the participants occurred due to the participant's changes of activities.

- Since Bahasa Indonesia is the first language spoken by all participants, they were given an option to do the interview in Bahasa Indonesia or in English

- When all interviews were completed, the participants were sent a thank you message via e-mail. 
Appendix 2. The Practical Guideline of participant selection based on the group's $G+$ online forum

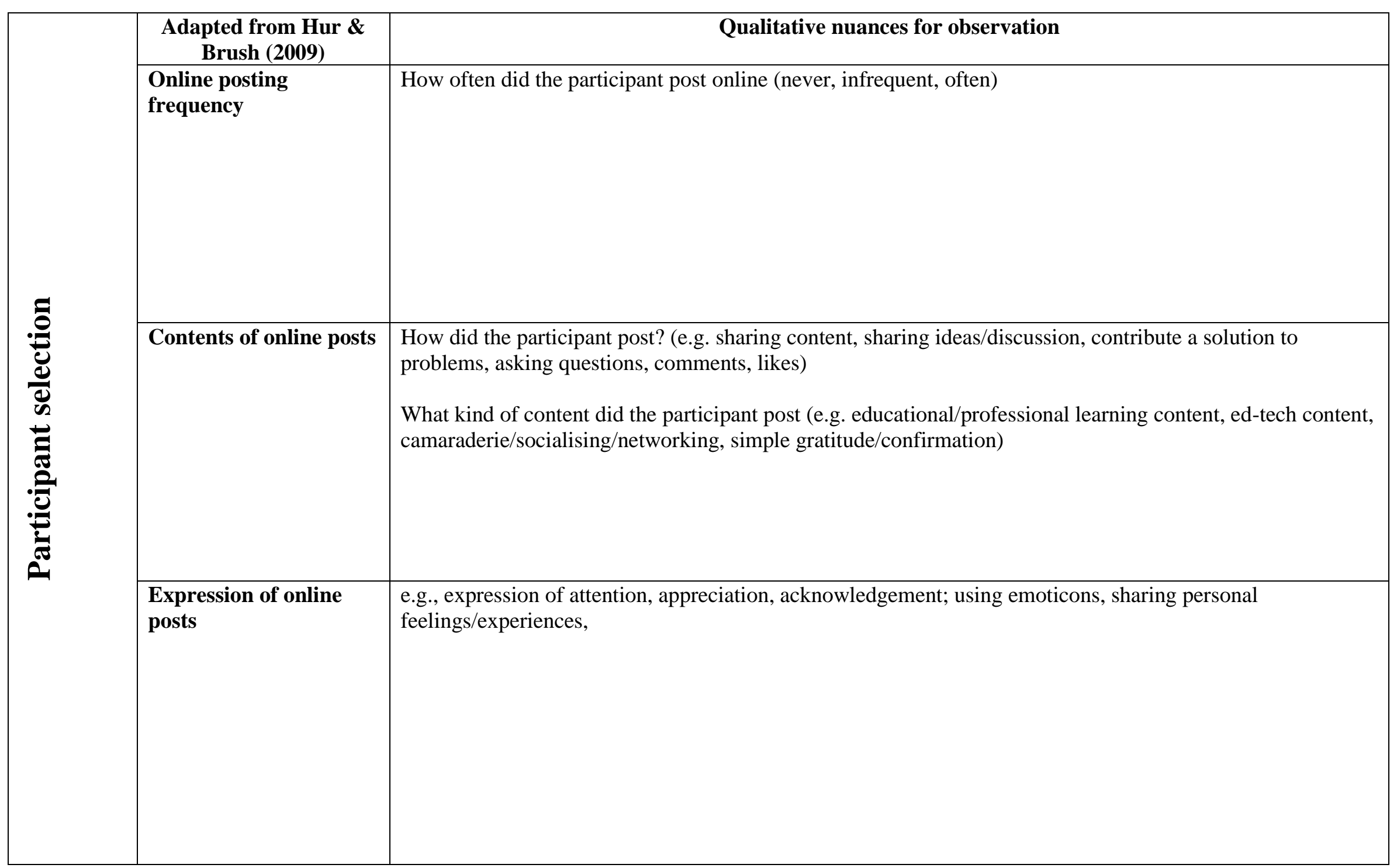


Appendix 3. The Online Observation Sheet/Rubrics

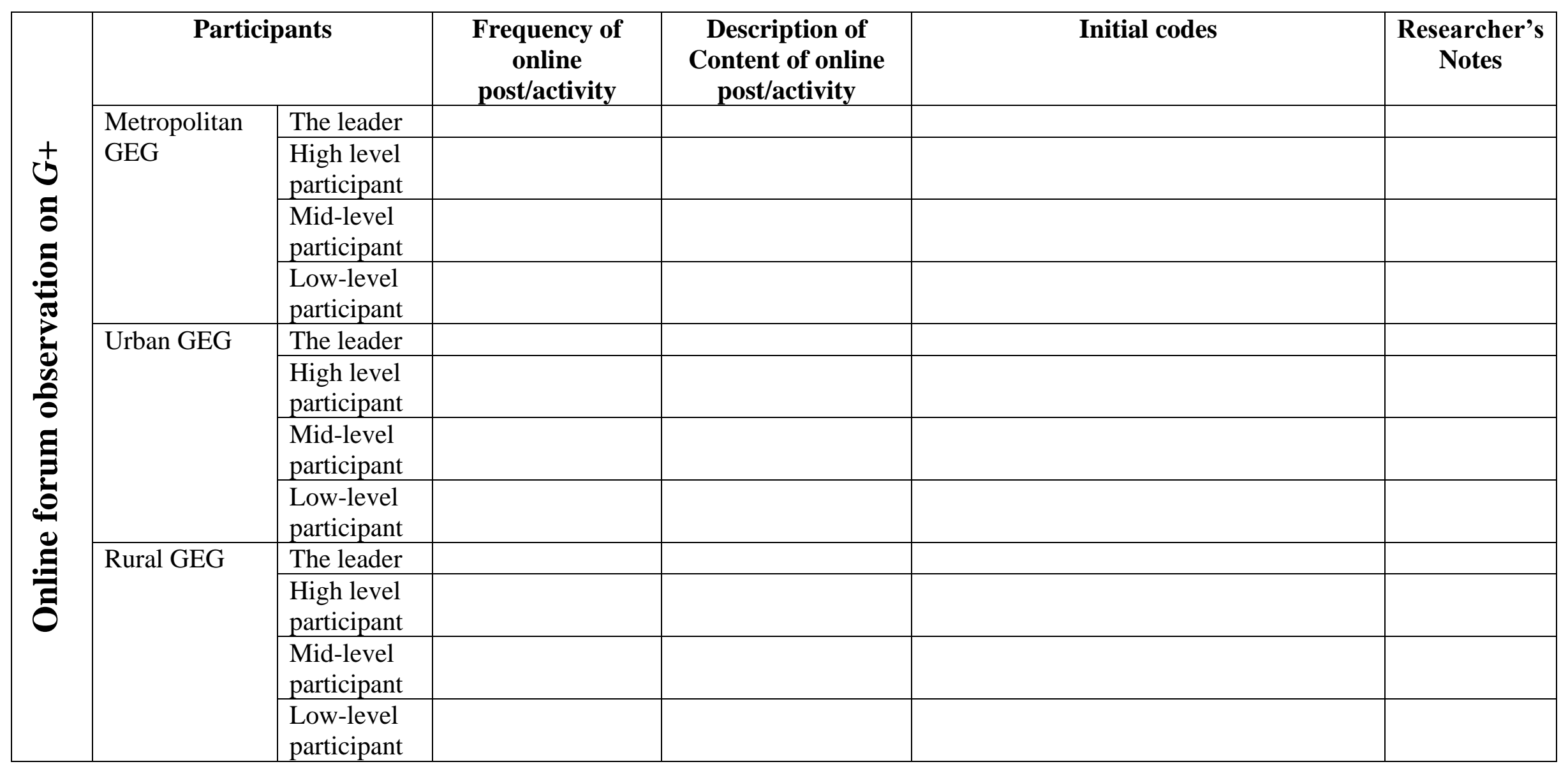




\section{Appendix 4. The comparison of assertions (for cross-case analysis)}

\begin{tabular}{|c|c|c|c|c|}
\hline \multicolumn{2}{|r|}{ Assertions } & M GEG & U GEG & R GEG \\
\hline \multirow{5}{*}{ 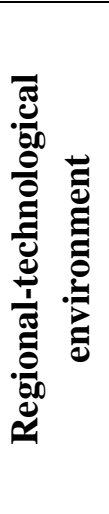 } & $\begin{array}{l}\text { The conducive ed-tech learning environment in the GEG supported participants' ed-tech } \\
\text { collaboration and encouraged them to explore leadership opportunities (M1) }\end{array}$ & $\mathbf{S}$ & $\mathrm{C}$ & $\mathrm{C}$ \\
\hline & $\begin{array}{l}\text { Global networks with collaborative events and activities provided diverse face to face and online } \\
\text { activities enabling a range of learning opportunities (M2) }\end{array}$ & $\mathbf{S}$ & $\mathrm{C}$ & $\mathrm{C}$ \\
\hline & $\begin{array}{l}\text { GEG participants were professionally challenged by a regional disparity in internet access and a } \\
\text { pervading emphasis on the use of hard copy, rather than digital resources (U1) }\end{array}$ & $\mathbf{C}$ & $\mathbf{S}$ & $\mathbf{R}$ \\
\hline & $\begin{array}{l}\text { With constrained digital resources and Internet connectivity, motivating and facilitating learning } \\
\text { using web-based technologies in the group became challenging (R1) }\end{array}$ & $\mathrm{C}$ & $\mathbf{R}$ & $\mathbf{S}$ \\
\hline & $\begin{array}{l}\text { As participants struggled with a lack of resources, they formed strong friendship and collegiality } \\
\text { through face-to-face and Telegram communication (R3) }\end{array}$ & $\mathrm{C}$ & $\mathbf{R}$ & $\mathbf{S}$ \\
\hline \multirow{7}{*}{ 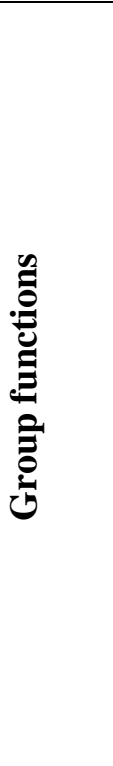 } & $\begin{array}{l}\text { Participants valued their learning experiences as they gained benefit from being part of the group } \\
\text { (M3) }\end{array}$ & $\mathbf{R}$ & $\mathbf{S}$ & $\mathbf{R}$ \\
\hline & $\begin{array}{l}\text { WhatsApp was used as a popular and practical mobile communication tool to extend interaction and } \\
\text { connectedness in the group (M5) }\end{array}$ & $\mathbf{S}$ & & \\
\hline & $\begin{array}{l}\text { The intensive use of English in the group's online forum enabled the group to facilitate global } \\
\text { interaction and gain global recognition (M6) }\end{array}$ & $\mathbf{S}$ & $\mathrm{C}$ & $\mathrm{C}$ \\
\hline & $\begin{array}{l}\text { Participants' interaction and communication were interconnected as the group blended face-to-face } \\
\text { and online activities (M7) }\end{array}$ & $\mathbf{S}$ & $\mathrm{C}$ & $\mathrm{C}$ \\
\hline & $\begin{array}{l}\text { Participants with minimal experience, practice, and confidence in sharing in the group's online } \\
\text { forum preferred Telegram as a more practical tool for collective and personal communication in the } \\
\text { group (U3) }\end{array}$ & & $\mathbf{S}$ & $\mathbf{R}$ \\
\hline & $\begin{array}{l}\text { Personal connectedness encouraged participants to actively seek support and be more open in } \\
\text { sharing experiences and practices (U4) }\end{array}$ & $\mathbf{R}$ & $\mathbf{S}$ & $\mathbf{R}$ \\
\hline & $\begin{array}{l}\text { When Google withdrew the financial incentive and the leader did not have the necessary resources } \\
\text { to support the group, its activities were reduced (R2). }\end{array}$ & $\mathbf{C}$ & $\mathbf{R}$ & $\bar{S}$ \\
\hline
\end{tabular}




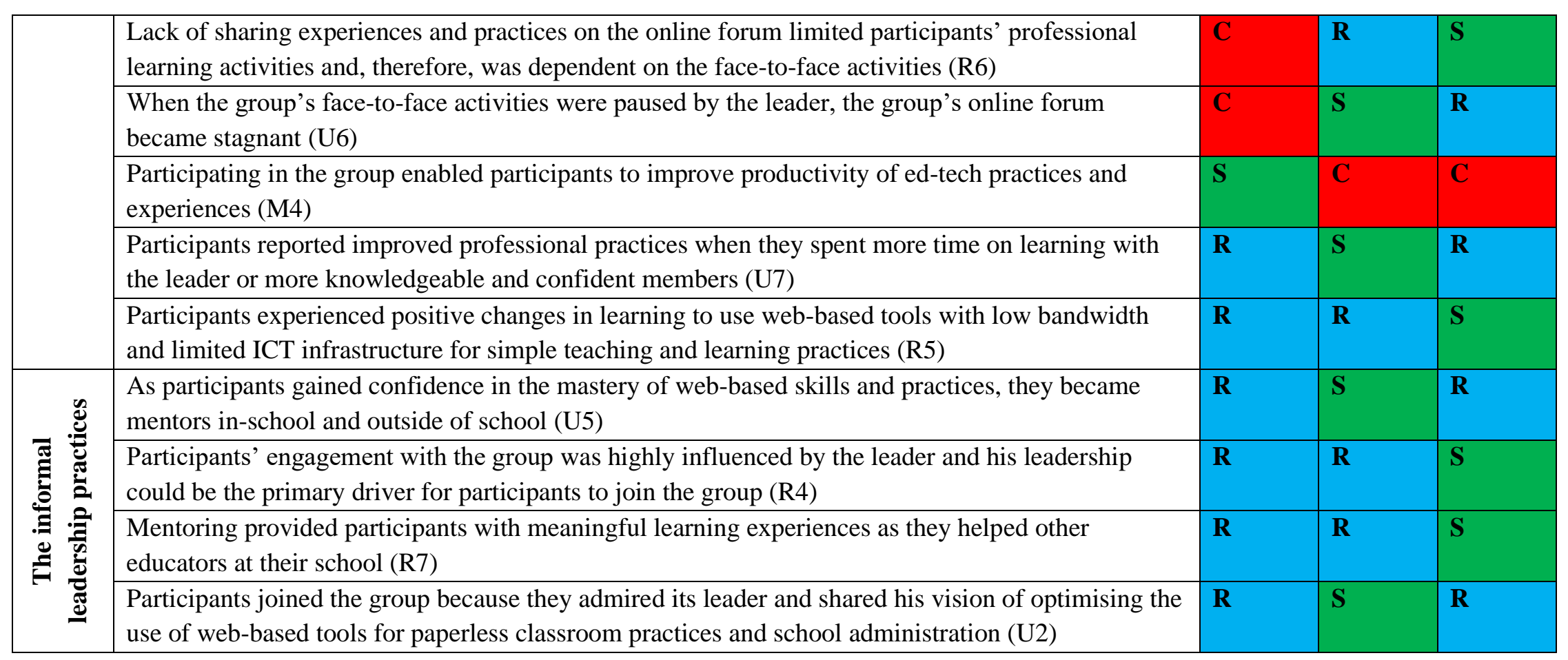

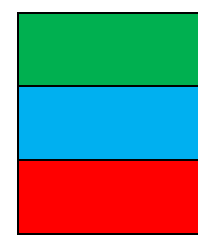

\section{Significant (S)}

Relevant (R)

Contradictory (C) 
Appendix 5. GEG Metropolitan's content on the online forum

\begin{tabular}{|c|c|c|}
\hline Type of content & Posting content description & Topics \\
\hline Link to blog post & $\begin{array}{l}\text { - Book review about helping } \\
\text { kids navigate digital lives } \\
\text { - Creative activities for the } \\
\text { first day of school } \\
\text { - Enhance learning with an } \\
\text { effective teacher and student } \\
\text { made a video and video } \\
\text { tutorial } \\
\text { - Finding journal in library } \\
\text { website } \\
\text { - Join TedEd clubs challenge } \\
\text { to amplify student's voice } \\
\text { - Technology in the classroom }\end{array}$ & \multirow[t]{4}{*}{ Technology in education } \\
\hline photo & $\begin{array}{l}\text { - 3D printing festival } \\
\text { - Workshop about favourite } \\
\text { applications for teacher and } \\
\text { school operator }\end{array}$ & \\
\hline Website & $\begin{array}{l}\text { - A fun way to improve } \\
\text { teacher skills } \\
\text { - Feedback for the creative } \\
\text { academy } \\
\text { - Vote to teaching 3D to } \\
\text { students and teachers in } \\
\text { India/rule breaker award } \\
\text { - Coding resource in every } \\
\text { class } \\
\text { - Finland education } \\
\text { - Facebook ads, Google } \\
\text { - } \text { AdWords, and social media } \\
\text { - Infochnology curriculum } \\
\text { - Strategies for collaborative } \\
\text { - } \text { practices and learning } \\
\text { - Space, a guide for educators } \\
\text { Virtual learning community }\end{array}$ & \\
\hline Link to Youtube & $\begin{array}{l}\text { - } \quad \text { Youtube use by teachers } \\
\text { - } \quad \text { video tutorial } \\
\text { - } \quad \text { Educational videos and talk }\end{array}$ & \\
\hline Link to BlogSpot & $\begin{array}{ll}\text { - } & \text { EdTech Team summit } 2017 \\
\text { - } & \text { extraordinary experience at } \\
& \text { Google for Education } \\
\end{array}$ & \multirow[t]{5}{*}{$\begin{array}{l}\text { Edutech gatherings, } \\
\text { conferences, events }\end{array}$} \\
\hline $\begin{array}{l}\text { Link to Google forms } \\
\text { picture }\end{array}$ & $\begin{array}{lll}\text { - } & \text { national } \\
\text { conference } & \text { educators } \\
\end{array}$ & \\
\hline Photo & 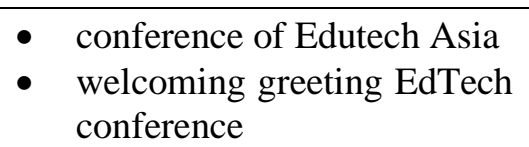 & \\
\hline Picture & $\begin{array}{l}\text { human resources } \\
\text { development in English } \\
\text { language teaching seminar }\end{array}$ & \\
\hline Link to video & - GESS conference & \\
\hline
\end{tabular}




\begin{tabular}{|c|c|c|}
\hline Vlog & $\begin{array}{ll}\text { - } & \text { EdTech summit } \\
\text { - } & \text { Highlight EdTech team } \\
\text { - } & \text { Highlight Edutech Asia } \\
\text { - } & \text { Meet up with most inspiring } \\
& \text { educators } \\
\end{array}$ & \\
\hline Website & $\begin{array}{ll}\text { - } & \text { Free conference } \\
\text { - } & \text { Support for creative talents } \\
\text { - } & \text { Teaching geeks gathering }\end{array}$ & \\
\hline $\mathrm{B} \log \operatorname{link}$ & $\begin{array}{l}\text { Five ways to make GCE } \\
\text { exam fun }\end{array}$ & \multirow[t]{9}{*}{ GEG and GCE } \\
\hline Link to blog & - How to become GCE & \\
\hline Vlog (Video Blog) & $\begin{array}{l}\text { - GCE study } \\
\text { groups/GCinnovator/Google } \\
\text { workshop (most commented } \\
\text { post) }\end{array}$ & \\
\hline Photo & $\begin{array}{ll}\text { - } & \text { Congratulating members } \\
& \text { who passed GCE exam } \\
\text { - } & \text { GCE study group } \\
\text { - } & \text { GCE } \\
\end{array}$ & \\
\hline Picture & $\begin{array}{ll}\text { - Coupon codes to get } \\
\text { discount for GCE exam }\end{array}$ & \\
\hline Text-Question & $\begin{array}{ll}- & \text { Request for Hangout } \\
& \text { activity among educators } \\
\end{array}$ & \\
\hline Vlog & 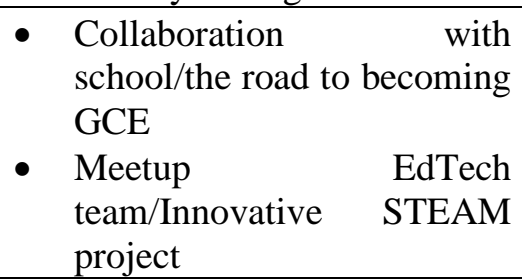 & \\
\hline Website & $\begin{array}{l}\text { - } 11 \text { big announcements from } \\
\text { Google Indonesia } \\
\text { - Applying GCE } \\
\text { - Congratulating members } \\
\text { who had been accepted at } \\
\text { Google for education } \\
\text { innovator program }\end{array}$ & \\
\hline Text-description & $\begin{array}{lll}\text { - } & \begin{array}{l}\text { Description of } \\
\text { Metropolitan }\end{array}\end{array}$ GEG & \\
\hline $\begin{array}{l}\text { Shared Google drive- } \\
\text { Google doc }\end{array}$ & $\begin{array}{l}\text { - Mini-research document on } \\
\text { Benefits and barriers using } \\
\text { Google classroom } \\
\text { Poster presentation } \\
\text { document on Benefits and } \\
\text { barriers using Google } \\
\text { classroom }\end{array}$ & Google classroom \\
\hline Picture & $\begin{array}{l}\text { Invitation to join Google } \\
\text { classroom via WA groups }\end{array}$ & \\
\hline Website & $\begin{array}{l}\text { - Google classroom is now } \\
\text { open to more learners } \\
\text { - Explore cultural resources } \\
\text { with Google classroom } \\
\text { - Google classroom } \\
\text { - New updates in Google suite }\end{array}$ & \\
\hline
\end{tabular}




\begin{tabular}{|c|c|c|}
\hline & $\begin{array}{l}\text { - Several updates on Google } \\
\text { classroom }\end{array}$ & \\
\hline Link to Youtube & $\begin{array}{l}\text { The complete Google } \\
\text { classroom guide from Kiker } \\
\text { learning } \\
\text { - } \begin{array}{l}\text { Tutorial on Google } \\
\text { classroom }\end{array} \\
\end{array}$ & \\
\hline Vlog & $\begin{array}{l}\text { - Earth outreach education } \\
\text { workshop/earthmazing } \\
\text { educator }\end{array}$ & \multirow[t]{2}{*}{ Google PD } \\
\hline Website & $\begin{array}{l}\text { Applying to Google } \\
\text { Innovator event }\end{array}$ & \\
\hline Link to BlogSpot & - Google PD week & \multirow[t]{8}{*}{ Google Tools } \\
\hline $\begin{array}{l}\text { Shared Google drive-google } \\
\text { doc }\end{array}$ & $\begin{array}{l}\text { - Google apps add a feature } \\
\text { on Gmail } \\
\text { - Make a place meaningful } \\
\text { with Google GEO tools } \\
\text { - Insert video from Google } \\
\text { drive in Google Slides } \\
\text { - Nearpod and google apps } \\
\text { integration for EdTech } \\
\text { fluidity }\end{array}$ & \\
\hline Link to blog post & $\begin{array}{l}\text { Make a place meaningful } \\
\text { with Google GEO tools }\end{array}$ & \\
\hline Photo & $\begin{array}{l}\text { Insert video from Google } \\
\text { drive in Google Slides }\end{array}$ & \\
\hline Picture & $\begin{array}{l}\text { Nearpod and google apps } \\
\text { integration for EdTech } \\
\text { fluidity }\end{array}$ & \\
\hline Link to video & $\begin{array}{l}\text { Google slides superhero } \\
\text { training }\end{array}$ & \\
\hline Vlog & $\begin{array}{l}\text { - New calendar app in Google } \\
\text { Suite }\end{array}$ & \\
\hline Website & $\begin{array}{l}\text { - } \text { Autocrat Google sheets add- } \\
\text { - } \text { on } \\
\text { - } \text { Google calendar } \\
\text { - Google apps level } 5 \text { local } \\
\text { guide } \\
\text { - Google Docs } \\
\text { - Go blitz project } \\
\text { - Google keep Google apps. } \\
\text { Bring them to life in Google } \\
\text { doc } \\
\text { - Google analytics } \\
\text { - Google apps } \\
\text { - Google autodraw } \\
\text { - } \text { the classroom } \\
\text { - Google doc tips and adds on } \\
\text { for teachers } \\
\text { Google forms or survey }\end{array}$ & \\
\hline
\end{tabular}




\begin{tabular}{|c|c|c|}
\hline & $\begin{array}{l}\text { - Google lens to turn the } \\
\text { - } \text { camera into a search box } \\
\text { - Google maps } \\
\text { - Google power searching } \\
\text { - } \text { Gaximising Google search } \\
\text { - } \text { part } 1 \\
\text { - New google earth } \\
\text { - } \text { New Google sites } \\
\text { - } \quad \text { updated differentiation with } \\
\quad \text { Google forms }\end{array}$ & \\
\hline Link to Youtube & $\begin{array}{l}\text { - Video tutorial on Google my } \\
\text { maps }\end{array}$ & \\
\hline Photo & $\begin{array}{ll}\text { - Sketch-up the web for } \\
\text { schools }\end{array}$ & \multirow[t]{3}{*}{ Non-Google Tools } \\
\hline Website & 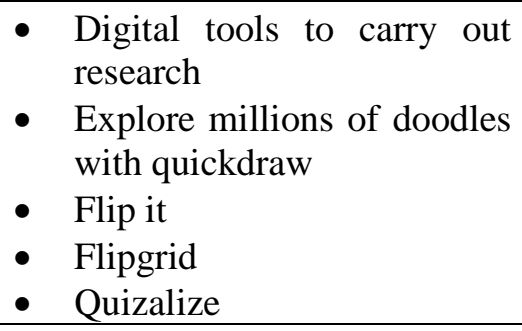 & \\
\hline Link to Youtube & $\begin{array}{l}\text { - Pdf doc and adobe acrobat } \\
\text { reader }\end{array}$ & \\
\hline
\end{tabular}


Appendix 6. GEG urban's content on the online forum

\begin{tabular}{|c|c|c|}
\hline Type of content & Posting Content Description & Topics \\
\hline Text & Introductory greeting & \multirow{8}{*}{$\begin{array}{l}\text { - The paperless } \\
\text { school with } \\
\text { Google } \\
\text { - Google (GSuite)- } \\
\text { related informal } \\
\text { gathering/meetin } \\
\text { g/workshop } \\
\text { - Islamic-related } \\
\text { motivational } \\
\text { video } \\
\text { - Politics-related } \\
\text { information } \\
\text { - Math-related } \\
\text { teaching } \\
\text { content/material }\end{array}$} \\
\hline $\begin{array}{l}\text { Text, link to the } \\
\text { website, and link } \\
\text { to Google forms }\end{array}$ & $\begin{array}{l}\text { Going to paperless school meetings announcement } \\
\text { with its technical instruction }\end{array}$ & \\
\hline $\begin{array}{l}\text { Link to public } \\
\text { photo album }\end{array}$ & $\begin{array}{l}\text { GSuite for Education and Computer science } \\
\text { workshop }\end{array}$ & \\
\hline $\begin{array}{l}\text { Link to Youtube } \\
\text { video }\end{array}$ & Islamic-related motivational video & \\
\hline Link to website & Politics-related information & \\
\hline $\begin{array}{l}\text { 123slide.org } \\
\text { (document } \\
\text { sharing web) }\end{array}$ & Math-related teaching content/material & \\
\hline Link to a blog & Politics-related information & \\
\hline $\begin{array}{l}\text { Link to a public } \\
\text { photo album }\end{array}$ & Going to paperless school and GSuite workshop & \\
\hline
\end{tabular}

\section{Appendix 7. GEG Rural's content on the online forum}

\begin{tabular}{|c|c|c|}
\hline Type of content & Posting Content Description & Topics \\
\hline $\begin{array}{l}\text { Link to google } \\
\text { drive photo doc }\end{array}$ & National seminar professional teacher with ICT & \multirow{5}{*}{$\begin{array}{l}\text { Edutech gatherings } \\
\text { conference/seminar } \\
\text { events }\end{array}$} \\
\hline photo & Meeting IGI (formal-regional teacher association) & \\
\hline Photo & National seminar professional teacher with ICT & \\
\hline picture & National seminar professional teacher with ICT & \\
\hline Link to blog post & Edutech-Google Science fair & \\
\hline $\begin{array}{l}\text { Link to Google } \\
\text { drive photo doc }\end{array}$ & Inaugural events documentation & \multirow[t]{4}{*}{ GEG } \\
\hline text & Description about GEG & \\
\hline picture & Inaugural meet up & \\
\hline App link & Invitation to join GEG Telegram group & \\
\hline website & $\begin{array}{l}\text { Q \& A about Google apps for education (Google } \\
\text { classroom) }\end{array}$ & Google Classroom \\
\hline $\begin{array}{l}\text { Link to a blog } \\
\text { post }\end{array}$ & Google rural teacher workshop & \multirow[t]{4}{*}{ Google PD } \\
\hline photo & Google classroom workshop & \\
\hline photo & Google forms workshop & \\
\hline photo & Google forms and Google classroom workshop & \\
\hline $\begin{array}{l}\text { Link to a blog } \\
\text { post }\end{array}$ & Expiration dates to access Google drive & \multirow[t]{3}{*}{ Google tools } \\
\hline website & Google local guide & \\
\hline Link to blog post & Modelling in Google Sheets & \\
\hline $\begin{array}{l}\text { Link to a blog } \\
\text { post }\end{array}$ & Learning the potential of Android & Non-Google Tools \\
\hline
\end{tabular}


Appendix 7. Participants' information sheet for data collection (English \& Bahasa)

TE WHARE WäNANGA O TE ÓPOKO O TE IKA A MÃu

59

A SOCIAL-COGNITIVE STUDY OF INDONESIAN GOOGLE EDUCATOR GROUPS

\section{INFORMATION SHEET FOR GEG LEADERS (English)}

Thank you for your kind interest in this project. Please read this information before deciding whether or not to take part. If you decide to participate, thank you. If you decide not to take part, thank you for considering my request.

\section{Who am I?}

My name is Pratiwi Wini Artati, a PhD candidate of Victoria University of Wellington, New Zealand. This research project is part of the requirements of the Doctoral of Philosophy (PhD) study.

\section{What is the aim of the project?}

This research will explore Indonesian teachers' informal professional learning within Google Educator Groups (GEGs). GEGs are informal and independent learning communities of practice on a global and local scale, including educators and teachers utilizing Google Plus Communities for communication, discussion, and interaction online. It is a collective case study of Indonesian GEGs in three different regions with teachers as leaders and members. The implementation of this research project arises from currently limited research and studies corresponding to an emerging case involving Indonesian teachers' informal professional learning as leaders and members of the GEGs.This research has been approved by the Victoria University of Wellington Human Ethics Committee number 22521.

\section{How can you help?}

I will contact you to request your consent for:

$\checkmark$ Posting the information about the researcher and her research online on GEG's Google Plus Group Page

$\checkmark$ Participating in initial interview online through Skype/Google Hangout and follow up interview in Indonesia face to face.

Please read the table below for further details of your rights as participants:

\begin{tabular}{|c|c|}
\hline If you give consent for initial and interview & $\begin{array}{l}\text { If you choose to withdraw from further } \\
\text { interview }\end{array}$ \\
\hline $\begin{array}{l}\checkmark \\
\checkmark \quad \text { Your online postings on GEG's Google Plus group page will be observed } \\
\checkmark \quad \text { Upon giving your consent for the interview, I will arrange a schedule to } \\
\text { initially interview you online through Skype/Google Hangout around } \\
\text { December 2016-January } 2017 \text { followed by follow up face-to-face } \\
\text { interview around July-September } 2017 \text { in Indonesia for further additional } \\
\text { information that is not yet discussed in the initial interview which may } \\
\text { lead to important findings. } \\
\checkmark \quad \text { Your statements (in Bahasa Indonesia) in the interview will be } \\
\text { paraphrased into English to avoid being identified on the public site. } \\
\checkmark \quad \text { You will be asked questions about how your informal } \\
\text { professional learning as leaders of GEG. } \\
\checkmark \quad \text { The interview will take approximately } 90 \text { minutes and will be audio- } \\
\text { recorded. You can ask for the recorder to be turned off at any time during } \\
\text { the interview I will write it up later with your consent. You can stop the } \\
\text { interview at any time. } \\
\checkmark \quad \text { You can choose not to answer any question. } \\
\checkmark \quad \text { You can ask any questions about the study at any time. }\end{array}$ & $\begin{array}{ll}\checkmark \quad \text { You can withdraw after the } \\
\text { interview has been conducted. } \\
\checkmark \quad \text { You do not need to provide any } \\
\text { explanation for your withdrawal } \\
\checkmark \quad \text { You can send an email notifying } \\
\text { that your withdrawal for the } \\
\text { interview to the researcher's email } \\
\text { address at Wini.Artati@vuw.ac.nz }\end{array}$ \\
\hline
\end{tabular}


$\checkmark \quad$ You will receive a copy of your interview transcript and summary of the interview

$\checkmark \quad$ You can read over your interview transcript and make additional comments

$\checkmark \quad$ Your participation and your identity will be kept confidential.

$\checkmark \quad$ You may withdraw from the study after the interview has been conducted.

$\checkmark \quad$ Your visual data on GEG's Google Plus group page will be protected by providing a written description.

$\checkmark \quad$ You will be able to read participants' report of this research by emailing the researcher to request a copy

$\checkmark$ Your experiences, thoughts, ideas, perspectives, aspiration, suggestions, and inputs will have significant value to the field of teacher informal professional learning with social media in Indonesia

\section{What will happen to the information you give?}

Your participation will be kept confidential in this research. I will not identify your real name in any reports, presentations, or public documents and I will not include any information that would relate to your real identity. Your identity will be reported as in codes, such as teacher A, teacher B, teacher $C$, and so on. However, the name "Google Educator Group (GEG)" in the three selected regions will be mentioned in codes as Metropolitan GEG, Urban GEG, and Rural GEG in the report without disclosing the affiliation to the real regional location. Only my supervisors and I will read the notes or transcript of the interview. The interview transcripts, summaries and any recordings will be kept securely in a password-protected portable hard drive and NVivo software and they will be destroyed after the research ends. I will ensure that findings from online observation and interview data will be presented (and written) in such a way where it will not be searchable through any search engine or social media platform to protect your true identity. In addition, any visual data will be described in writings to protect your true identity. Translation will be implemented as a further layer of anonymity. Bahasa Indonesia will be used in the interview and will be translated by the researcher into English. I will paraphrase your statements in Bahasa Indonesia from the interview into English based on the key ideas, preventing any data to be searchable online.

\section{What will the project produce?}

The information from my research will be used in my $\mathrm{PhD}$ dissertation/report but your real identity will be kept confidential in my report. I may also use the results of my research for conference presentations, and academic reports. I will take care not to identify you in any reports, presentations, or public documents.

If you have any questions or problems, who can you contact?

If you have any questions, either now or in the future, please feel free to contact either:

Student:

Supervisors:

\section{This content is unavailable.}

Please consult the print version for access

Human Ethics Committee information

This content is unavailable.

Please consult the print version for access 


\section{LEMBAR PEMBERITAHUAN UNTUK LEADER/PEMIMPIN GEG (Bahasa Indonesia)}

Terima kasih atas minat Anda dalam riset ini. Silahkan membaca terlebih dahulu lembar informasi ini sebelum Anda memutuskan untuk berpartisipasi di dalam riset ini. Jika Anda memutuskan untuk berpartisipasi, saya akan berterima kasih. Jika Anda memutuskan untuk tidak berpartisipasi, maka saya juga akan berterima kasih karena telah meluangkan waktu untuk mempertimbangkan permintaan saya dan membaca lembar pemberitahuan ini.

\section{Siapakah Saya?}

Nama lengkap saya adalah Pratiwi Wini Artati; seorang kandidat Doktor yang sedang menempuh studi program Doktoral (PhD) di Victoria University of Wellington, Selandia Baru. Proyek penelitian ini merupakan bagian dari persyaratan penyelesaian studi Doktoral (PhD).

\section{Apakah tujuan dari proyek riset ini?}

Penelitian ini akan mengeksplorasi tentang bagaimana pembelajaran professional guru-guru di Indonesia secara informal melalui Google Educator Groups (GEGs). GEGs adalah komunitas pebelajar informal pada skala global dan local, termasuk pendidik dan guru-guru menggunakan Google Plus Communities untuk berkomunikasi, berdiskusi, dan berinteraksi secara online. Penelitian ini adalah Penelitian ini adalah studi kasus GEG di tiga daerah dengan kategori yang berbeda di Indonesia dengan guru-guru sebagai inisiator/leader dan anggota/membernya. Penelitian ini dilakukan karena belum adanya studi mengenai bagaimana pembelajaran professional guru-guru di Indonesia secara informal sebagai inisiator/leader dan anggota/member dari GEG. Penelitian ini telah disetujui oleh Komite Etik Penelitian Victoria University of Wellington nomor 22521

\section{Bagaimana Anda dapat membantu?}

Saya akan menghubungi Anda guna meminta persetujuan Anda untuk :

$\checkmark \quad$ memposting informasi tentang peneliti dan penelitiannya secara online pada laman grup GEG di Google Plus

$\checkmark \quad$ memberikan ijin penggunaan materi online dari grup yang diposting secara public pada laman grup GEG di Google Plus untuk tujuan penelitian

$\checkmark \quad$ berpartisipasi dalam wawancara awal dan wawancara lanjutan di lokasi pilihan Anda.

Silahkan baca tabel di bawah ini untuk rincian lebih lanjut dari hak-hak Anda sebagai partisipan penelitian :

\begin{tabular}{|c|c|}
\hline Jika Anda memberikan ijin untuk interview lebih lanjut & $\begin{array}{l}\text { Jika Anda memilih untuk mengundurkan diri } \\
\text { dari interview }\end{array}$ \\
\hline $\begin{array}{l}\checkmark \\
\text { diamati } \\
\checkmark \quad \text { Anda akan dihubungi untuk wawancara lebih lanjut dengan } \\
\text { moda semi-structured } \\
\checkmark \quad \text { Setelah memberikan persetujuan Anda untuk wawancara, saya } \\
\text { akan mengatur jadwal dengan Anda untuk wawancara awal } \\
\text { secar Online melalui Skype/Google Hangout sekitar bulan } \\
\text { Desember 2016-Januari } 2017 \text { yang diikuti oleh wawancara } \\
\text { lanjutan secara langsung di Indonesia sekitar bulan Juli- } \\
\text { September } 2017 \text { untuk information tambahan yang belum } \\
\text { sempat didiskusikan dalam wawancara awal yang mungkin dapat } \\
\text { mengarah pada temuan penting. } \\
\checkmark \quad \text { Pernyataan Anda dalam Bahasa Indonesia dari wawancara akan } \\
\text { diparafrasekan ke dalam Bahasa Inggris untuk melindungi } \\
\text { identitas Anda pada website publik. } \\
\checkmark \text { Anda akan ditanya pertanyaan tentang pembelajaran } \\
\text { professional Anda secara informal sebagai inisiator/pemimpin } \\
\text { GEG. } \\
\checkmark \\
\text { Wawancara akan memakan waktu sekitar } 90 \text { menit dan akan } \\
\text { direkam dengan perekam audio/suara. Anda dapat meminta } \\
\text { perekam yang akan dimatikan setiap saat selama wawancara } \\
\text { saya akan menulis itu kemudian dengan persetujuan Anda. Anda } \\
\text { dapat menghentikan wawancara setiap saat. }\end{array}$ & $\begin{array}{l}\checkmark \quad \text { Anda boleh mengundurkan diri } \\
\text { dari wawancara setelah } \\
\text { dilakukannya wawancara. } \\
\checkmark \quad \text { Anda tidak perlu memberikan } \\
\text { penjelasan untuk pengunduran } \\
\text { diri Anda } \\
\checkmark \quad \text { Anda dapat mengirimkan email } \\
\text { yang memberitahukan tentang } \\
\text { pengunduran diri Anda dari } \\
\text { wawancara ke alamat email } \\
\text { peneliti di Wini.Artati@vuw.ac.nz }\end{array}$ \\
\hline
\end{tabular}




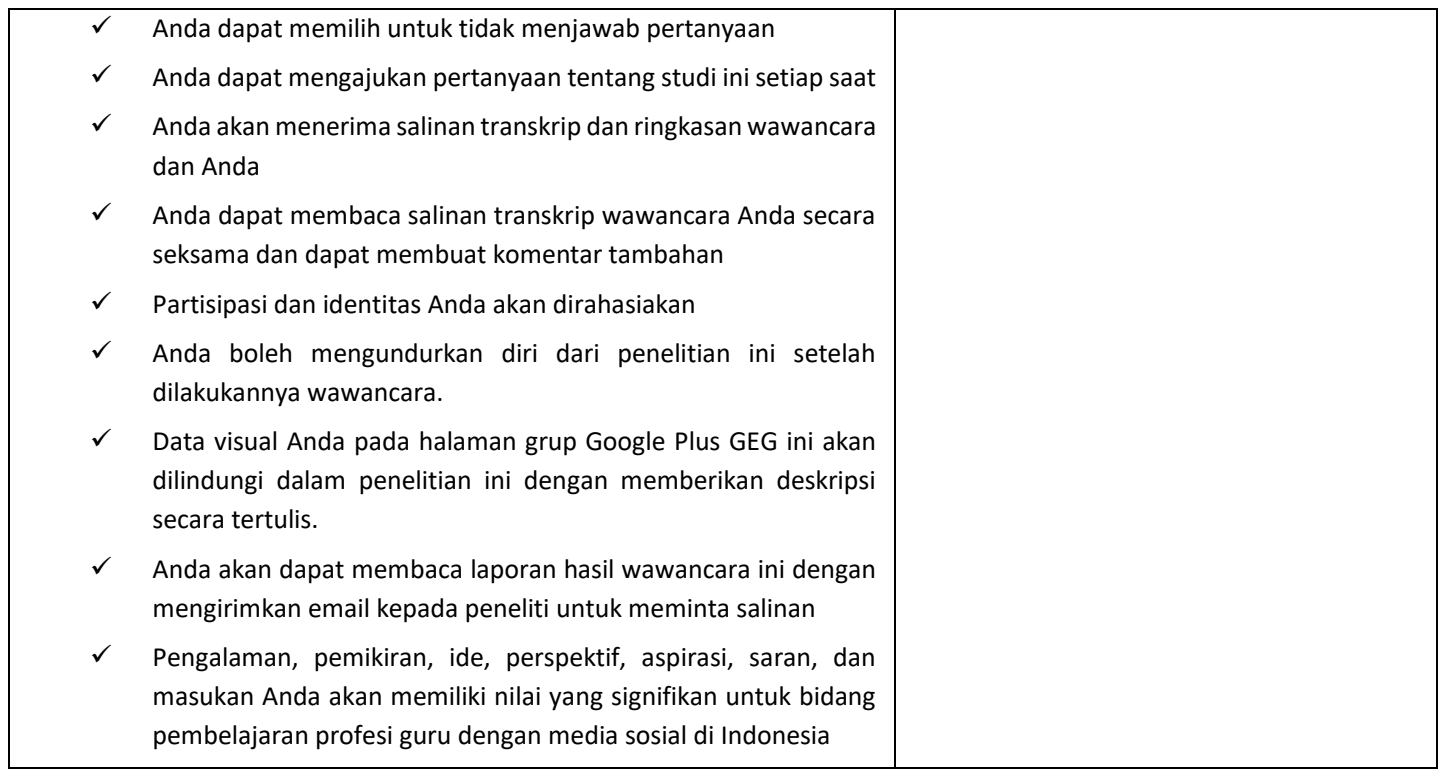

\section{Apa yang akan terjadi pada informasi yang Anda berikan ?}

Keikutsertaan Anda dalam penelitian ini bersifat rahasia. Saya tidak akan mengidentifikasi nama asli Anda dalam laporan, presentasi, atau dokumen publik apapun dan saya tidak akan mengikutsertakan informasi yang akan berhubungan dengan identitas asli Anda. Identitas Anda akan dideskripsikan dengan kode, contohnya guru A, guru B, guru C, dan seterusnya. Namun, istilah "Google Educator Group (GEG)" di tiga daerah penelitian akan disebutkan dengan pengkodean sebagai GEG Metropolitan, GEG Urban, GEG Rural dalam laporan tanpa mengungkapkan keterhubungan terhadap lokasi nyata daerah/regional. Hanya supervisor saya dan saya sendiri yang akan membaca catatan atau transkrip wawancara. Transkrip wawancara, ringkasan dan rekaman apapun akan disimpan dengan aman dalam hard- drive portable dengan sandi kunci dan piranti NVivo dan akan segera dihancurkan setelah penelitian berakhir. Saya akan memastikan bahwa temuan-temuan data dari observasi secara online dan wawancara akan disajikan (dan ditulis) sedemikian rupa supaya tidak dapat teridentifikasi oleh mesin pencari atau pada platform media sosial apapun untuk melindungi identitas Anda. Data visual apapun akan dideskripsikan secara tertulis untuk melindungi identitas Anda. Terjemahan akan dilakukan untuk menjaga anonimitas. Bahasa Indonesia akan digunakan dalam wawancara dan hasil wawancara akan diterjemahkan oleh saya ke dalam bahasa Inggris. Saya akan memparafrasekan pernyataan-pernyataan Anda dalam Bahasa Indonesia dari wawancara ke dalam Bahasa Inggris berdasarkan pada ide-ide kunci untuk mencegah identifikasi data secara Online.

\section{Apa yang akan dihasilkan dari riset ini ?}

Informasi dari proyek riset ini akan digunakan dalam pelaporan studi/disertasi $\mathrm{PhD}$ namun identitas asli Anda akan tetap terlindungi dalam laporan saya. Saya juga dapat menggunakan hasil penelitian ini untuk presentasi pada konferensi/seminar dan laporan akademik. Saya akan sangat berhati-hati untuk menjaga kerahasiaan identitas Anda dalam presentasi atau laporan apapun yang terkait dengan proyek riset ini.

Jika Anda memiliki pertanyaan atau masalah, siapakah yang dapat Anda hubungi ? Jika Anda memiliki pertanyaan, baik sekarang atau di masa depan, jangan ragu untuk menghubungi pihak-pihak dibawah ini:

Peneliti: Pembimbing Peneliti:

Konten ini tidak tersedia. Mohon dapat mengacu pada versi cetak untuk mengakses

\section{Informasi Umum Komite Etik}

Konten ini tidak tersedia. Mohon dapat mengacu pada versi cetak untuk mengakses 


\section{Appendix 8. Participants' informed consent forms for interviews (English \& Bahasa)}

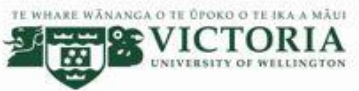

A SOCIO-COGNITIVE STUDY OF INDONESIAN GOOGLE EDUCATOR GROUPS

\section{Consent Form (English)}

(GEG Teacher-Members/Selected Participants)

\section{Researcher : Pratiwi Wini Artati, Faculty of Education, Victoria University of Wellington}

I have read the Information Sheet and the project has been explained to me. My questions have been answered to $m y$ satisfaction. I understand that I can ask further questions at any time

- I agree to paricipate in the direct audio-recorded interview in Indonesia on a schedule arranged by the researcher I understand that:

- My online activities on GEG's Google Plus public group page will be observed for research purposes.

- I may withdraw from this study after the interview, and any information that I have provided will be returned to me or destroyed.

- The information I have provided will be destroyed after the research is finished.

- Any iniormation I provide will be kept confidential to the researcher and the supenvisors I understand that the results will be used for a PhD report and a summary of the results may be used in academic repots and'or presented at conferences.

- Any information about my real name/identity will not be identified in any reports, presentations, or public documents

- I consent to information or opinions which I have given is for research purposes only ___-Yes $\square$ № $\square$

- I would like a copy of the transcript of my interview - _ ․드.

- I would like a summary of my interview - — 드 $\square$

- I would like to receive a copy of the final report and have added my email address below - - - Yes $\square$ № $\square$

Signature of the Participant :

Name of the participant

Date

Contact details

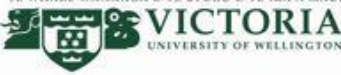

STUDI KASUS GOOGLE EDUCATOR GROUPS DI INDONESIA DALAM KERANGKA SOSIAL KOGNITIF

\section{Lembar Persetujuan (Bahasa Indonesia)}

(Anggota GEG/Partisipan Terpilih)

Peneliti : Pratiwi Wini Artati, Fakultas Pendidikan, Victoria University of Wellington

- Saya telah membaca Lembar Informasi dan telah diberikan penjelasan mengenai proyek riset ini. Segala pertanyaan pertanyaan yang saya ajukan telah dijawab dengan baik. Saya memahami bahwa saya dapat mengajukan pertanyaan pertanyaan yang saya ajukan telah dijawab dengan baik. Saya memahami bahwa saya dapat mengajukan pendenyan
lebih lanjut setiap saat. - Saya menyetujui untuk berpartisipasi dalam wawancara yang dilakukan secara
dengan perekam suara (audio) sesuai dengan jadwal yang telah disusun penelit.

Saya memahami bahwe

- Saya dapat mengundurkan diri dari riset ini sampai dua minggu setelah wawancara, dan informasi apapun yang saya berikan akan dikembalikan kepada saya atau dihancurkan.

- Informasi yang saya berikan akan segera dihancurkan setelah riset selesai.

- Informasi yang saya berikan akan dijaga kerahasiaanya dan hanya dapat diakses oleh peneliti dan pengawas penelifi. Saya memahami bahwa hasil temuan riset akan digunakan dalam pelaporan studi PhD serta ringkasan pelaporannya akan dilaporkan secara akademik dan dipresentasikan pada konferensiseminar.

- Nama/identitas asli dan segala informasi yang terkait dengan nama/identitas asli saya tidak akan digunakan dalam laporan

- Saya menyetujui bahwa informasi dan pendapat yang saya berikan dengan namalidentitas samara dapat dijadikan bagian dari pelaporan hasil riset ini: $\quad$ Yes $\square$ № $\square$

- Saya ingin mendapatkan salinan transkrip wawancara $\quad$ Yes $\square$ № $\square$

- Saya ingin mendapatkan ringkasan wawancara

- Saya ingin mendapatkan salinan pelaporan akhir melalui email yang telah saya tambahkan dibawah ini:
Tanda tangan Partisipan

Nama Partisipan

Tanggal

Detk Kontaklemail 


\section{Appendix 9. Online research announcement on the GEGs' online forums for data collection (English \& Bahasa)}

GENERAL INFORMATION TO BE POSTED ONLINE ON GEG GOOGLE PLUS (G+) PUBLIC GROUP PAGE

Assalamulaikum Wr Wb (Greetings to all),
Dear all GEG teachers,
My name is Pratiwi Wini Artati, a PhD candidate at Victoria University of Wellington, New Zealand. I am conducting research
to understand how Indonesian teacher professional learning informally occurs within Google Educator Groups (GEG) as this
could be useful knowledge for future development. I will be collecting data by observing the postings and interactions
occurring within this GEG G+. Your true identity will not be identified in any reports, presentations, or any public documents.
Your contributions to the group will be included in the research unless you notify me through this link at
http/lartatiwi wixsitecom/aboutresearch/contact-me
Further details of my research can be accessed through this website at http://artatiwi.wixsite.com/aboutresearch
I look forward to following your contributions.
Thank you

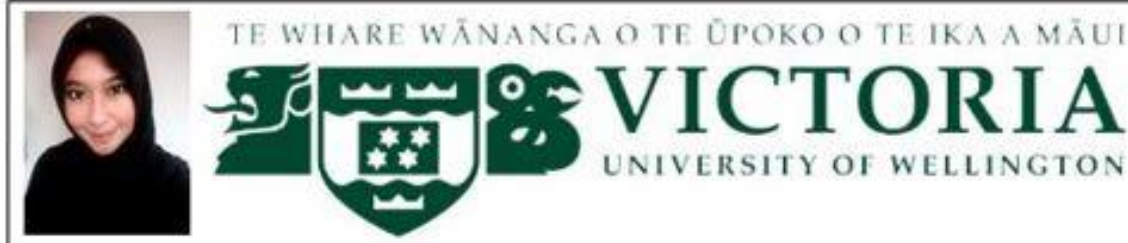

Assalamulaikum $W r W b$,

Kepada Yth seluruh guru anggota GEG,

Nama saya Pratiwi Wini Artati, seorang kandidat PhD di Victoria University of Wellington, Selandia Baru. Saya melakukan penelitian untuk memahami bagaimana pembelajaran professional secara informal yang dilakukan oleh guru-guru di Indonesia yang tergabung dalam Google Educator Groups (GEG) sehingga dapat menjadi pengetahuan yang berguna untuk pengembangan di masa depan. Saya akan mengumpulkan data pada laman publik dari GEG Google Plus (G+) plengan mengamati posting dan interaksi yang terjadi di dalam GEG G + ini. Identitas Anda akan dirahasiakan dalam laporan, presentasi, atau dokumen publik apapun. Kontribusi Anda ke grup akan dimasukkan dalam penelitian kecuali Anda memberitahu saya (untuk tidak diikutsertakan) melalui link ini di http://artatiwi.wixsite.com/aboutresearch/contact-me

Rincian lebih lanjut dari penelitian saya dapat diakses melalui website ini di http://artatiwi wixsite.com/aboutresearch

Kontribusi Anda sangat berharga bagi penelitian ini.

Terima kasih 
Appendix 10. The screenshot of the dedicated website for the public information of the study (English)

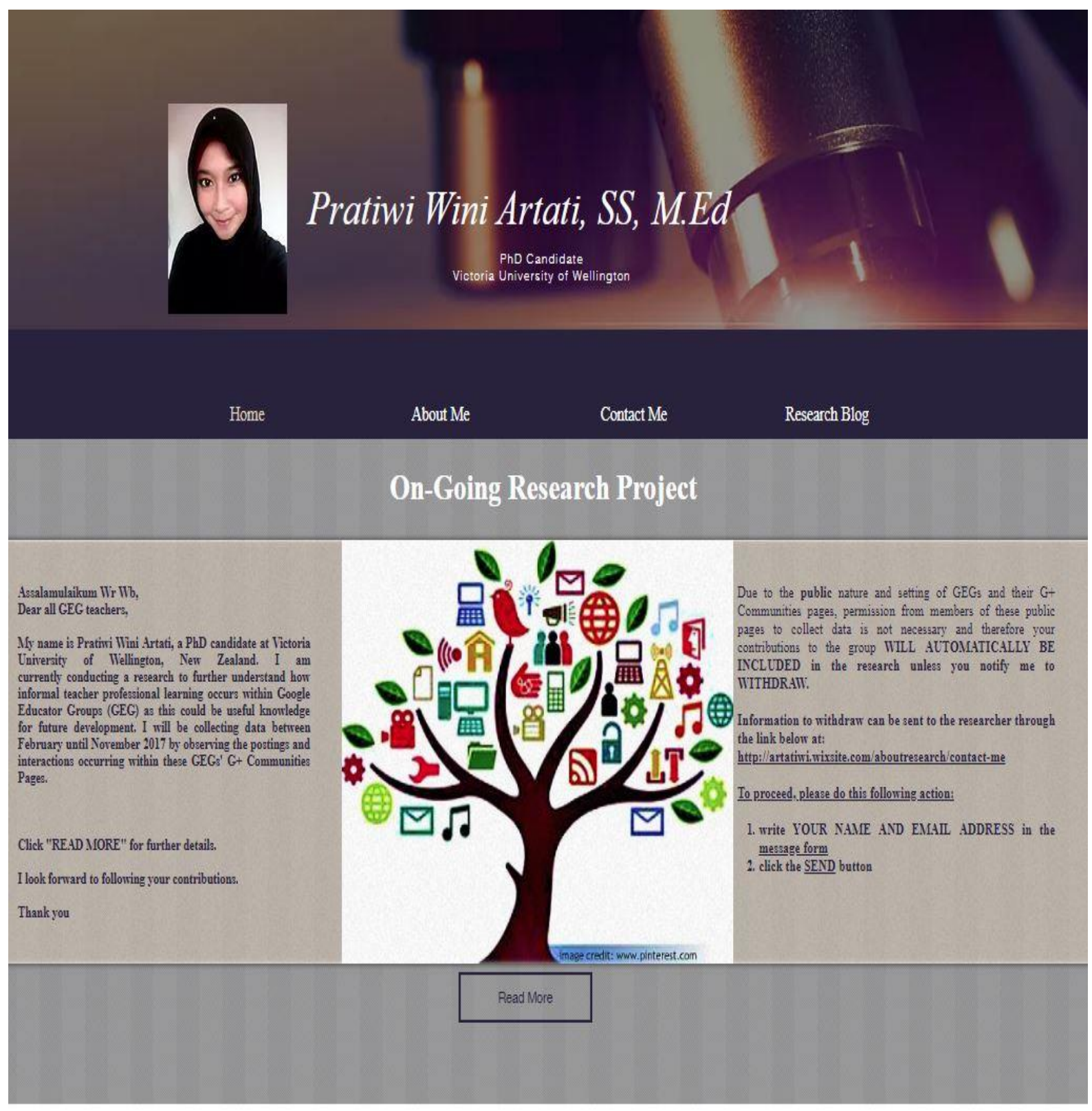




\section{Appendix 11. Ethics approval}

TE WHARE WANANGA O TE OPOKO O TE IKA A MÃUI

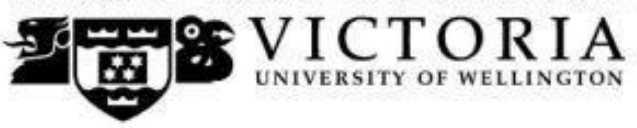

MEMORANDUM

Phone

Email
This content is unavailable

Please consult the print version for access

\begin{tabular}{|c|c|}
\hline TO & Wini Artati \\
\hline COPY TO & Dr Louise Starkey, Vicki Thorpe \\
\hline FROM & Prof Susan Corbett, Convener, Human Ethics Committee \\
\hline DATE & 8 December 2016 \\
\hline PAGES & 1 \\
\hline SUBJECT & $\begin{array}{l}\text { Ethics Approval: } 22521 \\
\text { A Social-Cognitive Study of Indonesian Google Educator Groups }\end{array}$ \\
\hline
\end{tabular}

Thank you for your application for ethical approval, which has now been considered by the Standing Committee of the Human Ethics Committee.

Your application has been approved from the above date and this approval continues until 8 December 2019. If your data collection is not completed by this date you should apply to the Human Ethics Committee for an extension to this approval.

Best wishes with the research.

Kind regards

\section{This content is unavailable.}

\section{Please consult the print version for}

access

\section{Susan Corbett}

Convener, Victoria University Human Ethics Committee 